\title{
Examining the Dynamics of Policy Change and U.S. Narcotics Policy: Implications for the Global Narcotics Regime
}

\author{
Felix Kumah-Abiwu \\ West Virginia University
}

Follow this and additional works at: https://researchrepository.wvu.edu/etd

\section{Recommended Citation}

Kumah-Abiwu, Felix, "Examining the Dynamics of Policy Change and U.S. Narcotics Policy: Implications for the Global Narcotics Regime" (2012). Graduate Theses, Dissertations, and Problem Reports. 4881. https://researchrepository.wvu.edu/etd/4881

This Dissertation is protected by copyright and/or related rights. It has been brought to you by the The Research Repository @ WVU with permission from the rights-holder(s). You are free to use this Dissertation in any way that is permitted by the copyright and related rights legislation that applies to your use. For other uses you must obtain permission from the rights-holder(s) directly, unless additional rights are indicated by a Creative Commons license in the record and/ or on the work itself. This Dissertation has been accepted for inclusion in WVU Graduate Theses, Dissertations, and Problem Reports collection by an authorized administrator of The Research Repository @ WVU. For more information, please contact researchrepository@mail.wvu.edu. 
Examining the Dynamics of Policy Change and U.S. Narcotics Policy: Implications for the Global Narcotics Regime

Felix Kumah-Abiwu

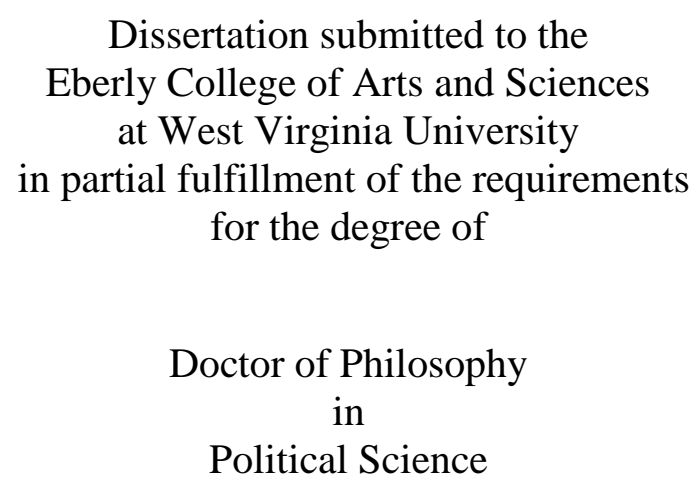

Donley Studlar, Ph.D., Chair

Scott Crichlow, Ph.D.

Susan Hunter, Ph.D.

Robert Duval, Ph.D.

Graeme Donovan, Ph.D.

Department of Political Science

Morgantown, West Virginia

2012

Keywords: Policy Change; Agenda-Setting; U.S. Narcotics Policy; Orders of Change;

Partisan Ideology; Global Narcotics Regime

Copyright 2012 Felix Kumah-Abiwu 


\author{
ABSTRACT \\ Examining the Dynamics of Policy Change and U.S. Narcotics Policy: Implications for the \\ Global Narcotics Regime \\ Felix Kumah-Abiwu
}

The prohibition approach to narcotics control has been the dominant policy paradigm of the United States (US) and the global narcotics regime under the United Nations (UN) for more than a century. In recent years, however, key questions have been raised on the existing prohibition policy approach, which many consider as ineffective and unchanging from a broader perspective. It is based on this appearance of unchanging policy that this study seeks to investigate whether the US narcotics policy is undergoing any type of change or not. The study also seeks to explore the implications of US narcotics policy change on the global narcotics regime. It draws on three domestic policy theories: agenda-setting, partisan ideology, and policy paradigm theory (orders of change) to examine the dynamics of US narcotics policy change since 1993. The research study employs these theories as competing explanations and concludes that the narcotics policy process has largely undergone Hall's (1993) conceptual second order change in policy. In essence, Hall's (1993) theoretical concept of policy paradigm theory (orders of change) offers a persuasive explanation for the changing nature of the US narcotics policy. For the global implications of US policy change, the study finds that the US is more likely to influence and shape similar policy changes on the global narcotics regime because of its dominant influence on the regime. 


\section{Dedication}

To Miranda, Prince, and Janice Kumah-Abiwu, Donley Studlar, Felicity Abiwu, and

Jennifer McIntosh. 


\section{ACKNOWLEDGEMENTS}

My academic journey has been very long and challenging, but very rewarding at the end. The road to this achievement could not have been possible without the Grace of Almighty God through our Lord and Savior Jesus Christ. My first and deepest thanks go to the Lord for His love, wisdom, and faithfulness. I also want to express my heartfelt gratitude to my dearest wife Miranda (Sena), my son Prince (Elinam), and my daughter Janice (Esinam) for their endless love and support. I am also grateful to the rest of my family, especially my mom, Felicity (Mama Sitsofe), my late dad, John Atakumah, and my brothers and sisters.

Indeed, my dissertation committee members deserve my special thanks and appreciation. I am deeply indebted to them for not only shaping and fine tuning my ideas, but also for their encouragement throughout the process of undertaking this research. I am particularly grateful to Dr. Donley Studlar (Eberly Family Distinguished Professor) for his outstanding guidance to the success of this work. His mentorship is not only exceptional but worthy of emulation. I am also grateful to Dr. Scott Crichlow (Chair of the Department), Dr. Susan Hunter, Dr. Robert Duval, and Dr. Graeme Donovan for their critical but useful comments on the work. I also want to thank Dr. Jeff Worsham, Director of Graduate Studies, Dr. Joe Hagan, and all the faculty and staff (LeeAnn, Ronny, and Donna) at the Department of Political Science for their support and encouragement. My thanks also go to the faculty and staff of the Department of History and Africana Studies Program at West Virginia University (WVU). I am especially grateful to Dr. Krystal Frazier (Coordinator of the Africana Studies Program). I want to also express my sincere thanks to the interviewees who took time to complete the questionnaires for the study. I also acknowledge the generous financial support I received from the President's Office for Social Justice as a Chancellor's Scholar towards my doctoral program. Thanks to you Jennifer McIntosh and Charles Morris for making it possible.

Finally, I must indicate that this journey to the ivory tower of knowledge has also been made possible because of my good friends, colleagues, and other wonderful individuals. I want to express my thanks to Eric Gavua \& family, Dr. Edward Brenya \& family, Dr. Bossman Asare, Dr. James Agbodzakey, Dr. Francis Abiew, Dr. Carolyn Lewis, Dr. Chali Nondo, Dr. Ebenezer Malcolm, Dr. Frederick Appah, Dr. Christine Lokko, Dr. Cyprien Lokko, Dr. Emmanuel Adugu, and Dr. Paul Filson. My thanks also go to Pastors Dave Hood, John Hood, Tony Sluzas, and the church family of Fresh Harvest Assembly of God in Morgantown, WV. I also appreciate the friendship of Pastor Adeniyi Adebisi and Rev. Dr. Adebola Adebayo of the Redeemed Christian Church of God (Morgantown, WV). Thanks also to Timothy, Kombe, Bagnini, Ellen, Saffa, Manfred, Dr. Nathaniel Iloanusi, Dr. Viviane Foyou, Dr. Maximo Martinez, and Dr. Sesime Adanu. I also want to thank Kofi \& Sophia, Daniel, Sheila, Toyin, Charity Abiew \& family, Liana Rahmawati, Julie \& Brice, Gideon \& Esther, Melanie Moroz, and last but not least, Rev. Kobina Ayitey. 


\section{Acronyms}

\begin{tabular}{|c|c|}
\hline $\mathrm{ABA}$ & American Bar Association \\
\hline $\mathrm{ACF}$ & Advocacy Coalition Framework \\
\hline AMA & American Medical Association \\
\hline ASL & Anti-Saloon League \\
\hline BNDD & Bureau of Narcotics and Dangerous Drugs \\
\hline BDAC & Bureau of Drug Abuse Control \\
\hline BWC & Better World Campaign \\
\hline CDAPCA & Comprehensive Drug Abuse Prevention and Control Act \\
\hline $\mathrm{CDC}$ & Centers for Disease Control and Prevention \\
\hline CIA & Central Intelligence Authority \\
\hline CMR & Californians for Medical Rights \\
\hline CNOA & California Narcotics Officers' Association \\
\hline $\mathrm{CMCA}$ & Comprehensive Methamphetamine Control Act \\
\hline CRS & Congressional Research Service \\
\hline CSIU & Customs Service Investigation Unit \\
\hline CSA & California Sheriffs' Association \\
\hline DCDATF & Domestic Council Drug Abuse Task Force \\
\hline DEA & Drug Enforcement Administration \\
\hline DPA & Drug Policy Alliance \\
\hline $\mathrm{DPF}$ & Drug Policy Foundation \\
\hline EU & European Union \\
\hline FBN & Federal Bureau of Narcotics \\
\hline FDA & Food and Drug Administration \\
\hline GCDP & Global Commission on Drug Policy \\
\hline GFWC & General Federation of Women's Clubs \\
\hline HST & Hegemonic Stability Theory \\
\hline IOC & International Opium Commission \\
\hline IOM & Institute of Medicine \\
\hline INCB & International Narcotics Control Board \\
\hline
\end{tabular}


INL International Narcotics and Law Enforcement Affairs

IRB Institutional Review Board

IRB Internal Revenue Bureau

JAMA Journal of the American Medical Association

LEAP Law Enforcement Against Prohibition

LON League of Nations

MCPA Maine Chiefs of Police Association

MPP Marijuana Policy Project

MTA Marijuana Tax Act

NCA Narcotics Control Act

NCMDA National Commission on Marijuana and Drug Abuse

NDCS National Drug Control Strategy

NDU Narcotics Division Unit

NIDA National Institute on Drug Abuse

NIH National Institute of Health

NORML National Organization for the Reform of Marijuana Laws

NTA Narcotics Treatment Administration

NSDUH National Survey on Drug Use and Health

OCCA Organized Crime Control Act

ODALE Office of Drug Abuse Law Enforcement

ONDCP Office of National Drug Control Policy

ONNI Office of National Narcotics Intelligence

OSI Open Society Institute

PM Progressive Movement

PE Punctuated Equilibrium

PRC Pew Research Center

PSA Program on Substance Abuse

SAODAP Special Action Office for Drug Abuse Prevention

SAMHSA Substance Abuse and Mental Health Services Administration

SFTF South Florida Task Force 
SSDP Students for Sensible Drug Policy

RICO Racketeer Influenced and Corrupt Organizations

TAN Transnational Advocacy Networks

US United States

UN United Nations

UNODC United Nations Office on Drugs and Crime

UNCND United Nations Commission on Narcotic Drugs

UNICRI Interregional Crime and Justice Research Institute

WDR World Drug Report

WCTU Women's Christian Temperance Union

WHO World Health Organization

WNDA World Narcotics Defense Association 


\section{TABLE OF CONTENTS}

Pages

Chapter 1: Narcotics Control Policy Process .........................................................

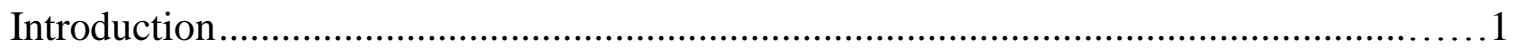

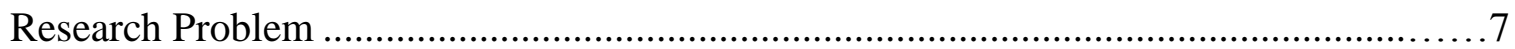

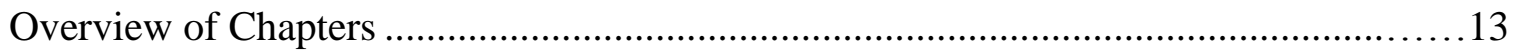

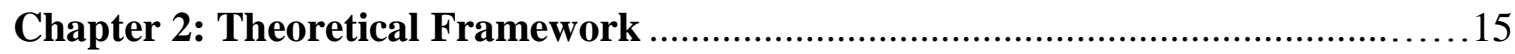

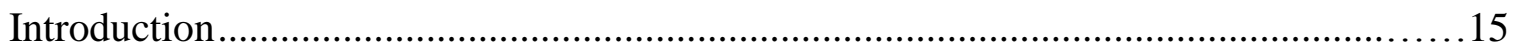

The Narcotics Control Literature .............................................................................

Supply-Side Debate of Narcotics Control..............................................................

Demand-Side Debate of Narcotics Control ..............................................22

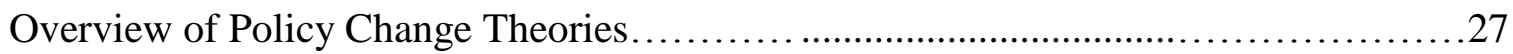

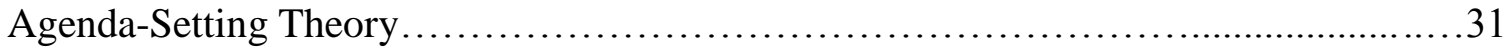

Subsystem Dynamics and Punctuated Equilibrium Theory.......................................33

Issue Definition/Venue Shifting and Policy Entrepreneurship ...................................39

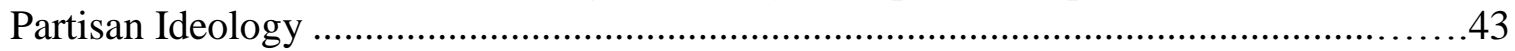

Policy Paradigm Theory (Orders of Change) ...............................................................45

Theoretical Overview of International Regimes .........................................................49

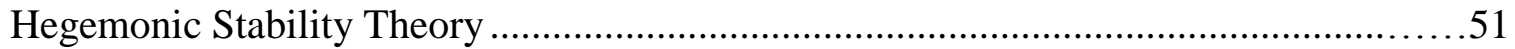

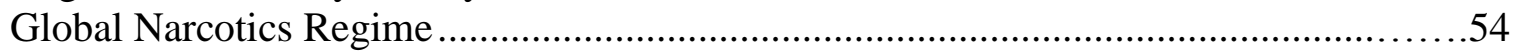

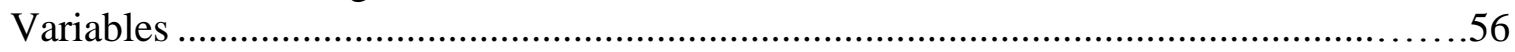

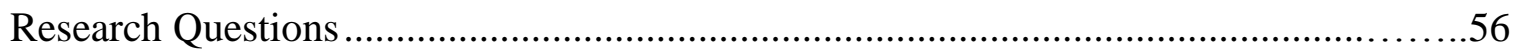

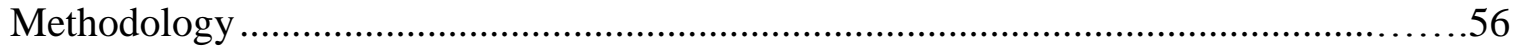

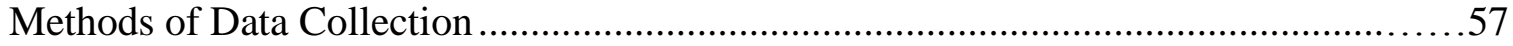

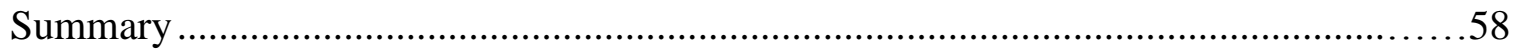

Chapter 3: Evolution of US Narcotics Policy (1906-1992) ......................................60

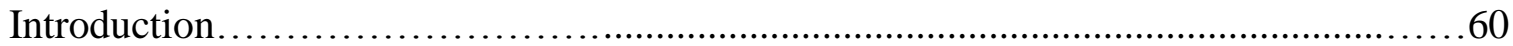

The Politics of Early Narcotics Policy Process...............................................................64

First Phase: Evolution of Punitive Narcotics Policy (1906-1968) ...................................66

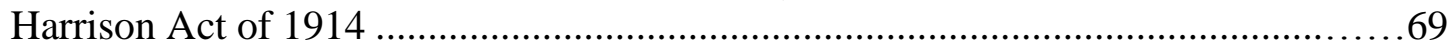

Consolidation of Punitive Narcotics Policy (1929-1968) .........................................74

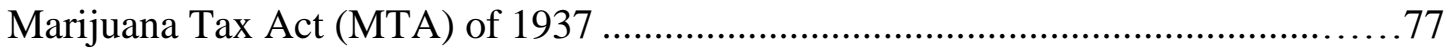

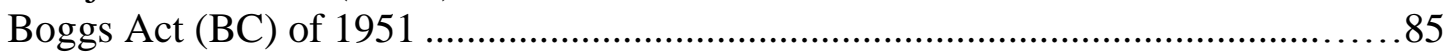

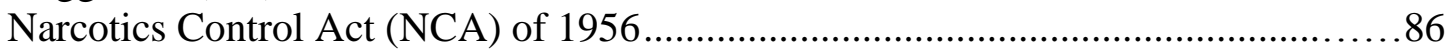

Second Phase: Emergence of the War on Drugs (1969-1980) ........................................91

Narcotics Control under Nixon: A Policy Change or Policy Contradiction? ............94

De-escalation of the War on Drugs (1974-1980)...................................................109

Third Phase: Escalation of the War on Drugs (1981-1992).........................................119 
Summary

Chapter 4: The US Narcotics Policy Process and Change (1993-2009) .................133

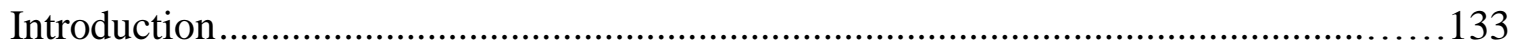

Fourth Phase: Explaining Narcotics Policy Change (Clinton and Bush Eras) ..............133

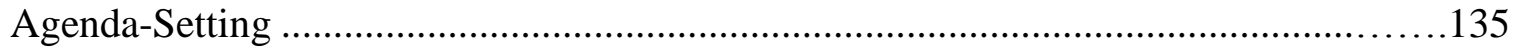

Issue Definition/Venue Shifting/ Policy Entrepreneurship and Policy Change. ......136

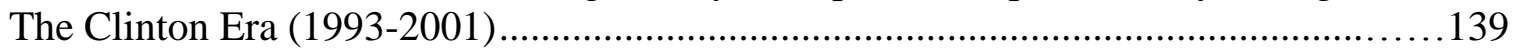

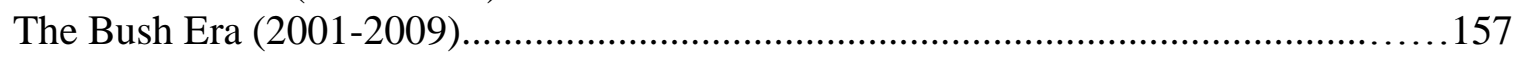

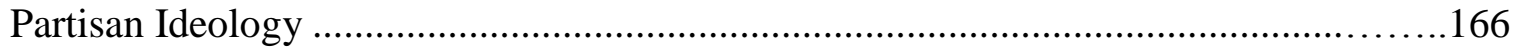

Policy Paradigm Theory (Orders of Policy Change) .....................................................171

Orders of Change and US Narcotics Policy: Towards an Explanation .......................175

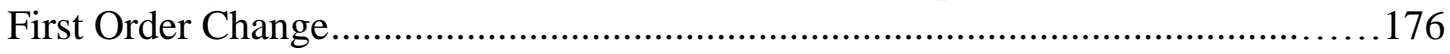

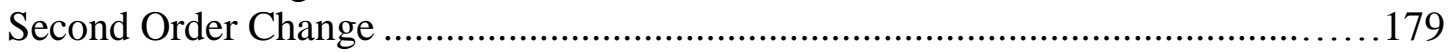

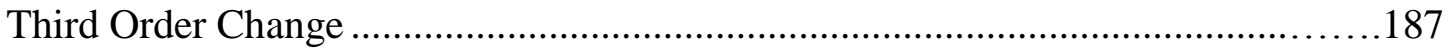

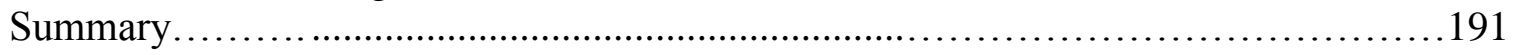

Chapter 5: US Policy Change: Implications for the Global Narcotics Regime......195

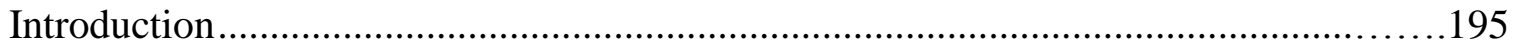

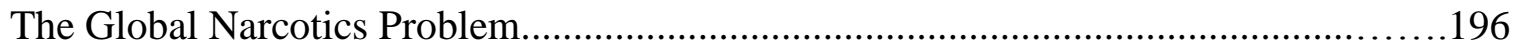

United States and the Global Narcotics Regime......................................................199

Stages in the Evolution of a Global Regime …………............................................202

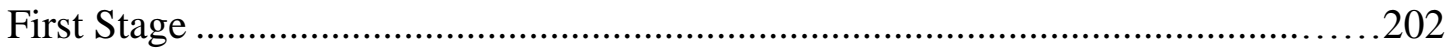

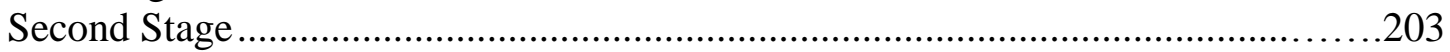

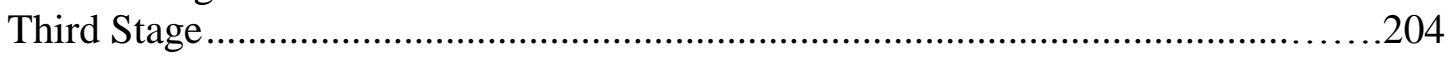

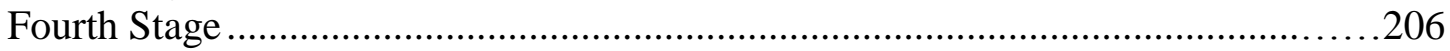

US Policy Tools and Global Narcotics Control .........................................................207

Two-Level Games: US Policy Change/Global Narcotics Regime ...............................2214

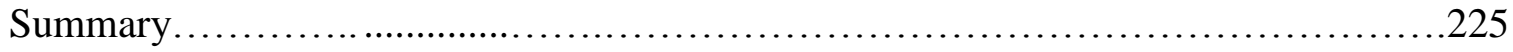

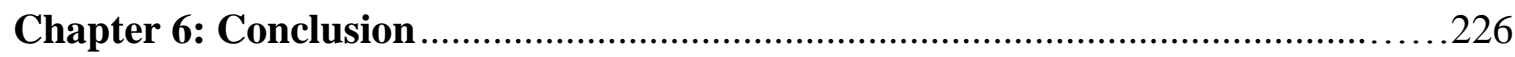

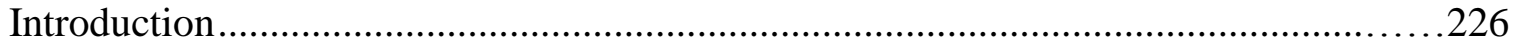

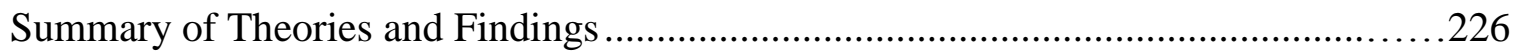

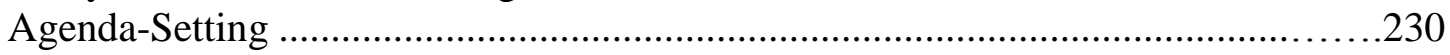

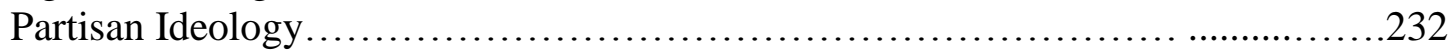

Policy Paradigm Theory (Orders of Change) .....................................................234

Hegemonic Stability Theory/Global Narcotics Regime ……................................236

Global Narcotics Policy Regime: Any Prospect for Paradigm Change? .......................238

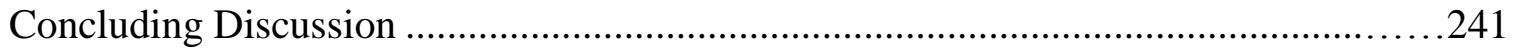

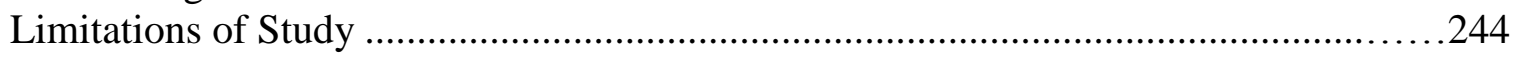

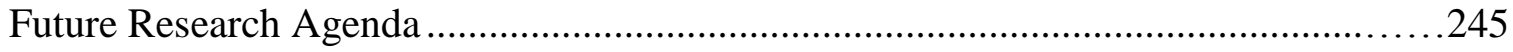




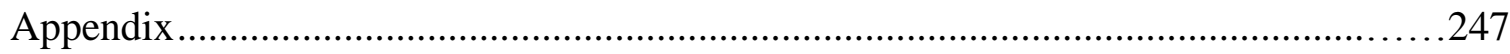

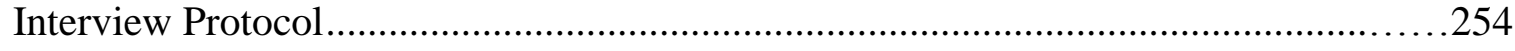

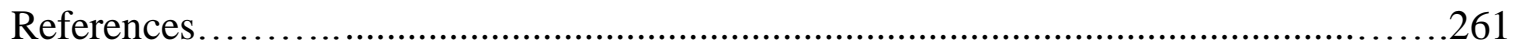




\section{Tables}

1.1 Chronology of Multilateral Conventions (1909-1988) …...................................5

2.1 Hall's Theoretical Typology of Policy Change ..................................................48

3.1 Phases/Chronology of Milestones of US Narcotics Control (1906-1992)............61

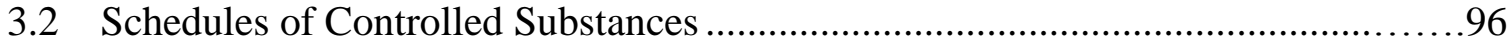

3.3 Racial Distribution in Drug Arrests (1950-1990) .............................................124

4.1 Statewide Medical Marijuana Policy Adoption (1996-2010).............................146

5.1 US Policy Tools of Influence (Global Narcotics Control) ...............................208 


\section{Figures}

3.1 Historical Development (phases) of US Narcotics Policy (1906-1992) ...............66

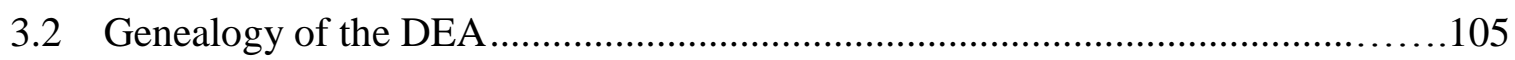

4.1 Fourth Phase of US Narcotics Policy (1993-2009).........................................134

4.2 Trends in Public Opinion about the Legalization of Marijuana (1969-2011)......147

4.3 Rates of Adult Drug Arrest by Race (1980-2007) ...........................................164

4.4 Schematic Representation of Hall's Orders of Policy Change ..........................172

4.5 The Three Components of a Policy ....................................................................173

5.1 Global and Domestic Dimensions of US Narcotics Control ............................198 


\section{Chapter 1}

\section{Narcotics Control Policy Process}

\section{Introduction}

The problem of illicit or narcotic drugs has been one of the major policy issues confronting both advanced and developing countries for many decades. In fact, the global narcotics prohibition regime, which constitutes one of the institutional frameworks of the United Nations (UN) with the mandate to control global illicit drugs, has been in existence for more than a century (UNODC, 2010). ${ }^{1}$ In recent years, however, key questions have been raised on the existing prohibition policy approach to narcotics control. For many, particularly in the United States (US), the existing narcotics policy does not only appear ineffective, but also unchanging from a broader perspective. It is based on this seemingly unchanging nature of the policy that this study seeks to investigate whether the narcotics policy process is undergoing any form of change, and what might be the likely implications of policy change in the US on the global narcotics regime.

In essence, this study has two basic objectives. First, it seeks to investigate the changing patterns or nature of US narcotics policy process over time. Three domestic policy theories (agenda-setting, partisan ideology and paradigm change/orders of change) are employed as the main theoretical frameworks of the study. Second, the study explores whether a US policy change or resistance to change is likely to shape the global narcotics regime with a similar change or resistance to change considering the dominant role of the US on the regime. For a conceptual explanation of the US influence and leadership of the global narcotics regime, the

\footnotetext{
${ }^{1}$ United Nations Office on Drugs and Crime's (UNODC) World Drug Report (WDR) 2010. United Nations Publication Sales No E.10.XI.13.
} 
study employs the theoretical concept of regime theory (Young, 1983; Keohane and Nye, 1977: Keohane, 1984, 2005) with specific reference to the hegemonic stability theory (Ikenberry, 1989; Kindleberger, 1981) to help with our understanding of how the US shapes issues concerning the global narcotics regime. Although the broad ideas of the hegemonic stability theory are applied, my interpretation of a hegemon, in the case of the US, is not in the original sense of the theory (see chapter two), since the US was not a global hegemon in the early 1900s. The term (hegemonic stability) is therefore broadly applied in this study to demonstrate the influential and leadership role of the US (Bewley-Taylor, 1999a) in key global issue areas such as narcotics control.

Before the end of the $19^{\text {th }}$ century, the use and trade in narcotic products were generally lawful in many countries, including the United States. However, with the discovery of opium derivatives and the hypodermic needle, coupled with the expansion of trade in opium, the level of addiction became rampant in the early 1900s, and this gave rise to a global demand for some level of control (Waddell, 1970). For example, the concern over the opium epidemic in China and its likely impact on other countries, particularly the US and other European countries, was one of the major issues that ignited the need to control narcotic drugs during the early years of the twentieth century. According to the UNODC's World Drug Report (WDR) ${ }^{2}$ the Chinese opium epidemic brought about the first global concerted action from great powers such as the United States, Britain, and China to discuss the Chinese opium problem from a multilateral perspective. Consequently, the 1909 International Opium Commission (IOC) meeting held in

\footnotetext{
${ }^{2}$ United Nations Office on Drugs and Crime's (UNODC) World Drug Report (WDR) 2010 United Nations Publication Sales No. E.10.XI.13. p.7.
} 
Shanghai, China, became the first such international gathering to discuss the modalities of a global narcotics control. The meeting also marked the genesis of subsequent international collaborations and concerted efforts within the international community toward an establishment of a global drug prohibition regime (Bewley-Taylor, 1999a).

As with other countries, the United States was not only concerned with the Chinese opium problem, but the US was the main convener of the Shanghai meeting. The US also played a very key role in the early discussions on the global methods and approaches of narcotics control. For Buxton (2008), the first global meeting did not produce any concrete international agreement on the strategies of narcotics control, but it was equally significant for two main reasons. First, the role of the US as the main convener of the Shanghai meeting marked an important milestone in its successive role and efforts in the evolution of the global narcotics prohibition regime. Second, the US emerged as the leading country during the initial negotiations, which eventually helped its successful definition of the drug problem and control strategies toward a prohibition approach. Having assumed the leading role in shaping the evolution of the global prohibition regime, the question of why the US became so much interested in efforts toward a global narcotics control is an important part of the discourse worth addressing.

For Waddell (1970:11), the involvement of the US in the multilateral collaboration against illicit drugs can be explained from two main perspectives. First, the US was influenced by its disdain for the widespread use and trade in opium by many immigrants from Asia, particularly among Chinese migrant laborers living in the US. Generally, the widespread use of opium and other narcotic drugs among these migrants changed the "respectability image" once associated with the use of these drugs (Sinha, 2001). For Sinha (2001: 5), the smoking of opium 
was now viewed by many Americans as a "Chinese scourge" or a curse with a link to immorality, criminality, and general social decay, hence the US role in the control of these drugs.

The second explanation for the active involvement of the US in the global narcotics control occurred after the acquisition of the Philippines. Bishop Charles Brent, the Protestant Episcopal Bishop of the Philippines, and other missionary groups were said to be appalled by the widespread use of narcotic drugs, particularly opium in the Philippines and across the US. With a strong influence from Christian missionary organizations, the US authorities prohibited the import, sale, and use of opium, except for medical purposes, across the Philippines in the early years of the 1900s (Andreas and Nadelmann, 2006; Buxton, 2006). Following these early successes, Bishop Brent and other leaders not only became the leading advocates for the global prohibition of other narcotic drugs, but they also played very prominent roles as key representatives of the US during the initial negotiations on the establishment of the global narcotics control regime (Buxton, 2006).

After the 1909 Shanghai Conference, several other international meetings were held to further discuss the strategies for global narcotics control. For example, the Hague Convention of 1912 was a follow up to the Shanghai (1909) meeting where the first international narcotics convention was actually signed into a binding agreement. As Bayer and Ghodse (2000) argue, the Hague Convention was unique because it was the Convention that set the actual institutional and legal frameworks for the establishment of the current global narcotics control regime. Unlike the Shanghai meeting, the Hague Convention clearly outlined the rules and regulations that prohibited the manufacture, trade, and use of narcotic drugs, such as opium and cocaine, except for medical purposes. Subsequent multilateral treaties followed the Hague Convention as shown in table 1.1 . 
Table 1.1

Chronology of Multilateral Conventions on Global Narcotics Control (1909-1988)

\begin{tabular}{|c|c|c|}
\hline Date and Place Signed & Title of Convention & Entry into Force \\
\hline $\begin{array}{lcc}26 & \text { February } & 1909 \\
\text { Shanghai, China } & \end{array}$ & $\begin{array}{l}\text { Final Resolutions of the International Opium } \\
\text { Commission }\end{array}$ & Not Applicable \\
\hline $\begin{array}{l}23 \text { January } 1912 \text { The } \\
\text { Hague, Netherlands }\end{array}$ & International Opium Convention & $\begin{array}{l}\text { 11 February 1915/28 } \\
\text { June } 1919\end{array}$ \\
\hline $\begin{array}{l}11 \quad \text { February } 1925 \\
\text { Geneva, Switzerland }\end{array}$ & $\begin{array}{l}\text { Agreement concerning the Manufacture of, Internal } \\
\text { Trade in and Use of Prepared Opium }\end{array}$ & 28 July 1926 \\
\hline $\begin{array}{l}19 \quad \text { February } 1925 \\
\text { Geneva, Switzerland }\end{array}$ & International Opium Convention & 25 September 1928 \\
\hline $\begin{array}{l}13 \text { July } 1931 \text { Geneva, } \\
\text { Switzerland }\end{array}$ & $\begin{array}{l}\text { Convention for Limiting the Manufacture and } \\
\text { Regulating the Distribution of Narcotics Drugs }\end{array}$ & 9 July 1933 \\
\hline $\begin{array}{lcl}27 & \text { November } 1931 \\
\text { Bangkok, Thailand }\end{array}$ & $\begin{array}{l}\text { Agreement for the Control of Opium Smoking in the } \\
\text { Far East }\end{array}$ & 22 April 1937 \\
\hline $\begin{array}{l}26 \text { June } 1936 \text { Geneva, } \\
\text { Switzerland }\end{array}$ & $\begin{array}{l}\text { Convention for the Suppression of the Illicit Traffic } \\
\text { in Dangerous Drugs }\end{array}$ & 26 October 1939 \\
\hline 11 December 1946 Lake & Protocol amending the Agreements, Conventions and & 11 December 1946 \\
\hline $\begin{array}{l}\text { Success, New York, } \\
\text { USA }\end{array}$ & $\begin{array}{l}\text { Protocols on Narcotic Drugs concluded at The Hague } \\
\text { on } 23 \text { January 1912, at Geneva on } 11 \text { February } 1925 \\
\text { and } 19 \text { February } 1925 \text { and } 13 \text { July } 1931 \text {, at Bangkok } \\
\text { on } 27 \text { November 1931, and at Geneva on } 26 \text { June } \\
1936\end{array}$ & \\
\hline $\begin{array}{l}19 \text { November } 1948 \\
\text { Paris, France }\end{array}$ & $\begin{array}{l}\text { Protocol Bringing under International Control Drugs } \\
\text { outside the Scope of the Convention of } 13 \text { July } 1931 \\
\text { for Limiting the Manufacture and Regulating the } \\
\text { Distribution of Narcotic Drugs, as amended by the } \\
\text { Protocol signed at Lake Success, New York, on } 11 \\
\text { December } 1946\end{array}$ & 1 December 1949 \\
\hline $\begin{array}{l}\text { 23 June } 1953 \text { New York, } \\
\text { USA }\end{array}$ & $\begin{array}{l}\text { Protocol for Limiting and Regulating the Cultivation } \\
\text { of the Poppy Plant, the Production of, International } \\
\text { and Wholesale Trade in, and Use of, Opium }\end{array}$ & 8 March 1963 \\
\hline $\begin{array}{l}30 \text { March } 1961 \text { New } \\
\text { York, USA }\end{array}$ & Single Convention on Narcotic Drugs, 1961 & 13 December 1964 \\
\hline $\begin{array}{lrr}21 & \text { February } 1971 \\
\text { Vienna, Austria } & \\
\end{array}$ & Convention on Psychotropic Substances & 16 August 1976 \\
\hline $\begin{array}{l}25 \text { March } 1972 \text { Geneva, } \\
\text { Switzerland }\end{array}$ & $\begin{array}{l}\text { Protocol amending the Single Convention on } \\
\text { Narcotic Drugs, } 1961\end{array}$ & 8 August 1975 \\
\hline $\begin{array}{lrl}20 & \text { December } & 1988 \\
\text { Vienna, Austria } & \end{array}$ & $\begin{array}{l}\text { United Nations Convention against Illicit Traffic in } \\
\text { Narcotic Drugs and Psychotropic Substances }\end{array}$ & 11 November 1990 \\
\hline
\end{tabular}

Source: Sinha Jay (2001:8). Also see, UN Narcotics Treaty Collection

http://treaties.un.org/Pages/Treaties.aspx?id=6\&subid=A\&lang=en Retrieved on 09/12/10. 
Signatory countries were also encouraged to enact domestic laws to prohibit these narcotic drugs (Buxton, 2008; Bewley Taylor, 2001).

In order to ensure a coordinated effort towards a global system of narcotics control, the administration of the global regime became part of the League of Nations (LON) after the League was created in 1919. Since then, the global narcotics control regime has been administered by various agencies under the League of Nations and the United Nations (UN). Presently, the United Nations Office on Drugs and Crime (UNODC) and the International Narcotics Control Board (INCB) ${ }^{3}$ are the two main bodies that serve as the guardian for the global narcotics control regime (Bewley-Taylor, 1999a; Sinha 2001). Similarly, UN-backed multilateral agreements on the global narcotics control are governed by three major international conventions: the 1961 Single Convention on Narcotic Drugs, the 1971 Convention on Psychotropic Substances, and the 1988 Convention against Illicit Traffic in Narcotic Drugs and Psychotropic Substances. These are the three main international agreements that currently define and shape the strategies of the existing global narcotics regime (Bayer and Ghodse, 2000; Bewley-Taylor and Fazey, 2003). Although these Conventions do have some leeway for member states to fashion their domestic drug policies based on their own political, socio-cultural, and economic realities, such flexibility is limited by the strong prohibition policy framework of the global narcotics regime (Nadelmann, 1990; Bewley-Taylor, 1999a; Sinha, 2001).

Clearly, the prohibition of narcotics production, trafficking, and use has been the core underlying principle of the global drug control system since the regime was created. As Buxton (2008:1) observes, there has been some level of global commitment to eliminate the production, distribution, and consumption of harmful drugs, with the prohibition approach as the overriding

\footnotetext{
${ }^{3}$ The two organizations are located in Vienna, Austria.
} 
policy option. Generally, the prohibition policy option or the supply-side approach to narcotics control involves the use of law enforcement (criminal justice system) to arrest illicit drug producers, traffickers, sellers, and users for criminal prosecution (Fisher, 2006; Nadelmann, 1990). The harsh punishment of this strategy is meant to deter and discourage the production, trafficking, and use of these narcotic drugs.

For many years, the US authorities have not only been influential in pushing for a prohibition policy option within the domestic narcotics policy domain, but also on the global narcotics regime as a result of its emergence on the global scene as one of the great powers. As noted, the US became engaged in addressing the opium issue after assuming responsibility of the Philippines following the defeat of Spain in the Spanish American War of 1898 (Buxton 2006:30). The US has since, as Bewley-Taylor (2003, 1999a) observes, succeeded in externalizing its prohibition approach of narcotics control across the globe with almost every country following the same prohibition strategy. On their part, Musto (1999) and Sinha (2001) argue that the passage of the 1914 Harrison Narcotics Act, which marked the first federal narcotics control law in the US with a strict prohibition option, became the policy framework for the existing (domestic and global) narcotics control policy.

\section{Research Problem}

Although there has been some level of global commitment to control narcotic drugs as previously noted, many scholars, political leaders, and ordinary citizens are divided on the best strategies for narcotics control. In fact, the existing prohibition policy has been commended and condemned by proponents and opponents alike. For the advocates of the existing prohibition control, drug use has generally created many social ills to both society and government. In 
essence, public morality will continue to triumph as long as illicit drugs are prohibited in the US and across other countries. Opponents of the existing regime argue that illicit drugs of all types such as marijuana, cocaine, and heroin are not only becoming more readily available and cheaper, but also that the drug trade has reached alarming proportions as one of the biggest and most lucrative enterprises. The trade has also led to increases in drug related crimes and violence across many parts of the world (Mexico) despite the prohibition approach to narcotics control (Fazey, 2003; Fish, 2006). A good case in point is the increasing drug-related crimes of murder, violence, and rape across the US and Mexico border in recent years. For the critics, the existing narcotics regime (prohibition) at the national and international levels are not only counterproductive, ineffective, and a policy failure, but these prohibitive policies are equally confronted with policy contradiction, fragmentation, and inaction on the part of many governments across the world, particularly the US (Fazey, 2003; Fish, 2006).

In view of this, many questions have been raised on the effectiveness and the apparent lack of progress in the global efforts to control narcotic drugs. For opponents of the existing strategy to narcotics control, a shift in policy towards a more liberal or demand-side approach to narcotics control should be the focus of countries (Levine, 2003; Bewley-Taylor, 2003; Nadelmann, 2005). In fact, the demand-side strategy (harm reduction, harm minimization, decriminalization, or legalization) has been around for some time. Most of its roots can be traced to the drug policies of the Netherlands. Inciardi and Harrison (2000:2) define harm reduction as the public health or socio-medical approach to drug policy, with emphasis on decreasing the negative consequences of drug use. The objective of the approach is to identify and support people who use psychoactive drugs in order that they can be assisted with treatment to minimize the harm of addiction and also to provide them with health support to quit the habit. The ultimate 
goal of many proponents of the liberal approach is to affect policy change towards the decriminalization of the use of narcotic drugs currently classified as illicit.

As earlier noted, the problem of narcotics control is intertwined with national and global policy issues confronting many countries (Levine, 2003), but the US has taken the lead in global narcotics control due to its influence within the international system (Nadelmann, 1990; Levine, 2003). As a result, the domestic narcotics policy in the US has evolved alongside the global drug control conventions, with the US becoming the de-facto watchdog in ensuring the enforcement of the prohibition strategy at home and abroad (Bewley-Taylor, 1999a; Andreas and Nadelmann, 2006). Broadly, the existing prohibition approach has been subjected to many criticisms because of the seemingly unchanging nature of the approach for more than a century of its implementation. In essence, the social and economic consequences associated with the implementation of the existing approach to narcotics control has become a major public policy problem confronting almost every country in the world, particularly in the US.

Similar to any public policy problem, the scholarly literature on the US narcotics policy process broadly focuses on policy definitions, initiatives, and policy solutions within the broad context of policy goals, contents, and policy instruments. Scholars often describe this scenario as policy dynamics. Central to the discussion on policy dynamics within a policy process is the concept of policy change. For many, public policies, particularly within the American policymaking system, are dynamic and these policies undergo changes over time. For Bennett and Howlett (1992), policies change in various ways and dimensions. While some policies radically change because of the introduction of new policy options, others are just an incremental refinement of older policies. Besides, the question of why policies change in the first place, why 
some changes are rapid and others are slow, and why others do not change as rapidly as expected are some of the critical questions that continue to engage the attention of policy scholars.

The key question that emerges in relation to the US narcotics policy is whether Bennett and Howlett's (1992) interpretation of policy dynamics in terms of policy change (radical or incremental) fit any aspect of the narcotics policy process. In other words, is the US narcotics policy undergoing any form of change? Indeed, this question is an important empirical one that this study seeks to investigate. In effect, the main puzzle is whether US drug or narcotics policy has changed or undergoing some types of policy change (radical or incremental) over time. The next part of the main research question is to explore whether the US narcotics policy change is likely to influence similar change (s) on the global narcotics regime as a result of the dominant role of the US on the regime. In summary, the main research questions this study seeks to explore are:

(1) Is the US narcotics policy changing?

(2) What are the types and nature of these changes?

(3) Who are the main actors that drive these policy changes?

(4) What are the implications of US narcotics policy change on the global drug prohibition regime?

Broadly, the main goal of the study is to examine policy change within the context of the US narcotics policy goals, instruments, and settings of the policy instruments. In terms of conceptual definition, I draw on Goldberg's (2004:551) definition of narcotics policy as a political decision taken by a country in relation to the problem of production, trafficking, and consumption of psychoactive substances. For policy change, I adopt Studlar's (2009:73) definition of policy change as "the movement of policy over time." This view is shared by Capano and Howlett (2009) and Skogstad (2009). For them, policy change involves the trend of 
how policies arise and develop over time. In terms of measurement, policy change is measured within the context of tempo (speed), mode (type of change), and scope (coverage) of the policy change process (Studlar, 2009). The study's focus on investigating the likely implications of the US policy change on the global drug control regime is a particularly significant one because of the dominant influence of the US in the evolution and maintenance of the global drug prohibition regime.

Although the study covers earlier periods of US narcotics policy development, the period 1993-2009 constitutes the main scope of the study. This period is important for three main reasons. First, it provides an opportunity to examine the dynamics of US narcotics policy change in an era characterized by the dominance of the US in the international system. Second, the period represents two different political administrations (Democratic and Republican) with different orientations toward narcotics control. By examining the drug policies under the administrations of President Bill Clinton (1993-2001) and President George W. Bush (20012009), it is expected that the analysis of the two different administrations will provide some understanding of how partisan ideological differences shape the US narcotics policy process. Third, this study extends the work of Baumgartner and Jones (1993) on the US drug policy change over time. In their classic work, Agendas and Instability in American Politics, the authors examined the US drug policy among other public policies from 1900 to 1990 through the theoretical lens of the punctuated equilibrium theory. Their study concludes that the US drug policy, like similar public policies examined in the study, underwent changes at different times and periods. To my knowledge, based on the review of the existing literature, the work of Baumgartner and Jones (1993) on US drug policy has not been extended beyond 1990. My goal 
is to fill this gap by systematically examining the trends of policy change in the US narcotics policy process from 1993 to 2009.

Generally, this research is grounded in the traditions of comparative public policy and international relations literature. It basically draws on three main theories of the policy process. The first is agenda-setting, with focus on conceptual models such as issue definition and redefinition, venue shifting, and policy entrepreneurship (Baumgartner and Jones, 1993). The second is partisan ideology (Stratmann, 2000; Imbeau et al. 2001; Studlar, 2002), and the third is Hall's (1993) paradigm change (orders of change). Basically, these three theories are employed as competing explanations of the narcotics policy process, with each examining the different dimensions of policy and policy change over time. Specifically, agenda-setting theory looks at policy agendas as the dependent variable, while partisan ideology examines campaign rhetoric and policy proposals. Paradigm change explores policy adoption and implementation. To investigate the likely implications of US narcotics policy change on the global narcotics regime as previously stated, the regime theory (hegemonic stability) is employed for the analysis.

In terms of methodology, the study is grounded in a qualitative research method (Patton, 2002; King, Keohane and Verba, 1994), with emphasis on documentary analysis and elite interviewing of policy experts involved in US narcotics policymaking. Specifically, many policy advocates, policy entrepreneurs, and other policy elites within many policy advocacy organizations whose main objective is to shape policy change from the existing prohibition narcotics policy towards a more liberal approach were interviewed.

By using these theories and the methodological approach, this study not only contributes to the existing literature for better understanding of the US narcotics policy change process, but has also enriched the political science literature by blending the theoretical fields of public policy 
and international relations. Finally, by employing these theories as competing explanations, the study concludes that Hall's (1993) theoretical concept of orders policy change provides a persuasive explanation for the changing nature of the US narcotics policy since 1993. The findings of the study also reveal that policy change in the US is more likely to affect similar policy change on the global narcotics prohibition regime as a result of the dominant influence of the US on the regime.

\section{Overview of Chapters}

The rest of the research is structured in five chapters, besides the introductory chapter. Chapter two examines the main theoretical framework of the study and reviews some major scholarly works in the literature on narcotics control. The chapter also outlines the research questions, the hypotheses, and the variables of interest of the study. Also included in this chapter is the discussion on the methodological approach to the study in terms of data collection and analysis.

The third chapter examines the historical background and the evolutionary process of the US narcotics policy through three major phases. These phases of the policy development process are also discussed within the key theoretical frameworks guiding this study. The discussion is primarily based on the documentary analysis of the US and the UN drug policy documents, reports, and other existing literature on their narcotics policymaking since the early $20^{\text {th }}$ century.

Chapter four constitutes the main empirical chapter of this study. It entails the key analysis of the US narcotics policy change since 1993 through the theoretical lens of the study. The narrative of chapter four combines the analysis of the results from the primary data gathered 
from the elite interviews with the secondary documentary data analysis ${ }^{4}$ of key policy documents to support my arguments. The significance of this chapter is the empirical testing of the main theoretical frameworks outlined in the study.

Chapter five extends the discussion of chapter four by illustrating the implications of the US narcotics policy change for the global narcotics regime. The chapter employs the hegemonic stability theory, particularly the influence and dominance of the US in shaping the global narcotics regime. Similar to chapter four, the analysis integrates the results of the primary data gathered from the elite interviews with secondary documentary analysis to support the arguments in the study.

Chapter six concludes the study by discussing the general findings. The chapter also discusses whether any possibility exists for a third order change (major policy change) to the existing global narcotics prohibition regime. These findings are examined through the perspective of the research questions, hypotheses, and the theoretical framework of the study. The chapter also outlines the theoretical and empirical contributions of the study to the broad political science literature.

\footnotetext{
${ }^{4}$ The documentary analysis involves the examination of US narcotic laws, budgets, policy agendas and reports.
} 


\section{Chapter 2}

\section{Theoretical Framework}

\section{Introduction}

This chapter examines the theoretical literature of comparative public policy and international relations by specifically drawing on agenda-setting theory (issue definition/redefinition, venue shifting, and policy entrepreneurship), partisan ideological explanation, and the theory of orders of policy change to explain the narcotics policy change process in the Unites States. The study employs these theories as competing explanations in order to establish the one that offers the best explanation for the narcotics policy change since 1993. The chapter also examines the broad concept of regime theory with emphasis on the hegemonic stability (Keohane, 1983; 1994) and its relation to the hegemonic influence of the US on the global narcotics regime. Simply put, this chapter sets the theoretical framework for the analyses in chapters three, four, and five of the study.

In addition, the chapter outlines the underlying hypotheses, research questions, and the methodological approach of the study. Before I focus on the theoretical discussion, I will first undertake a critical review of some major scholarly works in the field of narcotics control.

\section{The Narcotics Control Literature}

The literature on narcotics control is vast and complex, covering many scholarly fields. These fields include political science, history, sociology, policy studies, criminology, law, psychology, public health, and journalism. In view of the vast and complex nature of the field, my discussion of the literature will only focus on scholarly works in the literature that are relevant to this study. As previously stated, narcotics policy in the Unites States is inextricably 
linked to the institutional framework of the global narcotics control regime through multilateral treaties. Similarly, the US is also linked to other countries on the basis of bilateral relations and agreements on narcotics control. On the basis on this linkage, my review of the existing literature will focus on scholarly works on narcotics policy within the US policy domain on one hand, and works on the interactions between the US and other countries on narcotics control on the other hand. Broadly, the narcotics policy literature is defined by two broad areas of perspective: supply-side control and demand-side control.

\section{Supply-Side of Narcotics Control}

The supply-side of narcotics control, as noted in the introductory chapter, focuses on law enforcement (criminal justice system) with strict prohibition of drug producers, traffickers, buyers, and sellers with the war on drugs at the center of this approach of narcotics control (Fisher, 2006; Nadelmann, 1990). In fact, the so-called war on drugs was declared by President Nixon in the early 1970s. Ever since the war on drugs was declared, the United States' efforts toward a global campaign against illicit drugs has expanded and intensified in many dimensions. As Goldstein and Kalant (1993) observe, a declaration of war on a policy issue often represents a useful metaphor in the sense of declaring an actual war. This is because wars are generally used to mobilize social forces, material resources, and to set national priorities for common attainable goals and objectives. From Goldstein and Kalant's (1993) interpretation, it is possible to argue that President Nixon's purpose of declaring the war on drugs was an attempt to gain public support and to elevate the drug issue to the national policy agenda. Since the Nixon era, the narcotics issue has enjoyed a consistent attention from successive presidents of the United States regardless of their partisan ideological orientations. The drug issue has also captured the 
attention of the public, political institutions, and other attentive advocacy groups (Bertram et al. 1996; Musto, 1999). Until recently when the Obama administration's appointed drug czar, Gil Kerlikowske, signaled the need for a shift from the emphasis on the war on drugs, ${ }^{5}$ the drug war metaphor has been associated with not only past political administrations as mentioned above, but also with most presidential contenders in major presidential campaigns across the United States (Bertram et al., 1996).

For Gerber and Jensen (2001), the war on drugs is not only restricted to the US, but also within the global system for many decades following the relentless efforts by the US to externalize the prohibition regime to other countries. There has however been a growing dissatisfaction among scholars, policymakers, and ordinary people across the world, particularly the US, about the limited progress and success with the war on drugs. Sharing similar views, many scholars (Nadelmann, 1990; Gray, 2000; Husak, 2002; Fish, 2006; Fisher, 2006) argue that although the prohibition policy has been in existence for decades, the strategy has generally been unsuccessful in reducing the production, trafficking, and use of illicit drugs. In his recent book, The Political Power of Bad Ideas: Networks, Institutions, And Global Prohibition Wave, Schrad (2010:4) argues from a similar perspective regarding the inability of the US to win the so-called war on drugs. For Schrad (2010), a prohibition policy, which is aimed at altering behavior, in most cases, run the risk of failure as was clearly evident during the prohibition of alcohol in the 1920s. In Schrad's (2010) view, the current prohibition strategy of narcotics control reflects a similar case to alcohol prohibition and the likelihood of the failure of the existing narcotics policy along the same lines as alcohol seems possible.

\footnotetext{
${ }^{5}$ This claim was reported in the May 14, 2009 edition of The Wall Street Journal. Article by Gary Field."White House Czar Calls for End to 'War on Drugs.' http://online.wsj.com/article/SB124225891527617397.html Retrieved on $06 / 24 / 2010$.
} 
In a related argument, Fish (2006:1-4) agrees with Schrad (2010:5) that the consequences of a non-working policy (prohibition) not only create the incentive for an expansion of black markets, but incidents of crime waves, acts of corruption, and disrespect for the law also increase. For Nadelmann (1989) and Lee (1993), the existing emphasis on prohibition of narcotics control has only succeeded in stigmatizing drug users as criminals rather than taking a public health approach to dealing with drug abuse. Similarly, Baggins (1998) contends that criminalizing the use of narcotic drugs has not, after all, helped reduce drug availability as intended, but rather succeeded in compounding the drug problem through huge expenses annually incurred by the federal, state, and local government agencies involved in the implementation of the policy. Akiba (1997) and Thoumi (2009) also reflect on the global narcotics regime from a similar perspective. According to them, the global prohibition regime's option for restrictive laws on narcotics mandates member states to enforce the law with little or no other option for policy modification towards a more liberal approach to narcotics control. As Thoumi (2009:76) observes, many of these countries have flexibility towards stricter criminal laws against illicit drugs, but no flexibility of modifying their narcotic laws toward a more liberal policy option because of the dominant policy preference for the prohibition approach by the global narcotics regime.

For many observers, the existing drug policy, particularly in the US, is ineffective and misguided in many ways. In an article published in the New York Times titled "Drugs Won the War, "Nicholas Kristof (2009) ${ }^{6}$ reflects on similar issues about the ineffectiveness of the war on drugs. Kristof (2009) argues that since the war on drugs was declared about four decades ago,

\footnotetext{
${ }^{6}$ This article was written by Nicholas Kristof and published in the June 14, 2009 edition of the New York Times. Available at http://www.nytimes.com/2009/06/14/opinion/14kristof.html, Retrieved 10/10/2010.
} 
trillions of dollars have been spent prosecuting the war, while victory seems illusive. For him, the emphasis on criminalizing drugs has resulted in perpetuating three major social consequences for the United States. First, the increasing proportion of the prison population in the US for drugs felony charges alone is said to be nearly five times the world's average. Husak (2002) shares a similar claim and contends that the current drug laws in the US and abroad not only created a personal suffering for families of jailed drug victims, but these conditions have also increased the level of corruption within the law enforcement agencies as well as providing incentives for organized criminal activities in many countries. In the US, for example, nearly half a million drug offenders are currently languishing in jails, with this number accounting for more than the total number of prisoners in 1980 alone, and more than the entire European Union (EU) prison population (Husak, 2002).

According to Kristof (2009:1-3), the second major social consequence facing the United States as a result of the drug war is that most criminals involved in narcotic drugs have been engaged in other criminal activities such as money laundering, terrorism, rape, and murder. The third social consequence is that there has been a steady increase in the overall cost of fighting the drug war. For example, huge tax dollars are spent each year by the government on the drug war in key areas such as interdiction, policing, prison expenses, and other aspects of law enforcement. Besides the domestic cost of fighting the drug war, the US government also provides huge financial aid packages in the form of expensive and sophisticated military equipment (military helicopters) to Andean countries such as Colombia and Bolivia in their collaborative efforts with the US on the global war on narcotics control (Kristof, 2009). For example, Wyler (2009:5) reports that the US government has requested an amount of $\$ 15.1$ billion for federal drug control programs for the 2010 fiscal year alone. Of the total amount, 41 
percent, or $\$ 6.2$ billion has been requested for the United States' efforts in international narcotics control.

In reference to the Andean region, it is important to note that the region has for decades been one of the major sources of supply of illicit drugs (cocaine, marijuana, and heroin) into the US drug market (Drexler, 1997; Friesendorf, 2007). For some, the region represents the "epicenter" regarding the external dimension of the war on drugs (Drexler, 1997; Friesendorf, 2007; Crandall, 2008). Following the importance of the region, as well as the importance of other Latin American countries on the war on drugs, it is not surprising that these countries have for many years taken center stage within the US on political discourses and debates on the drug war. Although many successive governments and presidential candidates in the US have always invoked the drug war metaphor for political support, especially during presidential campaigns as previously noted, only a small fraction of success is often achieved in reducing the flow of these drugs into the US (Bertram et al. 1996). For example, during one of his 1988 campaign speeches, President George H.W. Bush said that "the cheapest and safest way to eradicate narcotics is to destroy them at their source" (Andean region).......We need to wipe out crops where they are grown and take out labs wherever they exist." Subsequent leaders have also made similar pronouncements concerning narcotics control over the years with little or no successes (Bertram et al. 1996:14).

A few scholars (Drexler, 1997; Hinojosa, 2007; Friesendorf, 2007; Crandall, 2008) have examined narcotics control cooperation between the US and other Latin American countries such as Colombia, Bolivia, and Mexico. Drexler's (1997) work, for example, provides an in depth analysis of relations between the US and Colombia on narcotics control. For Drexler (1997), the lack of effective narco-foreign policy by the US and Colombia can be explained by what he calls 
the "clash of interests" between the US and Colombia on narcotics control policies. According to Drexler (1997), the inability of the American policy makers to clearly understand Colombia and the region as a whole created the ineffective narcotics policy formulation in both countries towards each other. For instance, while the US government made clear its preferences and insisted that the Colombian government devotes US foreign assistance exclusively to fighting the war against narcotics, the Colombian government on the other hand, recognizes the problem of violence, and not drugs, as the main threat to their national interest. This created what Drexler calls the "clash of interests" between the US and the Colombian authorities (Drexler, 1997:159). Drexler sums up the argument this way:

No two countries have harmed each other so severely while maintaining friendly governmental relations as the United States and Colombia have done in buying and selling cocaine

(Drexler, 1997:1).

Another important part of the narcotics literature focuses on the global influence of the US on narcotics control. Bewley-Taylor's (1999a:5) work is among few in the literature that has systematically examined the hegemonic role of the US in the evolution and maintenance of the global narcotics regime since $1909^{7}$ and the efforts by the US to expand its global reach and crusade against illegal drugs. Within the broader literature on global narcotics control, few other works have examined the increasing criticisms on the existing prohibition approach. For these scholars (Nadelmann, 1990; Levine, 2003; Fazey, 2003; Bewley-Taylor, 2005; Bewley-Taylor and Woodiwiss, 2005; Huggins, 2005), ${ }^{8}$ the continuous existence of the prohibition approach has

\footnotetext{
${ }^{7}$ As noted in the introductory chapter, the first international meeting was held in 1909 in Shanghai, China, to discuss the Chinese opium epidemic in terms of control. The United States was the main convener of the meeting. The meeting laid the basic foundation for the international narcotics control regime.

${ }^{8}$ Huggins' (2005) work “Drug War Deadlock: The Policy Battle Continues” is an edited volume with a collection of different perspectives regarding the debate on prohibition/criminalization and decriminalization and harm reduction.
} 
only succeeded in creating many incentives for the increasing trade and use of narcotic drugs across the world. According to the 2008 Congressional Research Service (CRS) report on international drug control policy, the illegal drug trade generates an average estimated global proceeds ranging from about $\$ 100$ billion to more than $\$ 1$ trillion per year (Wyler, 2008:1).

\section{Demand-Side of Narcotics Control}

Unlike the supply-side approach, the demand-side control (harm reduction, harm minimization, decriminalization, or legalization) focuses on decreasing the negative consequences of drug use among addicts. The demand-side also provides treatment services for addicts and other educational programs aimed at preventing drug use (Inciardi and Harrison, 2000). While the debate on the prohibition approach of narcotics control continues to take center stage within the US narcotics policy domain, the drug control literature has seen an increase in other scholarly works in recent times on alternative narcotic policy options, with emphasis on a more liberal policy approach (demand-side approach) to narcotics control. New ideas on policy solutions are constantly emerging on the drug policy agenda, with constant demands for policy shift from the existing policy. For instance, many policy advocates, particularly those advancing the demand-side option, have emerged alongside groups that continue to also favor the prohibition approach. In fact, the ongoing campaign for policy alteration from prohibition strategy towards a more permissive policy option is not new to some countries (Levine, 2003; Ferraiolo, 2007).

Since the 1980s, for instance, the Netherlands has successfully administered a system that has decriminalized the sale of cannabis in a regulated manner (Levine, 2003:150). Other countries such as Switzerland, Canada, and Australia are also experimenting with the Dutch 
approach on a limited basis. Similarly, about fifteen states and Washington DC (see table 4.1) in the US have enacted laws to allow the use of marijuana for medical purposes, such as pain relief for nausea, cancer, and other forms of debilitating diseases (Ferraiolo, 2007). Although these laws, as they currently stand, conflict with the existing US federal laws on narcotics control, there are also some discussions on the economic benefits of legalizing marijuana in some key states in the US. The state of California, for example, is one of the leading states where measures are being considered for an outright legalization of marijuana for the purpose of raising tax revenues as a way of coping with their budget and other economic problems confronting the state in recent times. Although Proposition 19 (outright legalization of marijuana use) was defeated in November 2010 elections, many advocates of the Proposition argue that the state of California could have mobilized close to $\$ 1.4$ billion in taxes if marijuana were legalized. ${ }^{9}$

In a similar claim, Elliott and colleagues made a case for decriminalizing illicit drugs from a cultural perspective. For these authors, the use of all kinds of drugs that have now been criminalized has not been a problem for traditional native systems such as Bolivia, where the livelihood of many people have always centered on the chewing of coca leaves for many generations. For them, harm reduction intervention should be aimed at promoting easier access to care and support for drug addicts (Elliott et al. 2005:109-110). In a related argument, Husak (2002) finds it very problematic when illicit drugs continue to take the center stage, while many people die each year from tobacco smoking and the use of other tobacco products as compared to illicit drugs.

As many tobacco control scholars (Studlar, 2002; Mamudu, 2005; Asare, 2007; Cairney, 2009) indicate, millions of people die each year from cigarette smoking and the consumption of

${ }^{9}$ New York Times, July $29^{\text {th }} 2010$ Edition:

http://topics.nytimes.com/top/reference/timestopics/subjects/m/marijuana/index.html Retrieve on 10/15/10. 
other tobacco products rather than from illicit drugs. In fact, the Centers for Disease Control and Prevention (CDC) reports that "more deaths are caused each year by tobacco use than by all deaths from human immunodeficiency virus (HIV), illegal drug use, alcohol use, motor vehicle injuries, suicides, and murders combined." 10 The CDC also notes that cigarettes smoking, including the exposure to second hand smoke, are responsible for about 443,000 deaths (one in every five deaths) each year in the US. ${ }^{11}$ Although restrictive regulatory policies exist in many advanced industrialized countries and some developing ones to reduce the incidence of tobacco smoking, the use of tobacco products has not been criminalized or prohibited as the case with illegal drugs, irrespective of the high annual increase in tobacco-related deaths. For many prochange advocacy groups and individuals, it is incomprehensible and ironic why illegal drugs should not be treated in the same way as tobacco products. Nadelmann (2006), ${ }^{12}$ however, shares a different interpretation on the tobacco debate. For him, the recognition of the dangers of smoking as reflected in a recent nation-wide poll (Zogby International), where about 57 percent of Americans between the ages 18 to 29 favor making cigarettes smoking prohibited within the next five to ten years, appears revealing and may create some problems in the long term. From Nadelmann's (2006) perspective, keeping tobacco legal is perhaps the best policy option because any attempt to prohibit tobacco products might end up becoming like the current ineffective and fragmented illicit drug policy.

\footnotetext{
${ }^{10}$ The overview page of CDC website contains this information. http://www.cdc.gov/tobacco/data_statistics/fact_sheets/health_effects/tobacco_related_mortality/index.htm Retrieved on 1/28/2012. Also see U.S. Department of Health and Human Services. How Tobacco Smoke Causes Disease: The Biology and Behavioral Basis for Smoking-Attributable Disease: A Report of the Surgeon General. Atlanta, GA: U.S. Department of Health and Human Services, Centers for Disease Control and Prevention, National Center for Chronic Disease Prevention and Health Promotion, Office on Smoking and Health, 2010.

${ }^{11}$ Centers for Disease Control and Prevention Smoking-Attributable Mortality, Years of Potential Life Lost, and Productivity Losses_-United States, 2000-2004. Morbidity and Mortality Weekly Report 2008; 57 (45):1226-8).

${ }^{12}$ This article was published in the Huffingtonpost.com (2006). http://www.huffingtonpost.com/ethannadelmann/keep-cigarettes-legal_b_32477.html Retrieved on 10/15/10.
} 
As we have discussed thus far, it is clear from the preceding review of the literature that the broad trend of the scholarly works have largely addressed the inability of the existing prohibition policy to effectively control the production, trafficking, and use of narcotic drugs. Although most of these works tend to favor a shift in policy towards a more liberal approach, it must be noted that a few other works have addressed the need to maintain the existing narcotics prohibition policy. In the next few pages, I will attempt to briefly examine some of these arguments.

Most of the key federal agencies in narcotics control in the US such as the Drug Enforcement Agency (DEA), the Justice Department, Bureau of International Narcotics at the State Department, and the Office of National Drug Control Policy and other agencies involved in narcotics policymaking are among the strongest advocates for maintaining the existing prohibition strategy. In a recent report by the Congressional Research Service (CRS) to the US Congress, Liana Wyler (2008), the principal author, raised some critical issues as a response to some of the criticisms leveled against the prohibition approach and the increasing push to legalize narcotic drugs. For Wyler (2008:30-36), legalizing illicit drugs could lead to several negative consequences that may outweigh many of the positive gains that have been achieved with the existing prohibition policy. For example, the possibility of an increase in the demand for and use of illicit drugs as well as the level of addiction will be extremely high when narcotic drugs are legalized. Besides, the unrestricted access to these drugs by way of legalizing them will undoubtedly increase many societal problems such as gang violence, murder, armed robbery, money laundering, rape, terrorism and other problems associated with narcotic drugs. It is also likely to reduce the perception of the social and health risk factors associated with drug abuse. 
As Wyler (2008:30-36) and other scholars (Bennett, 2005; Wilson, 2005; Walters, 2005) indicate, there are critical and complex regulatory and legislative issues that might create serious problems if narcotic drugs are legalized. Some of the critical concerns, for instance, involve fundamental questions such as: What type of narcotic drugs need to be decriminalized and where will these drugs be bought and sold? There is also the concern about whether the production and distribution of the 'legalized' drugs will be under private or government control. Another area of worry is the kind of regulatory, quality control, and safety measures that will be adopted after these drugs are legalized. There is also a concern about whether these drugs could be taxed or not.

The debate ${ }^{13}$ over whether drug use has generally been on the increase or decrease, particularly in the US, has also been part of the broader discourse on narcotics control. Establishing the trends of decrease in narcotics use is extremely important to many of the federal agencies in order to continue to make the case for the prohibition policy strategy. A 2011 policy statement, Successes in the Fight Against Drugs (2000 through 2010), by the DEA indicates that marijuana use among American teenagers has dropped by 9 percent while the use of methamphetamine fell by about 60 percent from 2000 to 2010. During the same period, the report indicates that cocaine use among high school seniors dropped by 38 percent, while crack cocaine use also decreased by 30 percent during the same period under review. In addition, drug use in the work place remains at one of the lowest levels in more than 20 years, according to the report. Besides, the level of positive drug tests in many work places have fallen from 13.6 percent in 1988 to 3.6 percent in 2010. Similarly, cocaine use in the American work place has

\footnotetext{
${ }^{13}$ DEA report on the "successes in the fight against drugs, impact on demand from 1999-2009" claims with supporting evidence that drug use has generally been on the decrease. http://www.justice.gov/dea/pubs/cngrtest/success_in_fight_against_drugs.pdf Retrieved 08/10/11.
} 
declined from unprecedented figure of 68 percent between 2006 and 2010. The data also reveals that marijuana use in the workplace decreased by 12.5 percent in 2010 as compared the year 2006. $^{14}$

Overall, it is clear from the preceding discussion that two main narcotics control perspectives dominate the literature: the prohibition strategy of narcotics control (supply-side) and decriminalization (demand-side) of narcotics control. The review of the literature also reveals that quite a number of scholarly works show unchanging trends of the US narcotics policy from the prohibition option over time. As noted in chapter one, whether policy change is occurring or not is an empirical question that needs to be explored. Simply put, is policy change occurring within the US narcotics policy domain? To better answer this question, it is extremely important to first lay out the theoretical framework to help explain and understand the main research questions of the study. In essence, the next section will examine the main theories (agenda-setting, partisan ideology, orders of change, and regime theory) underlying this study.

\section{Overview of Policy Change Theories}

The theoretical field of public policy has advanced considerably within the past few years following the development of major theoretical concepts and models in explaining the policymaking process. Similar to other political systems, public policymaking in pluralistic political systems, such as in the United States is not only complex, but a very difficult process (John, 2003). In view of this complexity, John (2003) observes that many policy scholars have always faced a daunting intellectual task of constructing parsimonious theories that can fully explain the complexities of the policy process. Nevertheless, some scholars have developed

\footnotetext{
${ }^{14}$ Drug Enforcement Administration, Office of Public Affairs. p.1. http://www.justice.gov/dea/2010_successes.html Retrieved 08/10/11.
} 
major policy theories such as the Stages Model (Lasswell, 1956; Jones, 1970), Agenda-Setting (Baumgartner and Jones, 1993), Advocacy Coalition Framework (ACF) of Sabatier and JenkinsSmith (1993), Multiple Streams Approach (Kingdon, 1995), and Policy Paradigm Change (Hall, 1993) in explaining the policymaking process.

Generally, theories are very important conceptual tools that help scholars to reduce the complexities of a phenomenon for better understanding of the specific area of study (Robinson et al. 2004; Mintrom and Vergari, 1996; Lowry, 2006). According to John (2003), theories are based on verifiable claims of human actions, interactions, and power relationships that seek to provide coherent and consistent explanations for a given phenomenon. The same logic permeates the field of policy science research as scholars seek to understand why, for example, policies change or stay stable over time (John, 2003:482). As previously mentioned, public policies are dynamic and change over time, but why change occurs is the subject of many empirical studies in the political science literature (Lowry, 2006).

Similar to the accumulation of any scientific knowledge in other fields of discipline, the more recent theories of the policy process are grounded in the previous scholarly works in the field of political science. For example, the stages or heuristic model is one of the earlier theories employed by political scientists to understand the policymaking process. As Sabatier (2007:6-7) observes, the stages model has dominated the field in explaining the steps of the policymaking process before the mid-1980s. The model, which was advanced by scholars such as Lasswell (1956), Jones (1970), Anderson (1975) and Brewer and deLeon (1983), ${ }^{15}$ basically describes the policy process as a discrete system of stages or cycles. These stages generally include: agenda

\footnotetext{
${ }^{15}$ The reference to the early work of scholars of the stages model was quoted in Sabatier's (2007) edited volume (Theories of the Policy Process).
} 
setting, policy formulation, legitimation, implementation, and evaluation. Each stage has become the focus of different research agendas over the years (Sabatier, 2007).

While the stages model has provided a useful theoretical grounding for recent policy theories, as previously mentioned, it is important to indicate what distinguishes the more recent theories from the stages model. First, unlike the stages model, which focuses on analyzing the policy process from a linear perspective, the more recent theories such as the ACF, Punctuated Equilibrium (PE), Multiple Streams, Orders of Change, among others, seek to understand the policymaking process from a fluid perspective. Second, the more recent theories, particularly the Punctuated Equilibrium concept of Baumgartner and Jones (1993) integrate both incremental and non-incremental elements in their theoretical concept in explaining policy stability and change over time and space. This marks another important difference between the stages model and the new policy theories. In fact, the concept of incrementalism is an important one in the policy literature (Lowry, 2006). Borrowing the ideas of Lindblom (1959) and Wildavsky (1964), ${ }^{16}$ Robinson et al. (2004) argue that incrementalism is a gradual change that occurs to a given policy, especially with budget allocations. Based on similar ideas, Breunig and Koski (2006:366) share Padgett's (1980) view that incrementalism involves a marginal change in policy outcomes that are relative to some base policy. Non-incremental change or a third order change (Hall, 1993) involves a radical change to a stable (equilibrium) policy process (Baumgartner and Jones, 1993).

Clearly, the concept of policy change in terms of incremental and non-incremental is central to the study of policy dynamics. For Mintrom and Vergari (1996:420), policy change either explicitly or implicitly takes the center stage in the discussion of major theories of the

\footnotetext{
${ }^{16}$ The reference to the early works of Lindblom and Wildavsky on incrementalism was quoted in Robinson et al. (2004) “Explaining Policy Punctuations: Bureaucratization and Budget Change." p:140.
} 
policy process. For them, many scholarly works in the field have specifically addressed important theoretical questions on the conceptual definition of policy change, how it occurs, as well as who often constitutes the drivers of these changes.

For this study, I draw on the broad definitions of policy change by Capano and Howlett (2009), and Studlar (2009). For Capano and Howlett (2009:3), policy change means "something (policy) inherited from the past that has undergone transformation.” Likewise, Studlar (2009:73) defines policy change as "the movement of policy over time." The interpretation of these definitions suggests that public policies evolve, persist, and change over time depending on the factors that drive these changes. Similar ideas on policy change as involving the shifting nature of policy over time are shared by Hall (1993), Cairney (2007a), Skogstad (2009), Howlett and Ramesh (2002), Schmidt and Radaelli (2004) and Givel (2010).

While considerable literature exists on the theoretical explanation of policy change, only a handful of studies have specifically examined policy change within the context of regulatory/prohibited control policies such as tobacco control (Studlar, 2009; Cairney, 2007), alcohol prohibition (Schrad, 2010), and illicit drug control policy (Baumgartner and Jones, 1993:152). Few studies have also examined the dynamics of the policy process within the context of policy change and the US narcotics policy. In his book The Politics of Sin: Drugs, Alcohol and Public Policy, Meier (1994) examines the policy process by investigating the politics of morality policymaking in the US, but with focus on drug and alcohol policies. Excluding tobacco control policy, the author discusses the politics of narcotics and alcohol policy change over time. Meier's (1994) work is one of the few that has systematically examined the competing domestic forces (political, economic, social, and cultural) that shape the politics of 
drug and alcohol policymaking in the US. This work is particularly significant to my study for two reasons.

First, my work draws on this study in terms of the domestic forces (political and economic) and other players involved in the politics of narcotics policymaking in the US and how their actions shape policy change. Second, my work extends his study by examining how domestic forces drive or resist narcotics policy change. Broadly, Meier (1994) concludes, among others, that the US narcotics policy adoption and change is largely driven by political reasons. Sharp's (1994) study, which examines the US narcotics policy through the theoretical lens of Kingdon's (1984) three streams concept, also provide a useful theoretical grounding to this study. Although Manderson's (1993) work falls within the broader literature on policy change and narcotics policy, his work is still useful because of its comparative analysis of narcotics prohibition in Australia and other advanced industrialized countries. A few other useful works are Erlen and Spillane (2004), ${ }^{17}$ and Musto (1999), which focused on the narcotics policy process from a historical perspective. Having laid out the broad theoretical background for the study, my next task is to examine each theory in detail and outline how they might best explain the dynamics of the US narcotics policy change over time.

\section{Agenda-Setting Theory}

McLendon (2003:482) defines agenda-setting theory as the process by which an issue moves from relative obscurity to become a priority issue as a result of a serious attention being given to the issue by political actors in a policy process. Studlar (2002:65) however reminds

\footnotetext{
${ }^{17}$ Erlen and Spillane (2004) is an edited work, with contributions from other scholars with the general trend showing the evolutionary process of the US federal drug control policy.
} 
scholars to distinguish between agenda setting as a stage, which involves the process by which political actors address policy issues from agenda-setting theory, which basically explains why governments act as they normally do on policy issues. As many scholars (Baumgartner and Jones, 1993; McLendon, 2003; Studlar, 2002; Sinclair, 1986) share, the centrality of key questions such as how issues become issues, how issues are usually defined and redefined, how they gain prominence, and how they change over time underline agenda-setting theory.

Essentially, scholarly works on agenda -setting research tend to manifest in many forms and varieties. Most studies follow a longitudinal research design with the purpose of determining the rise and fall of policy issues or trends of change over time (Baumgartner and Jones, 1993:4647; Pralle, 2006:987). Considering the different varieties of the theory, my discussion of agendasetting in this study will focus on Baumgartner and Jones' (1993) version of agenda-setting theory-punctuated equilibrium-with further application of conceptual models such as issue definition/redefinition,venue shifting, and policy entrepreneurship to explain the dynamics of the US narcotics policy change in chapters three and four.

Baumgartner and Jones (1993) introduced the concept of punctuated equilibrium to the political science literature in the early 1990s. Drawing on the biological theory of punctuated equilibrium (Givel, 2010), the model integrates insight from the agenda-setting literature with elements of incrementalism and institutional theory to develop a conceptual framework capable of explaining both stability and change in the American policymaking system (Mortensen, 2007). Although some other major theories exist in the field, the last ten years has seen numerous scholarly works that have employed the PE theory as a useful theoretical concept to study many policy areas (John, 2003). The central argument of the PE theory states that the American policymaking process is characterized by a long stability of policy, often interrupted by a sudden 
or a brief burst, which create the avenue for changes in policy (Baumgartner and Jones, 1993, Jones and Baumgartner, 2005, Jones, Baumgartner and True, 1998).

For Baumgartner and Jones (1993:5-7), the American government structure is highly disaggregated among policy subsystems, with public policy outcomes the result of many actors and interests who tend to oppose each other. Quite simply, the PE theory seeks to account for both long periods of stability and short but violent periods of change in the policymaking process (Baumgartner and Jones, 1993; True, Jones and Baumgartner, 2007). Although the theory is primarily grounded in the American pluralistic political system, it has been applied to nonAmerican political systems, with some findings consistent with the theory while others appear inconsistent (Howlett, 1999; Soroka, 1999). Nevertheless, quite a number of scholars (Bressers and Lulofs, 2009; Mortensen, 2007; Worsham, 2006; John, 2003) share the view that the PE theory is distinguished from other policy theories because of its power to explain stability and change in a given policy process. However, the key puzzle that has engaged the attention of scholars is to understand how policy change occurs and the role that actors (political parties and interest groups) play within the broad system of the policy process in shaping change. Perhaps the dynamics of the subsystem politics may provide some explanation of why and how these policy changes occur.

\section{Subsystem Dynamics and Punctuated Equilibrium Theory}

One of the theoretical pillars through which Baumgartner and Jones (1993) discussed the workings of their model is through the subsystem politics. The literature on subsystem politics is vast and complex, and certainly beyond the scope of this study. However, I will broadly discuss 
subsystem politics through the lens of the PE theory and its applicability to narcotics policy change in the US.

Drawing on the ideas of Thurber (1991) and Meier (1985), ${ }^{18}$ Baumgartner and Jones (1993:6) contend that the policymaking process centers on decision-making systems that are organized around specific programs and policy issue areas. These policy issue areas are often characterized by a single dominant interest, group of interests, or policy entrepreneurs, ${ }^{19}$ with the goal of establishing a system of monopoly (subsystem) in a policy area. In other words, the underlying idea of subsystem politics rests on the assumption of a system that is characterized by struggle for influence and control within a complex policy environment, with different actors and interests. For Worsham (1997: 1), a subsystem emerges as a solution to the complex nature of the American policymaking process where the display of "action" politics takes place.

Broadly, the subsystem, as noted, is characterized by a system where policy monopolies are regularly constructed and destroyed because of the desire by each monopoly to dominate the system through strong institutional structures and policy ideas. In most cases, policy monopolies, in an attempt to protect their turf or territory, restrict opposing interest groups and other actors in gaining access into the subsystem (Sabatier and Jenkins-Smith, 1993; McCool, 1998; Worsham, 1998; Givel, 2006; Mortensen, 2007). For Givel (2006), one of the ways that policy monopolies dominate the subsystem is to use resources such as lobbying, litigation, and other mechanisms to prevent change from occurring within the system. Baumgartner and Jones (1993) describe the systemic maintenance of the system as a negative feedback mechanism that

\footnotetext{
${ }^{18}$ These scholars' ideas on subsystems were cited by Baumgartner and Jones (1993:6).

${ }^{19}$ Mintrom and Vergari (1996:422) define policy entrepreneurs as policy advocates who undertake specific actions and perform certain key roles that affect the policymaking process as business entrepreneurs do for the market place. In essence, their main goal is to design new ideas, push for these ideas for radical policy change to occur.
} 
operates as a self-correcting system with institutional arrangements that favors the preservation of the status quo. However, when external pressure is exerted for change on the negative feedback system, the system reacts to such forces by making incremental policy adjustments (Worsham, 2006:438; Robinson et al, 2007; John, 2003). Besides, Baumgartner and Jones (1993:16) argue that issue redefinition and expansion to previously disinterested members also create avenues for policy changes.

On the other hand, positive feedback occurs as a result of an escalation of change occurring within the system due to major outside forces or critical junctures, which create the avenue for a major policy change (Baumgartner and Jones, 1993; Robinson et al. 2007). In fact, Brisbin and Hunter $(2007)^{20}$ made a similar observation on how policy punctuations and critical junctures create policy revision or change. For them, besides policy punctuations and critical junctures, policy change also occurs as a result of long policy conflicts and accumulated negative feedback processes, which create a window of opportunity for policy revisions to stable policies. Building on the ideas of policy punctuations, critical junctures, and the psychological models of decision making, Brisbin and Hunter (2007) proposed a theoretical concept of panic policymaking $^{21}$ to explain policy change. For Brisbin and Hunter (2007:2), policy change in the contest of panic policymaking occurs within a short time limit as a result of decisions often made through urgent or panic situations.

Worsham (1997:3-6; 1998) has also advanced the field of subsystem politics by identifying three main typologies of the subsystem (dominant, transitory, and competitive). For

\footnotetext{
${ }^{20}$ Brisbin and Hunter's argument is made in a paper presented on the topic "Panic Policymaking: Canine Breed Bans in Canada and the United States" at the 2007 Western Political Science Association Conference, Las Vergas, 2007

${ }^{21}$ Brisbin and Hunter (2007) define panic policymaking as the "speedy creation of new laws and regulations or new duties for governmental and private institutions in a situation of sudden, unreasoning, and excessive fear and anger."
} 
him, the dominant system resembles the iron triangles, while the transitory system is fluid, where dominant coalition members do break up into different interests. The competitive system comprises new coalitions capable of challenging the existing policy monopolies and the institutionalized ideas and dominant groups within the subsystem (Worsham, 1997; Givel 2006). Drawing on the logic of the PE theory in explaining subsystem variations, Worsham (1997:7-8) contends that if policy monopolies are formed as a result of strong institutionalized structures and powerful supporting ideas (Baumgartner and Jones, 1993), it is likely that one can also explain subsystem change by identifying the challenges to the institutional structure(s) and the underlying idea(s) to the system for policy change. Worsham (1997) concludes his study by arguing that the American subsystem politics, particularly the financial subsystem since the 1990s, depicts the nature of a wavering equilibrium (a concept that distinguishes between three types of subsystem politics) rather than a punctuated equilibrium.

Undoubtedly, subsystem politics, as most scholars (Baumgartner and Jones, 1993; Worsham, 1997; Givel, 2006) agree, is characterized by the politics of influence and control. The competitive system identified by Worsham (1997), appears to dominate most contested policy areas such as narcotic and tobacco control policies. Sabatier and Jenkins-Smith $(1999,1993)$ also advanced the study of subsystem politics with their theory of Advocacy Coalition Framework (ACF). As earlier noted, this study does not intend to test the validity of the ACF with this research project. It is certainly beyond the scope of this study. However, the ACF is still useful and will broadly and briefly be discussed within the concept of the subsystem politics to understand the nature of the US narcotics policy subsystem.

Grounded in the pluralist system of policymaking, the ACF assumes that policy making and change are the result of the interactions among key policy actors, interest groups, political 
parties, and government agencies within a given subsystem. The model identifies belief systems that are categorized into deep core and policy core within a subsystem. For Sabatier and Jenkins-Smith (1999), coalitions are often organized on the basis of dominant and minority groups, with the objective of dislodging the status quo interest, while others seek to maintain the status quo (Birkland, 1997:135).

Applying the ACF model to the US narcotics policy, it is apparent that the dominant actors are the pro-prohibitionist groups whose objective is to keep the status quo prohibition policy in place with limited change or no change at all to the existing policy. Baumgartner and Jones (1993:154) identify the federal narcotics enforcement agencies as the dominant coalitions within the US narcotics policy subsystem. These groups have for a long time dominated the system with strong established institutions and policy ideas based on the prohibition model of narcotics control. Outside interest groups with links to the dominant coalition groups in the subsystem also help to preserve the status quo policy. Natural allies of the federal drug enforcement agencies such as the Anti-Saloon League (ASL) and the Women's Christian Temperance Union (WCTU) have been very active in past years in their efforts to preserve the existing narcotics prohibition model (Baumgartner and Jones, 1993). As Sabatier and JenkinsSmith (1999) observe, groups with deep core beliefs about the system find it difficult in most cases to affect major policy changes to the system.

On other hand, the minority coalitions are the reformist groups such as many policy advocacy groups, think tanks, and policy entrepreneurs whose primary objectives are to shape policy change. In the case of US narcotics policy, anti-prohibition policy advocacy organizations such as the Drug Policy Alliance, Marijuana Policy Project, Law Enforcement Against Prohibition, and the Criminal Justice Policy Foundation constitute the main minority coalition 
groups involved in shaping the existing prohibition policy towards a more public health approach to narcotics control.

As revealed in the analysis of the subsystem and PE concepts, a radical policy change can occur when exogenous forces impact the subsystem, thereby creating a window of opportunity (Kingdon, 1984) for other coalitions to influence policy change. Similarly, changes can also occur as a result of a focusing event. ${ }^{22}$ For example, Birkland (1997) argues that pro-change groups often use a focusing event to elevate their issues into the policy agenda. However, this study assumes that it may be extremely difficult for a focusing event to occur within the narcotics policy domain, unlike other policy areas such as energy, health, and transportation. It is unlikely that a sudden change in the form of a focusing event might occur with the narcotics policy to warrant a drastic policy change to the existing policy. Perhaps the relentless efforts by some of these pro-change advocacy groups (national and transnational) might be the effective channel through which the existing prohibition policy regime will experience a drastic change. In fact, Keck and Sikkink's (1998) study has examined the important role of transnational advocacy networks in shaping global policy change. Policy change is more likely to be driven by these advocacy networks because of their concerted efforts, shared ideas, values, and the common goals and strategies they often employ to effect policy change. This is equally true for the domestic advocacy groups, particularly those in the narcotics policy domain whose objective is also to affect policy change.

The preceding analyses of the PE theory and the subsystem politics have clearly shown that these concepts could explain the dynamics of the US narcotics policy change from a broader perspective. While this broader perspective might be useful to some extent, one could argue that

${ }^{22}$ Birkland (1997:1) defines a focusing event as a sudden and an unpredictable event that tends to shape and influence a public policymaking process. 
the concepts of issue definition/redefinition, venue shifting, and policy entrepreneurship, which constitute an important framework of the agenda-setting theory, might offer a better explanation for the US narcotics policy change over time. The next section will examine these concepts and their theoretical usefulness in shaping the US narcotics policy change.

\section{Issue Definition/Venue Shifting and Policy Entrepreneurship}

For students of agenda-setting theory, the concepts of issue definition/redefinition, venue shifting, and policy entrepreneurship are crucial in understanding the dynamics of policy change within the broader theoretical framework of agenda-setting (Howlett, 1997; Studlar, 2002; Pralle, 2006; Princen, 2007). Baumgartner and Jones (1993:23) define issue definition as a purposeful process by which political leaders accomplish certain goals and objectives. In their book: The Politics of Problem Definition in Shaping the Policy Agenda, Rochefort and Cobb (1994) argue that problem definition has to do with what the public and political leaders choose to identify as public issues and how people generally think and talk about those issues. As Baumgartner and Jones (1993) put it, issues are defined and redefined through the construction of policy monopolies and the destruction of other monopolies.

As revealed in the discussion on subsystem politics, the overriding goal of a policy monopoly is to dominate the policy subsystem with their ideas and institutional frameworks to sustain the system, while others with alternative ideas and interests also strive to infiltrate the system with their issues and ideas. In fact, the system can either be sustained or changed based on how an issue is defined or redefined, and more importantly, how an issue can be expanded to previously disinterested groups (Baumgartner and Jones, 1993; Pralle, 2006). Recounting 
Schattschneider's $(1960)^{23}$ idea on the enlargement of political conflicts and policy change, Baumgartner and Jones (1993:11) share a similar view that the essence of political conflict does not only facilitate the scope of participation, but in most cases, contentious policy issues have always attracted more disinterested people than those closely involved with the issue. This is equally true for the existing narcotics prohibition policy. Applying this concept to the broad narcotics policy process, it is clear that the US narcotics policy issue has been defined and redefined from many perspectives over the years. The third and fourth chapters will examine the details of this argument with evidence to support the theoretical significance of issue definition/redefinition to this study.

Venue shopping or shifting is another concept within the broader agenda-setting theory that explains the dynamics of policy change. According to Baumgartner and Jones (1993:32), "policy venues are the institutional locations where authoritative decisions are made concerning a given issue." For Pralle (2006:172), venue shopping entails the search for alternative policy arenas by policy entrepreneurs with the purpose of moving decision-making authority to new venues. In a similar study, Pralle (2003) contends that advocacy groups and policy entrepreneurs choose venues not only for the purpose of a short-term strategic interest, but for their new understanding of an old issue, with the possibility of affecting change on the issue.

As Pralle $(2006,2003)$ observes, venue shopping, which is intertwined with issue redefinition and policy entrepreneurship within the broad framework of agenda-setting, is significant for understanding the policy process from two main perspectives. First, a vital aspect of venue shifting also involves a redefinition of the image of an issue. Second, venue shopping has become an essential driving force for policy change. In the narcotics policy case, for

\footnotetext{
${ }^{23}$ Schattschneider's statement was quoted in Baumgartner and Jones (1993:11).
} 
example, the evidence of venue shifting in explaining policy change was evident in the successful change in venue of the medical marijuana issue to the state level following the introduction of the ballot initiative in some parts of the US in the early 1990s (see Chapter four).

Similarly, policy entrepreneurship also constitutes another important concept within the broad agenda-setting theory in explaining policy change. In Studlar's (2002:180) terms, political or policy entrepreneurship is "the ability to take advantage of circumstances to push an issue onto the public and government agenda." For Mintrom and Vergari (1996:422), policy entrepreneurs undertake specific actions and perform certain key roles that affect the policymaking process as business entrepreneurs also do for the market place. Like the business entrepreneur, the policy entrepreneur is often willing to invest their resources, time, reputation, energy, and money for a window of opportunity to be opened for the promotion of a policy change (Kingdon, 1984; Mintrom and Norman, 2009; Crow, 2010).

In fact, Kingdon (1984) has not only pioneered the use of the term policy entrepreneurs, (Mintrom and Norman, 2009) in his theoretical concept of multiple streams, but has also discussed the importance and the role of these entrepreneurs in pushing their "pet projects" or favored policy solutions onto the central agenda for action. More recently, other scholarly works (Mintrom and Norman, 2009; Bakir, 2009; Crow, 2010) have shown the importance of policy entrepreneurs as vital agents in promoting policy change. Besides individual policy entrepreneurs, groups, as Crow (2010:301) argues, have also been shown to have the ability to act as entrepreneurs due to their size, resources, and political influence in shaping policy change. Clearly, the concept of policy entrepreneurship provides a theoretical utility in explaining the dynamics of US narcotics policy change (see chapter four) over time. In fact, the role of individual policy entrepreneurs, such as George Soros, Montel Williams, Ethan Nadelmann, and 
the recently instituted Global Commissioners on Drug Policy (see appendix six) with the purpose of shaping the US and the global narcotics policy are good examples.

The preceding analysis clearly suggests that the agenda-setting theory with the punctuated equilibrium version can be widely applicable to study the narcotics policy process. More importantly, the specific versions of issue definition/redefinition, venue shifting, and policy entrepreneurship provide a better explanatory power for the US narcotics policy change over time (see chapters three and four). Yet still it is apparent through the reviewed literature that the US narcotics policy has undergone changes in the levels of attention on systemic and institutional agendas ${ }^{24}$ since the $1900 \mathrm{~s}$. For example, the narcotics issue, according to Baumgartner and Jones (1993:153-160), were not a primary concern for the media during the first few years of the twentieth century. While some level of attention (systematic and institutional) occurred in the 1930s, 40s, and 1950s, it was not until the mid-1960s to the early 1970s that the drug issue surged in public attention, particularly in the media, as a result of the increasing use of narcotics, the role of Anslinger and enforcement agencies, and Nixon's socalled declaration of war on drugs in the early 1970s (Baumgartner and Jones, 1993; Sharp, 1991).

In view of this, the question of whether similar changes are occurring to the narcotics policy since 1993 is of interest to the scope of the study. As previously noted, the key question this study seeks to explore is whether change is occurring with the US narcotics policy in terms

\footnotetext{
${ }^{24}$ Systemic (public or media) agenda involves the domain of the general public, where policy issues are discussed by the public. The media most often leads the discussion in the systemic agenda. Institutional (formal or governmental) agenda involves agencies of the main branches of government and other governmental agencies. This is where policy problems are given serious attention by decision makers (Cobb, Keith-Ross \& Ross, 1976:1-2;

Anderson, 2003).
} 
of nature, type, and scope. In essence, the two main hypotheses that emerge based on the examined theories are:

- The scope of the US narcotics policy has widened and is undergoing incremental policy change.

- The rise of drug liberalization advocacy groups/policy entrepreneurs has led to changes in the US narcotics policy since the 1990s, particularly at the state level.

\section{Partisan Ideology}

Partisan ideology is another theoretical concept that has been used to explain policy outcomes (Stratmann, 2000; Imbeau et al. 2001; Wright and Schaffner, 2002; Studlar, 2005), hence its possibility of explaining the US narcotics policy outcomes. As Wright and Schaffner (2002) have observed, political parties are widely considered as necessary for a modern democratic system of government. Unquestionably, political parties are rooted and clearly distinguished by their stable ideological orientations or system of beliefs and principles that permeate the very wide spectrum of policy issues. In most cases, political elites tend to reflect their partisan ideology either through their voting records, policy actions, or policy inactions (Stratmann, 2000; McCarthy el at. 2006).

Although there are considerable variations in liberal and conservative positions within the Democratic and Republican parties (Poole and Rosenthal, 1984) in the US political system, it is apparent that Democrats are generally liberal in their ideological orientation while Republicans are generally conservative in theirs (Entman, 1983; Schmidt, 1996; McCarthy el at. 2006). For McCarthy et al. (2006:1), the ideological divide between Democratic and Republican parties have, over the past years, made them desert the political center in favor of their extreme wings (left or right). 
While partisan ideology appears to be widely applicable in explaining differences and similarities in policy outcomes, Studlar (2002: 72) contends that there is no uniformity of opinion among scholars on how policy outcomes are shaped by partisan ideology. As Studlar (2002) argues, students of policy legacy theory (Rose and Davies, 1994; Rose, 1990) share the assumption that new policy outcomes are largely driven by policy inheritances (past policies). The interpretation of this assumption is simple. Most policies are inherited by new governments, who in most cases continue with the policies of the past government without often making huge changes to the existing policies. Although this argument is useful to the broader theoretical policy debate, many scholarly works (Entman, 1983; Schmidt, 1996; Imbeau et al. 2001; Stratmann, 2000; Studlar, 2002; 2005) have also shown with convincing evidence that policy outcomes are sometimes driven by partisan ideology. This has clearly been evident in the case of the US narcotics policy process over time. For example, while the Republican ideological approach has tendencies towards a more restrictive or dominant prohibition approach (emphasis on law enforcement) the Democratic ideology has tendencies towards a more permissive policy approach (emphasis on treatment and public health) to narcotics control (see chapters three and four).

Although some minor variations do occur over time and space within the two parties, in principle, the strict ideological division on narcotics control remains intact (Bertram et al.1996:140-141). In view of this theoretical analysis, this study hypothesizes that:

- Democrat presidents and legislators (Congress) are more willing to effect changes to the existing narcotics policy away from the strict prohibition policy regime than Republican presidents and legislators. 


\section{Policy Paradigm Theory (Orders of Change)}

This section examines Hall's (1993) theory of policy paradigm change (orders of change) in understanding the dynamics of change within the narcotics policy process. Hall's (1993) theory has gained momentum in recent years following the way in which the theory has shaped the thinking of the policy literature (Howlett and Ramesh, 2002:33; Breton et al. 2008:353; Skogstad, 2009:94). Quite a number of studies (Capano, 2003, 2009; Howlett and Ramesh, 2002; Skogstad, 2009, Studlar, 2009; Cashore and Howlett, 2007; Hausermann, 2009) have applied Hall's concept to study different policy sectors. Similarly, my study draws on these works, particularly on Hall's (1993) theoretical ideas to explain change within the US narcotics policy.

The central argument of Hall's theory is that policy change occurs in stages or orders. Hall (1993:281-285) conceptualized the policy change process into a typology of first order, second order, and third order changes. For Hall (1993:278), the policymaking process involves three fundamental components:

(a) The overall goals of a policy.

(b) The techniques or policy instruments used to attain those goals.

(c) The precise settings of the policy instruments.

For example, "if the goal of the policy is to alleviate the financial problems of the elderly, the chosen instrument might be an old age pension, and its setting would be at the level at which benefits were set" (Hall,1993:278). Hall's (1993) argument rests on the basic idea that change can best be understood when each component parts of a policy (policy goals, policy instruments, and the settings of policy instruments) are separately examined. In fact, Capano and Howlett (2009) have advanced Hall's (1993) conceptual ideas and termed it policy compartmentalization. For them, the policy process is complex and multi-dimensional, and what actually change in a 
policy is not simple the policy as a whole, but it is the specific component parts of a policy that experience the change.

According to the concept, first order change in policy occurs when the settings of a policy instrument changes. In other words, first order change occurs when the settings of an existing policy instrument are adjusted to attain some specific set of policy targets. In most cases, these changes are incremental (Lindblom, 1959) in nature. For example, changes in the annual budgets, personnel, or minimal severity in punishment regarding a particular narcotic prohibition laws. Besides, a change to increase the safety or emission requirement for an automobile manufacturer is another good example of a first order policy change (Cashore and Howlett, 2007:535). While these changes occur to the settings of the policy instrument, the policy goals and the policy instrument itself generally remain unchanged. For Hall (1993:278-281), internal bureaucratic experts, with minimal or no external influence, constitute the main driving force for the occurrence of a first order change in policy.

A second order change involves an alteration to the priority of a policy instrument. This process of change can also involve the introduction of a new policy instrument. In essence, the policy instrument is what actually experiences the change in a second order change in policy. In other cases, an innovative priority could be made to the existing policy or a new instrument added during the process of a second order change. An example that Cashore and Howlett (2007) provide to illustrate the occurrence a second order change is again useful here. For instance, a change from one policy instrument of an administered emission standard to another instrument of an emission tax may constitute a second order change in policy (Cashore and Howlett, 2007). In the case of narcotics policy, a shift in policy instrument towards a more restrictive policy 
option or towards a more permissive policy approach demonstrate a clear evidence of a second order change in policy (see chapters three and four).

It must also be noted that while changes occur to policy instruments during a second order change, the overall policy goals generally remain unchanged. In terms of the factors that often ignite these changes, Hall (1993) argues that a second order change might occur as a result of a general dissatisfaction with an existing policy instrument. In addition, the external influence of key policy advocates such as bureaucratic experts with a strong leaning for a policy change, particularly in the executive branch of government, could facilitate and drive a second order change in policy.

A third order change involves a major paradigm change or a radical shift in a policy (Hall, 1993; Studlar, 2009; Breton et al.2008). From Hall's (1993) conceptualization, a third order change occurs with concurrent changes to all the three component parts (settings of policy instruments, policy instruments, and policy goals) of a given policy. According to Hall (1993), the radical change from Keynesianism to monetarism as a system of economic policymaking in Great Britain during the 1970s and 1980s clearly demonstrate a very good case in point. While the existing US narcotics policy is yet to experience any evidence of a third order change (see chapter four and five), the dramatic change of tobacco policy from agriculture and economic policy domain, to public health and regulatory policy subject (Studlar, 2009), is a very good case in point of a third order change in policy. 
Table 2.1

\section{Hall's Theoretical Typology of Policy Change}

\begin{tabular}{|l|l|}
\hline Orders of Change & \multicolumn{1}{c|}{ Description of Change } \\
\hline First Order Change: Change occurs in the settings of the policy instruments. The decision \\
making process is routine and happens from the experiences of bureaucratic officials with new \\
knowledge and ideas. External influence is limited in the decision making process.
\end{tabular}

Second Order Change: Change in the priority of the policy instruments (policy tools) with the introduction of new policy instruments. Policy instruments are often altered in response to past experiences, new knowledge and ideas, or for strategic reasons, but within the same policy goals.

Third Order Change: A fundamental paradigm (radical) change in the policy goals, policy instruments, and the settings of the instruments (all the three components), e.g from Keynesianism to monetarism in the UK (1970-1989).

Source: Adapted from Breton et al. (2008:353 and Studlar, 2009:73) with some modifications.

A close observation of Hall's typology (table 2.1) reveals that both first order and second order changes in policy are generally incremental in nature (Lindblom, 1959). As noted in the introductory chapter, the theoretical goal of this study is to employ the three domestic policy theories (agenda-setting, partisan ideology, and policy paradigm theory or orders of change) as competing explanations for US narcotics policy change. The purpose is to determine the theory that offers the best explanation for the changes. As we will see in chapter four, Hall's (1993) theory appears to provide that persuasive explanation for the US narcotics policy change since 1993.

Clearly, the preceding discussion reveals that the underlying theories of this study provide useful tools in understanding the US narcotics policy process over time. It must, however, be noted that while the broad punctuated equilibrium version of agenda-setting theory, with conceptual variations (issue definition/definition, venue shifting, policy entrepreneurship), and the concept of partisan ideology provide very helpful theoretical tools in explaining the US 
narcotics policy change, this study argues that these theories (agenda-setting and partisan ideology) are limited in providing a complete explanation for the US narcotics policy process, particularly on the nature, tempo, and scope of the US narcotics policy change. In essence, my argument is that the change occurring within the US narcotics policy domain is largely incremental in nature and can best be explained by Hall's (1993) orders of policy change.

In essence, this study argues that Hall's (1993) orders of policy change offers a more persuasive explanation to the changes occurring within the US narcotics policy process in terms of nature, tempo, and scope, particularly from 1993. In view of this theoretical assumption, I hypothesize that:

- $\quad$ The nature of US narcotics policy has largely been a second order change.

- The tempo of US narcotics policy change has been one that is slow.

- $\quad$ The scope of US narcotics policy change has widened over time and space.

\section{Theoretical Overview of International Regimes}

International regimes have occupied a prominent place in the international relations literature ever since Ruggie (1975) first articulated the concept of regime dynamics (Hasenclever et al. 1997; Krasner, 1983) in the early 1970s. Various theoretical explanations exist on the emergence, continuity, and change of international regimes. In his early work on regime dynamics, Young (1983:93) defines international regimes "as social institutions governing the actions of those interested in specified activities or accepted sets of activities.” For Jervis (1983), international regimes have the primary responsibility of governing the relationship among states in an issue area through agreed principles, norms, and procedures. In Krasner's (1983:20) view, regimes are "sets of implicit or explicit principles, norms, rules and decision-making procedures around, which actors' expectation converge in a given area of international relations." Clearly, 
the expectations of states that converge through networks of rules and procedures, which regulate their behavior (Young, 1983; Keohane and Nye, 1977) cover many global issue areas such as tobacco control (Studlar, 2002, 2004, 2005; Mamudu, 2005; Asare, 2007), illicit drugs (Nadelmann, 1990: Bewley-Taylor, 1999), environment (Young, 1999), monetary and trade (Lipson, 1982; Krasner, 1983; Haggard and Simmons, 1987: 493).

As mentioned, the evolution, maintenance, and change of international regimes have been explained from different theoretical perspectives in the international relations literature. For Hansenclever, et al. (1997:1) and Krasner (1983:10), the emergence of international regimes can be examined from three main theoretical perspectives (interest-based, knowledge-based, and power-based). Grounded in neo-liberal assumption, ${ }^{25}$ the interest-based explanation argues that international regimes emerge when states with shared interests foster cooperation at the international level on issue areas of concern to them. The knowledge-based explanation emphasizes shared normative ideas, causal beliefs, and institutionalism as the most important incentives for regime formation among states.

The power-based explanation of regime formation and maintenance is linked to the presence of a hegemonic state in the international system (Hansenclever, et al. 1997). This explanation draws much from the realist and neo-realist theories of international relations. One of the central assumptions is that the structure of the international system is anarchical, ${ }^{26}$ and states survive through self-help with power capabilities (military, economic, technology), which tend to shape and drive their behavior in the system (Waltz, 1979; Mearsheimer, 2001).

\footnotetext{
${ }^{25}$ The neo-liberal assumption is within the context of the concepts of global interdependency and cooperation.

${ }^{26}$ The international system is anarchic because it lacks an authoritative government that can enact and enforce rules of behavior. Simply, the anarchy nature of the global system is a self-help system (Keohane, 1984, Mearsheimer, 2001).
} 
Although the system is anarchical in nature, states do cooperate among themselves (Keohane, 1984). The structural explanation for the conduct of states in the international system has, however, been challenged by emerging scholarly works on the theoretical concept of domestic explanations of foreign policy decision making (Hagan, 1994, 2001) and the recent field of psychological determinants of foreign policy decision making (Crichlow, 2002; 2005; Hermann and Hermann, 1989; Schafer and Crichlow, 2002) in the international system. As Crichlow (2002:694) rightly noted, the research on political psychology has shown with compelling evidence that individual psychological characteristics, leaders' cognitive complexity, and their worldview, tend to shape their foreign policy decision-making process and their overall relations with other countries in the global system. Notwithstanding, the centrality of the structural explanation with emphasis on hegemonic influence in regime formation and maintenance continues to dominate the regime literature.

\section{Hegemonic Stability Theory}

The hegemonic stability theory (HST) is a well established research tradition in the regime literature. As noted in chapter one, my definition and application of the broad ideas of the theory is not in the original sense of the term since the US was not a global hegemon before 1909. This study applies the term in a broad sense to illustrate the leadership role of the US (Bewley-Taylor, 1999a) in global issue areas such as narcotics control since 1909. The obvious question is: what is a hegemonic stability theory and what are its basic tenets? According to Gilpin (1987:72), the conceptual idea of a hegemonic stability theory was set forth by Charles 
Kindleberger ${ }^{27}$ "although he preferred the term leadership or responsibility." Originally applied to the world economic system, Gilpin (1987) argues that the theory advocates and supports the existence of a hegemonic or a dominant power in maintaining order in an open and chaotic liberal world economic system. Expounding on the basic ideas of the theory, Keohane (2005:31) notes that the HST has two principal tenets. First, the theory assumes that order in the global political system is typically created by a single dominant power. Second, the theory claims that the maintenance of order in the international economic system requires the continuous presence of a hegemonic power.

In Cronin's (2001) terms, a hegemonic dynamic reflects in unequal power relations among states where one state becomes so powerful to exert control and influence over other states in the global system. For Ikenberry (1989), the necessity of a great power with the ability to create and maintain order in the international system is what constitutes the central assumption of the hegemonic stability theory. For example, the "Pax Britannica and Pax Americana ${ }^{28}$ both represent historical eras when a hegemonic power held sway and use its dominant position to ensure an orderly and peaceful international system" (Ikenberry, 1989:377). By implication, many regime scholars such as Ikenberry (1989), Gilpin (1987), Young (1983), and Krasner (1983) agree that a hegemonic power has the capacity to establish and maintain norms and rules for order within the global system. In his classic work, After Hegemony, Cooperation and Discord in the World Political Economy, Keohane (1984; 2005), however, contends that international regimes do emerge by state actions in order to promote cooperation and mutual

\footnotetext{
${ }^{27}$ The original idea of hegemonic stability theory was in Kindleberger's work (1973). This information was quoted in Keohane (2005:31).

${ }^{28}$ Pax connotes a period of relative stability and peace in the international system with a hegemonic power in control of the system. Great Britain in the nineteenth-century is a very good example. Also see Keohane (2005:31).
} 
benefits. Keohane $(1984 ; 2005)$ also argues that a hegemonic power may not necessarily be a sufficient condition for the evolution of cooperative relationships among states.

As previously noted, the US did not attain a hegemonic status when the global concern over narcotics (Chinese opium problem) emerged on the international stage in 1909. However, the US acted in that capacity by not only convening the first international meeting, but became very instrumental in the evolution of the global narcotics regime. In fact, Bewley-Taylor (1999a) and Cronin (2001:115) agree that the leading role by the United States in global narcotics control intensified after the US attained a hegemonic status in 1945 (post-World War II era) and in the 1990s (post-Cold War era).

Without doubt, the US has played and continues to play such a leading role in many international issue areas, including global narcotics control for the past several decades (Andreas and Nadelmann, 2006; Bewley-Taylor, 1999a). There is also a growing perception among some scholars (Clark, 2009; Russett, 1985:208) about America's vanishing hegemonic influence, particularly when competing economic power bases such as Germany and Japan emerged in the post World War II era. The debate over the decline of America's dominant power has actually increased in recent years, particularly over the perception of America's inability to maintain a global systemic order following the recent global economic turmoil (Dieter, 2009).

On the contrary, other scholars (Nye, 2010; Huntington, 1999:36; Brooks and Wohlforth, 2002) maintain that the US is not in absolute decline in hegemonic status as has been argued by some scholars. For these scholars (Huntington, 1999:36; Brooks and Wohlforth, 2002), the US in the post-Cold War era is still the sole country with the preeminence of major power capabilities (economic, military, ideological, diplomatic, technological, and cultural), and the only nation with global reach in promoting its interests and influence. Applying the hegemonic 
stability theory to the global narcotics regime, it is apparent that the theory reflects a similar behavior of the US as the dominant power on the existing global narcotics prohibition regime.

\section{Global Narcotics Regime}

While considerable scholarly works exist on the theoretical evolution and maintenance of many international regimes, only few have applied regime theory to analyze the global narcotics prohibition regime. Drawing on the broad regime theory, Nadelmann (1990) first introduced the concept of global prohibition regime into the regime literature. His work traces the emergence of norms in the international system that prohibit issues such as piracy, slavery, counterfeiting in national currencies, aircraft hijacking, and the production, sale, and trafficking of controlled psychoactive substances (Nadelmann, 1990: 479).

Under the global narcotics regime, production, trafficking, sale, possession, and use of narcotic drugs, hallucinogens, barbiturates, amphetamines and tranquillizers, except for scientific and medical purposes, are prohibited and punished with criminal sanctions in almost every country in the world (Nadelmann, 1990:503; Bewley-Taylor, 1999a, 2003; Levine, 2003) with the US as the lead country involved in the regime. In fact, the assumption that a hegemonic power shapes international regimes to reflect its interests and values (Levine, 2003; BewleyTaylor, 1999a, 2005; Hinojosa, 2007; Coulkins et al. 2005; Friesendorf, 2007) is a very wellestablished argument in the regime literature. Clearly, the rise of the US to great power status, by the middle of the twentieth century, greatly shaped the maintenance of the global narcotics control regime (Bewley-Taylor, 1999a, 2005). As Andreas and Nadelmann (2006) posit, the internationalization of policing across the globe in the form of global regimes reflects efforts by generations of Western powers, including the US, to export their own interpretation of crime in 
the form of prohibition norms and values on the rest of the world. In a related argument, Bruun et al. (1975:273-274) contend that the international narcotics control regime, for example, cannot be said to be truly international in dimension, but it is a reflection of the ideas and norms of the dominant member (United States) in the global system.

Bewley-Taylor (1999a) has rightly captured this argument in his study on the role of the US as a hegemonic power in the evolution of the global drug prohibition regime. Grounded in the regime theory (Krasner, 1983; Keohane, 1984), Bewley-Taylor's (1999a:5) work examines what he called the "American international crusade against illegal drugs and the central role played by the United States in the creation of the contemporary global drug prohibition regime." Room and Paglia (1999:310) share a similar view that the US has not only pursued a domestic prohibition strategy of narcotics control, as previously stated, but has extended the same strategy to the rest of the world because of its globally dominant position.

The preceding theoretical discourse regarding the influential role of the US on the global narcotics regime (see chapter five) clearly supports this study's argument that the global narcotics prohibition regime has largely been influenced by the US towards its preferred prohibition option of narcotics control. This argument is consistent with the existing literature (Bewley-Taylor, 1999a; Andreas and Nadelmann, 2006; Bruun et al., 1975) on the influential role of the US on the global narcotics regime. In view of this assumption, one might argue that a policy change or resistance to change within the US narcotics policy domain is more likely to have a similar pattern on the global narcotics policy regime. In essence, this study hypothesizes that:

- The US has successfully resisted pressure for third order policy change within the global narcotics regime as a result of its dominant influence on the regime. 


\section{Variables}

The dependent variable is the US narcotics policy change and the implications for the global narcotics regime. The independent or explanatory variables are the drivers of the US domestic narcotics policy change. These variables include: policy entrepreneurs, institutions, political parties, ideas, bureaucratic agencies, interest groups, media, congress, and the president. It must be noted that these variables are not distinctively examined, but rather discussed as part of the broader debate on the dynamics of US narcotics policy change over time.

\section{Research Questions}

The main research questions are:

(1) Is the US narcotics policy changing?

(a) What is the nature of the change?

(b) Who are the drivers of the change?

(2) To what extent are these changes driven by internal or external factors?

(3) To what extent do parties and partisan ideology (Liberal or Conservative) shape the US narcotics policy process?

(4) What are the likely implications of US narcotics policy change on the global narcotics prohibition regime?

\section{Methodology}

Purposeful qualitative research methodology is the main approach employed for this study. In their work Designing Social Inquiry: Scientific Inquiry in Qualitative Research, King et al. (1994: 4) observe that the underlying goal of qualitative research is to get an in-depth understanding of a given phenomenon. This outcome can be achieved with a focus on one case 
or small number of cases with the use of a thorough interview or an in-depth analysis of historical documents (King, et al.1994; Peters, 1998; Patton, 2002).

Similarly, Eisenhardt (1989:535) argues that case study research is useful in accomplishing a similar pattern of other research outcomes, such as generating a theory, providing in-depth explanation of a phenomenon, or testing a given theory. For this study, I employed the case study approach with single case analysis of the US narcotics policy domain in order to get an in-depth understanding of the US narcotics policy change over time.

\section{Methods of Data Collection}

According to Dexter (1970), Richards (1996) and Berry (2002), elite or specialized interviewing through purposive sampling is one of the useful methodological approaches in gathering data for analysis. The data for this study was obtained from two main sources (primary and secondary). The elite interviews I conducted constitute the main source of the primary data. Documentary analysis of existing literature on narcotics policy, academic research reports, policy reports from advocacy groups and narcotics control agencies, newspaper stories, and other relevant documents constitute the main source of the secondary data. The combination of elite interviews and documentary analysis was to ensure a high degree of consistency in the study of the US narcotics policy process. As Merriam (1998) and Berg (2004) observe, purposive sampling gives the researcher the opportunity to seek a deeper understanding and discovery of a social phenomenon by carefully selecting a sample from which most of the valuable information in the form of data could be obtained.

Based on this understanding, I employed a snow ball sampling method of selecting my sample size of elites with the specialized knowledge of the US narcotics policy arena for the 
interviews. The interviews were conducted in the United States. It started in August 2010 and ended in May 2011. Once the policy experts were selected, email and telephone contacts were made with them for their approval for the interviews. However, as a result of the difficulty of scheduling time for the telephone interview, most of the interviewees opted for an email communication with me. The survey questionnaires (see appendix five) with an authorization letter from the Institutional Review Board (IRB) at West Virginia University to conduct the interviews were sent through email attachment to the respondents. Ten successfully completed questionnaires were returned and used for the analysis. Appendix five contains the list of persons interviewed for the study.

In terms of measurement, the study draws on Rose's (1984) measurement of public policy as consisting of laws, personnel, and budgets. I employed these empirical indicators to apply to the US narcotic policies in the form of narcotic laws, personnel, and budgets. For methodological lucidity in measuring policy change, the study draws on Studlar (2009), Capano and Howlett's (2009) measurement of change as consisting of tempo (speed), mode (amount of change) and scope (coverage). These measurement criteria were integrated into the survey questionnaires (see appendix five) in gathering the data on the US narcotics policy change since 1993.

\section{Summary}

The preceding discussion in this chapter has systematically examined the theoretical and methodological ground work for the study. The underlying element of each theoretical framework was critically examined within the broad context of the existing literature on narcotics policy and policy change. The chapter also examined the likely implications of the US 
narcotics policy change on the global narcotics regime through the theoretical lens of the hegemonic stability theory and the role of the US as a hegemonic power in shaping the regime. Finally, the chapter laid out the underlying hypotheses, research questions, and the methodological approach to the study. 


\section{Chapter 3}

\section{Evolution of US Narcotics Policy (1906-1992)}

\section{Introduction}

This chapter examines the historical evolution of the US narcotics policy process within a broad structure of three main phases ${ }^{29}$ (1906 to 1992). Each phase is examined through the three domestic theories (agenda-setting, partisan ideology, and orders of policy change) of this study. Although chapter four constitutes the main empirical section where the validity (explanatory power) of the theories will be examined in terms of the narcotics policy process, this chapter broadly employs the three domestic theories as competing explanations for the US narcotics process over time and space. Additionally, the three domestic policy theories will be examined within the context of different dimensions of policy, and therefore policy change.

The first dimension looks at agenda-setting theory within the broad context of narcotics policy agendas. My discussion will specifically focus on Baumgartner and Jones' (1993) version of agenda-setting theory (punctuated equilibrium) with further emphasis on conceptual models such as issue definition/redefinition, venue shifting, and policy entrepreneurship in explaining the US narcotics policy change. The theory of partisan ideology examines the policy dimension of campaign rhetoric and policy proposals in the narcotics policy process. Hall's (1993) theory of paradigm change (orders of change) explores narcotics policy adoption and implementation.

Like other studies of this nature, my rationale for examining the historical background of the US narcotics policy process is grounded in the concept of policy legacy (Rose, 1990; Boyum

\footnotetext{
${ }^{29}$ I draw on McWilliams' (1992) categorization of the US narcotics policy development into phases with some modifications to reflect the focus of my study. The three phases of chapter three will examine narcotics policy development from 1906 to 1992. The fourth chapter will be broadly examined under one phase, which is categorized as the fourth phase (1993-2009) of the US narcotics policy development. In essence, the fourth phase is not discussed in this chapter (three), but will be extensively covered in the next chapter (four).
} 
and Reuter, 2005). Since policy legacy provides a useful tool in understanding an existing public policy from the perspective of a past policy, it is pertinent to examine the past US narcotic policies for a better understanding of the existing narcotics policy process, especially the scope (1993 to 2009) of the study. Although the three phases interconnect, each phase is different and generally shaped by policy agendas, policy proposals, milestone of narcotics legislations, key players involved in the passage of these legislations, campaign rhetoric, policy adoption and implementation, and the trends in narcotics policy change. For the purpose of justifying the differences of each phase (evolution of narcotics policy), I have categorized each of them under a broad theme that reflects the patterns of US narcotics policy development since 1906. For example, the first phase reflects the evolution of punitive narcotics policy, the second phase demonstrates the emergence of the war on drugs, and the third phase indicates the escalation of the war on drugs as shown in table 3.1.

\section{Table 3.1}

\section{Phases/Chronology of Milestones of US Narcotics Control (1906-1992)}

\begin{tabular}{|l|l|}
\hline Years & \multicolumn{1}{|c|}{ Phase 1: Evolution of Punitive Narcotics Policy } \\
\hline $\mathbf{1 9 0 6}$ & United States enacts the Pure Food and Drug Act of 1906. \\
\hline $\mathbf{1 9 0 9}$ & US federal law regulates opium importation, except for medical purposes. \\
\hline $\mathbf{1 9 1 2}$ & $\begin{array}{l}\text { Hague Treaty restricts the manufacture, trade, and use of opium and cocaine except for medical } \\
\text { purposes. United States pushes for prohibition with strong domestic laws for narcotics control. }\end{array}$ \\
\hline $\mathbf{1 9 1 4}$ & $\begin{array}{l}\text { Congress enacts the 1914 Harrison Narcotics Act. The Act mandates federal involvement in } \\
\text { illicit drug control. }\end{array}$ \\
\hline $\mathbf{1 9 1 5}$ & $\begin{array}{l}\text { IRS agents (162) put in the Miscellaneous Division of Treasury Department to enforce revenue } \\
\text { provisions of Harrison Act. }\end{array}$ \\
\hline $\mathbf{1 9 1 9 -}$ & $\begin{array}{l}\text { The Narcotics Division of the Treasury Department pushes for the prosecution of over 25,000 } \\
\text { doctors for the violations of the Harrison Act. }\end{array}$ \\
\hline $\mathbf{1 9 2 2}$ & \begin{tabular}{l} 
The Supreme Court declares the prescription by doctors for cocaine addicts as unlawful. \\
\hline $\mathbf{1 9 2 9}$
\end{tabular} $\begin{array}{l}\text { Colonel Levi Nutt resigns as head of Narcotics Division of the Treasury Department on charges } \\
\text { of drug misconduct. The scandal provides an opportunity for the creation of the Federal Bureau } \\
\text { of Narcotics (FBN). }\end{array}$ \\
\hline $\mathbf{1 9 3 0}$ & $\begin{array}{l}\text { Government establishes the Federal Bureau of Narcotics within the department of Treasury. } \\
\text { Harry Anslinger assumes the responsibility as head of the FBN. }\end{array}$ \\
\hline $\mathbf{1 9 3 2}$ & $\begin{array}{l}\text { Harry Anslinger transforms the FBN into a strong bureaucratic agency with full control and } \\
\text { influence over the drug policy subsystem. }\end{array}$ \\
\hline
\end{tabular}




\begin{tabular}{|c|c|}
\hline 1937 & ongress enacts the Marijuana Tax Act of 1937. \\
\hline 1941 & The discovery of Methadone. \\
\hline 1942 & $\begin{array}{l}\text { The FBN establishes itself as the main law enforcement agency of US drug control. FBN pushes } \\
\text { for the prominence of narcotics on both systemic and congressional agendas. }\end{array}$ \\
\hline 1951 & $\begin{array}{l}\text { Congress enacts the Boggs Act. The Act imposes compulsory prison sentences for all drug } \\
\text { offenders, including first time drug related offenders. }\end{array}$ \\
\hline 1956 & $\begin{array}{l}\text { Congress enacts the Narcotics Control Act. The Act introduces the death penalty for the first } \\
\text { time, especially for drug offenders caught selling hard drugs to minors. }\end{array}$ \\
\hline 1960s & $\begin{array}{l}\text { Recreational drug use rises in the US. Social stigmatization previously associated with drugs } \\
\text { decreases. }\end{array}$ \\
\hline 1966 & $\begin{array}{l}\text { Government creates the Bureau of Drug Abuse Control (BDAC), with } 100 \text { agents and the police } \\
\text { to control the supply of "dangerous drugs" (amphetamines and barbiturates). }\end{array}$ \\
\hline \multirow[t]{2}{*}{1968} & $\begin{array}{l}\text { President Johnson submits the Reorganization Plan No.1 to Congress. The Plan consolidates the } \\
\text { FBN and BDAC into the Bureau of Narcotics and Dangerous Drugs (BNDD), under the } \\
\text { authority of the US Department of Justice. }\end{array}$ \\
\hline & Phase 2: Emergence of the War on Drugs \\
\hline 1969 & $\begin{array}{l}\text { President Nixon declares narcotics abuse as "a national emergency afflicting both the body and } \\
\text { soul of America." He subsequently declares the war on drugs. The issue (narcotic drugs) } \\
\text { becomes salient on the presidential agenda. }\end{array}$ \\
\hline 1970 & $\begin{array}{l}\text { Congress enacts the Comprehensive Drug Abuse Act with emphasis on both law enforcement } \\
\text { and treatment towards narcotics control. The Act provides for the establishment of Schedules of } \\
\text { Controlled Substances. Congress also enacts the Organized Crime Act. The National } \\
\text { Organization for the reform of Marijuana Laws (NORML) emerges on the scene. }\end{array}$ \\
\hline 1971 & $\begin{array}{l}\text { By Executive Order, the Special Action Office for Drug Abuse Prevention to oversee treatment, } \\
\text { rehabilitation, education, and research program was created. Majority of the funding was } \\
\text { provided for treatment, rather than law enforcement. It was the only time this happened in the } \\
\text { history of the war on drugs. }\end{array}$ \\
\hline 1972 & $\begin{array}{l}\text { President Nixon creates the Office of Drug Abuse Law Enforcement (ODALE) and the Office of } \\
\text { National Narcotics Intelligence (ONNI) to focus on street "pushers" of drugs. }\end{array}$ \\
\hline 1973 & $\begin{array}{l}\text { President Nixon submits the Reorganization Plan No. 2. The Plan consolidates the BNDD, } \\
\text { ODALE, ONNI, and Customs Service Drug Investigation Unit into Drug Enforcement } \\
\text { Administration (DEA) with } 2,000 \text { agents and a half }(1 / 2) \text { a billion DEA budget. }\end{array}$ \\
\hline 1974 & $\begin{array}{l}\text { President Nixon resigns. The issue (narcotic drugs) receives less war-like attention in the Ford } \\
\text { and Carter administrations. }\end{array}$ \\
\hline 1975 & $\begin{array}{l}\text { Ford administration releases a White Paper on Drug Abuse. The White Paper names marijuana } \\
\text { as "low priority drug" in contrast to heroin, amphetamines, and mixed barbiturates. }\end{array}$ \\
\hline 1976 & $\begin{array}{l}\text { President Carter proposes for the decriminalization of marijuana. Carter favors the relinquishing } \\
\text { of federal criminal penalties for the possession of up to one ounce of marijuana. Anti-drug } \\
\text { parents' movement begins. }\end{array}$ \\
\hline 1977 & Media continues to glamorize cocaine use. \\
\hline 1978 & $\begin{array}{l}\text { Bourne resigns as Carter's chief policy advisor on narcotics. Resignation led to major narcotics } \\
\text { policy setback for the Administration. }\end{array}$ \\
\hline 1979 & $\begin{array}{l}\text { NIDA household survey indicates a total of } 9.7 \text { million people had used cocaine in 1978. About } \\
15.4 \text { million Americans have tried it at least once. Cocaine trade becomes increasingly violent. }\end{array}$ \\
\hline \multirow[t]{2}{*}{1980} & $\begin{array}{l}\text { Supply of cocaine to the US estimated by Government at } 40 \text { to } 48 \text { metric tons. Operation } \\
\text { Greenback begins to trace money laundering operations. }\end{array}$ \\
\hline & Phase 3: Escalation of the War on Drugs \\
\hline 1981 & $\begin{array}{l}\text { The war on drugs reemerges and escalates under Reagan. The drug issue attains high attention } \\
\text { on his presidential agenda. Congress repeals the century-old prohibition (Posse Comitatus Act), }\end{array}$ \\
\hline
\end{tabular}




\begin{tabular}{|c|c|}
\hline & $\begin{array}{l}\text { which forbids the involvement of the military in civilian law enforcement. All branches of the } \\
\text { military became involved in the war on drugs. Spraying of herbicides on illegal drug crops in the } \\
\text { source countries intensifies under the International Security and Dev. Act. United States and } \\
\text { Colombia ratify a bilateral extradition treaty. }\end{array}$ \\
\hline 1982 & $\begin{array}{l}\text { President Reagan announces the formation of the Vice President cabinet-level task force (South } \\
\text { Florida Drug Task Force) to control massive drug smuggling along the US borders. An } \\
\text { Executive Order by Reagan also includes the involvement of the CIA in the drug war. }\end{array}$ \\
\hline 1983 & $\begin{array}{l}\text { Government creates many offices of the Drug Enforcement Agencies in six border cities to } \\
\text { coordinate drug interdiction. }\end{array}$ \\
\hline 1984 & $\begin{array}{l}\text { Congress enacts the Crime Control Act of 1984. Nancy Reagan launches her "Just say No" anti- } \\
\text { drug campaign. President Reagan signs a proclamation for National Drug Abuse Education and } \\
\text { Prevention Week. }\end{array}$ \\
\hline 1985 & $\begin{array}{l}\text { IRS reports that US financial institutions launder about } \$ 80 \text { billion per year in illegal drugs } \\
\text { money. Crack cocaine appears on the scene for the first time. }\end{array}$ \\
\hline 1986 & $\begin{array}{l}\text { Reagan signs the Anti-Drug Abuse Act of } 1986 \text {, which provides about } \$ 1.7 \text { billion to fight the } \\
\text { drug war. Reagan also signs an Executive Order on Drug-Free Workplace. The Administration } \\
\text { makes a proposal for a mandatory drug testing of all federal employees and federal contractors. } \\
\text { US Magistrate, Peter Nimkoff, resigns in partial protest over the so-called government abuses of } \\
\text { power regarding the war on drugs. The US initiates the Certification Process (US presidents to } \\
\text { report to Congress every year on the efforts by other countries on narcotics control). }\end{array}$ \\
\hline 1987 & Colombia annuls the extradition treaty with the US. The war on drugs escalates. \\
\hline 1988 & President Reagan signs the Anti-Drug Abuse Act of 1988. \\
\hline 1989 & $\begin{array}{l}\text { President W.H. Bush creates the Office of National Drug Control Policy (ONDCP) and appoints } \\
\text { William Bennett as his first "drug czar." United States invades Panama (Dec.1989). }\end{array}$ \\
\hline 1990 & $\begin{array}{l}\text { President W.H. Bush proposes a } 50 \% \text { increase in military spending on the war on drugs by } \\
\text { requesting additional } \$ 1.2 \text { billion to the annual drug war budget. General Manuel Noriega } \\
\text { surrenders to US authorities for drug trafficking (Jan.1990). }\end{array}$ \\
\hline 1991 & $\begin{array}{l}\text { DEA makes the largest seizure of heroin in US history in San Francisco. Over } 1,000 \text { pounds of } \\
\text { Southeast Asian white heroin, with an estimated wholesale value of more than } \$ 1 \text { billion. }\end{array}$ \\
\hline 1992 & $\begin{array}{l}\text { Government rejects the petition by the National Organization for Reform of Marijuana Laws } \\
\text { (NORML) to reschedule marijuana from Schedule I to Schedule II (for medical use) of the } \\
\text { Controlled Substance Act. }\end{array}$ \\
\hline
\end{tabular}

${ }^{30}$ I compiled the data and information from many sources to create my own chronology table.

Wisotsky, Steven. 1986. Breaking the Impasse in the War on Drugs. NY: Greenwood Press. Appendix 2, pp.249-

256. Belenko, Steven. 2000. Drugs and Drug Policy in America. Westport: Greenwood Press

Thirty Years of American Drug War: A Chronology, Frontline-Public Broadcasting Service

http://www.pbs.org/wgbh/pages/frontline/shows/drugs/cron/

http://www.npr.org/templates/story/story.php?storyId=9252490 Also in Huggins, Laura (ed.) 2005. Drug War

Deadlock: The Policy Battle Continues. Stanford: Hoover Institution Press. pp: 17-30

Drug Enforcement Administration: A Tradition of Excellence 1973-2008. 


\section{The Politics of the Early Narcotics Policy Process}

For more than a century, the issue of drug abuse and the policy responses from governments in controlling the production, trafficking, and use of narcotic drugs has remained one of the key public policy issues on the agenda of many countries, particularly the United States. Although the drug issue has experienced low levels of attention at various points in time, the general awareness about the dangers of illicit drugs to society has never diminished completely (Belenko, 2000). In essence, the US narcotics policy process has not only waxed and waned on the systemic (media) and institutional (governmental) agendas, but the issue also has been defined, redefined, and shaped by many key players, such as the federal and state government institutions, political parties, bureaucratic agencies, advocacy groups, and policy entrepreneurs for the past decades (Belenko, 2000).

As in other parts of the world, until the late 1890s to the early 1900s, drugs such as opium, heroin, cocaine, and marijuana, among others, were all legal substances that were accessible to anyone who wanted them (Bertram, et al.,1996; Musto,1999). In the US, for example, these drugs were not only widely available, but were either prescribed by medical officers or could easily be bought at any grocery store. Moreover, these drugs were so common to the extent that they were found in several unregulated medicines for the treatment of regular ailments such as stomach aches, headaches, and common colds. Cocaine for example, was a favorite ingredient for the production of Coca-Cola until 1903 when caffeine was substituted for the use of cocaine (Meier, 1994:22). It was also used as an important ingredient for the production of medicines and food additives (Bertram, et al., 1996:61; Meier, 1994:22). 
As Meier (1994:22-23) observes, the production, sale, and prescription of these narcotic drugs, including hallucinogenic drugs, during the late nineteenth century, became one of the lucrative businesses for many physicians and pharmacists. Besides cocaine and opium, marijuana was, perhaps, the most commonly used drug in the US during the period under review. The hemp plant (marijuana), which was first introduced to the American colonies, especially in Virginia in 1611, became so widely used that George Washington, the first president of the United States, was believed, through his diary records, to have grown marijuana (Meier, 1994:22; Benavie, 2009:21). The widespread use of these drugs led to higher levels of addiction across many parts of the country. For example, Meier (1994:23) recounts that about 200,000 to 275,000 Americans were drug addicts in 1915.

The history of America's narcotics control policy has been characterized by important changing trends. These trends range from the cocaine and opium scares of the early 1900s, to the marijuana concerns in the 1920 s, to the heroin addiction problem in the 1960 s, and to crack cocaine in the mid-1980s and 1990s (Belenko, 2000). In addition to key narcotics legislations that were enacted in almost every phase, other notable milestones have been part of the US narcotics policy development since 1906 (see table 3.1).

As noted, the US narcotics policy has undergone many different phases since the involvement of the federal government in the narcotics policymaking in the early years of the twentieth century. The broad literature on the evolutionary process of the narcotics policy development is basically categorized into key historical phases (McWilliams, 1992:8). My study draws on a similar categorization of these phases for my analysis as shown in Figure 3.1. 
Figure 3.1

Historical Development (phases) of US Narcotics Policy (1906-1992)

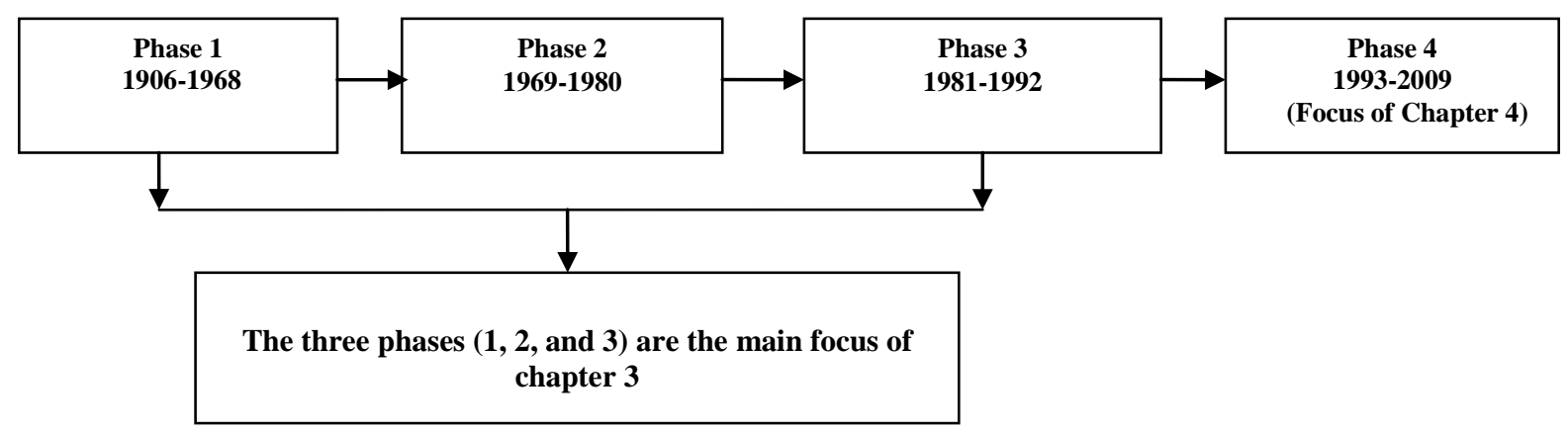

Source: Adapted from Jones (2002:119) with some modifications.

According to Boyum and Reuter (2005:5), US anti-drug laws were, for the most part, within the domain and jurisdiction of states and local authorities until the early twentieth century when the federal government became an important player in drug policymaking. Prior to the passage of the Harrison Act of 1914, two important legislations (narcotics) were passed by the US Congress (Pure Food and Drug Act of 1906 and the 1909 Law on Opium). The passage of these anti-drug laws clearly shaped the starting point of the early years of the US narcotics policy process.

First Phase: Evolution of Punitive Narcotics Policy (1906-1968)

The passage of the 1906 Pure Food and Drug Act was the first major federal legislation on narcotics control in the US following the concern over the abuse of narcotic drugs. In fact, these early years (1906-1929) of phase one also represents what this study describes as the formative years of punitive narcotics policy development. Although the first major federal law (1906 Pure Food and Drug Act) was short of fully addressing some important issues of nonmedical use of these drugs, certain key provisions of the law still prohibited the misbranding of 
pharmaceutical and other patent medicines containing drugs such as heroin, opium, cocaine, and marijuana. The law allowed the sale of pharmaceutical products containing these drugs, but only on a condition that these products were clearly and properly labeled by name (Meier, 1994:23).

The second piece of legislation was the 1909 Act (Opium Act). The law prohibited the importation of opium except for medical purposes. Unlike the 1906 Act, the main provision of the 1909 law was exclusively restricted to opium prohibition. In fact, the year 1909 was also particularly important to the US for two main reasons. First, it was the first time that the international community met in China, as earlier noted, to discuss the Chinese opium epidemic. Second, the US was not only a participant at the conference, but was also the main convener of the meeting. According to Sharp (1994:20), Meier (1994:24) and Musto (1999:3), the 1909 US federal law prohibiting opium smoking had a direct connection to the China opium conference, in which the US convened and was also instrumental in influencing other countries to regulate opium use.

Clearly, the key question of why the US federal government became actively involved in both domestic and global narcotics control by the mid-1900s is an important part of the drug policy debate. Several arguments have been advanced for the emergence of the narcotics policy on the federal government's agenda. As generally shared, the widespread drug abuse among many Americans was primarily responsible for the genesis of many anti-drug laws enacted in the early years of the twentieth century. As narcotic drugs became readily available, the addiction rate increased in high proportion, and the fear of foreigners led to a widespread public outcry and the subsequent demand for change.

Attitudes by the public negatively changed toward drug users once the public understanding of the drug issue deepened. McWilliams (1992) argues that the rise of the 
Progressive Movement (PM) was particularly responsible for the shift in public attitudes against drug users. For example, the Movement, according to McWilliams (1992), expressed worry about what they called the weakening nature of the American moral society and other cherished values following the increasing use of narcotic drugs and alcohol. In order to affect policy change, the Movement pushed for strong punitive anti-drug and alcohol laws as the solution to restoring the strong moral values of the American society. In fact, Baumgartner and Jones' (2009) theoretical interpretation of agenda-setting framework provides a useful insight into understanding how a shift in public attitude can affect the outcome of a policy issue.

For Baumgartner and Jones (2009:153), policy outcomes are determined by the extent to which an issue is defined as a private issue or a public one. According to them, when an issue is defined as a private one, there is often no pressure or demand for government intervention. On the other hand, an issue that is defined from a public perspective, which might cause harm to others, tends to attract quick demand for government action. This was clearly the case with the drug abuse issue in the early 1900s. As Baumgartner and Jones (2009) observe, the problem of drug abuse, particularly before the 1900 s, was defined as a private problem that demanded no government intervention. When the same problem was, however, redefined from a societal perspective by the mid-1900 (narcotics control laws-1906 and 1909 laws) and considered potentially dangerous to others, societal pressure became intensified for government action on the drug issue. For example, once the use of narcotic drugs was deemed to affect the level of productivity, social control of minorities, and the likely linkage to acts of criminal behavior, government intervention was immediately sought by the public for policy action. To Baumgartner and Jones (2009), the problem of drug abuse, like any other public policy issue, had floated between the two perspectives (private and public definition of issues) for decades. 
Another important argument advanced for the emergence of the US anti-drug laws was the prevalent use of narcotic drugs among many poor African-Americans and Chinese immigrant communities. In the words of McWilliams (1992:9), the use of cocaine, for example, in many immigrant communities was considered "a more unsavory clientele who wanted only to experience euphoria, as opposed to those who relied on cocaine as a source of increasing productivity in the workplace." Clearly, the racial undertone of this argument became apparent when many poor Blacks and Chinese immigrants were targeted as the main culprits responsible for the drug problem across America. Once these groups were defined in this way, it became easy for those opposed to the widespread use of these drugs, such as the Progressive Movement, to add more support for the passage of the anti-drug laws. Scholars such as Musto (1999), Meier (1994), McWilliams (1992), argue that the racial dimension that emerged in the early years of the US narcotics policy process has since become an important element of the US anti-drug policy outcomes in recent years.

While many scholars share the view that narcotic laws of 1906 and 1909 have provided

the foundation for the subsequent US anti-drug laws, others argue that it was the Harrison Act of 1914 that clearly set the parameters for the US narcotic policy goals. For these scholars, (Musto, 1999; Sharp, 1994; Zimring and Hawkins, 1992), the 1914 Act not only marked the starting point of the major anti-drug legislations, but the Act also became the model in which many future narcotic policies were based.

\section{Harrison Act of 1914}

As noted, the Harrison Act of 1914 represented an important piece of legislation in the development of the US narcotics policy. Not only did the Act shape the narcotics policy process, 
but also transformed the course of the policy landscape for many years (Inciardi et al. 1996; Meier, 1994; Oppenheimer, 1993). As Faupel (1991) rightly noted:

The long-term result of the legislation was dramatic. Narcotics use was transformed from a relatively benign vice practiced by some of society's most respectable citizens to an openly disdained activity prohibited by law, relegating the narcotics user to pariah status in most communities. ${ }^{31}$

Named after Francis Harrison, a New York Democrat who was very instrumental in the passage of the law (Meier, 1994:2), the Act required those in the medical and other allied health professions such as physicians, dentists, pharmacists, and other health related agencies to:

(a) Register with the federal government.

(b) Keep proper record of all transactions on narcotic drugs.

(c) Pay special tax on their transactions.

The legislation was largely framed in a form of taxation or a revenue act to be administered by the officials of the Treasury Department (Oppenheimer, 1993:196; Boyum and Reuter, 2005; Jonnes, 1996:47; Spillane and McAllister, 2003; Bertram, et al. 1996:68). Not only were health professionals targeted in the implementation of the law, but the law also was extended to cover producers, importers, and the manufacturers of opium, and all coca products. The major rationale behind the law was to ensure that narcotic drugs were produced and prescribed only for medical purposes (Bertram, et al. 1996). In the case of marijuana, Meier (1994:25) and Musto (1999) observe that it was part of the initial draft of the legislation, but was later excluded in response to the strong resistance from the pharmaceutical industry. The industry

\footnotetext{
${ }^{31}$ Faupel's (1991) statement about the transformative role of the 1914 Harrison Act in changing the nature of the narcotics policy process was cited by Inciardi et al. (1996:5).
} 
argued that marijuana was only used in veterinary medicines and other non-intoxicating uses that did not necessitate its inclusion with other dangerous drugs such as opium and cocaine.

The bill was successfully passed into law, but the implementation faced some difficulties between the agents of the Internal Revenue Bureau (IRB) and many health practitioners. The disagreement centered on the interpretation of some of the key provisions of the law. For example, Inciardi et al. (1996:5) observe that under certain provision of the law, doctors were allowed to "prescribe, dispense, and administer narcotics to their patients for legitimate medical purposes in the course of their medical practice." The interpretation of this provision by the medical establishment was based on its framing of the drug addiction problem as a disease that needs treatment. On the contrary, the IRB interpreted this provision of the law differently and considered the prescription of narcotic drugs to addicts as unlawful (Inciardi et al., 1996). For many IRB agents, narcotics users were thus helpless addicts who needed a strong punitive punishment for their rehabilitation (Oppenheimer, 1993:197).

Not long after that, the IRB consolidated its enforcement powers under the law by establishing strong bureaucratic structures, procedures, and other policy strategies for a long lasting trend of narcotics enforcement policy. Examining some of the strategies employed in the enforcement of the Harrison Act, Meier (1994:27) points out how the IRB agents relied on two main tactical methods in the implementation of the law. First, officials of the agency used misinformation and propaganda mechanisms to label narcotic users as one of the most dangerous social evils facing the American society. Second, the agency, in an attempt to showcase its socalled successes over the drug problem, managed to frame itself as being fully in control of the increasing drug problem. 
The unresolved differences of interpretation between the medical profession and the punitive law enforcement agents led to the deepening of mistrust between the IRB agents and many health professionals. The mistrust was followed by numerous allegations and massive accusations leveled against many health professionals by IRB agents, especially doctors who were accused of unlawfully prescribing illegal drugs to addicts. Meier (1994:27) describes this scenario as an additional strategy used by the IRB agents in the enforcement of the Harrison Act. What happened next was very devastating for many in the medical community. Quite a number of physicians and other health professionals faced constant arrests and detention by IRB agents (McWilliams, 1992:11; Oppenheimer, 1993:197). According to Sharp (1994:20), between 1915 and 1938 , for example, more than 25,000 physicians were under the radar screen of the IRB agents who were determined to enforce the Harrison Act. During the same period, about 5,000 doctors and other health professionals were fined, convicted, or jailed for many violations of the law. Two key rulings by the US Supreme Court regarding the Harrison Act further strengthened the bureaucratic tactics and enforcement apparatus of the IRB.

The first case was the 1919 ruling (Webb v. United States), where the Court held that it was against the law for narcotic drugs to be prescribed by a doctor to a drug addict (Sharp, 1994; Bertram, et al. 1996). The second case was the 1922 ruling (United States v. Behrman). Like the 1919 ruling, the second case made the prescription of narcotic drugs to any addicts by a physician unlawful, even if prescribed as part of a cure program (Inciardi et al., 1996). In the midst of constant harassment and the threat of arrests of those engaged in the lucrative drug business, an incentive was created for various acts of bribery and corruption among many law enforcement agents (Meier, 1994: 30). The first recorded case of a federal agent convicted of a corruption act was in 1917. Subsequent corruption scandals were recorded among many IRB 
agents from 1917 onwards. Overall, the consensus among scholars such as Inciardi et al. (1996), McWilliams (1992) and Erlen and Spillane (2004) is that the 1914 Harrison Act set the stage for the long decades of a law enforcement strategy of narcotics control policy in the US.

Clearly, the preceding discussion of the punitive formative years (1906-1929) of the first phase reveals some evidence of agenda-setting theory in the development of the narcotic policy process, particularly on the shifting nature of public opinion and activities of interest groups in shaping the policy process. As Studlar (2002), Kingdon (1984), and Baumgartner and Jones (2009) observe, public opinion plays an important role in agenda-setting theory. The discussion shows a major shift in the American public opinion on narcotic drugs. For example, prior to the passage of the first federal anti-drug laws, the use of narcotics was generally accepted by the public as a normal practice. As previously mentioned, many of these drugs during the late $1800 \mathrm{~s}$ to the early 1900 s were lawful. Public opinion, however, shifted to the de-normalization of these drugs following the increasing abuse and the societal problems associated with them. Discussing similar issues, Ferraiolo (2007:152) contends that the widespread negative view of drug use was primarily responsible for the shift in attitudes of many Americans against these drugs.

As opinions changed toward these narcotic drugs, the issue moved from a systemic agenda to a formal or institutional agenda (Kingdon, 1984; Cobb, Keith-Ross, and Ross, 1976), for government attention and consideration. The federal government's response in terms of policy change was the passage of the federal narcotic legislations in the early years of the twentieth century. In fact, Kingdon (1984) describes avenues for policy change as windows of opportunity. Indeed, it was the window of the apparent problems and dissatisfaction associated with the narcotics use that created the opportunity for the emergence of the three major anti-drug 
legislations (Pure Food Act of 1906, Opium law of 1909, Harrison Act of 1914) in the early 1900s.

Similarly, the influence of organized interest groups, such as the Progressive Movement, in shaping the early years of the narcotics policy process has demonstrated evidence of interest group activities in agenda-setting and subsystem politics. As Worsham (1997) argues, the question of influence is at the heart of understanding the policy process. It is also clear that the US narcotics policy process had experienced a first order change in policy in the early years of the policy development. As Hall (1993) argues, a change in the settings of a policy instrument constitutes a first order change. Applying Hall's (1993) concept to the early years of the policy process shows an incremental change in the anti-drug laws from a less restrictive Food Act of 1906, to a more punitive 1914 Harrison Act. On partisan ideology, there was no evidence to support the assumption that partisanship played a role in shaping the early years of the narcotics policy development.

\section{Consolidation of Punitive Narcotics Policy (1929-1968)}

The second part of the first phase is another important dimension in the evolution of the US narcotics policy process. I categorize this period as the era that consolidated the punitive approach to narcotics control. The period was dominated by the passage of three important legislations (Marijuana Tax Act of 1937, Boggs Act of 1951, and Narcotics Act of 1956). While the era deepened the punitive approach to narcotics control, it was the establishment of the Federal Bureau of Narcotics (FBN) and the role played by Harry Anslinger, the head of the FBN, that defined and distinguished this phase from other phases. As Sharp (1994:22) observes, the 
1930s throughout the 1960s marked a different era in narcotics control because of the strong bureaucratic control of the narcotics policy subsystem by the FBN.

The creation of the FBN stemmed from the disagreement and mistrust between many IRB agents and members of the health community, especially doctors, over the interpretation of some provisions of the Harrison Act. As noted, the American medical establishment favored a treatment option for drug addicts over a punitive law enforcement strategy. However, many state governments and other local authorities pressed for an exclusively punitive law enforcement approach over the treatment option (Spillane, 2004:25). Once a punitive policy approach was firmly secured, the law enforcement powers of many bureaucratic agencies such as the IRB were strengthened, expanded, and institutionalized towards the implementation of these laws (Ryan, 2001:19).

What happened next was perhaps not widely expected. The consequence of the punitive policy option created an underground illegal market for these banned drugs for many people who needed them. Likewise, a number of IRB agents were also exposed to all forms of bribery and corruption (Meier, 1994). As noted, a well-known case occurred in 1929 involving the family of Levi Nutt, who was the head of the Narcotics Division Unit at the Treasury Department (McWilliams, 1992: Meier, 1994). While Nutt lost his position because of the scandal, the situation provided an opportunity for the reorganization of the Narcotics Division Unit, particularly the office of the IRB. This led to the creation of the Federal Bureau of Narcotics on July 1, 1930 (Musto, 1999:208), with the appointment of Harry J. Anslinger as the first Commissioner of the FBN (Whiteside, 1997:58). In fact, aside the FBN, which was mandated with the responsibility of regulating narcotic substances, the Food and Drug Administration 
(FDA), which was also created as a result of the reorganization, was tasked to regulate nonnarcotic drugs (Spillane, 2004).

The narcotics policy landscape was quickly transformed into full-fledged bureaucratic influence and control over the US drug policymaking soon after Anslinger took the reign of the FBN. Meier (1994:32) and McWilliams (1992:14), for example, argue that the FBN under Anslinger created a policy niche for the agency to the extent that the agency succeeded in establishing a powerful narcotics policy subsystem by the late 1930s. In fact, Baumgartner and Jones' (1993, 2009) concept of policy monopoly provides an important theoretical guide in understanding the emergence of the FBN as a powerful force in the evolution of the narcotics policy subsystem. As Baumgartner and Jones (1993: 6-7) argue, the basic goal of interest groups, policy entrepreneurs, and bureaucratic agencies, such as the FBN in a policy subsystem, is to establish a policy monopoly at any opportunity for the purpose of control and influence over policymaking. For them, a policy monopoly is often sustained by two very important elements: a strong institutional policy structure and a powerful supporting idea.

In the case of the narcotics policy domain, the FBN was the strong institutional structure over drug policymaking. When it comes to the supporting ideas, punitive or prohibitive policy option was the dominant policy preference of the agency. The supportive interest groups were the federal narcotics law enforcement agencies and their natural allies such as the Women's Christian Temperance Union (WTCU) and the Anti-Saloon League (Baumgartner and Jones, 1993). A good example of how the FBN successfully established its monopoly over the narcotics policy process is discussed in the next section. The discussion will show how the bureaucratic agency had redefined the drug issue, controlled the policy agenda, and influenced other players over the passage of the 1937 Marijuana Tax Act. 


\section{Marijuana Tax Act (MTA) of 1937}

The battle to outlaw the use of marijuana except for medical purposes dates back to the previous efforts by the federal government to control narcotics use. Although the importation of marijuana was prohibited, except for medical purposes under the Pure Food Drug Act, it was not covered by the Harrison Act, because of the lack of a strong organized support for the inclusion of marijuana (Meier, 1994:33; Bertram et al., 1996:80). Consequently, the use of marijuana from the late 1920s throughout the early 30s became widespread in many parts of the US. The literature reveals two major reasons for the widespread use of marijuana during the period under review. First, marijuana use became prevalent as the recreational demands for the drug increased, especially among many young people. The second reason was the influx of many agricultural workers from Mexico to many southwestern states in the US. Their use of marijuana was said to have been very widespread (Meier, 1994; McWilliams, 1992). For Kornblum (1993:120), marijuana became popular in many poor communities because the drug was legal, relatively cheap, and pleasurable to use in many social settings, while alcohol was prohibited during the same time.

Irrespective of the public resentment over the marijuana problem, the pervasive use of the drug continued, with no concrete legislative action at the federal level to control the drug problem. For some, the inability to enact a federal legislation against marijuana use was primarily due to the inadequate attention and priority given to the drug problem by Anslinger and his agency (Ferraiolo, 2007). The likely explanation for the FBN's inaction might be the fact that the drug problem was already being handled at the state level, while the agency wanted to focus on hard drugs (heroin and cocaine) instead of marijuana, which was generally considered as a soft drug. Likewise, the inability of the FBN to push for legislation against marijuana might be 
due to the constitutional challenge that had confronted the implementation of the Harrison Act. Perhaps the FBN wanted to avoid any further litigation that could arise with a federal antimarijuana law. Instead, the FBN endorsed the passage of the Uniform State Narcotics Act under the jurisdiction of many state laws in the early 1930s (Ferraiolo, 2007).

The FBN's approach of policy inertia did not work in favor of the agency for a very long time. The bureau became the subject of public criticism because of the constant media reports on crimes reportedly associated with marijuana use across the country. The attention of some lawmakers was quickly drawn to the persistent public resentment against the policy inertia of the FBN. The bureau's annual budgetary allocation was subsequently reduced from $\$ 1.7$ million in 1932 to $\$ 1.0$ million in 1934 (Meier, 1994:33), as one of the measures for an expected action from the agency. Faced with the barrage of challenges and the fear of completely losing its public trust, the FBN responded to these challenges by directing their attention to the marijuana issue. As Meier (1994) observes, the reason for the FBN's decision to actively get more engaged with the marijuana issue was to regain its public trust and some level of control over the drug policy process. The policy outcome of FBN's active role was the passage of a federal law (Marijuana Tax Act), which prohibited the use of marijuana (McWilliams, 1992:15).

Soon after the passage of the Marijuana Tax Act (MTA), key questions began to emerge on some of the campaign strategies that were used by the FBN in getting the marijuana law enacted. Not only was the agency involved in drafting the legislation for passage, but Anslinger also personally mounted a gruesome media campaign linking marijuana use to increasing crime across America (Zimring and Hawkins 1992; Bertram et al., 1996; Kinder, 1992). For example, during one of the Congressional hearings on the bill (Marijuana), Anslinger gave a testimony citing numerous cases where he linked marijuana users to serious criminal activities such as sex 
crimes and murder. He also cited cases where marijuana use was responsible for incidents of insanity and addiction among many young people across America (Carroll, 2004:74; Sharp, 1994:21).

In one of these famous cases linking marijuana use to criminal activities, Ferraiolo (2007:154) and McWilliams (1992:16) recount how Anslinger in his congressional testimony mentioned a case involving a twenty-one year old Victor Licata of Florida, who was reported to have killed his parents, two brothers, and a sister while under the influence of marijuana. Anslinger also cited Chicago and Baltimore as examples of other cases of marijuana-induced crimes to the Congressional committee. He, for example, indicated that: "In Chicago, recently two boys murdered a policeman while under the influence of marijuana...Recently, in Baltimore, a young man was sent to the electric chair for having raped a girl while under the influence of marijuana. ${ }^{32}$ As clearly revealed, Anslinger led the campaign for the prohibition of marijuana by amplifying his horrific cases in an attempt to frame the marijuana issue to the advantage of his agency. Undoubtedly, these gruesome stories had a strong impact in reinforcing public opinion against marijuana use, hence the massive public support for the marijuana law.

Regardless of the overwhelming public and congressional support, it is also important to note that the bill was not without some ardent critics. In fact, Dr. William C. Woodward, the only outspoken opponent and a representative of the American Medical Association (AMA), questioned the credibility of Anslinger's Congressional testimony that linked marijuana use to many criminal activities across the country (Carroll, 2004; Ferraiolo, 2007). Dr. William C. Woodward and other critics of Anslinger accused him of presenting incomplete and inconsistent

\footnotetext{
${ }^{32}$ These cases were part of the recorded testimony during the Congressional hearing of Anslinger on the marijuana bill. Cases cited by Ferraiolo (2007) and McWilliams (1992).
} 
stories regarding the connection between marijuana use and criminal activities. For example, McWilliams (1992) observes that although the famous Licata case cited by Anslinger appeared factual, the complete story was not told by him. According to McWilliams (1992:16), few days after the alleged murder, it was also reported that Licata was earlier diagnosed with some mental problems, and the criminal act committed might not necessarily be linked to marijuana use.

Notwithstanding the controversy surrounding the bill, the Marijuana Tax Act was passed into law as a revenue act in 1937 (Carroll, 2004; Musto 1999; Zimring and Hawkins, 1992). The law, which was modeled on the provisions of the 1914 Harrison Act, prohibited the possession and use of marijuana in any form, except for medical purposes (Sharp, 1994). Although the law was framed as a revenue tax (Carroll, 2004; Musto 1999), Benavie (2009:22) argues that the real objective of the MTA was not primarily concerned with revenue collection. Instead, the law was strictly aimed at enforcing the prohibition of marijuana under the guise of a revenue act. For example, some of the provisions of the law for physician compliance were not only complex, but were too extensive for simple comprehension (Ferraiolo, 2007:154).

Moreover, the interpretation of the law was also subject to diverse administrative discretion by the enforcement agencies. A similar provision of the law included a prohibitive tax of $\$ 100$ for unlicensed transactions in marijuana. Failure to pay these taxes or any violation related to the taxes on marijuana attracted a steep fine of $\$ 2,000$ or arrest and imprisonment up to five years (Benavie, 2009). As expected, the passage of the MTA not only allowed Anslinger and his FBN to regain their bureaucratic control and dominance over the narcotics issue, but the law also intensified the punitive option of narcotics control across many parts of America.

With the strong bureaucratic control by the FBN in shaping the implementation of the MTA, two policy-related outcomes occurred. First, the FBN's reliance on law enforcement 
powers to persecute marijuana users facilitated the development of a strong punitive law enforcement-oriented approach to the US narcotics control policy (Ferraiolo, 2007; Sharp, 1994:22). The emphasis on an exclusively law enforcement strategy not only shaped the three decades of Anslinger's reign as head of the FBN, but also the strategy became the cornerstone of subsequent anti-drug policies in the US and in many other countries. During his early years in office for example, Anslinger was quoted to have urged many American judges to "jail offenders, then throw away the key" (MacWilliams, 1992:17).

The second policy outcome that occurred was the shrewd implementation strategy that was adopted against many marijuana users by the agency. In many instances, FBN agents were accused of using propaganda media campaign to demonize drug users. Baumgartner and Jones (1993:152) share a similar argument on how the punitive option of narcotic drugs received a considerable emphasis against other policy options (treatment) during the 1930s. For them, the law enforcement policy option under Anslinger was much more severe than the period of alcohol prohibition in the 1920s. Moreover, from the 1940s throughout the 1960s, the FBN had successfully eliminated any existing recognition of marijuana as a viable medicinal option for the treatment of some chronic diseases (Bertram et al., 1996). In 1941, for instance, the United States Pharmacopeia ${ }^{33}$ excluded marijuana from its list of recognized medical substances for the first time since 1850, because of a directive from Anslinger to do so (Ferraiolo, 2007:155; Bertram et al., 1996:81).

By the early 1950s, the FBN was firmly in control of the US narcotics policy subsystem with considerable support from the general public and some members of Congress. As Sharp (1994:22) argues, the FBN also attracted further support from key organized groups, such as the

\footnotetext{
${ }^{33}$ The US Pharmacopeia is an official public standards-setting authority for the quality, purity, identity, and strength of all medicinal drugs. http://www.usp.org/aboutUSP/ Retrieved 08/24/11.
} 
General Federation of Women's Clubs (GFWC),Women's Christian Temperance Union (WCTU), and the World Narcotics Defense Association (WNDA) ${ }^{34}$ Clearly, this kind of subsystem policy arrangement became apparent within the US narcotics policy domain by the 1940s. As students of subsystem politics (Baumgartner and Jones, 1993, 2009; Worsham, 1997; McCool, 1989; Sabatier and Jenkins-Smith, 1993) argue, a dominant policy subsystem (iron triangle) often develops among three major players that exercise influence over the course of a policy process. These include: bureaucratic agencies, interest groups, and congressional committees. As we have seen, the theoretical concept of subsystem politics was particularly apparent in the US narcotics policy sphere from the mid 1940s throughout the late 1960s. On one side, for example, was the bureaucratic influence of the FBN over the narcotics policy process. On the other side were powerful interest groups, such as the GFWC and the WCTU among others. The congressional subcommittees (subcommittee on Improvement of the Federal Criminal Code) with oversight responsibilities on narcotics were also involved within the narcotics subsystem. Broadly, their shared belief and policy ideas generally favored a law enforcement approach to narcotics control. These core policy ideas were well-institutionalized with limited avenues of policy change, other than incremental changes in policy (McWilliams, 1992; Bertram et al., 1996).

Essentially, the punitive anti-drug laws did not end with the passage of the 1937 Marijuana Law. Considering the strong subsystem dominance and the increasing public support against these drugs, the FBN went a step further and redefined narcotics use as a national crisis. By the early 1950s, further tougher penalties were proposed for offenders (McWilliams, 1992). The important question to ask is: why has the drug problem been redefined and reframed by the

\footnotetext{
${ }^{34}$ These organizations were one of the oldest advocacy groups that were involved in preserving the narcotics policy status quo of prohibition.
} 
FBN as a national crisis? Indeed, the answer to this question will be helpful with some theoretical exposition for better appreciation of the policy process. In this regard, I will draw on the theoretical concept of policy image ${ }^{35}$ of Baumgartner and Jones (1993:25-26) to explain this scenario.

According to Baumgartner and Jones (1993), policy image is "how a policy is understood and discussed." Examining this concept under the broad punctuated equilibrium theory, Baumgartner and Jones (1993) contend that the public understanding (policy image) of a policy tends to shape the overall outcome of such a policy. Worsham (1997:11) makes a similar argument when he examines the concept of issue salience in his work on subsystem politics. For Worsham (1997), it can be very difficult to restrict public participation in policy domains that are non-technical, such as narcotics policy, unlike technical policies (economic, nuclear, and space), which might be difficult for quick public understanding of the key issues. In most cases, the media serves as the main channel in stimulating public debate on key policy issues. This was particularly the case with the narcotics policy. Once the public interest and participation in the drug debate intensified, the FBN saw the public interest as a good opportunity to redefine and expand the image of the issue by linking it to key national concerns at the time (Bertram et al. 1996). Perhaps, their purpose was to attract the attention of previously apathetic groups (Schattschneider, 1960) to the drug issue.

For example, the FBN exploited the Cold War politics at the time to create fear and insecurity by linking drug trafficking and use to communism. Communism was said to have infiltrated the American society through illegal drug trade (Bertram et al., 1996: McWilliams,

\footnotetext{
${ }^{35}$ The concept of policy image is part of the broader theoretical framework of agenda-setting (Baumgartner and Jones, 1993).
} 
1992; Caroll, 2004; McWilliams, 1990). Musto (1999: 231) adds that the FBN used infamous stories that Red communist China had secret plans to destroy Western societies, particularly the US, by injecting large amounts of narcotic drugs into these countries. Once the conscience of the American public was "tainted" with these scare tactics of linking narcotic drugs to communism, the narcotics policy image became successfully reframed as an urgent national issue. Many Americans became convinced of the need to support the adoption of tougher anti-drug legislation at the expense of other options (treatment) in narcotics control (Ferraiolo, 2007).

In addition to the usefulness of policy image in explaining the emergence of the tougher punitive anti-drug laws, two other perspectives exist in the literature in explaining the adoption of the punitive anti-drug laws in the 1940s throughout the 1960s. First, the FBN expressed dissatisfaction with the existing penalties for narcotic violations, which they considered as inadequate to deter users and likely users from these drugs. Second, the judicial system was considered too soft and unwilling to impose long prison sentences on drug offenders (McWilliams, 1992). Once the policy recommendations for tougher anti-drug laws were articulated by the FBN with strong public support, Congress took serious notice of the problem as well. Congressman Hale Boggs (D-Louisiana) was among many legislators who were key allies of the FBN in Congress, and shared similar supporting ideas for tougher anti-drug laws. Subsequently, Congressman Boggs with the support of other members of Congress, introduced a tougher anti-drug bill, which led to the passage of the Boggs Narcotics Act of 1951. 


\section{Boggs Act (BC) of 1951}

In his book the Protectors, ${ }^{36}$ McWilliams (1990:108) examined Congressional records to determine the number of legislators who introduced key legislation for stiffer drug control policy during the 1950s. The results of the study are very revealing. In 1951 for instance, twenty six bills (twenty two in the House and four in the Senate) were introduced in Congress, and many of those proposed bills were related to law enforcement regarding illegal drugs alone. Some of the proposed bills ranged from a stiffer penalty for drug offenders to the deportation of foreign nationals living in the US who were drug addicts (McWilliams, 1990).

Regardless of the criticisms leveled against the Boggs bill due to its stiffer provisions, the bill was successfully passed into law with an overwhelming support for stiffer and a more punitive federal drug control (Meier, 1994; Gray, 2000; McAllister, 2004). One of the main provisions of the Boggs Act created a compulsory prison sentence for all first time drug related offenders. In addition to the compulsory prison sentence, a fine of $\$ 2,000$ was also imposed on offenders. For first offenders, the law provided a penalty of a five-year jail sentence with a minimum of a two-year mandatory sentence.

For second offenders of the same offense, the law provided a mandatory prison sentence of five to ten years, with no opportunity for probation or for a suspended sentence (McWilliams, 1992). In fact, the suspended prison sentence, which was part of the previous narcotic laws, was completely eliminated in the Boggs Act. Third, those guilty of the same offense also faced a prison term of ten to twenty years, with no provision for a suspended sentence (McWilliams, 1992:19). For some scholars (Oppenheimer, 1993: 197; Courtwright, 2002:3; White, 2002:139;

\footnotetext{
${ }^{36}$ McWilliams' (1990) book: The Protectors: Harry Anslinger and the Federal Bureau of Narcotics 1930-1962, analyzed the professional life of Anslinger's extensive work during his tenure at the FBN.
} 
Fisher, 2006:58), the Boggs Act set the stage for one of the toughest, if not the toughest, federal anti-drug laws ever passed in the US. Clearly, these calibrations appear to fit Hall's (1993) conceptualization of a first order change in policy. Although the narcotics policy instrument (punitive approach) did not change, the settings of the instrument (severity of the punishment) experienced change from one level to another. Hall describes this scenario as a first order change in policy. Still, the FBN never gave up on its efforts in promoting a tougher punitive legislation against illegal drugs even after the passage of the Boggs Act. The Narcotics Control Act of 1956 was the outcome of their efforts.

\section{Narcotics Control Act (NCA) of 1956}

Like the previous anti-drug laws, the FBN made every attempt to continue with its criminalization and tougher punishment for narcotics producers, traffickers, and users. Similarly, quite a number of opponents from key interest groups and individuals who were opposed to the criminalization of narcotic drugs, especially the mandatory prison sentences imposed in the Boggs Act, never ceased to campaign against these stiffer laws (Sharp, 1994). The American Medical Association (AMA) and the American Bar Association (ABA) were among the few professional interest groups who raised serious objections to the stiffer penalties under the Boggs Act. These groups appealed to Congress to reevaluate the mandatory provisions of the Boggs Act (Meier, 1994). In response to these demands, Congress in 1955, set up a Congressional hearing committee to reevaluate some of the existing narcotic laws across America. The country wide hearing was under the chairmanship of Senator Price Daniel, a Texas Democrat (Sharp, 1994).

The question of why these interest groups succeeded in drawing the attention of Congress to a revision of the mandatory sentence under the Boggs Act might be of a theoretical interest to 
any student of the policy science, including the author of this study. Typically, the strength of resources (numbers and financial) of some interest groups, whose goal is to shape and influence public policy (Studlar, 2002) in a pluralistic democracy, such as the US, constitutes an important explanatory factor for the reason why the AMA and ABA succeeded in drawing the attention of Congress to the issue. As Studlar (2002:69) contends, organized groups such as the AMA and the ABA's close relationship with government is an important part of interest group theory as well as subsystems politics.

Sharing similar views with Sabatier and Jenkins-Smith (1993), Studlar (2002:70) argues that actors in a policy subsystem usually form coalitions, which are based on shared set of beliefs and ideas. Subsystem players, including interest groups, also do engage in a coordinated activity in order to achieve their policy goals. Applying this theoretical concept to the activities of these interest groups (AMA and ABA) suggests that these groups shared similar set of beliefs and ideas against the mandatory prison sentence under the Boggs Act. The implication of the coordinated efforts by these groups, as the theory suggests, may have provided a strong influence on Congress' decision to reexamine the law.

The country wide hearings, which were conducted by the Senate Judiciary subcommittee on behalf of Congress, heard a total of 345 witnesses, including drug addicts and other ordinary people within the entire segment of the American population. A total of 8,667 pages of testimony were generated and submitted to Congress for review. Some of the revelations from the report conveyed gruesome pictures of how drug addiction had affected many people and the likely consequences of drug abuse on the American society. ${ }^{37}$ It was also revealed in the report that the

\footnotetext{
${ }^{37}$ The information on the Senate Judiciary Committee Hearings (Senate Resolution 67, January 23, 1956, 2) is documented in Belenko ed. (2000). A Documentary History: Drugs and Drug Policy in America. p. 202-203.
} 
US alone had about 60,000 more drug addicts than all the other Western countries' combined in the early 1950s. The rate of increase, the report noted, was about 1,000 per month. Interestingly, the final report from the hearings also linked drug addiction to criminal activities across many parts of the country. The report, for example, noted that drug addiction constituted about 50 percent of all crimes committed in major US cities and 25 percent of all crimes committed in the entire country. However, some critics expressed skepticism about the pattern of the congressional report, which they believed was similar to the tactics used by the FBN in shaping public opinion against the drug problem. ${ }^{38}$

The policy implication of the report was the passage of the Narcotics Control Act in 1956. In fact, scholars (Gray, 2000; Musto, 1999; Sharp, 1994; Fisher, 2006) observe that many provisions of the NCA ended up being more punitive than expected. Many key provisions of the law doubled the existing penalties under the Boggs Act. More importantly, for the first time in the history of the US narcotics policy, the death penalty was introduced for offenders caught selling hard drugs, such as heroin to minors (Balenko, 2000). A major policy change regarding the prison sentence was clearly evident in the passage of the NCA as compared to the Boggs Act. Unlike the previous provisions on the prison sentences, the provision on the prison sentence under the NCA, for example, increased from 5 to 10 years for first offenders, and from 10 to 20 years for second offenders. ${ }^{39}$ The implementation of the law also received some considerable enhancement for effective enforcement from the agencies. For example, while the processing of drug offenders was simplified for police officers and state prosecutors (Gray, 2000), the discretionary powers given to judges to postpone sentences for probationary periods were completely eliminated (McWilliams, 1992). Again, the nature of these changes shows a clear

\footnotetext{
${ }^{38}$ Ibid., p.202-203.

${ }^{39}$ Ibid., p. 203.
} 
evidence of changes in the settings of the punitive policy instrument, but not with the policy instrument itself. In essence, these changes largely represent a first order change in the narcotics policy.

The overall implications of the new anti-drug laws (Boggs Act and NCA) had farreaching consequences for the US narcotics policy outcomes. Two specific policy-related outcomes occurred between the early 1930s to the late 1960s. First, the influence of the FBN, as previously discussed, created a powerful narcotics policy subsystem with a punitive supporting idea (Baumgartner and Jones, 1993; Worsham, 1997; Ferraiolo, 2007). The second policy implication was the emergence of a strong personalized leadership influence within the drug policy arena. Mintrom and Vergari (1996) and Baumgartner and Jones (1993:85) describe this kind of personal leadership as policy entrepreneurship. ${ }^{40}$ In fact, Anslinger exemplified the entrepreneurial role by way of the personal efforts he exerted in shaping the narcotics policy process for about three decades (1930s to 1960s). Besides Anslinger, the personal entrepreneurial efforts by Congressman Hale Boggs and other congressional leaders in the passage of the Boggs Act also showed further evidence of how policy entrepreneurs shape the narcotics policy process.

From a broad theoretical standpoint, one can argue that agenda-setting theory (issue definition/redefinition, policy image, issue salience, framing, and policy entrepreneurship) was evident in the first phase of the US narcotics policy development. The politics of attention, a major theoretical element in agenda-setting, was also apparent in the phase. For example, the focus of attention on the drug issue came from key domestic groups of actors, such as the Congress, the media, the American public, bureaucratic agencies, policy entrepreneurs, and key interest groups in shaping the narcotics policy process. Although the drug issue received a high

\footnotetext{
${ }^{40}$ A policy entrepreneur is defined by Baumgartner and Jones (1993:85) as a policy advocate who takes advantage of a favorable public attention to quickly move a policy issue on an institutional agenda for policy change.
} 
level of attention from these key policy actors, there is no compelling evidence to suggest that the issue received a high presidential attention during this phase. While partisan ideology was less dominant in the policy process in this phase, subsystem politics, on other hand, played an important role in shaping the narcotics policy process.

More importantly, the preceding discussion reveals that the narcotics policy process has generally undergone a first order policy change. As laid out in chapter two, a change in the settings of a policy instrument with no change occurring in the policy instrument itself, let alone the overall policy goals, constitute a first (incremental) order of policy change.

In the case of the narcotics policy, the policy instrument of punitive and law enforcement approach did not change, but the severity of the anti-drug punitive laws changed in an incremental mode. For example, there were changes in the prison sentences, fines, and in the administrative procedures and practices (McWilliams, 1992; Meier, 1994; Gray, 2000; McAllister, 2004) aimed at facilitating the implementation of the policy instrument (punitive policy). Although a treatment policy option existed as an alternative strategy, its application was very limited in scope and practice. Quite simply, the policy instrument during the first phase was generally punitive and law enforcement focused (Meier, 1994). In fact, the degree of severity of the anti-drug laws increased from one level to another. This was clearly revealed in the Marijuana Tax Act of 1937, the Boggs Act of 1951, and the Narcotics Control Act of 1956. In essence, Hall's theoretical model of a first order change in policy provides a compelling explanation for the nature and type of the US narcotics policy process. 


\section{Second Phase: Emergence of the War on Drugs (1969-1980)}

The US narcotics policy process during the second phase took a totally different direction and focus as compared to the previous phase. The phase is shaped by the emergence of the war on drugs in the Nixon era and the de-escalation of the so-called drug war during the administrations of Ford and Carter. Unlike the previous phase, the narcotics policy issue in the second phase received a high presidential attention especially in the Nixon era, which led to the issue being sustained on both the systemic and institutional agendas for quite some time.

In fact, Sharp (1994: 23) describes the Nixon era as "one of the most dramatic episodes of drug policymaking in American history." Broadly, the second phase extends the discussion on the US narcotics policy development by examining the underlying explanations for the war on drugs, key narcotic legislations enacted, presidential agenda-setting dynamics, and the patterns of policy change from Hall's (1993) perspective. The interplay of partisan politics in narcotics policymaking will also be analyzed in this phase. For a better understanding of the Nixon era, it is imperative first to examine the drug situation prior to the declaration of the so-called war on drugs.

Soon after his inauguration in January 1969, President Richard Nixon redefined the drug problem as America's number one public enemy and subsequently declared an all-out "war" on drugs (Wisotsky, 1986; Meier, 1994; McWilliams, 1992; Musto, 1999; Krogh, 2002). While some share the view that Nixon's initial approach to the drug issue was a candid policy response to the deteriorating drug situation in the country, others believe that the so-called war on drugs was an attempt by Nixon and the Republican party to fulfill their "law and order," or toughness on drugs promises they made to the American people during the presidential campaign (Bertram et al.1996: 105). In any case, scholars such as Thoumi (2003), Massing (2000), and Spillane 
(2004) agree that the abuse of psychoactive substances substantially increased from the late 1950s throughout the 1960s, and may have been a more likely reason for Nixon's declaration of the war on drugs. What accounted for the widespread use of these drugs is, however, a subject of many debates and different interpretations among scholars. I will attempt to examine some of these explanations in the next few paragraphs.

According to Boyum and Reuter (2005:5), the inability of the federal government to provide enough budgetary and logistical support for the implementation of the earlier drug laws may have accounted for the widespread use of these drugs. For Boyum and Reuter (2005), in spite of the so-called public and institutional fanfare that characterized much of the anti-drug legislation of the 1930s throughout the late 1960s (MTA of 1937, the Boggs Act of 1951, and the NCA 1956), the implementation of these anti-drug laws suffered many budgetary constraints. On the contrary, Musto (1999) offers a different view regarding the factors responsible for the drug menace during the 1960s. For Musto (1999:247), economic, socio-cultural, and political factors best explain the drug phenomenon. Advancing his argument, Musto believes that the surge in drug use among many Americans was directly connected to the expanding economic wealth of the US during the 1960s where increased national productivity, coupled with the availability of money, created a large market for consumer goods. In effect, anything that promised to make people feel comfortable, including narcotic drugs, was easily accessible. Although narcotic drugs were unlawful and socially unacceptable, it soon became associated with the rich and famous, and a symbol of pride among the so-called successful Americans (Musto, 1999).

From a socio-cultural perspective, Musto (1999) contends that the increase in drug use was due to the generation of "baby boomers" who had reached their adolescent years (15 through 24) in the 1960s. Caulkins et al. (2005:12-13) share a similar cultural view and argue that the 
increase in drug use epitomized the prevailing cultural forces of "anti-establishment" attitudes and sentiments among many young people during the 1960s. Strangely, illegal drug use was seen as a way to counter the established culture and the political establishment at the time (Ferraiolo, 2007; Caulkins et al., 2005; Sharp, 1994). Likewise, many college students were dissatisfied with the Vietnam War and joined the "drug counter culture movement" to express their dissatisfaction with the political establishment (Musto, 1999:248; Caulkins et al., 2005:12). In actual fact, marijuana use was not only glorified in movies and in popular songs, but the drug became directly associated with the anti-war movement (Ferraiolo, 2007:157; Sharp, 1994). The drug subsequently attained an important political significance in the 1960s. The escalation in the number of marijuana related arrests across many cities and towns in the US showed the overall effect of the drug problem.

A national survey report during the late 1960s revealed that close to 24 million Americans over the age of 11 had used marijuana at least once since 1965 (Musto, 1999). It was also revealed that the use of marijuana was not only popular among many minority groups, but the drug use also widened in scope from the so-called rich and famous to those in the middle class. Another survey by the National Commission on Marijuana and Drug Abuse (NCMDA) in the late 1960s revealed that about 5.14 percent of college students reported to have tried heroin at some point in time in their lives. This figure was up from 3.2 percent from the previous year. Also, from 1960 to 1966, the lifetime use of marijuana among young people, ages eighteen to twenty-four, saw a dramatic increase of about threefold. ${ }^{41}$ Based on these troubling figures and the increasing pervasiveness of the drug problem, the Nixon government was forced to reframe

\footnotetext{
${ }^{41}$ The data on Marijuana use in the 1960s was reported in Musto and Korsmeyer (2002:38-39).
} 
the drug problem as a national crisis. The problem was also reframed as an urgent war that must be fought on all fronts (Bertram et al.,1996; Musto, 1999).

The late 1960s was also particularly important because the era signified a major breaking point for the narcotics policy agenda. For the first time in the history of US narcotics policy making, drug policy basically shifted from a low attention issue to a high presidential attention issue. In their study Who Influences Whom? The President, Congress, and the Media, Edwards and Wood (1999), argue that although other key domestic players, such as the Congress and the media, do set policy agendas, presidents frequently act in an entrepreneurial capacity in setting agendas because of the unique role (bully pulpit) they can play in directing the attention of other key players to a policy issue. For Edwards and Wood (1999), influencing a policy agenda is an important source of political power that creates the momentum for policy change.

Given Nixon's political background, ideological orientation, and his presidential control over the narcotics policy agenda, many expected an exclusively law enforcement approach to his narcotics policymaking. Instead, Nixon adopted a comprehensive approach where treatment option was also incorporated with law enforcement to narcotics control. What led to this policy strategy remains an important question that continues to engage the attention of scholars. The question is: was Nixon's comprehensive drug policy an embodiment of a policy change or a policy contradiction? The next section examines both sides of the debate.

\section{Narcotics Control under Nixon: A Policy Change or Policy Contradiction?}

Faced with the increasing drug abuse problem, the administration responded to the issue in many different ways. One of the strategies that the Nixon White House adopted was to draw on the long-standing connection between drug use and the increasing crime rate as the basis for 
his policy approach. Many drug addicts were not only stigmatized, but viewed as symbols of criminality (Bertram et al., 1996). In his first major address to Congress, for example, Nixon made a compelling case for tougher anti-drug laws. His message resonated with both Congress and the American public regarding the need for tougher laws on narcotic drugs (Bertram et al. 1996).

The administration became actively involved in many policy initiatives for tougher antidrug legislations. As McWilliams (1992:20-21) observes, the extent to which the administration was directly involved in the narcotics policy process was a remarkable characteristic feature of the Nixon White House. Some of the efforts by the White House ranged from anti-drug legislative proposals, to public campaign programs, to major influence over the bureaucratic enforcement agencies. For McWilliams (1992), never before had the executive branch of government played such an influential role on narcotics policy than during the Nixon era. As agenda-setting theorists (Baumgartner and Jones, 1993; Worsham, 1998; Studlar, 2002) argue, the purpose of presidential influence and control is to shape the course of a policy agenda on both the systemic and institutional levels, and the narcotics policy under Nixon was no exception to this conceptual idea.

The first major legislation passed under the Nixon era was the Comprehensive Drug Abuse Prevention and Control Act (CDAPCA) of 1970 (Musto and Korsmeyer, 2002:83). The Act was distinguished from earlier legislation on the basis of its two essential provisions. First, the law created five categories of controlled substances, known as schedules as shown in table 3.2 . 
Table 3.2

\section{Schedules of Controlled Substances}

\begin{tabular}{|c|c|}
\hline 1.Schedule I & $\begin{array}{l}\text { Example; heroin, LSD, Marijuana, and Methaqualone } \\
\text { (a) The drug or other substance has a high potential for abuse } \\
\text { (b) The drug or other substance has no currently accepted medical use in treatment in } \\
\text { the United States } \\
\text { (c) There is a lack of accepted safety for use of the drug or other substance under } \\
\text { medical supervision }\end{array}$ \\
\hline 2. Schedule II & $\begin{array}{l}\text { Example; morphine \& cocaine } \\
\text { (a) The drug or other substance has a high potential for abuse } \\
\text { (b) The drug or other substance has currently been accepted for medical use in the } \\
\text { United States with severe restrictions } \\
\text { (c) Abuse of the drug or other substances may lead to severe psychological or physical } \\
\text { dependence }\end{array}$ \\
\hline 3. Schedule III & $\begin{array}{l}\text { Example; barbiturates } \\
\text { (a) The drug or other substance has a potential for abuse less than the drugs or other } \\
\text { substances in schedules I and II } \\
\text { (b) The drug or other substance has currently been accepted for medical use in the } \\
\text { United States } \\
\text { (c) Abuse of the drug or other substance may lead to moderate or low physical } \\
\text { dependence or high psychological dependence }\end{array}$ \\
\hline 4. Schedule IV & $\begin{array}{l}\text { Example; tranquilizers } \\
\text { (a) The drug or other substance has a low potential for abuse relative to the drugs of } \\
\text { other substances in schedules III } \\
\text { (b) The drug or other substance has currently been accepted for medical use in the } \\
\text { United States } \\
\text { (c) Abuse of the drug or other substance may lead to limited physical dependence or } \\
\text { psychological dependence relative to drugs or other substances in schedule III }\end{array}$ \\
\hline 5.Schedule V & $\begin{array}{l}\text { Example; cough syrups containing codeine } \\
\text { (a) The drug or other substance has a low potential for abuse relative to drugs and other } \\
\text { substances in schedules IV } \\
\text { (b) The drug or other substances has currently been accepted for medical use in the } \\
\text { United States } \\
\text { (c) Abuse of the drug or other substances may lead to limited physical dependence or } \\
\text { psychological dependence relative to drugs or other substances in schedules IV }\end{array}$ \\
\hline
\end{tabular}

Source: Adapted from Belenko (2000:279). Also see http://www.deadiversion.usdoj.gov/schedules/ Retrieved on $1 / 31 / 2012$.

The controlled substances are classified into the following categories: the degree of potential abuse of the substances, the likelihood of the drug's harmfulness, and the possibility for some 
legitimate medical use of the substance (Sharp, 1994:25; Spillane and McAllister, 2003: S8; Abadinsky, 2005:13; Belenko, 2000:278).

In fact, the Office of Diversion Control (US Department of Justice) describes substances under schedule I as drugs that have no accepted medical use in the United States. In essence, drugs under schedule I cannot be prescribed for medical use. On the contrary, drugs listed under schedules II to V are considered as having some accepted medical use and may be prescribed for medical purposes. ${ }^{42}$ Although marijuana is still classified under schedule I as heroin and LSD, Dennis and White (1999) note that many states have treated it as belonging to other schedules (II to $\mathrm{V}$ ) by reducing the penalties for marijuana possession.

The second important provision was the consolidation of all the previous federal narcotic laws enacted since the Harrison Act of 1914. The comprehensive nature of the CDAPCA was a unique characteristic of the era as well a significant provision of the Act. Against expectation, the treatment option received some considerable financial and logistical support, unlike previous narcotic legislation (MacCoun and Reuter, 2001:33). For example, budgetary allocations were provided for treatment and prevention programs. Also, many existing Mental Health Centers for drug addicts across the country were expanded. A chronology report on the US narcotics policy since the 1960s by Frontline-Public Broadcasting Service (PBS) indicates that the majority of funding for narcotics policy under the Nixon era was allocated to treatment, prevention, and educational programs, as compared to law enforcement.

As Massing (2000) indicates, a total amount of $\$ 85$ million was provided for treatment of drug addicts, while $\$ 39$ million was allocated for drug abuse educational projects and campaigns

\footnotetext{
${ }^{42}$ http://www.deadiversion.usdoj.gov/schedules/ Retrieved on 1/31/2012.
} 
in the early years of the Nixon era. With the unprecedented support for the treatment option, Massing (2000:119) maintains that the federal spending on treatment and prevention in 1973, for example, increased by $\$ 420$ million more since Nixon took office. In essence, demand-side (treatment option) programs took about two-thirds of the federal drug budget as compared to one-third for supply-side or law enforcement approach (Massing, 2000). In fact, this was the only time in the history of the US narcotics policymaking that treatment option received a considerable funding over law enforcement approach to narcotics control. ${ }^{43}$

The expansion of the heroin addiction treatment program under the support of the Department of Corrections in the District of Colombia (DC) was another example of the treatment option programs. The program, which was extended under the Narcotics Treatment Administration (NTA), used methadone for the treatment of heroin addicts (DuPont, 2002:67-68; Kleber, 2002; Reuter and MacCoun, 2002; Krogh, 2002). Part of the provisions of the law provided for the establishment of a Special Action Office for Drug Abuse Prevention (SAODAP). The SAODAP was subsequently created in 1971 with the purpose of coordinating all federal prevention and treatment programs in the country. Also, the methadone treatment program experienced a dramatic expansion following the establishment of the SAODAP program, as well as the client services of the SAODAP, which saw an increase from 20, 000 in October 1971 , to over 60,000 by December 1972 , and another increase to about 80,000 by October 1973 (Musto, 1999:253).

In addition, there were relative increases in budget allocations from $\$ 8.5$ million in 1970 to $\$ 45.7$ million in 1973 for prevention, training, and other treatment focused educational

\footnotetext{
${ }^{43}$ Thirty Years of American Drug War: A Chronology, Frontline-Public Broadcasting Service http://www.pbs.org/wgbh/pages/frontline/shows/drugs/cron/ http://www.npr.org/templates/story/story.php?storyId=9252490 Also in Huggins, Laura (ed.) 2005. Drug War Deadlock: The Policy Battle Continues. Stanford: Hoover Institution Press. p 17-30.
} 
programs (Sharp, 1994:29). This was followed by the establishment of the National Institute on Drug Abuse (NIDA) with the responsibility of overseeing drug research, treatment, and prevention across the country (Ferraiolo, 2007, McBride and McCoy, 2003).

In terms of theoretical application, the analysis in this phase, particularly the narcotics policy in the Nixon era, shows some level of policy change. Clearly, the policy changed from an exclusively law enforcement approach, which characterized the previous drug policies, towards a more balanced strategy that incorporated the treatment option with law enforcement in narcotics control (DuPont, 2002; Musto, 1999:255). Regardless of how one looks at it, drug policy under Nixon had experienced some level of policy change. Examining the US drug policy process from a comparative perspective, for example, Sharp (1994:134-36) demonstrates with compelling evidence how policy change had occurred during the Nixon era, as compared to previous eras. By systematically examining a number of congressional records from the Harrison-Anslinger era to the Nixon era, Sharp (1994) reveals that the pro-enforcement interest groups ${ }^{44}$ appeared much more often during the congressional hearings on narcotic drugs than the treatment oriented interest groups during the Harrison-Anslinger era (1914-1960s).

In the 1970s (Nixon era: 1969-1973), however, the pro-treatment interest groups ${ }^{45}$ appeared much more in the congressional hearings than did the enforcement-oriented interest groups. The interpretation of Sharp's (1994:134-136) findings is quite simple. The emphasis on enforcement of narcotics control was clearly evident during the congressional hearings between 1914 to the late 1960s. In contrast, the emphasis on treatment was equally apparent during the

\footnotetext{
${ }^{44}$ Sharp (1994) categorizes the pro-enforcement groups to include: federal, state, and local government agencies such as the FBN, Customs Bureau, Justice, and Police Departments. Also included were Sheriffs and prosecuting attorneys.

${ }^{45}$ Sharp (1994) categorizes the pro-treatment groups to include: policy advocacy groups, professional associations (AMA and ABA), and university hospitals.
} 
congressional hearings from 1969 to 1973 when Nixon was in the White House. Again, the results show how interest groups dominated the congressional hearings during the period under review.

Given the fact that interest groups, to some extent, shaped the narcotics policy process under Nixon, it is equally imperative also to explore other agents and policy incentives that created the window of opportunity for these changes. For Ferraiolo (2007), Anslinger's departure from the scene was an important factor in explaining the policy shift during the Nixon era. As earlier noted, Anslinger's personal leadership and style under the FBN, without doubt greatly influenced the consolidation of the punitive law enforcement approach for decades without any major shift in policy. The FBN, however, lost its policy dominance and their influence diminished following the retirement of Anslinger in 1962. According to Ferraiolo (2007:157), this was also the same period that the FBN's control over information began to crumble as public health professionals in charge of treating drug addicts began to also gain much voice in the narcotics policy arena.

As agenda-setting theorists agree, the need for policy control is crucial in reframing a policy issue (Baumgartner and Jones, 1993; Studlar, 2002). In the case of the US drug policy, for example, the activities of many pro-treatment interest groups (health professionals) to reframe the drug abuse problem as a disease and a public health issue started to gain some attention in the early 1970s. These groups took advantage of their influence to shape public opinion to support the treatment option for drug addicts. For the proponents of the treatment option, drug addiction, like any other disease, needs treatment instead of the existing punitive approach to narcotics control (Ferraiolo, 2007). In a congressional testimony before the House in support of the 1970 Act, Daniel Freedman (psychiatrist from the University of Chicago), expressed disappointment 
with the long-standing punitive strategy of narcotics control in America. According to Freedman, the constant threats and harassment of pro-treatment advocates from Anslinger and his agency not only repressed the advancement of research into treatment options, but the stigmatization of drug addicts also created a public disaffection for both users and advocates of the treatment option. $^{46}$

It is noticeable from the above discussion that some level of policy change occurred during this phase. Unlike the previous narcotic policies that were exclusively punitive, the discussion showed a shift in policy towards treatment approach in the Nixon era. Perhaps, the marijuana decriminalization policy in the late 1960s to the early 1970s provides a good reflection of the permissive narcotics policy of the era. Also, the changes that occurred in the severity of punishment for drug offenders demonstrate another evidence of policy change. Prior to the 1970s, for example, the federal penalties for marijuana possession and use attracted severe punishment as did other hard drugs (heroin and cocaine). The punishment was five to twenty years imprisonment for first time offenders and ten to forty years for second time offenders (Sharp, 1994:40). However, the penalties for marijuana possession and distribution were reduced to a maximum of five years imprisonment and $\$ 15,000$ in fines for first offenders, and $\$ 30,000$ for second offenders and some jail time. In some circumstances, first time offenders were permitted to serve probation without a guilty verdict being placed on their records. Much evidence suggests that similar policy change, especially on marijuana laws, occurred in a number of US states (Sharp, 1994). For example, Alaska, California, and Vermont in 1968 lowered the penalties for the possession of marijuana. Thirty-three other states reduced marijuana possession

\footnotetext{
${ }^{46}$ A paraphrase version of Daniel X. Freedman's Congressional testimony was cited in Ferraiolo (2007:159).
} 
to a misdemeanor offense while Oregon completely decriminalized marijuana possession, with only a fine of $\$ 100$ for the possession of less than one ounce of marijuana. ${ }^{47}$

Clearly, Hall's (1993) theoretical concept of orders of policy change appears to be on display again. By applying the concept to the preceding analysis, it appears that both first order and second order change in narcotics policy have occurred in this phase. As discussed, first order change refers to changes in the settings of a policy instrument. The incremental changes in reducing the punishment for marijuana offenders demonstrate a change in the setting of the policy instrument from an exclusive prohibition option. Hall (1993) describes these kinds of incremental changes as first order changes in policy. Besides, Nixon's narcotics policy shift from an exclusively law enforcement approach, which characterized the previous phases, to a balanced approach with more budgetary allocations to treatment approach, demonstrates a degree of a shift in the policy instrument (second order change in policy). In essence, this study contends that a combination first and second order change occurred in the US narcotics policy domain during the second phase.

Although Nixon's narcotics policy goal was generally comprehensive (treatment and law enforcement) and considered distinctive and novel, it was not without controversy. Key questions were raised regarding the real intentions of the overall policy goals of the Administration. Sharp (1994:25) for instance, observes that some members of Nixon's Republican Party in Congress were not exactly sure of the direction of his narcotics policy. For some, Nixon's reversal from an exclusively punitive law and order approach, a key component of his political campaign promise, towards a treatment option after he became president contradicts his earlier known position on narcotic drugs. In fact, Nixon's narcotics policy shift (more emphasis on treatment) became a

\footnotetext{
${ }^{47}$ Sharp (1994) cited the Select Committee on Narcotics Abuse and Control of 1977 as the primary source of the data.
} 
bone of contention, which some described as a clear demonstration of his contradictory narcotics policy regime (Sharp, 1994).

Sharp (1994) offers some explanations as to why the Nixon administration reversed the exclusively punitive drug policy to an integrated policy option. For Sharp (1994:29), Nixon had to embrace the treatment approach and its distinctive methadone maintenance program for heroin addicts, for example, as a political ploy devised to show some results in the face of the increasing menace of drug abuse across the country. This strategy was necessary for Nixon's re-election campaign. The reason why Nixon's policy decision was believed to be politically motivated was that barely ten months after his re-election in 1972, the President declared victory over the drug abuse problem in 1973, citing a decline in the supply and use of heroin (Bertram et al.,1996).

In contrast to the argument that Nixon's narcotics policy overemphasized the treatment approach, others share the view that the apparent focus on treatment by the Administration did not undermine his relentless efforts in pushing for a strong punitive law enforcement strategy of narcotics control. Courtwright (1992:42), for example, argues that law enforcement was actually intensified with numerous arrests, interdiction, prosecution, imprisonment, and the seizure of assets belonging to drug offenders during the Nixon era. For Bertram et al. (1996: 107), Nixon's anti-drug campaign and law enforcement spending saw a substantial increase from $\$ 43$ million in the early 1970 s to $\$ 321$ million by the middle of the 1970 s.

In a similar argument, Sharp (1994) contends that while the treatment approach received some level of emphasis, the Nixon era was equally characterized by a more restrictive narcotics policy. For Sharp (1994:25-26), the Comprehensive Act of 1970 was a "landmark legislation primarily because of its contribution to the criminal justice side of drug policy." For example, the mandatory minimum prison sentence set by the Act was ten years for first time drug offenders, 
with a $\$ 100,000$ maximum fine. In addition, the "no-knock" provision of the Act has been considered as one of the most punitive elements in the Comprehensive Act (Sharp, 1994:26). The "no-knock" provision allowed law enforcement officers to enter private facilities without a warrant from judges to arrest suspected drug dealers. They were also not required to give any advance notice before entering a private property in a situation where they suspected some activities related to the possession of illegal drugs (Sharp, 1994:26).

The other punitive element of the legislation was the Organized Crime Control Act (OCCA) of 1970. The notable aspect of this law was the Title IX provision. The provision, also called the Racketeer Influenced and Corrupt Organizations (RICO), instituted stern penalties where violators of drug laws were not only personally punished for their drug offences, but any drug-related property involved was subject to confiscation by the state (Sharp, 1994). Applying Hall's (1993) perspective to the above discussion, one could argue that these calibrations in policy toward a more restrictive approach (increases in the severity of existing punitive laws) demonstrates evidence of a first order change in narcotics policy during the period under review.

Besides Nixon's anti-drug legislative gains, the bureaucratic agencies involved in the implementation of his narcotic policies were expanded and reorganized for more influence and control. As generally shared, the executive office of the presidency and the bureaucratic agencies do engage in policy battles over the question of influence and control (Rachal, 1982:66-67). This was particularly the case with Nixon's White House and the bureaucratic agencies involved in the implementation of the narcotics policy.

In his Reorganization Plan No 2 Initiative to Congress in 1973, Nixon proposed the creation of a single federal agency to consolidate and coordinate many separate government 
agencies involved in narcotics control. ${ }^{48}$ Many drug control agencies, such as the Bureau of Narcotics and Dangerous Drugs (BNDD), Office of Drug Abuse Law Enforcement (ODALE), Office of National Narcotics Intelligence (ONNI), and the Customs Service Investigation Unit (CSIU) were consolidated into a single new agency called the Drug Enforcement Administration (DEA) as shown in figure 3.2. As expected, the reorganization gave the Nixon White House much more control and influence over the enforcement agencies involved in narcotics control (Bertram, et al., 1996; Meier, 1994).

\section{Figure 3.2}

\section{Genealogy of the DEA}

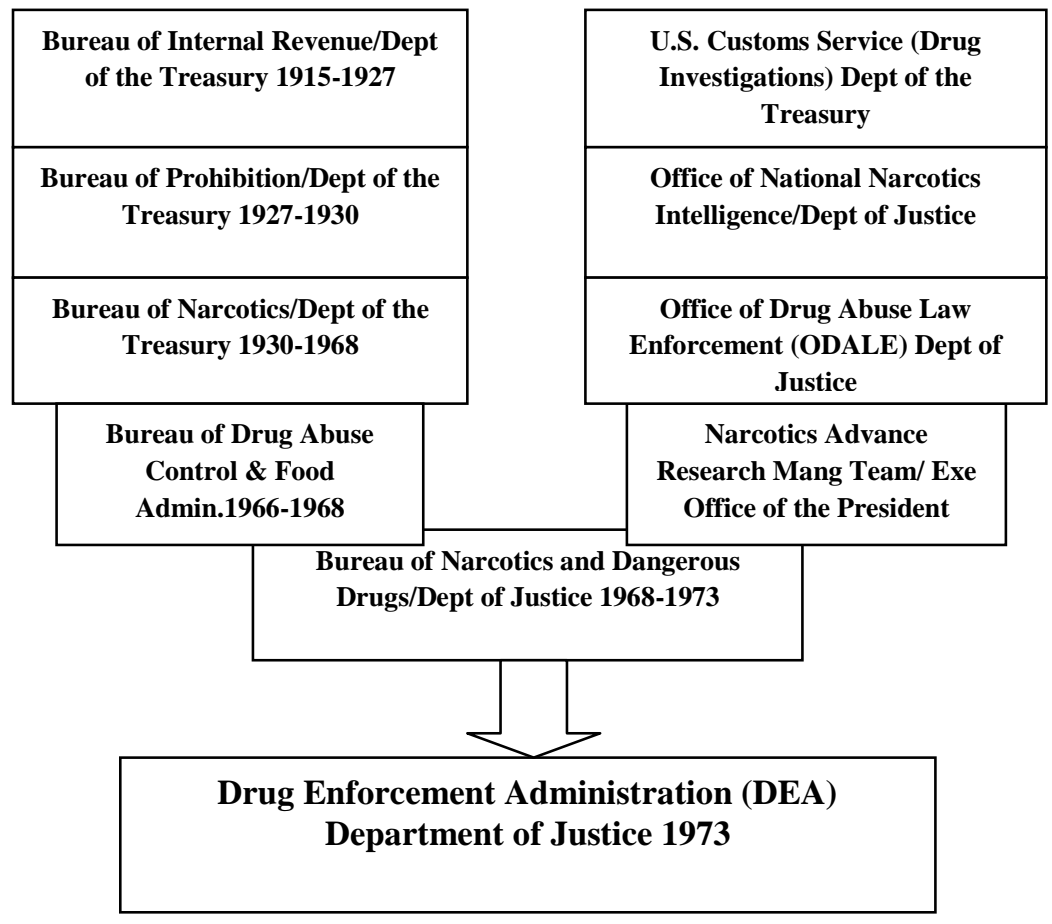

Source: Adapted from DEA 2008 Report with some modifications p.7.

${ }^{48}$ Drug Enforcement Administration (DEA): A Tradition of Excellence 1973-2008 report. P: 13. 
Essentially, the question of why presidents frequently reorganize bureaucratic agencies may provide some useful indication to understanding Nixon's action.

In her book, Federal Narcotics Enforcement; Reorganization and Reform, Rachal (1982:70) addresses the question of why presidents embrace the reorganization of bureaucratic agencies. According to Rachal (1982), presidents often reorganize federal bureaucratic agencies for management or political reasons. In the case of Nixon, Rachal (1982) argues that although some evidence suggests that his Reorganization Plan (No 2) was based on organizational factors, strong evidence points to the fact that Nixon's decision to reorganize the drug implementation agencies into a single bureau was politically motivated for control and influence over these agencies.

Unlike the first phase, the second phase was characterized by the expansion of the US role in international narcotics control, particularly in the Nixon era. As Marcy (2010) observes, the underlying assumption of Nixon's foreign narcotics policy was based on the logic that once the US succeeded in destroying the supply side of the drug equation, the likelihood of stopping the production and trafficking of these drugs into the US would be reduced. In essence, the drug war spilled over into the global arena (Marcy, 2010; Massing, 2000; Ryan, 2001; Friman, 1996; Zagaris and Macdonald, 1992). Besides Mexico, the main source of supply of these drugs into the US during the period under review was Turkey and the region of Southeast Asia. Turkey was particularly important to the Nixon administration because it was the main source of heroin production for the US drug market (Musto and Korsmeyer, 2002:45; Walker, 1989:191). To address the global supply of these drugs, the Nixon administration employed interdiction policy instruments such as military and economic aid as forms of incentives to force the targeted countries to reduce the manufacture and the supply these narcotic drugs (Marcy, 2010:10). 
Undoubtedly, Nixon's narcotics policy legacy has been a subject of varied interpretations by scholars and policy experts. For Bertram et al. (1996), the Nixon era was significant because of the integrated approach to narcotics control. As against the view that Nixon's narcotics policy was contradictory, Bertram et al. (1996) contend that there was no indication of a policy contradiction. Instead, the comprehensive narcotics policy of the Nixon era represented two different policy instruments employed by the Administration in tackling the narcotics problem (Bertram et al., 1996:108).

For others, Nixon's integrated narcotics policy was a matter of political compromise and not a policy contradiction. For many, the nature of the legislative process in the US sometime appears contradictory due to the occurrence of divided (partisan) governments. In most cases, political parties tend to compromise some aspect of their ideological ideas on policies in order to obtain a winning coalition to pass legislations. In a pluralistic two party system of government such as the US, for example, where divided government ${ }^{49}$ (Newman and Lammert, 2011; Lohmann and O'Halloran, 1994; Coleman, 1999) constitutes the norm, rather than exception, compromise and consensus building often take the center stage in the passage of major legislations. Since the Nixon era was also characterized by a divided government, it was very likely that his Administration compromised on his restrictive narcotics policy orientation for a comprehensive strategy of narcotics control with Democrats, who favor a more permissive or liberal approach to narcotics control.

\footnotetext{
${ }^{49}$ A divided partisan government is typical of a presidential system of government with two dominant political parties. Divided government occurs when the Presidency is controlled by a different political party, while the Legislature-Congress (House of Representatives and Senate) is also controlled by another different political party. The Obama era (2011) is a recent good example of a divided government. In contrast, a unified government occurs when one party controls the Presidency and the Congress (House and Senate).
} 
Clearly, the narcotics policy development in the Nixon era has shown key evidence of the main theories guiding this study. As revealed in the preceding discussion, agenda-setting versions of issue redefinition, saliency, and framing were evident in the discussion. For example, not only was the narcotics policy issue redefined and reframed as a national crisis when President Nixon declared the war on drugs, but also for the first time, the issue was elevated from a low profile issue to a high profile (salient) issue as a result of the presidential attention given to it. Also, partisan rhetoric appears to have played a role, but on a limited scale, in shaping Nixon's narcotics policy. This was exemplified by the earlier discussion on the concept of divided governments and policy outcomes.

Similarly, while the scope of the US narcotics policy had widened to include treatment option in the Nixon era, it was also evident that the policy process had undergone some types of change. Whether towards a more restrictive narcotics policy with emphasis on the war on drugs, or towards a more permissive approach with focus on treatment option, policy change in one form or the other had occurred (McBride and McCoy, 2003). Indeed, Hall's (1993) concept of policy change is again on display during the period under review. In fact, my interpretation of the Nixon era from Hall's perspective could be explained from two points of view. First, although the treatment option of narcotics control received some attention in the Nixon administration, it was also evident in the preceding analysis that incremental changes (stiffer punitive laws) occurred to the prohibition policy instrument of the policy. Hall (1993) describes these kinds of incremental policy adjustments as a first order change in policy. Second, one could also argue that the high presidential attention and the subsequent policies toward treatment-centered approach, as compared to the overriding punitive approach that characterized the first phase, revealed some amount of change to the narcotics policy instrument. Such a change in the policy 
instrument is what Hall (1993) describes as a second order change in policy. This study therefore contends that a combination of first and second order changes in narcotics policy occurred in the Nixon era.

Nonetheless, the increasing drug war rhetoric that characterized the Nixon era dissipated soon after he resigned as President in 1974. In fact, the rhetoric on the so-called drug war was de-escalated, when President Ford succeeded Nixon. A similar policy option (de-escalation of the drug war) was pursued in the Carter administration. The next section of this phase will address these policy issues.

\section{De-escalation of the War on Drugs (1974-1980)}

The second part of phase two marked another important period in the evolution of the US narcotics policy process. Unlike the Nixon era where the war on drugs received a high presidential focus and attention, the administrations of Gerald Ford and Jimmy Carter devoted less attention to the drug war rhetoric. In effect, the so-called war on drugs was de-escalated not only on the public agenda, but also on the institutional agenda as well. Instead, the permissive approach to narcotics control received more emphasis and attention as compared to the restrictive policy option (Sharp, 1994).

As noted, the second part of this phase began in 1974 when Gerald Ford, who was the Vice President in the Nixon administration, assumed the presidency after President Richard Nixon resigned over the Watergate scandal. Although Ford's presidency was very brief, there was quite a major transformation in the overall public tone and direction of the US narcotics policy. President Ford may have shared some aspects of Nixon's narcotics policy when he was Vice President, but the framing of his narcotics policy changed from the core ideas of Nixon's 
narcotics policy after he became the President. Although a Republican, Ford's narcotics policy was generally opposed to the forceful, war-like narcotics policy position taken by the Nixon era (Musto, 1999; Belenko, 2000).

Unlike Nixon, Ford rejected the idea of the possibility of totally eliminating the drug problem. For him, it was unrealistic and probably unachievable to think of waging an all out war on illegal drugs. Instead, Ford emphasized what became known as the policy of narcotics containment, which involved major adjustments to the inherited narcotics policy strategies from the Nixon era (Musto, 1999:257, Belenko, 2000:285). The de-escalation of the drug war rhetoric was one of the major changes made to the narcotics policy strategy. In 1975, for example, the Ford administration issued a white paper through the Domestic Council Drug Abuse Task Force (DCDATF), recommending the need for law enforcement agencies to only focus their attention on the users of very dangerous narcotic drugs (cocaine and heroin).

Against many expectations, the white paper excluded marijuana from the category of very dangerous drugs (Fisher, 2006:4). Marijuana was subsequently de-emphasized and given low priority status, even though most states and local authorities, who actually had the enforcement responsibilities, continued to enforce the punitive laws on marijuana (Meier, 1994:48). Clearly, the narcotics policy agenda during the Ford era was redefined towards a more permissive approach to narcotics control. However, no major anti-drug legislation was enacted during the era to back the permissive narcotics policy initiatives of the Administration. Perhaps, the brief period of Ford's presidency, as Meier (1994) rightly contends, may have been largely responsible for the inability to pass any major anti-drug laws before Jimmy Carter succeeded President Ford. 
Generally, the narcotics policy under the Carter administration was clearly distinguished from other eras, particularly the Nixon era, on two major policy grounds. First, President Carter, like Ford, toned down the drug war rhetoric. Second, the President publicly endorsed a policy proposal to decriminalize marijuana use (Sharp, 1994; McWilliams, 1992; Belenko, 2000). Although, Carter spoke less publicly about the drug problem than Nixon before him or Reagan after him (Ferraiolo, 1997), the drug problem was still prominent on Carter's domestic policy agenda, but with a different policy focus.

In a comparative analysis of the Carter era with those of Nixon and Reagan, Sharp (1994) observes that the drug issue was on the domestic agendas of these Presidents, but the fundamental differences between them was the approach each employed in setting the agenda. Employing Cobb, Ross, and Keith-Ross' (1976) version of agenda-setting theory in explaining their policy differences, Sharp (1994:35) argues that while Nixon used the mobilization ${ }^{50}$ form of agenda setting, which focuses on getting public support for a given policy issue, Carter, on the contrary, used the inside-access ${ }^{51}$ agenda setting approach, which gives greater influence and control to policy experts without necessarily drawing much public attention to the issue.

Considering the many years of the punitive approach to narcotics control before the Carter era, it might be possible that the Administration's inside-access strategy to narcotics agenda was to avoid public discontent towards Carter's liberal narcotics policy goals. As noted,

\footnotetext{
${ }^{50}$ Cobb, Ross, and Keith-Ross (1976:127) conceptualized this version of agenda-setting. For them, the mobilization model occurs when a policy issue is initiated within a government (formal agenda), but the issue needs to be extended to the public (public agenda) for their support before any serious consideration is given to the issue. In other words, the issue must be expanded from the formal agenda to the public agenda to gain the popular public support needed before an action is taken on the issue. This model fits the drug agenda approach used by the Reagan administration.

${ }^{51}$ The inside-access or inside-initiative model (Cobb, Ross, and Keith-Ross, 1976:128) occurs when a policy issue arises within a governmental agenda, especially among technocrats and policy experts for consideration. Unlike the mobilization model, the inside-access model restricts the issue from expanding to the public agenda. This model was clearly evident in Carter's approach to narcotics policy.
} 
Carter's narcotics policy agenda was clearly towards a more permissive approach, with the overriding objective of decriminalizing marijuana use. In a speech to Congress in August 1977, the President urged law makers to consider reducing the penalty against the possession of marijuana to a civil fine. For Carter, the penalties against the possession of narcotic drugs should not be more detrimental to the individual than the use of the drug itself (Musto, 1999). Although the initiative did not translate into any concrete narcotics policy, Carter believes that it was essentially important to approach the drug problem from a more humane point of view, where drug users do not feel stigmatized as criminals (Bertram et al., 1996:109; Musto, 1999:261).

Applying a theoretical perspective to the policy option in the two administrations (Ford and Carter) appears to indicate some changes in the narcotics policy instrument. For example, the change in tone (de-escalation of the rhetoric on the drug war) and the policy proposal to decriminalize marijuana fit into Hall's (1993) description of a second order change in policy. That is a change from an exclusively law enforcement approach to a more liberal policy option to narcotics control. Also, the agenda-setting version of issue expansion (Cobb, Ross, and Ross, 1976:127) and venue switching (Studlar, 2002) provide useful tools in understanding the narcotics policy in this phase. As previously noted, the possibility of an issue being redefined is an important source of influence in the process of issue expansion. Redefining and expanding an issue to other venues also involves a substitution of one aspect of an issue for another, particularly to interested actors who desire to shape the policy process (Cobb, Ross, and KeithRoss, 1976; Studlar, 2002).

Essentially, these concepts of agenda-setting (issue expansion and venue switching) are particularly relevant to the marijuana case. Prior to the 1960s, for example, marijuana was generally categorized as a "killer weed" (Ferraiolo, 2007), which was commonly found among 
the most dangerous segment (deviants and criminals) of the American society (Ferraiolo, 2007). As earlier noted, Sharp (1994:41) asserts that the trend of marijuana use switched in the late 1960s and 1970s from being associated with the poor and ethnic minorities, to become associated with America's affluent and the middle-class. Once the marijuana issue expanded to these classes, it was redefined to the level of social acceptability, giving some limited level of public support to Carter's decriminalization initiative.

Pro-decriminalization interest groups, such as the National Organization for the Reform of Marijuana Laws (NORML) became actively involved in expanding the marijuana issue to the American public for acceptance and support, which helped sustained the issue on Carter's policy agenda. Created in 1971, NORML has been instrumental in shaping the marijuana laws toward a more liberal approach. In Studlar's (2002:200) words, agenda-setting underscores 'the struggle over issue definitions and how political actors, especially entrepreneurs" take advantage of strategic opportunities to advance their policies. Indeed, one could argue that the action by the pro-decriminalization interest and lobby groups regarding President Carter's decriminalization policy proposal fit Studlar's (2002) analysis. These versions of agenda-setting (issue expansion and venue switching) again helped us to understand the interplay of key interest groups in shaping Carter's marijuana decriminalization policy initiative.

In spite of the appearance of Carter's determination to decriminalize marijuana as part of his broader liberal narcotics policy agenda, the law enforcement aspect of his narcotics control also received some considerable attention. This raises some questions about Carter's overall narcotics policy goals and policy consistency. Irrespective of the Administration's so-called drug war de-escalation, Bertram et al. (1996) argue that the federal budget programs for anti-drug law enforcement in most of the bureaucratic agencies increased during the Ford and Carter 
administrations. Although the rate of inflation accounted for some of the increases, the budget allocations for narcotics control increased from $\$ 382$ million in 1977 under Ford to $\$ 855$ million by the fiscal year of 1981 under Carter (Bertram et al., 1996).

Another important theme that emerged on Carter's drug policy agenda was the medical use of marijuana. The push for the marijuana initiative was introduced perhaps to compensate for the lack of public support for the marijuana legalization proposal by the Carter era. Gallup poll results conducted during the period under review indicate that about two-thirds of Americans who participated in the survey rejected a total legalization of marijuana, and about fifty-five percent believed that the use of marijuana could be physically harmful (Sharp, 1994:41). Dr. Peter Bourne, the chief policy advisor on narcotics policy in the Carter administration, was the principal expert behind the initiative on medical marijuana use. Bourne proposed a legislation that would allow the use of medical marijuana in some selected facilities across the country. In fact, Bourne also suggested the possibility of supporting a medical use of heroin (Schroder, 1975:15), but the idea failed to gain much public and institutional supports.

Once the medical use of marijuana agenda was set by the federal government, a few drug centers were established to provide medical marijuana services to a handful of patients on trial basis. By 1978, for example, eleven states passed marijuana decriminalization statues, while four other states passed resolutions to recognize the medical value of marijuana. Other laws legalizing marijuana use for patients with certain chronic diseases also came into effect, but patients were required to obtain a prescription in most cases for these drugs (Ferraiolo, 1997:159). For many analysts, the Carter period was distinguished from other eras on several levels. From a policy perspective, it is undeniable that Carter's policy priority to decriminalize marijuana use helped set the stage for the ongoing debate on marijuana decriminalization in the country. 
Moreover, the presidential attention, although limited, provided an incentive to sustain the issue on both the formal and public agendas for some considerable time. Besides the few states that passed marijuana decriminalization statues and resolutions to recognize the medical value of marijuana, the Carter administration failed to pass a federal narcotics legislation to decriminalize marijuana use (Musto, 1999; Sharp, 1994). Quite a number of reasons have been offered to explain the policy inertia on the part of the Carter administration.

The resignation of Dr. Peter Bourne from the government was one of the explanations offered for Carter's inability to pass a federal legislation to decriminalize marijuana use. Dr. Bourne, who was President Carter's chief policy advisor on narcotics and architect of the Administration's liberal narcotics policy agenda, resigned his position when he was found to have prescribed an illegal drug substance (tranquilizer and methaqualone tablets) to an aide who worked with him (Musto, 1999: 262; Sharp, 1994:44; Meier, 1994:48). The problem, as many scholars (Musto, 1999; Sharp, 1994) observed, was not with Bourne's prescription, since he was a qualified medical doctor. The scandal rather centered on his use of a fictitious name for the prescription in order to avoid any record of his activities in the White House. Not only was his credibility damaged, but Bourne's departure also had a significant impact on Carter's drug policy initiatives (Sharp, 1994).

For others, the unsuccessful attempt to decriminalize marijuana use was due to a strong public opposition to the policy. Carter's decriminalization idea, for example, was generally interpreted by many Americans as being too soft on illegal drugs and the criminal activities associated with drug use. As previously stated, the possible explanation why President Carter was described as being too soft on drugs might have originated from the long decades of punitive and law enforcement approach, which appeared to have been ingrained in the consciousness of 
the American public (Bertram et al., 1996). As the literature reveals, almost all illegal drugs were not only criminalized, but framed as dangerous to the American society (Bertram et al. 1996). Meier (1994) also highlights some useful insight to the limits of narcotics policy change during Carter's presidency. According to Meier (1994:48), President Carter's inability to effect a major narcotics policy change, particularly on marijuana decriminalization, was due to his single term in office. In addition to the single term, Carter's administration was also characterized by series of foreign policy crises.

Similarly, Carter's inability to achieve a policy change could partly be explained from an institutional point of view. Explaining the institutional perspective, Bertram et al. (1996) argue that despite the shift in the drug war rhetoric during the Ford and Carter eras, neither of them was able to curtail the enlargement of the federal anti-drug apparatus. In other words, the law enforcement oriented drug-war bureaucratic agencies' operational costs could not be reduced during their presidency. In essence, the incapability of the Carter administration to reduce the increasing growth of the federal bureaucratic anti-drug machinery clearly suggests what Bertram et al. (1996:110) described as the "inherited constraints- institutional and ideological-that restrict presidents interested in even minor drug-policy reforms." In effect, the deep-seated institutional interests provided the incentive for many centers of resistance to major changes in narcotics policy within the bureaucratic agencies. Besides the institutional and ideological constraints, there were widely shared assumptions toward tougher laws on illegal drugs, which imply more inclination toward a law enforcement approach to narcotics control (Bertram et al.,1996).

In fact, Sabatier and Jenkins-Smith's (1993) concept of how policy core ideas and belief systems shape the policy process in subsystem politics reflect a similar situation in the Carter era. Expanding on similar ideas, Worsham (1997:13) suggests that a belief system often serves as an 
institutional guard in policy subsystems. This was exactly the case in the Carter era. In 1978, for instance, Carter's legislative proposal for the revision of the criminal code ${ }^{52}$ on marijuana was unable to pass into law in the US Congress. While several reasons could be responsible for the unwillingness of Congress to change the existing criminal code, it might be possible that the institutional constraints and shared assumptions on how narcotic drugs should be controlled were responsible for the inability of Congress to pass the legislation. Apparently, the very institutional structures that limited major policy changes in the Carter era became the main driving force for the escalation of the war on drugs under Ronald Reagan and George H.W. Bush (Bertram et al.,1996).

As previously stated, the bureaucratic agencies constitute another source of institutional constraint on the narcotics policy reform (Bertram et al., 1996). Although most presidents do prefer to set and lead policy agendas for the bureaucratic agencies to follow, institutional conflicts tend to arise in some instances because of different policy ideas (Worsham, 1997). For Worsham (1997: 9), new political administrations (presidents) in their enthusiasm as newcomers with different policy agendas, often try to reorganize, alter, and modernize existing policy goals and the bureaucracy, but these policy initiatives most often run into serious problems. As many policy experts argue, the bureaucratic agencies constitute the main domain in the implementation of public policies. Equally important is the fact that the bureaucracy as an institution can also develop policy core ideas and belief systems (Sabatier and Jenkins-Smith, 1993) that may differ from the policy agenda of a president. In Carter's case, it was evident that the increase in the budgetary allocation for the narcotics law enforcement agencies could be possible because of the

\footnotetext{
52 The bill proposed that a possession of less than 150 grams of marijuana was to be classified as a misdemeanor and a possession of less than 30 grams be considered a mere infraction with no prison sentence (Bertram et al., 1996).
} 
strong policy core ideas of these agencies that were unwilling to adopt Carter's policy reforms toward a more liberal narcotics approach.

Overall, the second phase, like the first, has shown a similar theoretical fitness in explaining the evolution of the US narcotics policy. Although the three domestic theories (agenda-setting, partisan ideology and orders of change) offer useful explanations to the development of the narcotics policy, some have done a better job in explaining the policy process than others. The preceding discussion, for example, shows that the versions of agenda-setting theory (issue salience, issue expansion, issue definition, and venue switching) provide a more useful explanatory power in understanding the narcotics policy process. Besides, the subsystem's politics and the role of interest groups in setting the narcotics policy agenda not only emerge as prominent themes in the second phase, but they also provide useful explanations for the US narcotics policy change. Although partisan ideology appeared not to have played a dominant role, still, the phase has shown some evidence of partisan influence in the narcotics policy process. For example, President Carter's liberal narcotics policy proposal has again attested to the argument that Democratic administrations are more likely to pursue a more permissive narcotics policy than Republican administrations.

The second phase has also shown some evidence of Hall's (1993) theory of orders change in policy (first and second order). Notwithstanding, it is important to note that the changes that occurred in the US narcotics policy during the first and second phases, were largely incremental in nature as shown by the evidence of first and second order changes in policy, rather than a third order (radical change) kind. 


\section{Third Phase: Escalation of the War on Drugs (1981-1992)}

The third phase represents another major era in the history of the US narcotics policy development. In contrast to the later years of phase two (de-escalation of drug war era), this phase witnessed an increase in presidential rhetoric and attention to the war on drugs. Simply put, the war on drugs escalated (increased in scope of rhetoric and proportion in terms of punitive laws) during this phase. Various key issues related to narcotics control again attained high level saliency on both the institutional and systemic agendas during the administrations of Ronald Reagan and George H.W. Bush. Like the previous phases, this phase is also examined through the three domestic policy theories underlying this study. Theories such as agendasetting, partisan ideology, and orders of policy change are employed in the analyses.

While President Nixon was credited with launching the so-called war on drugs, it was during the early 1980s that the drug war escalated following the election of Ronald Reagan as President of the United States. Reagan re-energized the war by exclusively emphasizing punitive anti-drug laws (Goode, 2005:109; Thoumi, 2003:303; Wisotsky, 1990:91; Belenko, 2000:285). Like other past narcotics policy goals, the overriding policy goal of the Reagan administration included efforts to reduce the demands for drugs through law enforcement (Sharp, 1994). The drug issue was redefined by the Administration through many efforts of reinforcing the drug war rhetoric. President Reagan also declared the drug problem as one of the greatest threats facing the American society (Baggins, 1998). In his words, “drugs are bad, and we're going after them......As I've said before, we've taken down the surrender flag and run up the battle flag... and we're going to win the war on drugs" (Zimring and Hawkins, 1992:47; Gray, 
2000:100). ${ }^{53}$ Clearly, Reagan's reference to the "surrendered flag" epitomized his interpretation of the liberal approach to narcotics control that his government inherited from the Carter administration. In effect, it was not surprising that the federally funded drug-treatment initiative, which received lots of support in the Carter era, became the target for financial cutbacks.

As the case with other previous narcotic laws, the anti-drug policy during the Reagan era was equally shaped by several factors. From ideological standpoint, one could argue that Reagan's narcotics policy outcomes were largely influenced by his conservative ideas (Belenko, 2000). These conservative ideas were clearly evident in Reagan's overwhelming preference for law enforcement policy approach over treatment option (Sharp, 1994; Belenko, 2000). Besides, the exclusive emphasis on law enforcement for narcotics control was also driven by Reagan's ability to win a lot of support from the American public. One of the key sources of support for the Reagan administration was from the moral majority movement, ${ }^{54}$ which helped elect Reagan to the White House in the first place. Their key message, particularly in the 1980s, was to restore the American society to its cherished moral values, including the control of illegal drug use (Bertram et al., 1996; Musto and Korsmeyer, 2002:241).

In addition to the above discussed factors, the US narcotics policy was also shaped in this phase by the societal patterns of drug use in the 1980s (Ferraiolo, 2007: 160). The 1980s were particularly important because it was the period that crack cocaine ${ }^{55}$ emerged on the scene, and the drug quickly became one of the most widely used because its strongly addictive nature (Sharp, 1994). In fact, the extensive use of crack cocaine was deemed to be the most frightening

\footnotetext{
${ }^{53}$ This statement by President Reagan on reclaiming the war on drugs was cited by Zimring and Hawkins (1992) and Gray (2000).

${ }^{54}$ The moral majority movement promoted views that were exclusively based on the defense of the traditional family values, conservative Christianity, morality issues, and patriotism (Bertram, et al., 1996:111).

${ }^{55}$ Sharp (1994) distinguishes "crack" from regular powdered-cocaine. She defines "crack' as smokable, highly addictive, and inexpensive form of cocaine.
} 
threat to the American society for two main reasons. First, crack cocaine was reported to be more highly addictive than regular cocaine. Second, crack cocaine was less expensive and much more accessible to the poor, particularly African-Americans, than regular cocaine (Sharp, 1994). In addition to the widespread use and other social problems associated with these illegal drugs, it was also discovered that these drugs aided the spread of the newly HIV/AIDS disease (Sharp, 1994:53). Consequently, the policy image (Baumgartner and Jones, 1993) of the drug issue was not only redefined as a national crisis, but the problem also became one of the top policy issues on the agenda of the Reagan administration.

One of the first visible political actions taken by the Administration was to introduce Nancy Reagan's “Just Say No” anti-drug campaign program (Goode, 2005; Stares, 1996: Fisher, 2006; Gordon, 1994) to alert the public of the increasing dangers of drug abuse. Basically, the initiative created a huge public awareness about the drug issue through the mass media and other educational campaign channels. Although contested by some policy analysts, Benavie (2009:89) argues that the "Just Say No" policy initiative was quite effective in creating public awareness about the dangers of drug use.

On the policy front, the Reagan administration initiated new major narcotics policy control mechanisms. For example, through a number of executive orders and support from Congress, the Administration integrated many of the federal intelligence agencies, such as the Central Intelligence Authority (CIA), into the war on drugs (Wisotsky, 1986:92). Similarly, by framing the drug problem as a "national security threat" (Kraska, 2003:297), which required a more determined tougher law enforcement effort (Bayer and Oppenheimer, 1993), the Reagan administration, for the first time in the history of the United States, secured a Congressional 
amendment to a century old law (Posse Comitatus Act), which forbids the involvement of the military in any civilian law enforcement.

Apparently, the amendment to the Posse Comitatus Act allowed the use of the military in the broader war on drugs with an expanded role both at home and abroad. While the Navy was tasked to coordinate with the Coast Guard in interdicting illegal drugs at sea, other units of the military were empowered to assist the Customs, Coast Guard, and the DEA with training, information sharing, and the use of their hardware equipment for drug-related operations. Subsequently, the budgetary allocation to the military's new role increased from $\$ 4.9$ million in 1982 to more than $\$ 1$ billion by the early 1990s (Bertram et al., 1996:112).

As part of the military involvement in the drug war, a unit known as the South Florida Task Force (SFTF) was established in 1982 under the leadership of the Vice President, George H.W Bush. The SFTF relied extensively on the military in its efforts in drug enforcement and interdiction operations along the southern US borders. The activities of the Task Force were later extended to cover 13 other cities (Houston, New York, Detroit, Denver, Los Angeles, Baltimore, Chicago, Boston, San Francisco, St. Louis, Atlanta, San Diego, and Miami) by the mid 1980s (Sharp, 1994; Lynch, 2000).

From the legislative front, this phase witnessed the enactment of key narcotic legislations, especially during the Reagan era. Backed by his control of the bureaucratic apparatus, Reagan announced a "legislative offensive" (Wisotsky, 1986) against illegal drugs by the mid-1980s. In effect, the 1984, 1986, and 1988 anti-drug laws were products of Reagan's broad policy agenda towards the so-called legislative offensive against narcotic drugs. These anti-drug laws were tough and very punitive (Ferraiolo, 2007). Labeled with the slogan..."zero tolerance for illegal drugs," the Reagan White House pushed for the passage of the 1984 Anti-Crime Law with strong 
punitive provisions. For instance, one of the provisions of the 1984 Act, known as the forfeiture, empowered the narcotics enforcement agencies with the authority to seize any property and assets that may be obtained from drug traffickers. A similar provision of the law also increased the penalties for drug-related offences and gave the Attorney General some emergency powers to categorize new drugs under the schedule I program (Sharp, 1994:53).

The 1986 Anti-Drug Abuse Act was another major narcotics legislation passed in the Reagan era. Similar to the 1984 Act, the punishment associated with drug offences in the 1986 Act was equally severe and tough (Musto, 1999). One of the core provisions of the law included a mandatory minimum sentence for drug offenders, especially those committed around public and private school zones. Given the widespread use of cocaine during the era, as earlier discussed, most of the drug sentences were based on evidence of the amount of powdered or crack cocaine found in possession of drug offenders (Musto, 1999). For Musto (1999), although many illegal drugs are harmful, some members of Congress during the Reagan era were convinced that crack cocaine use was more harmful than other illegal drugs.

Interestingly, this assumption became the basis for some of the key provisions of the 1986 anti-drug legislation. For example, the law provided a stiffer punishment for drug offenders found with crack cocaine as compared to offenders found with powdered cocaine. In fact, as Musto, (1999:274-275) observes, the "penalty for the possession of 5 grams of crack cocaine, equal to the penalty for possession of 500 grams (about one pound) of powdered cocaine, a ratio 1:100." The prison sentences were also tougher and punitive and range from five to forty years with no option for a suspended sentence or for probation (Musto, 1999).

Clearly, these disparities in the sentences between crack cocaine and powdered cocaine users suggest that race dynamics played some role in shaping the 1986 Anti-Drug Abuse Act. 
Although race has been part of the US narcotics policy history since the early 1900s, the implications of the sentence disparity between crack and powered cocaine offenders in the 1986 Act were far reaching. As previously noted, since crack cocaine was relatively cheap and commonly used mostly by Blacks (African-Americans), it was not surprising that many Black offenders became the largest segment of those arrested and jailed for crack cocaine use as compared to White (European descent) offenders (Musto, 1999). Table 3.3 provides some support to the argument.

\section{Table 3.3}

\section{Racial Distribution in Drug Arrests (1950-1990)}

\begin{tabular}{|l|l|l|l|}
\hline Year & Total & \% White & \% Black \\
\hline 1950 & 8,539 & 46.1 & 49.9 \\
\hline 1960 & 16,370 & 52.0 & 46.2 \\
\hline 1970 & 415,600 & 77.8 & 21.0 \\
\hline 1980 & 580,900 & 75.6 & 23.6 \\
\hline 1990 & $1,089,500$ & 58.5 & 40.7 \\
\hline
\end{tabular}

Source: Adapted from Meier (1994:45). Original data cited from Federal Bureau of Investigation, Uniform Annual Crime Report.

Although Blacks constitute a small percentage of the total US population as compared to Whites, the statistical data in table 3.3 shows a higher proportion of Black arrests, to that of Whites.

Musto (1999:276), further reports that the Sentencing Commission's 1997 Annual Report has shown that White Americans accounted for about 97 percent of the federal offenders on $\mathrm{LSD}^{56}$ use, 66 percent for methamphetamine, and 21percent for powdered cocaine. On the other hand, 86 percent of those charged for crack cocaine offenses were Blacks. Zerai and Banks (2002) argue from a similar perspective on what they describe as the media-driven rage regarding crack cocaine use among Blacks, especially Black women in 1980s. For them,

\footnotetext{
${ }^{56}$ LSD is d-lysergic acid diethylamide. It is one of the most potent mood-changing chemicals. It was discovered in 1938 and commonly used by many Americans, especially white Americans.
} 
institutional power and its policing force are perhaps responsible for most of the anti-drug policies, which tend to perpetuate inequalities of race, class, and gender within the American society (Zerai and Banks, 2002:37).

The race question and the disparity in prison sentences regarding narcotic drugs might continue to dominant the narcotics policy discourse in the US unless the issues surrounding the disparity in sentencing are addressed. In fact, the recent attempt to address this imbalance in sentencing is worth mentioning. In an article titled: Prison Terms for Crack Cocaine Offenses Reduced, Serrano (2011) reports that the US Sentencing Commission voted recently to end the unfairly long sentences for crack cocaine offenders, who are mostly African-Americans, to be consistent with the shorter sentences often given to powder cocaine offenders, who are mostly Whites and other affluent Americans. The Commission's action was a response to the Fair Sentencing Act, which was passed by Congress and signed into law by President Obama in 2010 to reduce the disparity in sentencing between offenders involving crack and power cocaine. The law also had a retroactive effect, which allows for the reduction of the prison term (37 months) of about 12,000 prisoners who were connected to the disparity in sentencing (Serrano, 2011).

As expected, the 1986 Anti-drug Act provided an increase in funding for law enforcement, but decreased funding for educational and treatment programs. Out of the total budgetary allocation of $\$ 1.7$ billion in the mid-1980s, about $\$ 1.1$ billion was allocated for local, state, and federal law enforcement, with only $\$ 200$ million or 12 percent of the entire fund for education and treatment programs (McWilliams, 1992:24). The proportion of the budgetary allocation to treatment does not, however, suggest any major shift from the law enforcement approach of the Reagan era. The change rather reinforced the punitive approach than the treatment policy option. Hall (1993) describes this kind of policy shift as first order change in 
policy. By exploiting the advantage of the executive "bully pulpit," Reagan also shaped the public attitude towards the drug war through his regular speeches, radio addresses, and other special events (Bertram, et al., 1996).

Another distinctive feature of the third phase, especially during the Reagan era, was the focus on the global aspect (supply-side) of narcotics control. In addition to targeting the domestic producers of illegal drugs, billions of dollars were also spent on fighting the drug war outside the US (Glasser, 1991). By the late 1980s, however, the tone of Reagan's narcotics rhetoric shifted a little towards the domestic users (demand-side) of these drugs. Briefing the White House media officials in 1988, for example, the President, remarked that, "drug use is not a victimless crime, it is not a private matter... we must demonstrate our great concern for the millions of innocent citizens who pay the high price for illegal drug use" (Sharp, 1994:56).

The third major legislative achievement of the Reagan era was the passage of the 1988 anti-drug law. Recounting the competitive partisan politics that engulfed the passage of the bill, Meier (1994:53) notes that the 1988 anti-drug legislation reached some sort of a compromise bill which, according to him, resembles a "Christmas tree with something for everyone." For Meier (1994), while the Democratic members of Congress pressed to receive more funding for drug treatment and prevention programs, the Republicans, however, pushed for greater funding for law enforcement, interdiction, and for the prisons. Notwithstanding the compromise, the Reagan administration emerged with a greater share of funding for narcotics control through law enforcement (Meier, 1994).

In fact, the display of partisanship and narcotics policymaking as Meier (1994) rightly discussed is theoretically relevant here. Indeed, the display of partisanship in the narcotics policymaking is consistent with the theoretical argument on partisanship and policy outcomes 
outlined in chapter two. As discussed in the theory chapter, although some variations do occur regarding narcotics control policies by Republican and Democratic administrations, in principle, their ideological differences on narcotics control remains intact (Bertram et al., 1996:140-141). For example, while the Republican ideological approach has a tendency towards a restrictive/ prohibitive approach (law enforcement) to narcotics control, the Democratic ideology tends to favor a permissive option (treatment). Again, the evidence of partisan ideological orientations and narcotics policymaking has clearly been shown in the Reagan era.

As we have seen with the previous Acts, one of the key provisions of the 1988 legislation was the introduction of a new and stiffer penalty for drug offenders. The penalties for crack cocaine offenders, for example, increased across the board. For three time drug offenders, the penalty included the possibility of a life imprisonment without a parole. Also, the death penalty was introduced in the Act for crimes committed by notorious drug traffickers (Meier, 1994; McWilliams, 1992). Added to this, the law required severe punishment for anyone caught with even a small amount of illegal drugs. Besides, convicted drug offenders also risked being denied public housing, federal grants, loans, contract, and federal occupational licenses. For effective implementation of these laws, Reagan created a cabinet-level position with the responsibility of coordinating the new laws (Meier, 1994; McWilliams, 1992).

Like the Reagan era, the narcotics control policy under George H. W. Bush is examined as the second part of the third phase and within the same theoretical framework. After George $\mathrm{H}$. W. Bush became President in 1989, one of the first few public statements was about his strong intolerance towards illegal drugs. Clearly, the US narcotics policy in the Bush years could best be described as an extension of the Reagan era. The explanation for the policy overlap in the two eras is the fact that Bush served under Reagan as the Vice-president. Moreover, Bush was tasked 
to supervise many of Reagan's drug policy programs. In essence, the narcotics policy agenda of the Bush era was almost the same (law enforcement) as the Reagan era although President Bush tried to define his own narcotics policy agenda (Bertram, et al., 1996; Musto 1999).

In his first public statement on the drug issue, President Bush, like his predecessors, defined drug abuse as one of the most serious domestic problems facing the country and urged Americans to help confront the problem of illegal drugs. To underscore his commitment to fighting the drug war, Bush demanded a $\$ 1.5$ billion increase in domestic law enforcement on narcotics control and $\$ 3.5$ billion for international interdiction and foreign supply reduction of illegal drugs into the United States. As part of his broader objective to increase the funding for narcotics control, the military's drug enforcement budget increased from $\$ 357$ million in 1989 to more than \$1 billion in 1992 (Bertram, et al., 1996).

Similar to the previous narcotics policy initiatives, the presidential influence over the federal law enforcement agencies was also broadened under the Bush era. A number of executive orders aimed at exerting greater level of control over these agencies were issued by the President. One distinctive administrative influence was the establishment of the Office of National Drug Control Policy (ONDCP), which was part of the 1988 anti-drug legislation provision (Belenko, 2000; MacCoun and Reuter, 2001). Soon after the establishment of the ONDCP, William Bennett was appointed as the first director of the ONDCP and he outlined the government's drug policy goals toward a strong law enforcement approach to narcotics control (Musto, 1999). Bennett defined himself as the "tough guy" against drug pushers and users and urged all Americans to join the fight against the war on drugs. He reiterated the Bush administration's determination to use all means possible to fight the war on drugs. For Bennett, the only viable 
solution to the drug problem is to pursue a confrontation policy against the producers, traffickers, and users of illegal drugs (Fisher, 2006; MacWilliams, 1992; Musto, 1999).

Like the Reagan era, the drug issue received some considerable attention in terms of rhetoric and policy focus in the Bush era as well. Saliency of the issue was heightened a result of the increased media campaign against narcotics use, particularly in the late 1980s. Musto (1999) argues that the media campaign and public awareness against drug abuse actually intensified during the Bush presidency. This was evident, according to Musto (1999: 281), in a New York Times poll that was conducted in September 1989, which revealed that the problem of drug abuse surpassed all other sources of concern for many Americans. This helped to sustain the issue on both formal and public agendas throughout the 1980s to the 1990s.

The preceding analysis of this third phase (Reagan and Bush eras) has again shown some evidence of the theoretical framework (agenda setting, partisan ideology, and orders of policy change) at display. In terms of agenda-setting, for example, the discussion reveals evidence of agenda-setting concepts of issue redefining, framing, and issue saliency (Baumgartner and Jones, 1993, Studlar, 2002: Worsham, 1997). For instance, the drug issue has not only been redefined and framed as a national issue, but the saliency of the issue in terms of institutional (presidential) and public attention (media) attained one of the highest as compared to the previous phases.

There have also been some considerable changes in the narcotics policy agenda towards law enforcement strategies in the Reagan and Bush eras as compared to the Ford and Carter years. While law enforcement policy option receded and the treatment option gained more attention on the narcotics policy agenda in the second phase (Ford and Carter eras), the third phase (Reagan and Bush eras) witnessed an increase in attention on the law enforcement approach to narcotics control as compared to the treatment approach. In fact, Sharp (1994), as 
mentioned earlier, employed agenda mobilization and inside-initiative models (Cobb, Ross and Keith-Ross, 1976) to study narcotics policy in the Carter and the Reagan administrations and found similar findings. While the Reagan era fits the agenda mobilization theory because of the heightened presidential attention to the issue, the inside-initiative model best applies to the Carter era as a result of the less public attention to the drug issue.

The theory of partisanship appears to be on display in the third phase as well. In contrast to the previous era, particularly in the Carter years where partisan ideology to narcotics control was geared towards a more permissive approach, narcotics policy in the third phase was more towards a restrictive policy option to narcotics control. For Bertram et al. (1996), the prohibitive policy approach to US narcotics control was actually institutionalized under Reagan and Bush. Although the narcotics policy content of Republican administrations (Nixon, Reagan, and Bush) were slightly different, their overall policy goals were strongly driven by law enforcement ideology to narcotics control. However, some punitive narcotic laws were also passed under Democrats. For example, the 1951 Boggs Act was actually sponsored by a Democrat and passed under a Democratic led government. Nevertheless, one could still argue from a partisan theoretical perspective that the most punitive anti-drug laws were enacted under Republican led governments of Reagan and George H.W. Bush.

This observation again confirms the hypothesis of this study (see chapter two) that partisanship shapes US narcotics policy outcomes. In essence, Republicans and Conservative leaning political governments tend to emphasize "toughness" on crime with strict law and order approach to narcotics control, while Democrats and Liberal leaning political administrations tend to favor a more permissive approach. It is therefore plausible to conclude that partisan ideology has partly driven the US narcotics policymaking in the third phase. 
While agenda setting theory and partisan ideology provide some useful understanding of the broad pattern of US narcotics policy change, this study contends that Hall's (1993) orders of change perhaps provide a better understanding of the nature of these changes. As shown in the discussion, the severity of Reagan's anti-drug laws, for example, increased incrementally from the 1984 Act to the 1988 Act, which showed a clear evidence of what Hall (1993) describes as a first order change in policy. In terms of Hall's second order change, a comparative analysis will be useful here. As shown in the preceding analysis, the third phase was characterized by a more punitive approach (reliance on law enforcement) to narcotics control, particularly in the Reagan era, as compared to the liberal approach in the Carter era. Hall (1993) describes this as a change in the policy instrument from one level to the other. For Hall (1993), a change in the policy instrument, with the policy goal remaining unchanged (see chapter two), constitutes a second order change in policy. There was no indication, whatsoever, of a third order or paradigm change in the narcotics policy of the phases discussed so far. In assessing the explanatory power of the theories employed in this chapter, I argue, based on the preceding analysis, that partisanship provides a partial explanation for the US narcotics policy change, while agenda-setting and orders of change offer the best explanation for the narcotics policy process and change.

\section{Summary}

The US narcotics policy has indeed undergone many changes since the early $20^{\text {th }}$ century. These changes ranged from punitive law enforcement approach to narcotics control to liberal approach (treatment option), and to some extent, a balanced policy strategy, since the early $20^{\text {th }}$ century. The analysis in this chapter has basically examined the historical development of the US narcotics policy since the early 1900 through three main historical phases. The discussion in this 
chapter also highlights the major anti-drug laws that were enacted, the key players involved, the nature and type of policy change that has occurred, and the implications of these changes on future narcotics policy. The three domestic policy theories were essentially examined within the context of different dimensions of policy, and therefore policy change. For example, agendasetting theory looks at narcotics policy agendas in terms of issue attention, definition/ redefinition, and issue framing. Partisan ideology examines campaign rhetoric and policy proposals. The escalation of drug war rhetoric in the Nixon and Reagan eras are good examples. Key policy proposal to decriminalize marijuana use in the Carter era is another case in point. Orders of change explored policy adoption and implementation of narcotic laws in the three phases.

Finally, it must be noted that the three historical phases examined in this chapter exclude the administrations of President Bill Clinton and George W. Bush. These two Administrations are purposefully excluded in this chapter in order to examine them in the next chapter. In essence, the fourth phase will discuss the US narcotics policy change within the context of the two eras (Clinton and George W. Bush). 


\section{Chapter 4}

\section{The US Narcotics Policy Process and Change (1993-2009)}

\section{Introduction}

This chapter investigates the dynamics of US narcotics policy change since 1993. Unlike

chapter three, this chapter is examined within the context of only one broad phase (1993 to 2009). Like chapter three, my goal in this chapter is twofold: First, to demonstrate the relevance of the main theoretical concepts underlying the study. The second is to determine the theory that offers the best explanation for the US narcotics policy change since 1993. Agenda-setting theory with versions of issue definition/redefinition, venue shifting, and policy entrepreneurship will be the first to be examined. The dynamics of partisan ideology in shaping the narcotics policy process will be the second to be discussed, while Hall's (1993) orders of policy change will constitute the final theory to be examined.

As discussed in the previous chapters, the three domestic policy theories will be explored within the context of different dimensions of policy, and therefore policy change. While agendasetting examines narcotics policy agendas, partisan ideology focuses on campaign rhetoric and policy proposals in the narcotics policy process. Hall's (1993) theory of paradigm change (orders of change) explores narcotics policy adoption and implementation.

\section{Fourth Phase: Explaining Narcotics Policy Change (Clinton and Bush Eras)}

Although phase four constitutes one broad era, my analysis of the phase is sub-divided into two different political Administrations. The Clinton era (1993-2001) and the Bush era (2001-2009) as shown in figure 4.1. 


\section{Figure 4.1}

Fourth Phase of US Narcotics Policy (1993-2009)

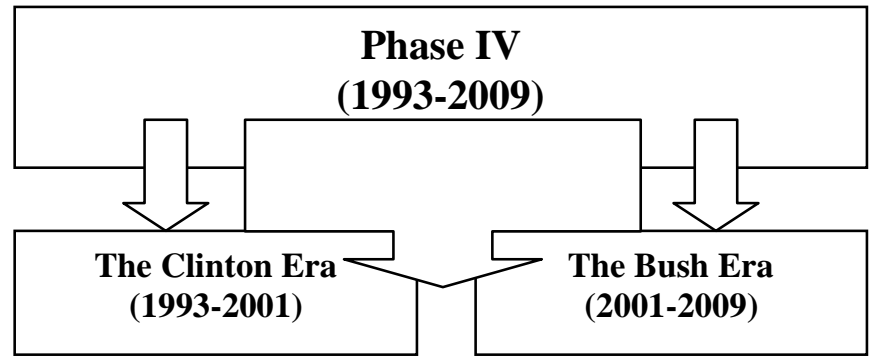

Source: This chart is modeled in line with earlier chart in figure 3.1 (Jones 2002:119).

The first sub-phase examines narcotics policy under the administration of President Bill Clinton (1993-2001). The second sub-phase explores the administration of President George W. Bush (2001-2009). The examination of the narcotics policy of the two Administrations is important for two main reasons. The first is to determine the nature and the type of policy change that has occurred within the US narcotics policy process since 1993, and the second is to explore in more depth the extent to which partisan ideology has shaped the narcotics policy process.

As earlier noted, understanding change is at the core of all sciences, including policy science (Capano, 2009:7). The field of policy science has advanced considerably in the formulation of complex theoretical concepts that seek to explain the dynamics of policy change. Although change is fundamental to the understanding of the policy process (Capano, 2009; Pralle, 2006), the task of investigating the nature, type, and scope of change in a given policy process, is one of the difficult and complex undertakings. This study shares the views of Capano (2009) and Pralle (2006) that the complexity of the process can be minimized when change is 
conceptually well-defined in terms of degrees or amount (macro or micro) ${ }^{57}$ of change occurring within given phenomenon.

Like chapter three, this chapter will also examine the three domestic policy theories (agenda-setting, partisan ideology, and policy paradigm change) as competing explanations for the US narcotics policy change since 1993. Evidence from secondary documentary sources and primary data collected from interviews with leading narcotics policy experts constitute the underlying methodology for the analysis. I started the narrative of this chapter by first examining the Clinton administration before the Bush era. For a better overview of US narcotics policy change, I will discuss the two Administrations from a broader changing pattern of narcotics policy adoption and outcomes.

\section{Agenda-Setting}

As discussed in chapter two, agenda-setting is the process by which a public policy issue moves from relative obscurity to becoming a priority issue because of some serious attention that is given to the issue by policymakers and other actors in the policymaking process (McLendon, 2003:482). Central to agenda-setting theory are questions of how issues become issues, how they are defined and redefined, how they gain prominence, and how these issues change over time (Baumgartner and Jones, 1993; McLendon, 2003; Studlar, 2002; Sinclair, 1986). While some policy scholars consider agenda setting as one of the most important stages in the policymaking process (McLendon, 2003), Studlar (2002) reminds scholars to distinguish between agenda

\footnotetext{
${ }^{57}$ I apply the term macro in this case to describe the type of policy change that is radical. Micro describes the type of change that is incremental. Since change occurs in different forms, it becomes important for policy scholars to cautiously apply policy theories that can best explain a phenomenon of policy change. Indeed, one will not argue that all policy theories can best explain all types of change in a policy process. My argument is simple. Scholars must carefully select policy theories that can best explain a given outcome. This is the approach this study has adopted in the process of selecting the theories that can best explain the US narcotics policy process over time.
} 
setting stage and agenda-setting theory. Like other scholars, Studlar (2002) defines agendasetting as the process where issues are seriously considered toward the achievement of a policy goal (Studlar, 2002:65).

The agenda-setting literature is vast and complex with different versions that explain the rise and fall of issues on policy agendas or the extent to which change occurs to a policy issue (Baumgartner and Jones, 1993; Pralle, 2006). Regardless of the varieties of agenda-setting theory, Studlar (2002:170) contends that the concept is essentially dependent on two important questions:

(a) How policy issues are often defined and redefined?

(b) Who are the key actors usually involved in setting a policy agenda?

For the purpose of this study, I will explore related questions such as who is paying the most attention to the narcotics issue, and what policy outcomes (major narcotic legislations) emerged in the fourth phase. As previously noted, my analysis will focus on Baumgartner and Jones' (1993) version of agenda-setting theory (punctuated equilibrium) with further concentration on issue definition/redefinition, venue shifting, and policy entrepreneurship. My primary task is to demonstrate with empirical evidence how these concepts have driven the US narcotics policy change since 1993. In other words, these theories are employed to determine their explanatory power in shaping the US narcotics policy process and change since 1993.

\section{Issue Definition/Venue Shifting and Narcotics Policy Change}

One of the key research questions this study seeks to investigate is whether the US narcotics policy has undergone or undergoing policy change and who are the drivers of these changes? These questions are very important because any casual observer of the existing US 
narcotics policy is very likely to consider it as unchanging from a broader perspective. Although the policy might broadly appear unchanging, a systematic examination of it through various theoretical lenses might show that the US narcotics policy has indeed undergone, and still undergoing some types of changes, especially at the state government level (since the early 1990s). Most of these changes are being driven by the efforts of policy entrepreneurs and antiprohibition advocacy groups.

While a change in policy towards a more punitive narcotics control has generally been minimal, the demand for policy change towards a more permissive approach to narcotics control have largely been on the increase in the 1990s, particularly on the marijuana policy initiative (Musto, 1999; Ferraiolo, 2007). The question is this: why has the demand for a permissive policy on marijuana intensified in the 1990s? To fully answer this empirical question, it is important to ask two further questions that have previously been stated. First, how has the narcotics policy issue been defined/redefined in the 1990s? Second, who are the key actors involved in setting the narcotics policy agenda? Drawing on the seminal work of Baumgartner and Jones' (1993) theoretical concepts of issue definition and venue shifting/shopping under the broad punctuated equilibrium and agenda-setting theories, I argue that these concepts (issue definition and venue shifting) offer a compelling explanation for the US narcotics policy change, especially marijuana policy, during the 1990s.

For many students of agenda-setting theory, issue definition constitutes an important concept in the policymaking process (Pralle, 2006; Studlar, 2002; Princen, 2007; Worsham, 1997; Howlett, 1997). According to Baumgartner and Jones (1993:23), issue definition or policy 
image $^{58}$ is a purposive process by which political leaders try to accomplish certain goals and objectives. This goal can be manifested through the construction of a policy monopoly or the destruction of another monopoly in a policy sub-system. In other words, defining an issue can serve as a driving force either to sustain an existing policy issue, or create a condition for a change of the issue by mobilizing previously disinterested actors toward the issue (Schattschneider, 1960; Baumgartner and Jones, 1993).

Essentially, the interpretation of Baumgartner and Jones' (1993) idea on how issues are defined clearly suggest the importance of political leaders as one of the dominant change agents in issue definition. While this definition is useful, I will expand the scope of their definition, for the purpose of this study, to include advocacy groups and policy entrepreneurs in the process of defining an issue. In fact, Pralle (2006:172) shares a similar perspective and argues that issue definition strategies are not only driven by policymakers, but also by the public and other actors interested in changing the understanding of a policy issue. Rochefort and Cobb (1994) in their book: The Politics of Problem Definition in Shaping the Policy Agenda, share similar views. For them, problem definition has to do with what the public and political leaders choose to identify as public issues and how these issues could be discussed by them.

Venue shopping or shifting is the next important concept intertwined with the concept of issue definition and policy change. As discussed in the previous chapters, Baumgartner and Jones (1993:32) describe policy venues as the "institutional locations where authoritative decisions are made concerning a given issue.” In Pralle's (2006:172) terms, venue shopping entails the search for alternative policy arenas by policy entrepreneurs who try to move decision-

\footnotetext{
${ }^{58}$ Baumgartner and Jones (1993) conceptualize issue definition as a process in which policy issues are discussed and understood or the public understanding of a public policy problem. This understanding is crucial, according to the authors, in the expansion of an issue to a previously apathetic group.
} 
making authority to new venues for the purpose of control and influence. In a similar study, Pralle (2003) contends that advocacy groups often choose venues for the purpose of short-term strategic interest. These groups also choose venues that will allow them to gain public support towards the understanding of an old issue.

For Pralle (2006, 2003), venue shopping and issue definition are intertwined and significant in two ways. First, issue redefinition also involves the process of shifting the venue of a policy issue. Second, issue redefinition and venue shifting have become one of the key driving forces for policy change. Considering the importance of these theoretical concepts to our understanding of the policy process, the key question to ask is whether these concepts can offer some explanations for US narcotics policy change since 1993. In other words, does the US narcotics policy domain provides a useful fit for the application of these agenda-setting concepts in explaining policy change? I will explore these guiding questions with empirical evidence to support my argument in the next section.

\section{The Clinton Era (1993-2001)}

Like the previous phases, the narcotics policy issue received some level of attention in the early 1990s. In fact, before Bill Clinton was inaugurated as President of the United States in January 1993, the problem of illicit drugs featured prominently during the 1992 presidential campaign. Following the saliency of the issue within the public domain prior to the general election, Clinton promised the American people to combine tough law enforcement with treatment and prevention programs if elected as president (Chepesiuk, 1999). Farmer and Marion (2004) made a similar observation in their study that examines the relationship between presidential campaign promises and policy actions after elections. For them, Clinton actually 
made several campaign promises to fight drug abuse and related criminal activities during his 1992 and 1996 presidential campaigns.

Soon after becoming President, Clinton put forward some policy initiatives on narcotics control. Although some modest changes were made to the existing narcotics policy, the overall narcotics policy of the Administration was defined within the broad parameters of the US narcotics policy legacy (Bertram et al., 1996). As Rose (1990) observes, a policy legacy is an important variable that shapes a policymaking process. For Rose (1990:266), most newly elected political administrations often inherit past commitments and policies made under previous political regimes. Although a new government may alter some aspect of a past policy, as was the case with the Clinton era, Rose (1990) maintains that the core elements of past policies (policy goals and instruments) hardly experience huge changes in a new administration.

One might consider Rose's (1990) concept of policy legacy as broadly applicable to the US narcotics policy process as well. This is because of the overriding policy goal of reducing the production, trafficking, and use of illegal drugs by every US administration (Democrats or Republicans). Another dimension of understanding the narcotics policy legacy is the manner in which the drug issue has been framed and defined over the years. In fact, regardless of the different partisan orientations toward narcotics control, the literature clearly reveals that the prohibition policy option has been dominant as compared to other alternative policies (treatment) from most successive political administrations since the early 1920s (Nadelmann, 1990; Fisher, 2006; Levine, 2003; Meier, 1994; Bertram et al.,1996).

In spite of the dominance of the prohibition approach to narcotics control, the issue has undergone many types of change in terms of policy focus over the years. For example, the focus of the narcotics issue, as discussed in chapter three, escalated at one point and was de-escalated 
at another (Bertram et al., 1996:5), especially after the war on drugs was declared in the early 1970s. Whereas President Ford, for instance, de-escalated the war on drugs soon after he succeeded President Nixon, President Carter, on the hand, took a more liberal approach by defining his narcotics policy initiative on the need to decriminalize marijuana use. Similarly, while narcotics policy was given an important consideration (liberal approach) on Clinton's domestic policy agenda (Perl, 1993:143), the drug war rhetoric that characterized the previous eras, (Reagan and Bush) was de-escalated by the Clinton administration.

There have also been some changes, particularly on the anti-drug policies that were adopted in the Clinton era. Before Clinton was elected for example, he pledged during the election campaign to combine law enforcement with a more liberal narcotics policy (Chepesiuk, 1999). The policy initiative of the Administration, however, shifted in focus toward a more liberal approach as evident by the public statements made by some top officials. Two major policy responses of the Administration also provide further evidence to support the policy shift in the era. First, the budgetary allocation for the ONDCP was drastically reduced, and the number of personnel staff assigned to the organization was also reduced from 146 to 25 (Chepesiuk, 1999:36; Bouley, 2001:172; Musto, 1999). In fact, the Administration's liberal narcotics policy became clearly visible as Clinton's cabinet took shape (Bertram, et al., 1996). Many attempts were made to frame and redefine the image of the drug problem through various policy statements made by the President and his top policy officials. In one of the policy statements, for example, Clinton, argued for a "drug treatment on demand" as an option for narcotics control. 
According to him, drug treatment on demand was a necessary component to prevent criminals from reverting to illegal drugs when released from prison. ${ }^{59}$

Other top officials in the Clinton administration such as Lee Brown (Drug Czar) and Janet Reno (Attorney General) were also very active in articulating the treatment and prevention policy option to narcotics control in an attempt to redefine the drug problem differently. Lee Brown, for example, was said never to use the "drug war" metaphor, as was commonly used in the previous administrations of Reagan and George H.W. Bush (Bertram et al., 1996:118). In the case of Janet Reno, her views toward a more liberal narcotics policy were revealed during her confirmation hearings as Attorney General Nominee in May 1993 (Chepesiuk, 1999:36). After her confirmation as Attorney General, Reno not only continued her advocacy for treatment for drug addicts, but she also intensified her criticism of the existing prohibition approach.

In one of her narcotics policy initiatives, the Attorney General proposed a reevaluation of the mandatory sentences for drug offenders. For her, "the limited resources available to the justice department should be directed against violent offenders and not against addicts who were caught selling drugs and who needed treatment more than punishment" (Bertram, et al., 1996:119). Theoretically, it is apparent that the Clinton administration's initial narcotics policy demonstrates a clear evidence of agenda-setting concepts of issue definition and framing in the narcotics policy issue. It also shows that some key officials in the Administration, including the President himself, were paying serious attention to the narcotics issue.

The contentious debate that emerged in the 1990s over the legalization of some illegal drugs, especially marijuana, provides another important empirical evidence of agenda-setting concepts of issue definition, venue switching, and policy entrepreneurship in explaining the

\footnotetext{
${ }^{59}$ Kramer 1993. "Clinton's Drug Policy is a Bust.” Time Magazine, 20 December. p. 35.
} 
dynamics of the US narcotics process of policy change. Since the 1914 Harrison Act was enacted, there has been an ongoing debate on the need to legalize some narcotic drugs. At the center of this debate are policy advocacy groups and policy entrepreneurs whose primary objective is to shape, redefine, and shift the narcotics policy from the predominantly punitive policy regime towards a more public health approach to narcotics control (Balenko, 2000). Faced with the challenge of achieving greater public support for a total legalization of some of these drugs, critics of the existing prohibition system in recent years began to shift their focus from the idea of a total legalization toward a policy option that will minimize the harms ${ }^{60}$ associated with the use of these illegal drugs (Balenko, 2000).

As discussed in chapter three, several studies have shown that marijuana is the most commonly used illegal drug in the United States. A recent national survey conducted by the Substance Abuse and Mental Health Services Administration (SAMHSA) shows an overall increase in the use of illicit drugs among many Americans. According to the report, the use of these drugs have increased from about 8.0 percent of the population of age 12 and older in 2008 to 8.7 percent in 2009 , with the overall increase largely driven by the rise in marijuana use. ${ }^{61}$ The situation was not different in the 1990s either. A study conducted by the National Institutes of Health (NIH) and published in the Journal of the American Medical Association (JAMA) shows

\footnotetext{
${ }^{60}$ Advocates for the harm reduction model argue that illegal drug use must be recognized as a reality and addiction to drugs considered as a medical and a social problem that require public health response. The proposal for legalization has also taken many different forms over the years. They range from total free market in the use of narcotics without government control, to allowing a limited decriminalization of certain drugs for medical use, especially marijuana (Balenko, 2000:335).

${ }^{61}$ SAMHSA Report (2010). Results from the 2009 National Survey on Drug Use and Health: Volume I. Summary of National Findings (Office of Applied Studies, NSDUH Series H-38A, HHS Publication No. SMA 10-4856 findings) Rockville, MD.
} 
an increase in the use of marijuana in the 1990s. ${ }^{62}$ Similar findings were also reported by Golub et al. (2006) in their study on marijuana use from the 1990s to the early part of the year 2000 .

Clearly, the above analysis and the information from the respondents of my interview for this study show that marijuana does not only constitute the commonly used drug in the US, but also that the drug has become the epicenter or the focal point for the legalization debate. In fact, the 1990s was particularly important because the debate over the legalization of marijuana for medical purposes intensified and attained a high salience on the formal and public agendas. Perhaps, the emergence of prominent advocacy groups, such as the National Organization for the Reform of Marijuana Laws (NORML) whose primary objective is to effect a radical change in the marijuana policy, might help explain the saliency of the issue. As one interviewee said:

NORML seeks to change Cannabis Prohibition laws via lobbying, litigation, and education.

Currently, less than 1 percent of cannabis consumers are involved in their own liberation.

Getting so many like-minded, but too-afraid-of-their-government to act in positive direction is the key to completing the reforms undertaken since the 1970 s. $^{63}$

We have also seen in the previous chapter that the medical marijuana movement was actually accorded a high presidential attention when Carter endorsed the decriminalization of marijuana barely six months after he was elected as President of the United States (Sharp, 2005; Ferraiolo, 2007; Dupont, 1996). Although Carter's proposal did not materialize into any concrete policy option, a few state governments passed many resolutions authorizing the use of marijuana for certain illnesses, but only to be prescribed by a medical doctor. Similarly, state laws as we know are subject to federal laws in principle and by virtue of how the US federal system is

\footnotetext{
${ }^{62}$ The data was reported in the US Department of Health and Human Services News Release (HIH News) 2004.

${ }^{63}$ An official interviewed at the National Organization for the Reform of Marijuana Laws (NORML). This interview was part of the elites selected for this study.
} 
designed. However, many state governments since the late 1960s have experimented with their own policy on marijuana use.

For example, some states, as previously stated, reduced the penalties for marijuana use and possession, with Oregon as the first state to decriminalize the use of marijuana in the early 1970s (Khatapoush and Hallfors, 2004:752). However, no provisions were made for a general supply of the drug, since doctors were still forbidden, under federal law (Schedule I Controlled Substances) from prescribing marijuana for addicts (Ferraiolo, 2007: 159-160). Consequently, what started as a modest movement to allow the use of marijuana for medical purposes took a different turn by the mid-1990s, following the widespread assumption that marijuana could be used as an effective medicine for people suffering from the HIV/AIDS disease and other forms of severe chronic pains and terminal diseases (Ferraiolo, 2007).

Faced with the possibility of using marijuana for these medicinal purposes, many AIDS patients, particularly in the San Francisco area, supported the marijuana reform movement. The Movement also received support from many reform-minded advocacy groups, such as NORML in most of the western states like Oregon and California. No wonder that California became the first state to vote for the use of medical marijuana in 1996. The California marijuana law (Proposition 215-Compassionate Use Act) was overwhelmingly passed through the ballot box initiative (direct democracy). The law allowed patients suffering from illnesses such as AIDS, cancer, anorexia, and migraine to use marijuana for medical purposes, but with a doctor's referral (O'Connell and Bou-Matar, 2007; Khatapoush and Hallfors, 2004). Since California is often described as a policy leading state due to the size of its economy and influence, it was not surprising that other states quickly followed the California example (Khatapoush and Hallfors, 2004) using the ballot box to enact the medical marijuana laws. Clearly, the shift of the issue to 
another venue (state level) offers a good explanation for the change in the marijuana policy (Ferraiolo, 2007). Table 4.1 shows the number of states that have so far enacted the medical marijuana laws through either the ballot initiative or the state legislature.

\section{Table 4.1}

\section{Statewide Medical Marijuana Policy Adoption (1996-2010)}

\begin{tabular}{|l|l|l|l|l|}
\hline State & Year & Laws Enacted & Vote (Yes) & Vote (No) \\
\hline California & 1996 & Voter referendum & $56 \%$ & $44 \%$ \\
\hline Arizona & 1996 & Voter referendum & $65 \%$ & $35 \%$ \\
\hline Alaska & 1998 & Voter referendum & $58 \%$ & $42 \%$ \\
\hline Oregon & 1998 & Voter referendum & $55 \%$ & $45 \%$ \\
\hline Nevada & 1998 & Voter referendum & $59 \%$ & $41 \%$ \\
\hline Washington & 1998 & Voter referendum & $59 \%$ & $41 \%$ \\
\hline Maine & 1999 & Voter referendum & $61 \%$ & $39 \%$ \\
\hline Colorado & 2000 & Voter referendum & $54 \%$ & $46 \%$ \\
\hline Hawaii & 2000 & *Legislative vote & 13 & 12 \\
\hline Montana & 2004 & Voter referendum & $62 \%$ & $38 \%$ \\
\hline Vermont & 2004 & *Legislative vote & 25 & 4 \\
\hline Rhode Island & 2006 & *Legislative vote & 28 & 6 \\
\hline New Mexico & 2007 & *Legislative vote & 32 & 3 \\
\hline Michigan & 2008 & Voter referendum & $63 \%$ & $37 \%$ \\
\hline New Jersey & 2010 & *Legislative vote & 25 & 13 \\
\hline
\end{tabular}

Source: Ferraiolo (2007:148). http://norml.org/index.cfm?Group_ID=3391\#Alaska Retrieved on 05/19/11 *Senate legislative votes. The District of Columbia (DC) is excluded from this table.

The law was recently passed (2010) in the District of Columbia (DC). The vote was (13-0) in favor.

As shown in table ${ }^{64} 4.1$, the medical marijuana ballot initiative received quite very high level of support, as indicated by the high percentage of the yes votes in the elections. The data also reveals that the option for voter referendum appear to dominate the early years (1996-2000) of the ballot initiative in states where the laws were enacted. Again, it can clearly be noticed from the preceding analysis that key policy actors, such as advocacy groups, state political officials,

\footnotetext{
${ }^{64} *$ Hawaii (Senate vote 13/12, House vote 32/18) http://www.dpfhi.org/news/honad328.htm

*Vermont (Senate vote 25/4, House vote 99/44).

http://stopthedrugwar.com/chronicle/2011/may/09/vermont_legislature_passes_medic

*Rhode Island (Senate vote 28/6, House vote 59/13).

http://www.cannabissearch.com/medical_marijuana_law/rhode-island/

*New Mexico (Senate vote 32/3, House vote 36/31) http://www.cannabissearch.com/medical_marijuana_law/newmexico/* New Jersey ( Senate vote $25 / 13$, House vote $48 / 14$ ).

http://www.nytimes.com/2010/01/12/nyregion/12marijuana.html
} 
and the public, were those paying the most attention to the marijuana issue during the period under review.

As noted at the beginning of this chapter, the question to ask is: what explains the intensity in the passage of many marijuana laws in the 1990s? This study argues that the active involvement of key advocacy groups, such as NORML and many others, and the nature of how the narcotics issue was redefined towards a more public health approach, provide a convincing explanation for the increasing intensity of marijuana policy change in the 1990s. Also, the increasing trend of public support (see figure 4.2) regarding the adoption of the medical marijuana law provides another explanation for the support for the marijuana movement in the 1990s.

\section{Figure 4.2}

Trends in Public Opinion about the Legalization of Marijuana (1969-2011)

Support for Making Use of Marïuana Legal

Do you think the use of marijuana should be made legal, or not?

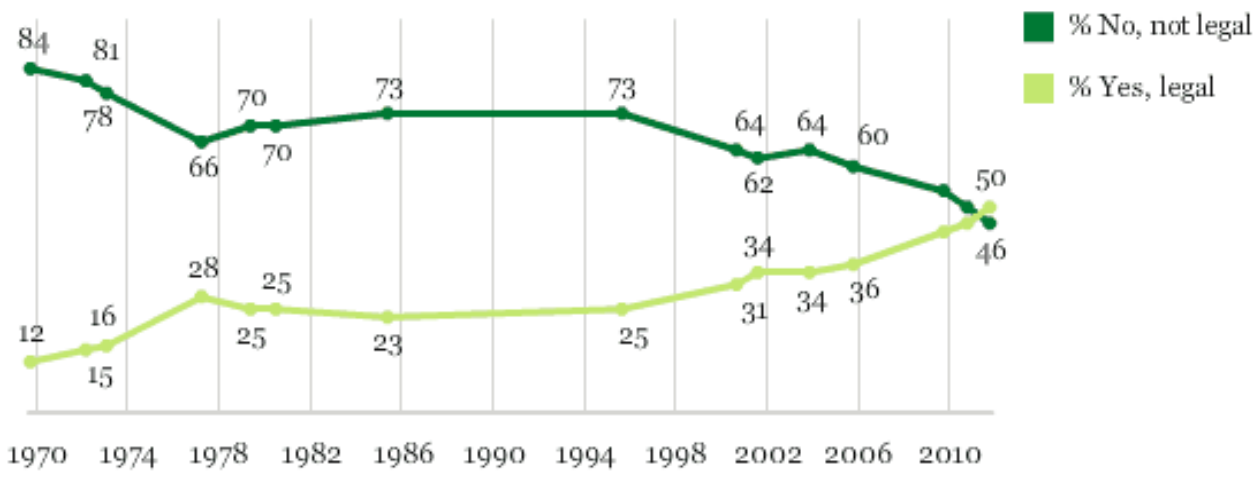

GALLUP'

Source: Gallup poll survey report compiled by Frank Newport. October, 2011. Retrieved from (11/02/11) http://www.gallup.com/poll/150149/Record-High-Americans-Favor-Legalizing-Marijuana.aspx 
As Studlar (2002) argues, public opinion is an important element of agenda-setting theory. In the case of marijuana policy, a Gallup poll report ${ }^{65}$ indicates that the number of Americans who currently support the use of marijuana for medical purposes has steadily increased compared to the 1970s (Saad, 2009). A recent poll conducted by the Pew Research Center (PRC) shows that nearly three-quarters of most Americans, about 73 percent of the total population, favor the use of marijuana for medical purposes. ${ }^{66} \mathrm{~A}$ more recent Gallup poll as shown in figure 4.2 indicates that a record-high 50 percent of Americans who favor the legalization of marijuana use. In fact, the trend of the survey report shows that close to 84 percent of Americans were opposed to marijuana legalization when Gallup first asked the question in 1969. Support remained in the mid-20 percent in the 1970s into the 1990s. The support increased to 30 percent in 2000 and to more than 40 percent in 2009 , before finally reaching the 50 percent threshold in $2011^{67}$ (see figure 4.2).

Many interviewees, particularly the advocates of the liberal approach to narcotics control also agreed that the general support for marijuana legalization will continue to increase because of the new understanding by the public on the medical efficacy of the drug. For Millhorn et al. (2009), the increasing public support for the medical use of marijuana might have been particularly influenced by the dynamics of the changing times where more people are becoming more tolerant of morality policy issues.

\footnotetext{
${ }^{65}$ Saad, Lydia. 2009. Gallup Poll Report. Retrieved on 05/19/2011. http://www.gallup.com/poll/123728/u.s.-support-legalizing-marijuana- reaches-new-high.aspx

${ }^{66}$ Pew Research Center (2011) http://pewresearch.org/pubs/1548/broad-public-support-for-legalizing-medicalMarijuana Retrieved on 05/19/2011.

${ }^{67}$ Gallup poll survey report compiled by Frank Newport. Retrieved on 11/10/2011. http://www.gallup.com/poll/150149/Record-High-Americans-Favor-Legalizing-Marijuana.aspx
} 
What is, however, important to note is that many people are still divided on the question of whether to legalize marijuana use or not. It is important to clearly distinguish between those who currently favor a complete legalization of marijuana and those who argue for the drug to be used only for medical purposes. Although the recent poll suggests an increasing support for a complete legalization of marijuana use, there are still going to be uncertainties on how the policy will be implemented. For others, it might be ideal first to implement the medical marijuana policy before considering the option of completely legalizing marijuana and other narcotic drugs.

The question of what explains the increasing success rate of the ballot box initiative in other states after the California experience is an important empirical issue that needs to be explored as well. As briefly mentioned in the earlier discussion, my theoretical assumption, which appears to be consistent with similar agenda-setting theorists (Baumgartner and Jones, 1993; Sinclair, 1986; Pralle, 2006; Studlar, 2005; Howlett, 1997) is that the concepts of issue definition and venue shifting offer one of the best explanations for the marijuana policy change since the 1990s. As clearly evident in the literature, defining the drug issue has been an ongoing struggle for many decades. For proponents of the prohibition paradigm, narcotic drugs, especially marijuana, must be kept illegal and criminalized (Bennett, 2005; Walters, 2005). On the contrary, advocates for narcotics policy reforms (Nadelmann, 1990, Andreas and Nadelmann, 2006; Husak, 2002; Inciardi, 1999) not only continue to push for policy change, but also try to redefine the drug issue towards a more liberal approach, particularly marijuana.

Generally, the redefining of the issue has principally been achieved by the activation of the growing public support base for more liberal marijuana laws (Ferraiolo, 2007). Aside from the redefinition of the issue, a new understanding of the medical value of marijuana has also been gaining some grounds as a result of the growing sympathetic view of marijuana and the 
remedy it could provide for those suffering from chronic diseases. There has also been the dimension to the marijuana issue not only from a public health perspective, but also from a patient right issue, and the compassion for drug addicts (Ferraiolo, 2007:149).

What is also important to note is that once the marijuana issue was successfully framed as a public health issue, the reform-minded advocacy groups and other policy entrepreneurs shifted the venue through the popular electoral ballot voting system (direct democracy) and legislative approval at the state levels (Ferraiolo, 2007). In fact, Matsusaka's (2005) argument on the recent popularity of the ballot initiative in many states provides a useful insight into the broader discussion on the medical marijuana movement. According to Matsusaka, the eclipse of the ballot initiative in public policymaking in the passage of key laws could generally be attributed to the declining public confidence in state legislatures.

The logic behind Matsusaka's (2005) argument could possibly be interpreted to mean that the ballot initiative is becoming popular, particularly in the 1990s, because of the lack of public confidence in the state legislatures. Indeed, Matsusaka's (2005) argument tends to fit the medical marijuana movement with two positive outcomes. First, the result of public discontentment in many state legislatures created the incentive for the popularity of the ballot initiative, which also facilitated the passage of the medical marijuana laws at the state level. Second, it could also be argued that the popularity of the ballot initiative created the window of opportunity (Kingdon, 1984) for reform-minded advocacy groups to successfully shift the venue of the marijuana issue to the state level for policy change.

In the earlier discussion of venue shifting, this study shares Pralle's (2006:172) view that venue shifting involves effort by advocacy groups and policy entrepreneurs to keep issues out of their disadvantaged venues and shift them to advantage venues for popular support. In the 
marijuana case, for example, Ferraiolo (2007) argues that many marijuana reform groups who were faced with institutional constraints from Congress and federal narcotics agencies had to look for new venues (state level) for support. Regarding the institutional constraint, NORML's unsuccessful attempt to petition the federal government to reschedule marijuana from schedule one to a less restrictive category since the 1970 s is a good example of an institutional constraint these advocacy groups usually encounter (Ferraiolo, 2007). These conditions (disadvantaged venues), in effect, created the incentives for these reform-minded advocacy groups to shift the venue of the marijuana issue to the state level through the ballot box initiative for policy change.

From Ferraiolo's (2007:164-165) standpoint, the ballot initiative that was introduced at the state level created two important consequences for the narcotics policy process. First, the initiative allowed proponents of the medical marijuana movement to expand the scope of the issue from the powerful law-enforcement agencies and proponents of the existing system to ordinary Americans at the state level. Second, supporters of the marijuana movement were convinced of their victory in marijuana policy change following their success in shifting the venue of the issue to the state level. As one interviewee observes:

The nature of the movement towards decriminalizing has been tentative. There is awareness that decriminalization is still a non-starter in many legislative chambers. Marijuana decriminalization and legalization is where there has been a substantial focus at the state level in certain states. Ballot initiatives in certain states and legislation in state legislatures have been the primary instruments of seeking the decriminalization of marijuana. ${ }^{68}$

Aside many advocacy groups, other attentive actors were also very instrumental in shaping the marijuana policy issue since the 1990s. Who were these major players driving the

\footnotetext{
${ }^{68}$ An official interviewed at the Drug Policy Alliance (DPA).
} 
issue? The literature describes these actors as policy entrepreneurs (Mintrom, 1997; Mintrom and Vergari, 1996; Kingdon, 1995: Baumgartner and Jones, 1993; Studlar, 2002). For Mintrom (1997:739), policy entrepreneurs are "people who seek to initiate dynamic policy change." Studlar (2002:180) refers to them as political entrepreneurs. He defines the concept (political entrepreneurship) as "the ability to take advantage of circumstances to push an issue onto the public and governmental agenda." As Mintrom (1997) argues, policy entrepreneurs play very important roles in the policymaking process by primarily promoting their policy ideas through (a) problem identification (b) networking in policy circles (c) shaping policy debates (d) building coalitions. Within the definitional context, one can infer that the dynamics of policy change is partly driven by policy entrepreneurs.

Applying the concept to the US narcotics policy, it is evident that the terrain of the narcotics policy process has been occupied by policy entrepreneurs and other key policy actors (reform-minded advocacy groups) in shaping narcotics policy change. On Crow's (2010:301) part, policy entrepreneurs are very important in the promotion of policy change in many public policy fields. Although the concept of policy entrepreneurship mostly relates to an individual policy entrepreneur, Crow (2010) argues that a group might also have the ability to act as entrepreneurs in shaping policy changes. I will employ this idea of group entrepreneurs (reformminded advocacy groups) to explain the marijuana reform movement during the 1990s.

As discussed in the previous chapter, the narcotics policy debate is broadly shaped by two main policy perspectives: the pro-legalization and the anti-legalization groups. The federal and the state government agencies in charge of narcotics control constitute the main antilegalization groups. During the 1996 ballot box initiative in California, for example, state lawenforcement agencies like the California Narcotics Officers' Association (CNOA), the California 
Sheriffs' Association (CSA), and the office of the DEA were the primary opponents of the medical marijuana movement (Ferraiolo, 2007). In the case of Maine, where a similar law was passed in 1999 (see table 4.1), the Maine Chiefs of Police Association (MCPA) and the federal narcotics agencies were some of the key opponents to the initiative (Ferraiolo, 2007).

The key policy actors involved in the pro-legalization (marijuana) movement on the other hand, were advocacy groups such as NORML, Drug Policy Foundation (DPF), and Californians for Medical Rights (CMR). An important policy entrepreneur is George Soros (Philanthropist). Mr. Soros has been one of the prominent individual policy advocates for the marijuana reform movement for many years now. He is not only an activist for policy change from the existing policy, but also a major financier of many marijuana ballot initiatives at the state level since the 1990s (Ferraiolo, 2007). According to Musto (1999:288), since 1993, George Soros has contributed about $\$ 15$ million to programs aimed at shaping the marijuana reform issue across the US. Most of the contributions made by Mr. Soros were through his Open Society Institute (OSI) to advocacy groups such as the Drug Policy Alliance to support medical marijuana ballot initiative programs.

Apparently, the active involvement of these advocacy groups and policy entrepreneurs in narcotics policy change is consistent with most of the responses from the interviewees, especially on the medical marijuana issue.

As one respondent said:

In most of the states which have adopted medical marijuana laws, the issue has been put on the ballot or pushed through the legislature by advocacy organizations. ${ }^{69}$

\footnotetext{
${ }^{69}$ An official interviewed at the Criminal Justice Policy Foundation (CJPF).
} 
According to another respondent:

The recent economic downturn has accelerated support for marijuana decriminalization and scaling back of criminalization of drugs. Combined efforts of NGOs working to roll back the war on drugs, along with the growing support for marijuana legalization and other objectives, have largely driven the US drug policy change. ${ }^{70}$

In essence, one might argue, based on the evidence shown in the foregoing discussion, that policy entrepreneurs and other key advocacy groups have largely shaped the US narcotics policy process towards change since the 1990s. It is also important to mention that the growth of these anti-prohibition advocacy groups might be a very good indication of the growing public support towards policy change from the existing policy. A case in point, as previously noted, is the recent public opinion survey by Gallup poll, which shows a rising support among many Americans for marijuana legalization. Again, the usefulness of the concepts of policy entrepreneurship and advocacy groups within the broad agenda-setting theory has been reinforced in this study.

So far, my discussion of the US narcotics policy, especially during the Clinton era, has been primarily focused on the medical marijuana initiative at the state level. In fact, my choice of marijuana and the rationale for its extensive discussion in this chapter as compared to other illegal drugs is important for one main reason. That is marijuana has not only been the most commonly used illegal drug, but the drug has also become the center of the legalization debate (Annas, 1997) for many decades now.

Also, there is another aspect of the US narcotics debate that needs to be examined. It is important because it shows evidence of policy change to the long standing prohibition narcotics

${ }^{70}$ An official interviewed at the Drug Policy Alliance (DPA). 
paradigm at the state level. As we have discussed, many policy changes are occurring at the state level with respect to the existing marijuana laws, but marijuana use is still prohibited at the federal level. That leads us to the question of how the federal authorities have responded to the medical marijuana laws passed at the state level since the late 1990s. I will address this question from two different policy responses that this study categorizes as confrontational response and $a$ cooperational response.

Generally, the nature of the US political system is designed for authoritative decision making points at many different levels for the purpose of power sharing. These levels include the federal, state, and local government authorities. Although power sharing among the authoritative decision making points appears to be a useful balance of power against each other, the system is equally susceptible to various forms of institutional conflicts and confrontations among the authoritative decision making points (Radin and Boase, 2000). Broadly, the US Constitution gives Congress the power to supersede state laws. However, in recent times, the authority of the federal government has seriously been challenged by the ballot initiative at the state level with respect to the medical marijuana laws (Dresser, 2009; Ferraiolo, 2007).

The initial response by the federal government on the state ballot initiative was swift and confrontational, despite the attempt by proponents of the marijuana movement to frame the issue from a more humane and public health perspective. For example, several attempts were made by the Clinton administration to prevent the implementation of the California medical marijuana law soon after it was passed (Annas, 1997). In a response to the 1996 California law at a White House press conference, the director of the ONDCP, Barry McCaffrey, noted that the federal law on marijuana and other illegal drugs remained unchanged in the face of the marijuana law that was enacted in California. McCaffrey actually described the use of marijuana as a "gateway 
drug" that has the potential to lead to the use of other hard drugs such as heroin and cocaine (Annas, 1997).

Other top government officials such as the Attorney General, Janet Reno, and the Secretary of Health and Human Services, Donna Shalala, also threatened to revoke the licenses of physicians who prescribe marijuana for the so-called medical reasons (Ferraiolo, 2007; Annas, 1997). Apparently, these were some of the officials in the Clinton administration who initially advocated in favor of a more liberal approach to narcotics control. Nonetheless, the Clinton administration's response to the 1996 California marijuana law could best be described as a confrontational policy response.

Despite the strong opposition from the federal government on the marijuana laws at the state level, positive steps (cooperational response) were taken by the Clinton administration to re-examine the potential medical benefits of marijuana use. In January 1997, for instance, the Director of ONDCP commissioned the Institute of Medicine (IOM), a subsidiary unit of the National Academy of Sciences, to review the scientific evidence regarding the likely health benefits of medical marijuana (Eddy, 2010; Musto, 1999). The report, which was based on a series of public hearings and consultations held across the country, concluded that smoked marijuana is unlikely to be a safe medication for any chronic medical condition. However, the report did find more probable promise in synthetic cannabinoid drugs than in smoked marijuana for medical use. The report recommended the need for well-formulated, scientific research into the therapeutic effects of marijuana on patients with specific chronic diseases (Eddy, 2010:10).

The passage of the Comprehensive Methamphetamine Control Act (CMCA) of 1996 in the Clinton era ${ }^{71}$ also deserves a special mention in this chapter. The Act was one of the major

\footnotetext{
${ }^{71}$ Drug Enforcement Administration (DEA) Report (2008:104). A Tradition of Excellence, 1973-2008.
} 
narcotic legislations passed during the Clinton era. The bill was signed into law by the President on October 3, 1996. The law mandates drug enforcement authorities to control the production, trafficking, and distribution of methamphetamine in the US. ${ }^{72}$

Finally, an overview of the analysis in the first section of the fourth phase (see figure 4.1) reveals an interesting changing pattern of the US narcotics policy process and the allocation of attention since 1993. In this section (Clinton era), the narcotics issue not only surged and waned on both the systemic and institutional agendas, but the issue was also redefined and shifted in venue through the activities of many advocacy groups and policy entrepreneurs at the state level. The interplay of these concepts (issue definition, venue shifting and policy entrepreneurship) offer a convincing explanation for the US narcotics policy change, especially on marijuana policy in this phase. Again, the applicability of these concepts of agenda-setting has been well demonstrated as evident in the preceding discussion. It also shows that these theoretical concepts provide some utility in explaining the US narcotics policy process and change since 1993.

\section{The Bush Era (2001-2009)}

Similar to the Clinton era, the narcotics policy process during the era of President George W. Bush was also shaped by the broad parameters of the past US anti-drug policies, but with some modifications. In effect, my analytical narrative of the Bush era will be examined with the same theoretical framework used to discuss the Clinton era. In essence, this section will be analyzed within the context of the research questions, and the broad theoretical concepts outlined at the beginning of this chapter. Specifically, the core elements of agenda-setting theory (issue

\footnotetext{
${ }^{72}$ Ibid, p: 105.
} 
definition, venue shifting and policy entrepreneurship) will be employed in understanding the narcotics policy process in the Bush era.

As the literature reveals, the problem of drug abuse in the Bush era was not too different from the previous eras. According to the Office of National Drug Control Policy (ONDCP), the publishers of the National Drug Control Strategy (NDCS), some 16 million Americans on average use many forms of illegal drugs (marijuana, cocaine, heroin, and methamphetamine) on a regular basis, despite the existence of many punitive control measures (ONDCP, 2003). Among these illegal drugs, marijuana again appears to be the most accessible and widely used drug in America (ONDCP, 2003). Of the 5.6 million Americans who were diagnosed for drug treatment in the early part of the year 2000, about 62 percent were found to have abused or dependent on marijuana (ONDCP, 2003:14).

Similarly, the 2009 National Survey on Drug Use and Health (NSDUH), a study conducted by the Substance Abuse and Mental Health Services Administration (SAMHSA), confirms a similar finding on the increasing rate of illegal drug use in recent times. According to the report, an estimated 21.8 million Americans aged 12 or older used various narcotic drugs in 2009 alone. The NSDUH report adds that among persons aged 12 and older, the rate of marijuana use increased from 6.1 percent or 15.2 million in 2008 to 6.6 percent, or 16.7 million in $2009 .{ }^{73}$ Like other studies, the report confirms that marijuana continues to be the most commonly used narcotic drug in America. This might explain why marijuana continues to take center stage in the politics of US narcotics policymaking.

\footnotetext{
${ }^{73}$ The 2009 National Survey on Drug Use and Health (NSDUH) Report conducted by Substance Abuse and Mental Health Services Administration (SAMHSA) p.1 http://oas.samhsa.gov/NSDUH/2k9NSDUH/2k9ResultsP.pdf
} 
The 2003 NDCS report rightly captures this assertion this way:

No analysis of drug prevention would be complete without a discussion of marijuana, the drug so widespread in today's schools that nearly half of all high school seniors report having tried it by graduation. ${ }^{74}$

Faced with these perturbing statistics, the drug issue took center stage in the Bush administration. The commitment to the issue was particularly evident in some official policy statements made by the President and his top appointees. In his official policy statement announcing the new head of the ONDCP, for example, President Bush was emphatic on the fact that any attempt to legalize illegal drugs would totally undermine the harmful message of narcotics use (Husak, 2006). John Walters, the drug czar during the Bush era, also made a similar statement. According to him, the so-called emphasis on harm reduction and the call for legalizing some narcotic drugs might signal a misrepresentation of the harmfulness of drug use (McVay, 2006:14).

For Bennett (2005: 81), the fight against illegal drugs needs to be continued because of what he describes as the "attitude of surrender to the drug war." Bennett's (2005) assumption for the so-called attitude of surrender could be interpreted mainly from the increasing support for harm reduction and the state initiative in promoting the medical use of marijuana through referendum and legislation at the state level. Critics of this line of thinking would, however, argue otherwise. For example, Reinarman (2000:106), one of the ardent critics of the existing US narcotics policy, claims that the so-called toughness rhetoric on narcotic drugs by political elites is often displayed only to serve their political purposes as these leaders compete for votes on the basis of who is "tougher" on narcotics control (Reinarman, 2000).

\footnotetext{
74 The 2003 National Drug Control Strategy (NDCS) report, p: 13 of the ONDCP. Retrieved on 07/14/11.
} 
Apparently, the medical marijuana movement did not stop with the Clinton era. It certainly continued into the Bush administration. However, a careful observation of the era reveals that most of the medical marijuana laws from the year 2000 onwards were approved by state legislatures and not through the ballot box initiative (see table 4.1). My interpretation of this pattern, as far as the theoretical concept of this study is concerned, is that of the concept of venue shifting being on display again. Clearly, the shift in venue in terms of the authoritative decision on the issue from the ballot initiatives (1990s) to state legislatures (2000s) could be explained by the popular support already existing in most of these states towards medical marijuana laws.

There is also the possibility that the shift in venue regarding the authoritative decision on the marijuana issue from popular elections to state legislatures was because of a window of opportunity that was opened through public support ${ }^{75}$ for the marijuana initiative. Once antiprohibition advocacy groups and policy entrepreneurs realized the strength of their support on the issue, it was reasonable for them to lobby state lawmakers to enact the marijuana law. This scenario could also be interpreted as another policy venue (window of opportunity), which was utilized by the advocacy groups and policy entrepreneurs to push for the enactment of the medical marijuana law in the state legislatures, instead of using the ballot box initiative.

One could also argue that the public confidence in many state legislatures re-emerged from the year 2000 onwards as against Matsusaka's (2005) contention of the decline in public trust for many state legislatures. Part of the reason for the shift from the ballot box initiative might also be the result of the time-consuming and expensive nature of electoral campaigns (ballot box initiative) in effecting marijuana policy change. In other cases, the ballot initiative led

\footnotetext{
${ }^{75}$ See figure 4.2 for the gradual rise in public support towards the legalization of marijuana from the late 1990s.
} 
to divisiveness and unpredictable results as Ferraiolo (2007) rightly articulated. In effect, any authoritative decision point, such as state legislatures, that is likely to maximize utility and minimize cost will be attractive to any advocacy group. A careful look at the votes (see table 4.1) on the passage of the marijuana laws show a very high level of "yes" votes in the state legislatures.

On the theoretical question of narcotics issue definition, the narcotics policy trend in the Bush era was quite similar to the Clinton era. Advocacy groups such as the Marijuana Policy Project (MPP), Drug Policy Alliance (DPA), Law Enforcement Against Prohibition (LEAP), and Students for Sensible Drug Policy (SSDP) continued with their efforts to shape and redefine the drug issue towards a more public health perspective. Key policy entrepreneurs were equally active in shaping the narcotics policy domain during the Bush era. Clearly, the narcotics policy process in the Bush era, like in the Clinton years, was equally shaped by the medical marijuana issue (ONDCP, 2003, 2004).

The trends in public opinion (see figure 4.2) about medical marijuana use constitute another important theme in the Bush era. Public opinion, as Studlar (2002) posits, is not only intertwined with agenda-setting theory, but the concept constitutes an important part of the policy science literature. Soroka (2002) shares a similar thought on the centrality of public opinion on agenda-setting research and argues that the effect of public opinion on policymakers regarding policy outcomes is intimately connected in many dimensions. Although the opinion of many Americans toward the narcotics discourse shifted in many different directions over the years, the Bush era was particularly different in the sense that the public support for medical marijuana reached one of the record high levels. 
For example, a Gallup poll ${ }^{76}$ conducted in November 2003 indicates that about 75 percent of American adults favor the use of marijuana for medical purposes, while only 22 percent of respondents oppose such a policy action. Interestingly, the public support tends to vary across many demographical categories. For instance, about 62 percent of adults aged 65 and older seem less likely to support the idea, compared to those below 65 years. Differences in educational attainment have also been observed to affect the level of support. For example, Americans with some college education are said to be more likely to favor legalizing medical marijuana use than those with high school education. ${ }^{77}$

A similar poll conducted in 2010 by the Pew Research Center, as earlier noted, indicates almost the same findings concerning the rising public support for medical marijuana use. According to the result, nearly three-quarters of Americans, representing about 73 percent of the population, favor their state allowing the use of medical marijuana to be prescribed by a physician. Only 23 percent were not in favor of the policy option. ${ }^{78}$ The findings reveal that more Americans have a favorable attitude and support for the use of marijuana only for medical purposes rather than desiring a complete legalization. ${ }^{79}$

The global trends of public and elites opinion also reflect similar perspective. A recent report by very high-profile Commissioners made up of prominent personalities such as former Latin American Presidents, world public intellectuals including Kofi Annan, the former UN

\footnotetext{
${ }^{76}$ Coleen McMurray (2003), a senior staff writer reported the findings of the Gallup poll opinion research on Medical marijuana http://www.gallup.com/poll/10126/Medicinal-Marijuana-What-DoctorOrdered.aspx Retrieved 06/7/11.

${ }^{77}$ Ibid.

${ }^{78}$ The Pew Research for the People and the Press (Broad Public Support for Legalizing Medical Marijuana), April 2010. Retrieved 06/7/11. http://pewresearch.org/pubs/1548/broad-public-support-for-legalizing-medicalmarijuana

${ }^{79}$ Ibid.
} 
Secretary General, made a strong recommendation for a redefinition of the so-called global war on drugs towards a more liberal approach. According to the Commissioners:

The global war on drugs has failed with devastating consequences for individuals and societies around the world. Fifty years after the initiation of the UN Single Convention on Narcotics Drugs, and 40 years after President Nixon launched the US government's war on drugs, fundamental reforms in national and global control policies are urgently needed. ${ }^{80}$

A similar observation was made by Blow (2011) in his reflection on the recent $40^{\text {th }}$ anniversary declaration of the war on drugs. According to Charles Blow, ${ }^{81}$ the drug war has been one of the biggest and most expensive social policy experiments in the history of America's social policies. From Blow's point of view, since President Nixon declared the all-out offensive on the war on drugs on June 17, 1971, the war has not only waxed and waned over time, but trillions of dollars have been spent, community lives destroyed, and over 40 million estimated $\operatorname{arrests}^{82}$ were made for drug-related offenses (Blow, 2011). As discussed in chapter three, Blow (2011) reiterates the racial disparities in narcotics enforcement in the US and describes the disparity issue as the most tragic consequences of the war on drugs. For Blow (2011), no group has been more targeted than the African-American community, although other groups such as Caucasian-Americans also engage in the use narcotic drugs. Fellner (2009) shares Blow's (2011) perspective on the issue of race, narcotic drugs, and law enforcement in the United States. In fact, Fellner's (2009) recent study provides some useful insight on the issue, as shown in figure 4.3.

${ }^{80}$ Global Commission on Drug Policy (GCDP) Report (2011:2) Available at http://www.globalcommissionondrugs.org/Report

${ }^{81}$ Blow, M. Charles, 2011 "Drug Bust" New York Times, June 10 2011 (Op-ED Columnist). http://www.nytimes.com/2011/06/11/opinion/11blow.html?emc=eta1, Retrieved on 06/15/2011.

${ }^{82}$ See Appendix 1 for the statistical breakdown of the number of arrests. 


\section{Figure 4.3}

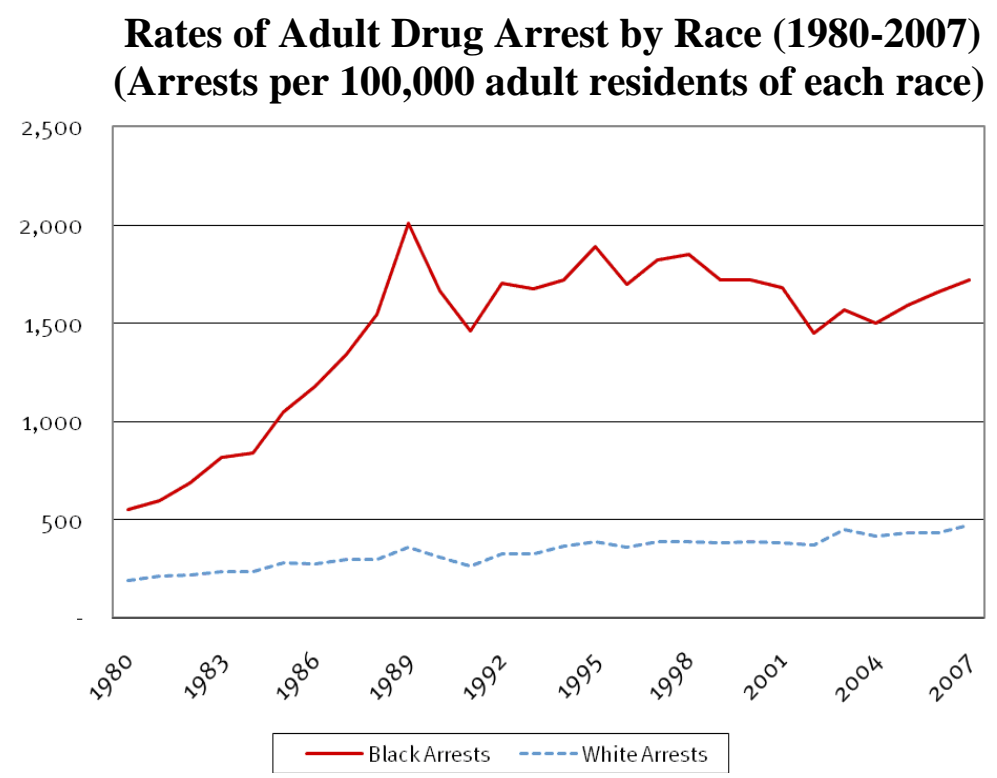

Source: Adapted from Fellner (2009: 272)

Despite the fact that the ratio of black to white arrests decreased in the mid 1990s, the disparity in racial arrests continued to exist in narcotics law enforcement (Fellner, 2009; Beckett, et al. 2006). Fellner (2009) further reports that a longitudinal analysis of urban drug arrests in some big cities, for example, indicates that drug arrests of Blacks rose at three times the rate for Whites between 1980 and 2003, representing 225 percent for Blacks, compared to 70 percent for Whites. In New York City for example, Blacks in 2002 presented about 10.7 percent of the population, yet they accounted for about 42.1 percent for the drug-related arrests (Fellner, 2009:273-274).

Based on the preceding analysis with respect to the current drug situation, it was not surprising that the final recommendations issued by the nineteen-member global narcotics Commissioners reflect similar opinions by many Americans on the need to shift the policy approach from the existing narcotics policy control towards a workable approach. Among other 
suggestions, these Commissioners (emerging global policy entrepreneurs) strongly recommend the end to the global narcotics policy of criminalization, marginalization, and the stigmatization of people who use narcotic drugs but do not harm others as a result of their drug use. Also, the report urges governments across the world to reform the existing prohibition laws by initiating models of legal regulation towards the decriminalization of narcotic drugs, especially cannabis or marijuana. The purpose of the recommended policy initiatives, as the report noted, is to undermine the power of organized crime that has been associated with narcotics production, trafficking, and use, and also to safeguard the health and security of the citizens of the world. ${ }^{83}$

The broad assessment of the US narcotics policy process during the fourth phase (Clinton and Bush eras) has so far shown some evidence of agenda-setting theories of issue definition, venue shifting, policy entrepreneurs, and trends in public opinion on display. As Pralle (2006: 1001) argues, the role of multiple venues or veto points in effecting policy change is dependent on the "mobilization and strategic savvy of policy actors pushing policy change on the one hand, or defending the status quo on the other." In essence, venue shifting has been shown as one of the effective policy strategies in effecting policy change without having to mobilize a large number of people and resources to compete in venues already controlled by policy competitors (Pralle, 2003:255).

Indeed, Pralle's (2006; 2003) theoretical argument has been clearly evident in the successful shift in venue of the marijuana issue to the state level by policy advocacy groups and policy entrepreneurs for the purpose of shaping the US narcotics policy process. But the difficult question that continues to linger among scholars is the unchanging nature of the marijuana law at the federal level. Ferraiolo (2007:171) rightly sums it up by noting that although marijuana

${ }^{83}$ Global Commission on Drug Policy (GCDP) Report (2011:2). 
policy change seems to be occurring at the state level, its impact is yet to be felt on the federal narcotic laws in a major way. Nevertheless, the marijuana policy reformers (policy entrepreneurs and advocacy groups) have achieved some level of success in changing the marijuana laws in some states because of their skillful shift in venue of the issue.

As we have seen in the preceding analysis, agenda-setting theory with versions of issue definition/redefinition, venue shifting, and policy entrepreneurship provide a good theoretical framework in explaining the US narcotics policy process and change in the fourth phase (Clinton and Bush eras). While the theory (agenda-setting) is useful, one cannot conclude that it provides a complete explanation for the US narcotics policy process. The question is: would partisan ideology or Hall's theory of paradigm change (orders of change) provide a stronger explanatory power for our understanding of the US narcotics policy change? The next section of this phase will examine this important question.

\section{Partisan Ideology}

Partisan ideology, as noted in chapter two, is another theoretical framework that offers some explanation for policy outcomes, although there is no consensus among scholars on its explanatory power in shaping major policy outcomes (Studlar, 2002: 72). For Studlar (2002), the concept of policy legacy (Rose and Davies, 1994; Rose, 1990), where new governments inherit past policies, irrespective of partisan influence on the past policies, pose a challenge to the strength of the partisan argument in shaping major policy outcomes. Nonetheless, quite a number of scholarly works (Studlar, 2005; Imbeau et al., 2001; Schmidt, 1996; Entman, 1983) have shown the usefulness of partisan ideology (left-wing and right-wing orientations) in shaping policy outcomes. Broadly, political parties are basically distinguished by different ideological 
orientations, system of beliefs, and principles, which tend to influence their policy outcomes. In most cases, political elites reflect their partisan ideology either through their voting records, policy actions, or policy inactions (Stratmann, 2000; McCarthy el at., 2006).

In the case of US narcotics policy process, particularly in the fourth phase (Clinton and Bush eras), the important puzzle that emerges is whether US narcotics policy change has been driven by partisan ideology and to what extent. In fact, Bertram et al. (1996) reflect on a similar argument and contend that partisan competition between Democrats and Republicans in the late 1980s to the 1990s not only kept the drug issue on the agenda of presidential elections, but major anti-drug policies were driven by partisan considerations. For example, the competition between the two political parties was primarily based on the question of who gets tougher on narcotic drugs and which policy option of control works better. Even though both Democrats and Republicans often display elements of toughness on the narcotics issue, the influence of partisan ideology in shaping their respective narcotics policy outcomes cannot be underestimated.

As previously discussed, variations exist in the liberal (Democrats) and the conservative (Republicans) ideological persuasions (Poole and Rosenthal, 1984). While Democrats tend to generally favor a permissive (liberal) approach to narcotics control, Republicans usually prefer a restrictive/punitive approach (Entman, 1983; Schmidt, 1996; McCarthy el at., 2006). Explaining the conceptual idea behind the restrictive drug policies of conservative governments, Bertram et al. (1996) argue that the ideology of many conservative leaning governments toward illegal drugs is based on the assumption that the widespread use of these drugs are responsible for the moral degeneration of the American society, hence the need to enact tougher laws on narcotics.

Although this assumption is not widely shared by liberal leaning governments (Democrats) because of their preferred permissive approach to narcotics control, there is still the 
recognition by Democrats of the threat that drug abuse poses to the society. This recognition offers some explanation for the shift towards a more comprehensive or balanced strategy (enforcement and treatment) of narcotics control under the Clinton and the Bush administrations (Bertram et al., 1996:140-141). While the drug policies of both Administrations converged in many areas as a result of the comprehensive policy option, the partisan rhetoric on narcotics control in the two eras remained intact. In essence, one might expect the narcotic policies of liberal leaning governments (Democratic) to be more permissive in nature as against restrictive policy preferences from conservative (Republican) leaning governments (Bertram et al., 1996).

In the Clinton era, for example, the narcotics policy was not only comprehensive in nature, but the Administration's preference for permissive narcotics policy was evident and consistent with the broad Democratic ideology on narcotics control. The 1994 National Drug Control Strategy report provides some support for this argument. For instance, the funding for the expansion of drug treatment facilities for about 140,000 drug addicts across the country saw an increase of $\$ 355$ million. ${ }^{84}$ In addition, the report underscored the need for a guaranteed use of basic treatment services as part of the President's Health Security Act. This was estimated to benefit about 50 million Americans when fully implemented. ${ }^{85}$ Similarly, the Administration's policy reputation towards a permissive narcotics approach was revealed in a letter sent to President Clinton in 1994 by Senate Republican leaders. The letter accused President Clinton of decreasing the prosecution of illegal drug users and other interdiction efforts, while increasing the budget allocation for treatment for hard-core drug addicts (Bertram et al., 1996:149). The interpretation of the letter illustrates the extent of partisanship divide in the narcotics policy process during the era of Clinton.

\footnotetext{
${ }^{84}$ Office of National Drug Control Policy (1994). The National Drug Control Strategy (p. 2).

${ }^{85}$ Ibid, p 2.
} 
Like the Clinton era, a similar narcotics policy (comprehensive approach) was pursued in the Bush era. This means that both law enforcement and treatment strategies of narcotics control received some serious attention from the Bush administration. The 2005 National Drug Control Strategy report, for example, reveals that the Administration focused its narcotics policy on both treatment programs as well as on law enforcement. ${ }^{86}$ Besides the comprehensive policy option, it was also apparent that partisan ideological policy preference for a more restrictive narcotics policy was evident in the Bush era. The budgetary allocation for narcotics control provides some support for this argument.

For example, the 2002 ONDCP-Budget Summary report reveals that both treatment programs and law enforcement received budgetary allocations. For instance, only 19.1 percent of the total budget was allocated for treatment and research programs, while about 50.5 percent of the total budget was allocated for domestic law enforcement alone. Overall, the budgetary allocation for the supply-side (law enforcement) approach to narcotics control during the same year (2002) was 67.4 percent as against 32.6 percent for a demand-side (treatment/prevention) approach to narcotics control (ONDCP-Budget Summary, 2002:6). A similar trend occurred in the 2006 drug control budget proposal. Only 38.7 percent of the total budget was allocated for treatment and prevention programs, while 61.3 percent was allocated to law enforcement, interdiction, and other drug-related intelligence. ${ }^{87}$

From a theoretical perspective, it is apparent from the analysis that partisan ideology provides some useful framework in understanding the narcotics policy process in the fourth phase. Still, the usefulness of partisan ideology has shown that the Clinton administration's narcotics policy was comprehensive in nature, but the preference of the administration was

\footnotetext{
${ }^{86}$ Office of National Drug Control Policy (2005). The National Drug Control Strategy p. 4.

${ }^{87}$ Ibid, p.4.
} 
largely permissive, particularly in rhetoric. A similar policy trend was evident in the Bush administration. For example, the narcotics policy of the Bush era was comprehensive in nature, but the policy preference of the administration was generally restrictive towards narcotics control (see appendix two). These findings appear to be consistent with similar findings in chapter three where the Republican administrations of Reagan and George H.W. Bush (Musto 1999; Bertram et al., 1996; McWilliams 1992; Sharp 1994) favored a more restrictive narcotics policy, unlike the Democratic administration of Carter that was more inclined towards a permissive approach to narcotics control (Sharp, 1994:37).

As noted in chapter two, my main objective in this study is to apply the three domestic policy theories (agenda-setting, partisanship, and policy paradigm change/orders of change) as competing explanations to determine the one that offers the best possible explanation for the changing trend and nature of US narcotics policy since 1993. While partisan ideology offers some utility in explaining the narcotics process, especially on partisan rhetoric, this study argues that the theoretical concept of partisan ideology provides a limited explanation for the narcotics policy process. Although the theory provides a broad perspective on how partisanship shapes the policy process, the theory could not offer a better explanation for the type and nature of policy change (s) or what Hall (1993) describes as orders of change in the narcotics policy process. This is equally true for the agenda-setting theory, even though it provides a better explanation for the narcotics policy process than partisanship.

Indeed, one cannot underestimate the usefulness of partisan ideology and agenda-setting in understanding the narcotics policy process. However, a systematic observation of these theories (partisan ideology and agenda-setting) reveals that they best explain the US narcotics policy change process from a broader or macro perspective. By definition, I consider the macro 
perspective, as earlier mentioned, as a broader analysis of the policy phenomena without necessarily analyzing the component parts of the policy. A careful review of Baumgartner and Jones' (1993) work on drug abuse shows a clear case of a broader perspective of analysis. For example, the study by Baumgartner and Jones (1993) focused on the politics of attention, or the changing nature of formal (congressional) and systemic (media) attention of US narcotics policy for a considerable period of time. Although this approach is generally useful in providing a general perspective to our understanding of policy change, I argue that this approach offers an incomplete explanation for the changing type and nature of US narcotics policy process.

In essence, my argument is simple. That is, the agenda-setting and partisanship theories are generally useful, but these theories provide an incomplete explanation to US narcotics policy process since 1993. How do we therefore explain the nature and type of changes occurring within the US narcotics policy domain? Can Hall's (1993) theory of policy paradigm (orders of change) offer a persuasive explanation for the US narcotics policy change since 1993 ?

\section{Policy Paradigm Theory (Orders of Policy Change)}

We have seen in chapter two that Hall's (1993) theory (policy paradigm or orders of change) has increasingly been employed by many scholars (Hausermann, 2009; Skogstad, 2009; Studlar, 2009; Cashore and Howlett, 2007; Breton et al., 2008; Capano, 2009; 2003) to study different substantive policy sectors in recent years. To the best of my knowledge of the literature, no scholarly work has applied Hall's concept to study narcotics policy change, hence the significance of applying this theory to the study of narcotics policy since 1993. 
Figure 4.4

\section{Schematic Representation of Hall's Orders of Policy Change}

Description of Change

\begin{tabular}{|l|}
\hline Change occurs in the settings of policy \\
instruments. Decision making is routine and \\
happens from experiences and new \\
knowledge with limited external influence. \\
\cline { 2 - 3 } Change in the priority of the policy \\
instruments with the introduction of new \\
ones. Policy tools are altered in response to \\
past experiences and new knowledge, but \\
within the same policy goals. \\
\hline $\begin{array}{l}\text { Change involves fundamental paradigm } \\
\text { change in policy goals with changes in } \\
\text { policy instruments and settings of policy } \\
\text { instruments as well. For example, a major } \\
\text { change from Keynesianism to monetarism } \\
\text { in the UK (1970-1989). }\end{array}$ \\
\cline { 2 - 3 }
\end{tabular}

Orders of Change

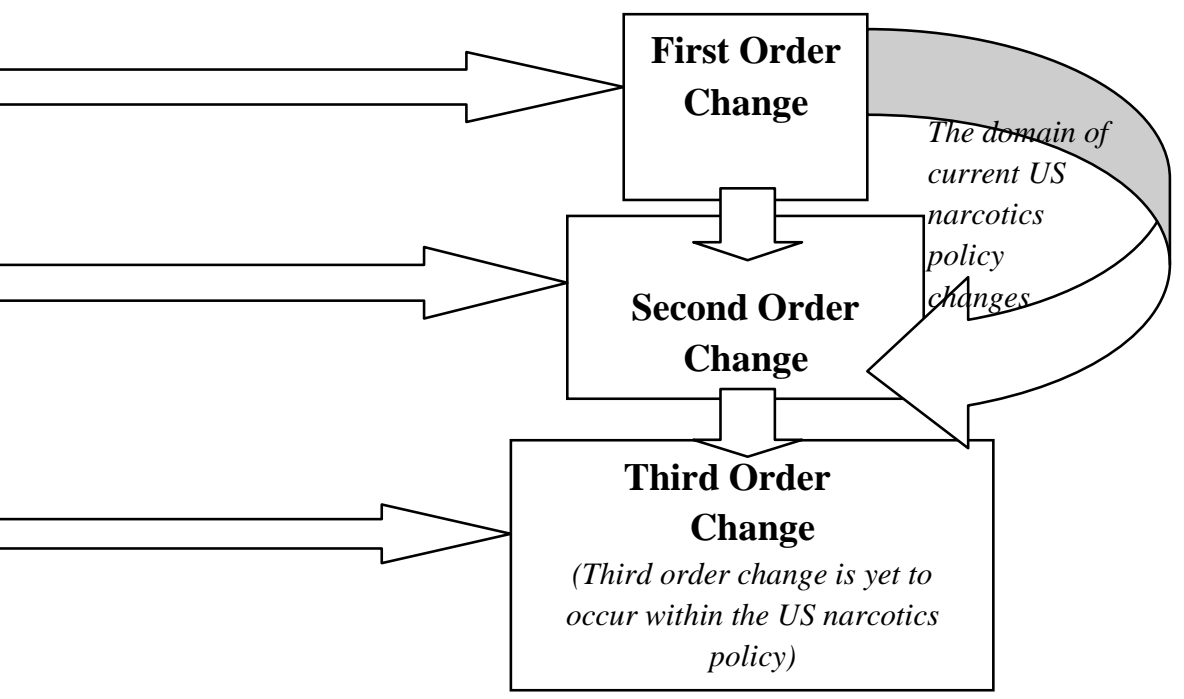

Source: Author's own schematic design with ideas based on Hall's (1993) concept of policy change.

As shown in figure 4.4, Hall (1993) conceptualizes the policy process or social learning (change) within a typology of first order, second order, and third order change (s) in policies. For Hall (1993), as shared by Breton et al. (2007), first order and second order change in policies are mostly driven by social learning. Hall (1993) defines social learning "as a deliberate attempt to adjust the goals or techniques of policy in response to past experience and new information. Learning is indicated when policy changes as the result of such a process" (Hall, 1993: 278). The central argument of the theory is that policy change occurs in three different types or forms. By definition, policy change, according to Hall (1993), involves the alteration or adjustment to a given policy from one level to another. Conceptualizing this argument within the context of social learning, Hall (1993) underscores the importance of disaggregating a given policy into three major components. The three components include "the overarching goals that guide a policy in a particular field, the techniques or policy instruments used to attain those goals and the 
precise settings of these instruments" (Hall, 1993:278). A good illustration by Hall (1993), as previously noted, is important to reiterate here.

For instance, if the policy goal of a government is to alleviate the financial problems of the elderly, the selected policy instrument or tool might be a pension scheme, and its settings of instrument could be the level of benefits set for beneficiaries of the scheme (Hall, 1993). Hall's (1993) theoretical argument was further advanced by Capano and Howlett's (2009) idea of "policy compartmentalization." For them, the policy process is complex and multi-dimensional, and what actually changes in a policy is not the policy itself, but the specific components such as the policy goal, policy instruments, and the settings of the policy instruments as shown in figure 4.5 .

\section{Figure 4.5}

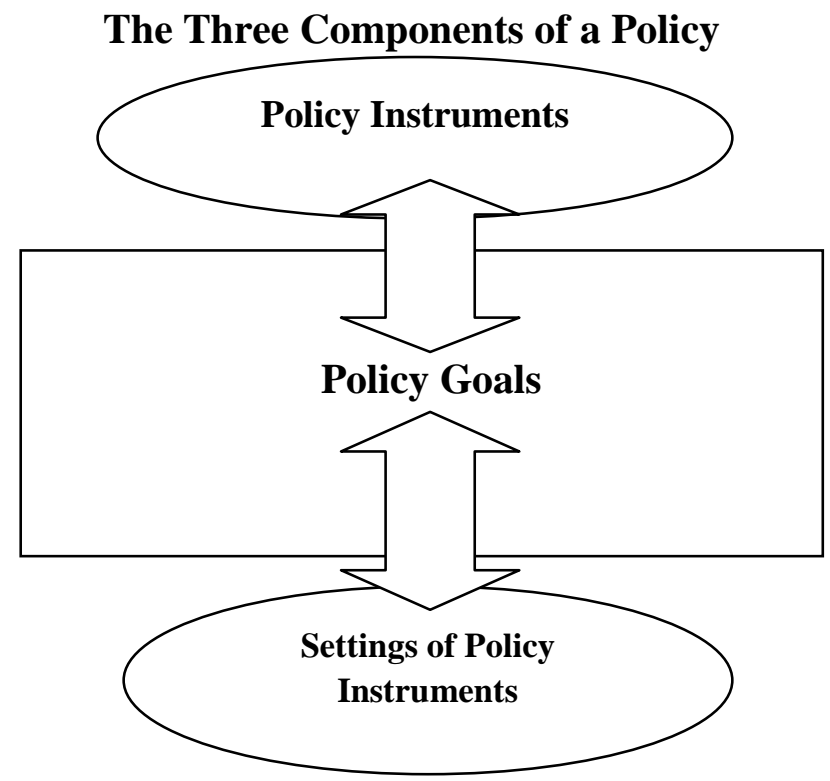

Source: Author's own schematic design with some ideas based on Hall's (1993) concept of policy components.

As clearly revealed in figure 4.5, the policy compartmentalization concept underscores the importance of changes in the type and nature of the three component parts of a policy. This theoretical assumption, I will argue, resembles a "policy black box" that needs to be opened for a 
better understanding of the specific changes that might occur with the various components of the policy. Explaining the idea further, Capano and Howlett (2009:3) maintain that policies are dynamic and change does occur regularly. What is important though, is for scholars to distinguish the type and the nature of the change (first, second, or third order) that occurs. This is where Hall's (1993) concept (orders of change) becomes very useful to understanding the policy process, particularly the US narcotics policy since 1993. For Hall (1993:277), two key research questions are significant in identifying the type, nature, and drivers of a given policy change. The first question is whether the process of policy change is relatively incremental or characterized by upheaval (punctuated equilibrium) changes to the policy system. The second question deals with the issue of key players or drivers of the change process. Simply put, my main objective in this section is to apply Hall's (1993) theoretical concept of orders of change (first, second, and third order) in order to determine the type, nature, tempo, and scope of policy change that has occurred, or is occurring to the US narcotics policy in the fourth phase (Clinton and Bush eras).

To investigate these questions, as earlier noted in chapter two, this study draws on the key measurements of policy change (Studlar, 2009; Capano and Howlett, 2009), which include: tempo (speed), mode (amount of change), and scope (coverage). The reason for selecting these measurement tools is because of its applicability to this research. Defining these measurements Studlar (2009:75), for example, argues that the tempo of a policy generally involves the speed at which new policy instruments are often introduced. The mode involves the amount of change that occurs to a given policy, while the scope deals with the extent to which a policy has been broadened or narrowed. 


\section{Orders of Change and US Narcotics Policy: Towards an Explanation}

As noted in the introductory section of this chapter, the fourth phase (1993 to 2009) constitutes one broad era, which also constitutes the scope of this study. However, my analysis of narcotics policy within the context of Hall's theory will be examined with focus on the two different political administrations (Clinton and Bush eras). The purpose is to demonstrate with supporting evidence and draw conclusions on whether the theory offers one of the best, if not the best, explanation for the US narcotics policy change since 1993.

In Hall's (1993:279-80) terms, the process of policy learning can be understood from three levels of change (orders of change). A first order change in policy involves an incremental (Lindblom, 1959) change in policy through routine policymaking by bureaucratic officials and other policy experts. A second order change in policy occurs when a new policy instrument is introduced or an existing instrument is adjusted for strategic policy reasons. While first and second order change in policies generally appear incremental (normal policymaking), a third order change on the other hand, occurs when a major paradigm (radical) shift takes place in policy goals of a given policy. In other words, a third order kind of change drastically transforms a policy landscape where all the three policy components (goals, instruments, and settings of instruments) undergo radical changes. Hall (1993:279) sums up the description of a third order change in policy this way: "If first and second order changes preserve the broad continuities usually found in patterns of policy, third order change is often a more disjunctive process associated with periodic discontinuities in policy." Hall (1993) adds that the implication of this analysis does not conclude that first and second order changes in policy automatically lead to third order changes. For him, normal policymaking and change, as in the case of scientific 
change, can continue without necessarily causing a paradigm or radical shift in a given policy (Hall, 1993:279-280).

The question that emerges is whether or not the US narcotics policy reflects Hall's (1993) concept of policy change. To answer this question, this study hypothesizes that the general trend of US narcotics policymaking, particularly during the scope of this study (1993-2009), has generally undergone first and second order changes in policy, with second order change more pronounced, and a third order change presently non-existent or yet to occur.

\section{First Order Change}

A first order change in policy occurs when the settings of a policy instrument change as a result of past experiences or because of the introduction of new knowledge and ideas. For Hall (1993), policies at time-1(yearly incremental settings of a policy instrument) are formulated based on the outcome of policies at time-0 (past policies). Besides, the adjustments to policies under first order are not only comfortably predicted, but tend to be incremental because of the nature of the routine policymaking by bureaucratic officials (Capano and Howlett 2009; Breton et al., 2008; Hall, 1993). Applying the concept of incrementalism to the US narcotics policy change, Sharp (1994:131) shares Lindblom's (1959) view that policymaking cannot be anything other than a yearly adjustment to policies. For Sharp (1994), an incremental change in public policymaking is typically driven by the limits on time and the inability to use huge amount of knowledge and data in the policymaking process. In effect, policy makers tend to consider only policy initiatives that involve marginal changes to the status quo policy rather than undertaking major changes in policy. Hall (1993) describes these minor incremental changes as first order change in policy with bureaucratic experts as the main drivers of these changes. Moreover, these 
minor policy changes occur in most cases with budget statements, personnel issues, laws, and other procedural issues. Rose (1984) shares a similar conceptualization of policy characteristics as comprising budget statements, personnel issues, and laws. I will integrate Rose's (1984) ideas with Hall's concept in analyzing the evidence of first order change in US narcotics policy process since the 1990s.

By applying Hall's (1993) concept (orders of policy change) to the US narcotics policy, it is apparent that the implementation of the policy, especially during the period under review (1993 to 2009) has generally undergone a first order change. In the early years of the 1990s, for example, the federal budget of the US narcotics policy witnessed a routine or incremental (mode of change) policy change. In fact, the total federal spending on narcotics control actually saw a sturdy increase since the Office of National Drug Control Policy (ONDCP) was established in 1989. According to the 1994 National Drug Control Strategy (ONDCP, 1994:66), President Clinton's budget request for narcotics control increased to $\$ 13.2$ billion, representing an increase of $\$ 1.0$ billion, or nine percent more than the previous fiscal year (ONDCP, 1994:75). For Fiscal Year (FY) 1997, the Clinton administration requested about \$ 15.1 billion in financial support for drug control efforts. The requested amount represented an increase of $\$ 1.3$ billion or 9.3 percent over the estimated amount in 1996 of \$13.8 billion (ONDCP, 1996:55).

Like the Clinton era, the Bush era (2001 to 2009) reveals a similar pattern of incremental change in the budgetary allocation for narcotics control. For example, the 2003 budgetary allocation for narcotics control was estimated at \$19.2 billion, representing an increase of \$356.9 million, or 1.9 percent over the 2002 fiscal year. The actual enacted budgetary allocation was $\$ 18.8$ billion (ONDCP-Budgetary Summary, 2002:1). Although there was a slight decline in funding for narcotics control from 2004 onwards as compared to the previous years, a minimal 
increase was still recorded in 2005 and 2006. For instance, the funding requested for the 2006 fiscal year was $\$ 12.4$ billion, which represented an increase of about $\$ 268.4$, or 2.2 percent over the 2005 fiscal year. Out of the requested amount of $\$ 12.4$ billion, the actual enacted amount was $\$ 12.2$ billion (ONDCP-Budgetary Summary, 2005:1). A corresponding budgetary pattern also reveals a similar trend in the 2009 budget report, where the Bush administration requested an amount of $\$ 14.1$ billion for narcotics control. The 2009 requested amount saw an increase of $\$ 459.0$ million, or 3.4 percent over the fiscal year of 2008 . The actual enacted amount for the 2009 fiscal year was 13.7 billion (ONDCP-Budgetary Summary, 2008:1). A general overview of the incremental changes in the budgetary allocations, particularly during the Clinton era, is shown in appendix two.

In addition to budgetary allocation, personnel issues, as Rose (1984) contends, constitute another important element in a policymaking process. Clearly, the personnel involved in the narcotics policy process saw a similar pattern of incremental change (first order) in the fourth phase. A good case in point is the Drug Enforcement Administration (DEA), which represents one of the largest enforcement agencies of US narcotics control programs. In 1994, for example, President Bill Clinton appointed Thomas Constantine as the Administrator of the DEA. In one of his official policy statements, the Administrator noted that although the DEA suffered a declining budget and personnel cut in the late 1980s, the agency had seen some incremental changes in its staffing from the mid-1990s to the late 1990s. For example, while the budget of the DEA increased from $\$ 1,050$ million in 1994 to $\$ 1,349$ million in 1998 , the organization also saw an increase in its special agents (personnel) from 3,418 in 1994 to 4,261 in 1998 (DEA Report 2008: 91). Also, by the end of 1998, ten foreign offices were opened, with additional staff members, as part of the agency's foreign obligations in narcotics control (DEA Report, 2008:91). 
Similar incremental changes (first order) occurred to other bureaucratic components (personnel and budget) of the DEA during the era of George W. Bush. The DEA special agents, for instance, increased from a total number of 4,841 in 2003 to 5,235 in 2008. The budget for the operations of the DEA also saw an increase from $\$ 1.9$ billion in 2003 to $\$ 2.4$ billion in 2008 (DEA Report, 2008:161). It is clear that these changes are first order changes because of the changes in the settings of the narcotics policy instrument. While the scope of the change has broadened, especially with the DEA's foreign expansion efforts on global narcotics control, the tempo of the change can generally be described as slow in nature. It is plausible to argue, in view of the analysis that Hall's (1993) first order change appears to fit the pattern of US narcotics policy process since 1993 .

\section{Second Order Change}

A second order change, according to Hall (1993), occurs when a policy instrument is adjusted for the purpose of introducing a new policy instrument or a redefinition of an old policy instrument. For Hall (1993), a change in a policy instrument occurs when there is a general dissatisfaction with the workings of an old policy instrument. A change in a policy instrument can also occur because of a strategic policy reason. As the policy instrument as well as its settings change, the overarching policy goals do not, however, undergo any form of change (Hall, 1993). Change agents of most second order changes are mostly driven by bureaucratic officials (Breton et al., 2007: 354; Hall, 1993:283). Applying this theoretical concept to the US narcotics policy, this study finds that second order change agents within the US narcotics policy field are not only exclusive to bureaucratic officials, but advocacy groups (anti-prohibition) and policy entrepreneurs play major roles in shaping the US narcotics policy process. 
On the narcotics policy instruments, Coulkins et al. (2005:15) categorize the US narcotics policy instruments (tools) into three main areas:

(a) Law enforcement/prohibition strategy.

(b) Treatment policy option.

(c) Education and prevention campaigns.

The broad literature has further grouped the three areas into two broader policy instruments known as the supply-side (law enforcement option) and demand-side (treatment option) to narcotics control (Boyum and Reuter, 2005; Burke 1992; Falco, 1989). For Boyum and Reuter (2005), and Musto (1999), the division of the US narcotics policy instruments into supply-reduction and demand-reduction has historically been rooted in the longstanding debate over whether drug abuse should be handled as criminal or medical policy issues. As previously noted, supply-reduction generally involves the enforcement of narcotic laws and strategies with emphasis on prohibition and criminalization regarding the production, trafficking, and use of narcotic drugs.

On the contrary, demand-reduction option involves prevention, education, and treatment programs. Of the two policy instruments, the supply-reduction option of prohibition and criminalization have largely dominated the entire narcotics control system for more than a century (Boyum and Reuter, 2005; Burke, 1992; Fisher, 2006, Nadelmann, 1990). Clearly, the broad pattern of the US narcotics policy instruments (supply-reduction and demand-reduction) has undergone some degree of change in priority, tempo, mode, and scope over a period of time. In fact, the dynamics of change in priority of the narcotics policy instrument, especially during the fourth phase, is significant to determining whether a second order change has occurred or 
not. To demonstrate the empirical evidence of this change, I will examine some cases in both the Clinton and the Bush eras to support my argument.

As we have seen in the previous discussion on partisanship and narcotics policymaking, Democratic presidents tend to be more sympathetic to a permissive approach to narcotics control than Republican presidents. Although the respective drug policies of both parties do converge, especially on the balanced policies that were adopted in the Clinton and the Bush eras, one could still argue that the rhetoric of the Clinton administration was geared towards a permissive approach. For example, some top officials in the early years of the Administration made a series of policy statements in support of a permissive policy option to narcotics control. In a statement to the National Press Club in December 1993, for example, Dr. Jocelyn Elders ${ }^{88}$ remarked that many criminal activities could be reduced in the country if illegal drugs were legalized (Musto, 1999:282). A similar view, as noted, was made by Janet Reno during her Congressional confirmation hearing as Attorney General in May 1993 (Chepesiuk, 1999; Bertram, et al., 1996).

President Clinton himself pledged during his presidential campaign and after he became president to put more emphasis on treatment and prevention programs of narcotics control (Chepesiuk, 1999:36). In a speech delivered at Prince George's County Correctional Center in 1994 to launch his national drug policy, the President reiterated the link between drug abuse and criminal activities, and stated that "no nation can fight crime and drugs without dealing honestly and forthrightly with the problem of drug addiction." 89 For Chepesiuk (1999), the plan by Clinton to reduce the staff size of the White House's Office of National Drug Control Policy

\footnotetext{
${ }^{88}$ Dr. Jocelyn Elders served as Commissioner of Health in Arkansas under Governor Clinton, before she was appointed as Surgeon-General (first African-American) in the early years of the Clinton presidency.

${ }^{89}$ Treaster, Joseph, B. 1994. "New Focus on Drugs: President's Strategy Reflect Concern about Crime and Changing Priorities." New York Times, February 12, 1994. http://www.nytimes.com/1994/02/12/us/new-focusdrugs-president-s-strategy-reflects-concern-about-crime-

changing.html?ssp=1\&sq=President+Clinton+and+drug++treatment++and+1995\&st=nyt, Retrieved on 07/10/2011.
} 
from 146 to 25 soon after becoming President, could also be interpreted as one of the signals of the Administration's commitment to downsizing the inherited prohibition apparatus of the past Republican governments.

Although the Clinton administration was committed to a more permissive approach, it was also apparent that the Administration's budgetary allocation to law enforcement witnessed some increases. ${ }^{90}$ For some observers, the justification for the increases in spending for law enforcement in the Clinton era was due to his balanced policy approach to narcotics control. Lee Brown, actually made a similar claim on the need to develop a comprehensive or balanced (law enforcement and treatment combined) anti-drug strategy during his Congressional confirmation hearing as a Drug Czar designate in February 1993 (Chepesiuk, 1999:36). It was also reported that an amount of $\$ 270$ million, out of a total amount $\$ 400$ million designated for prevention and treatment programs, was actually used to hire more officers for community policing and other law enforcement activities in the Clinton era. ${ }^{91}$

Moreover, Mathea Falco, who served as an assistant Secretary of State for international narcotics during the Carter administration, summed up the assessment of President Clinton's narcotics policy this way: "I love the rhetoric of this Administration about the importance of prevention and treatment... but unfortunately, their budget does not reflect any change in drug policy. ${ }^{, 92}$ Indeed, the US narcotics policy in the Clinton era has undergone some changes in policy (scope, mode, and priority), but not fully to the policy direction expected of a Democratic leaning government. Johnston and Weiner (1996) confirm this assumption by indicating that some amount (mode) and scope of change (second-order) did occur in the Clinton era.

\footnotetext{
${ }^{90}$ Ibid, p1.

${ }^{91}$ Ibid, cited in Treaster (1994:2) A New York Times article.

${ }^{92}$ Cited in Johnston and Weiner. 1996."Seizing the Crime Issue, Clinton Blurs Party Lines." New York Times, August 1, 1996. p. 6. Also see Appendix A.
} 
According to Johnston and Weiner (1996):

After nearly three decades of Republican dominance of the issue, President Clinton has scrapped his party's traditional approach to crime and criminal justice, embracing a series of punitive measures that have given him conservative credentials and threatened the Republicans' lock on law and order (Johnston and Weiner, 1996:1).

As Hall (1993) argues, changes are made to a policy instrument as a result of a gross dissatisfaction with an existing policy instrument, or for a strategic policy reason. As clearly evident in the preceding discussion, it is likely that the emphasis on the comprehensive approach may have stemmed from the need for a pragmatic narcotics policy initiative. Also, the strategic policy reason for change of policies that Hall (1993) outlined could also be responsible for the second order change during the Clinton era. For instance, President Clinton was said to have initially ignored and given less attention to the drug problem soon after taking office in 1993. However, the drug issue took a center stage on his domestic policy agenda from 1994 onwards. Perhaps the change was primarily due to his worsening poll numbers regarding his inaction on the narcotics problem as some analysts suggest (Treaster, 1994). In effect, the policy response (the comprehensive option) from the Administration may have been driven by a strategic policy action in order to avoid being characterized as too soft on drugs.

Regardless of one's interpretation of the Clinton narcotics policy, it is evidently clear that the policy instrument of the Administration had undergone policy changes. By interpreting the pattern of this change within the context of Hall's (1993) concept of second order change, reveals two important points worth addressing. First, the Clinton era shifted the tone of the narcotics issue from an exclusively law enforcement approach (policy instrument) that 
characterized the previous phase towards a more liberal tone of narcotics control, especially in rhetoric. Second, the emergence of the balanced approach signaled a shift in the direction of the narcotics policy instrument (policy tools) from an exclusively law enforcement approach, which was largely associated with the previous Republican eras (Reagan and George H.W. Bush).

In view of the above analysis, this study contends that Hall's theoretical concept of a second order change fit the changing trends of US narcotics policy in the fourth phase. Although the budgetary allocation for law enforcement (supply-side) increased in total percentage in the Clinton era, it must be noted that the absolute budgetary allocation for many liberal narcotics control programs (demand-side) saw an incremental change as well (see Appendix 2).

Similar to the Clinton era, the narcotics policy under President George W. Bush was also guided by the balanced strategy of narcotics control (Boyum and Reuter, 2005). Outlining the details of his official narcotics policy in the 2002 National Drug Control Strategic report, President Bush argues that the fight against the drug problem has not been very effective because of what he describes as the inability to address the problem from a comprehensive perspective (ONDCP, 2002: 4). According to the report, narcotics control policies tend to be largely shaped by partisan rhetoric, where some prefer an exclusive focus on law enforcement, while others advocate for a liberal approach (ONDCP, 2002).

However, what the country needs, noted the President, is an integrated approach with two basic components: (a) to modify individual behavior in order to reduce drug use and addiction. (b) To disrupt the market for illegal drugs (ONDCP, 2002: 4). For President Bush, the two components not only act as mutually reinforcing, but the connection between law enforcement and treatment options is also likely to strengthen the balanced strategy towards narcotics control. Clearly, the Bush administration, like the Clinton era, pursued a comprehensive drug control 
policy (ONDCP, 2002, 2004, 2006, and 2008). In fact, the annual national control budget statements ${ }^{93}$ of the Bush administration provide some support for his comprehensive policy.

In effect, the narcotics policy direction in the fourth phase (Clinton and Bush eras) was characterized by a balanced approach to narcotics control. Nonetheless, Boyum and Reuter (2005:11) argue that key differences in policy strategy existed between the Clinton and Bush eras. For example, while President Clinton focused more attention on the problem of chronic drug abuse, with less attention on reducing the general prevalence, the Bush administration, however, emphasized on the broad option of drug use reduction. Drawing on Hall's (1993) ideas on the reasons for a second order change in policy (see chapter two), it is also likely, as revealed in the preceding discussion, that the incentive towards a comprehensive narcotics policy strategy in the fourth phase could be attributed to the growing dissatisfaction with the exclusively law enforcement approach that has characterized the previous narcotics control measures.

Another important case that demonstrates the evidence of a second order change in policy in the fourth phase (Clinton and Bush eras) was the change in the policy instrument on marijuana policy in sixteen states, ${ }^{94}$ including the District of Columbia (DC). As previously discussed, while the state laws on marijuana continue to undergo changes as a response to the demand for the use of some amount of marijuana for medical purposes, the prohibitive laws on marijuana appear unchanging at the federal government level (Khatapoush and Hallfors, 2004). Faced with this challenge and the possibility that the marijuana ballot initiative might spread to other states, the federal government made several attempts since $1996^{95}$ to prevent the implementation of the

\footnotetext{
${ }^{93}$ See Appendix 3a, 3b, and 3c for trends of federal funding for treatment and law enforcement programs.

${ }^{94}$ Sixteen states as of 2010 . Also, see table 4.1 for the complete list of states where medical marijuana laws were enacted.

${ }^{95}$ California was the first state to pass the law in 1996. See table 4.1 for the complete list of states where medical marijuana laws were enacted.
} 
medical marijuana laws at the state level (Ferraiolo, 2007). In June 2005, for example, the Supreme Court ruled in Raich v. Ashcroft, that drug patients living in states that had ratified the marijuana ballot initiative were not protected from arrest and prosecution by federal law enforcement agents. Irrespective of the threats, quite a number of states continued not only to defend the marijuana ballot initiative, but state officials were also generally uncooperative with federal agents in the prosecution of medical marijuana cases across the country (Ferraiolo, 2007:170).

Again, the shift in the narcotics policy instrument (second order change) on marijuana was basically driven by the increasing dissatisfaction with the existing restrictive marijuana policies, especially at the state government level. Hall's (1993:282) argument that a growing dissatisfaction with an existing policy instrument creates the incentive for a second order change in policy could is applicable to changing trends in the marijuana laws. As noted, these changes are mostly driven by state officials and bureaucratic agents. What appears inconsistent, in the case of this study, is the fact that the demands for these changes (marijuana laws), particularly in the Clinton and George W. Bush eras, were not driven by state officials (Breton et al., 2007:354; Hall, 993). However, anti-advocacy prohibition groups and policy entrepreneurs such as Drug Policy Alliance and individual policy entrepreneurs such as George Soros were the active agents involved in supporting legislations and ballot initiatives for the medical use of marijuana across America (MacDonald, 2009; Ferraiolo, 2007).

The preceding analysis again supports the claim by this study that the domain of US narcotics policy has undergone a second order change in policy, particularly from 1993 to 2009. While the scope of the change has been broadened, especially at the state level, the tempo of the change has rather been slow. Without doubt, Hall's (1993) theoretical typology of first and 
second order change (s) in policy provide very useful theoretical framework in our understanding of US narcotics policy process and change since 1993. For a complete understanding of the type and nature of US narcotics policy change that has occurred, it is vital to explore whether any evidence of third order changes in policy exist within the policy domain. In other words, has the US narcotics policy undergone any form of a third order change in the fourth phase?

\section{Third Order Change}

A third order change, according to Hall (1993), involves a fundamental paradigm change in the overarching policy goals. In most cases, once the major goal of the policy changes, the other two components (policy instruments and settings of the policy instruments) also changes. In essence, a third order paradigm change implies a radical change in a policy regime ${ }^{96}$ (Studlar, 2009; Skogstad, 2009; Breton et al., 2007; Hall, 1993). This kind of change (third order) resembles and perhaps shares similar ideas with Baumgartner and Jones's (1993) punctuated equilibrium theory. Since changes in the overriding policy goals constitute the centrality of a third-order change in policy, it is important to outline the underlying policy goals of the US narcotics policy in order to determine whether a third order change has occurred or not.

The overall narcotics policy goal of the federal government have broadly been shaped by the need to reduce the production, trafficking, and use of illegal drugs. It was the establishment of the Office of National Drug Control Policy (ONDCP) in 1989 (a mandate of the1988 AntiDrug Abuse Act) that clearly outlined the general narcotics policy goal for US (Musto, 1999). Similar to the previous policy goal, the overriding policy goal of the ONDCP broadly focuses on

\footnotetext{
${ }^{96}$ Hall's classic example of a third order change in policy from Keynesianism to monetarism in Britain in the 1970s is a good case in point. While Studlar (2009) applied Hall's (1993) theory to examine the transformative change in tobacco control from a purely economic issue to health issue, Skogstad (2009) employed the theory to study agriculture policy in Canada. She describes the change as programmatic change (incremental) rather than a paradigmatic (radical) change in the policy (agriculture).
} 
reducing the availability of narcotic drugs through law enforcement strategies. Further, the narcotics policy goal of the ONDCP since its establishment has been guided by two main purposes:

(a) To formulate policies, priorities, and objectives for the country's drug control program.

(b) To coordinate domestic (federal, state, and local) and international efforts at narcotics control. ${ }^{97}$

While the first purpose transforms the priorities of the ONDCP into a major narcotics policy goal, the second purpose provides an important mechanism for the general guidance and specific policy directions to over fifty federal drug control agencies involved in all forms of narcotics control (ONDCP, 1996). Generally, the central policy goal of the ONDCP is "to reduce illicit drug use, manufacturing, trafficking, drug-related crime and violence, and drug-related health consequences." 98

To achieve these goals, the Director of the ONDCP is charged with the responsibility of presenting an annual report known as the National Drug Control Strategy (NDCS) to Congress each year with details of the nation's narcotics control policy. In fact, the 1996 National Drug Control Strategy describes the ONDCP's major policy goal as a "collective American effort to achieve a common purpose......and the common purpose of that collective effort is to reduce illegal drug use and its consequences in America." 99 Some of the key elements of the strategy include: the policy goals, policy strategies of control, budget statements, and the guidelines for cooperation among federal, state, and local narcotics agencies. ${ }^{100}$ The first major narcotics policy

\footnotetext{
${ }^{97}$ Office of National Drug Control Policy (Mission Statement). http://www.whitehousedrugpolicy.gov/about/index.html Retrieved 07/1/2011 Also see Chepesiuk (1999:250).

${ }^{98}$ The 1996 National Drug Control Strategy (NDCS) report, p.11 (ONDC).

${ }^{99}$ Ibid. p 11.

${ }^{100}$ Office of National Drug Control Policy (Mission Statement)
} 
goal and instrument in this phase was outlined in the 1993 Interim National Drug Control Strategic report. In his introductory remarks to the report, President Clinton noted that:

The drug issue is about the responsibility of government to its citizens and the kind of society we aspire to be. There must be a national imperative to reduce drug use. Surely this is the national goal that can unite us all, across the boundaries of party, race, region, and income. ${ }^{101}$

As shown in the President's remarks, the overriding goal of his Administration was to reduce the use of illegal drugs in the US. Indeed, the control of production, trafficking, and sale of narcotic drugs became the major policy goal of the Clinton years (ONDCP, 1993; 1994; 1996; 1998). A similar narcotics policy goal towards the overall reduction in the production, trafficking, and use in narcotic drugs characterized the Bush era as well (ONDCP, 2001; 2002; 2003; 2005; 2008; 2009). In 2002, for example, President George W. Bush set his major policy goal by targeting the reduction of narcotics use among teenagers (ONDCP, 2002:3).

As we have seen so far, the US narcotics policy goals have generally been shaped by the dominance of the prohibition policy framework (Fisher, 2006; Caulkins et al., 2005; BewleyTaylor, 2003; Bertram et al., 1996; Sharp, 1994; Nadelmann, 1990). In fact, the trend of the federal budgetary allocations (see appendix 2, 3a, b, \& c) and some interview responses support the dominance of the prohibition policy claim. Caulkins et al. (2005:15) also reflect on a similar assertion in their study. For them, the federal anti-drug budget, narcotics policy directions, and narcotics policy priorities have for many years been skewed toward law enforcement approach to narcotics control.

\footnotetext{
http://www.whitehousedrugpolicy.gov/about/index.html, Retrieved on 07/2/2011.

101 Cited in the Interim National Drug Control Strategy, Office of National Drug Control Policy.1993 p.1.
} 
In a response to one of my interview questions, one respondent said that:

In the 1990s and the early 2000s, there was certainly an emphasis placed on further criminalization of illicit drugs and the people who use them.... but most of the emphasis has been at the federal level. Emerging substances such as synthetic cannabis (a.k.a K2/Spice) have just recently been criminalized at the federal level, while another psychoactive drug, salvia divinorum, has remained unscheduled. ${ }^{102}$

Given that some degree of policy change had occurred to the US narcotics policy instrument and the settings of these instruments (ONDCP, 1993; 1996; 1998; 2002; 2006, 2009) as previously examined, the overriding narcotics policy goals, however, remained largely unchanged. In fact, while few interviewees were not sure whether any significant change is occurring, a greater number of respondents agree that the US narcotics policy has undergone many forms of incremental policy changes (first order and second order), but not a radical or a third order change. It is plausible to therefore argue, as other respondents ${ }^{103}$ have also expressed, that the changes occurring within the US narcotics policy domain have not only been incremental in nature, but the speed (tempo) of the change has been slow and deliberative. Durant and Diehl (1989) conceptualize this kind of slow tempo as protracted. For these respondents, a radical change (third order) in US narcotics policy might be possible through either a court decision or a binding voter initiative in the future.

In spite of the fact that a third order change in narcotics policy has not occurred, it is still important to underscore the fact that such a change might occur sometime in the future. This assertion is based on two assumptions that might help explain why a third order change is likely to occur at some point in time. First, all policies, as many policy scholars agree, are inherently

\footnotetext{
${ }^{102}$ An official interviewed at Drug Policy Alliance (DPA).

${ }^{103}$ Officials interviewed at Drug Policy Alliance (DPA), Rand Drug Policy Research Center (RDPRC), and NORML Foundation.
} 
dynamic and subject to change at some point in time and space (Capano and Howlett, 2009; Baumgartner and Jones, 1993; Hall, 1993). Second, policies change because of existing policy anomalies and failures (Skogstad, 2009:94; Hall, 1993). ${ }^{104}$ In essence, once all policies are subject to change, especially policies characterized by anomalies and failures as with the existing narcotics policy regime, one can speculate, based on these assumptions, that a third order change in US narcotics policy is likely to occur at some point. In the meantime, we have established in the preceding analysis that the US narcotics policy, particularly in this phase (1993-2009) has not shown any evidence of a paradigm or a third order change in policy. The changes that have occurred are largely incremental in nature (first and second order changes).

\section{Summary}

Two major objectives were set for this chapter. The first was to explore the dynamics of US narcotics policy process and change through the theoretical frameworks of the three domestic policy theories. The second objective was to assess the explanatory power of each theory and determine the one that offers the best and most compelling explanation for US narcotics policy change since 1993. While many aspects of the theories examined have contributed to our understanding of the US narcotics policy change over time, it is clear from the analysis that some of these theories have been more useful than others in explaining the type and nature of the narcotics policy process. In short, my argument is that some of the theories have performed better than others in explaining the narcotics policy process.

\footnotetext{
${ }^{104}$ Drawing on Hall (1993), Skogstad (2009) elaborates on the argument that policy anomalies and failures of existing policy paradigm tends to create the incentive for policy change. The increasing frustrations of many towards the existing narcotics policy represent a good case in point.
} 
Agenda-setting was the first theory examined in this chapter. By employing the concepts of issue definition, venue switching, and policy entrepreneurship, the cases examined in the narcotics policy domain show some consistency with the existing literature (Pralle, 2003, 2006a; Baumgartner and Jones, 1993; Studlar, 2002; McLendon, 2003; Sinclair, 1986; Howlett, 1997; Princen, 2007; Mintrom and Norman, 2009; Crow, 2010) on the usefulness of agenda-setting theory in explaining policy change. In fact, these scholars (above) are among many others that have applied agenda-setting theory to study many different policy spheres with results showing greater levels of utility and applicability to other policy fields. In the case of US narcotics policy, we have clearly seen that the concepts of agenda-setting have been well demonstrated in the policymaking process. The analysis also reveals that these concepts of agenda-setting (issue definition, venue switching, and policy entrepreneurship) ${ }^{105}$ offer a better explanation for some of the changes that have occurred within the US narcotics policy since 1993. On the other hand, this study does not find the broad concept of punctuated equilibrium as very useful in explaining the changes that have occurred within the US narcotics policy. This is because of the nonexistence of any evidence to support any sign of a sudden or abrupt interjection (punctuation) in the form of a focusing event or a major political factor (s) to cause a transformative (drastic) policy change in the narcotics policy. In effect, the policy dimension that looks at policy agendas was clearly displayed through the agenda-setting theory in this chapter.

The influence of partisanship and ideological orientation in shaping the narcotics policy process and therefore change was equally apparent. Like agenda-setting, partisanship provides a useful understanding of the narcotics policy process and change. The discussion on partisanship and policy outcomes, especially on the distinction between a restrictive policy approach

\footnotetext{
${ }^{105}$ This is Baumgartner and Jones' (1993) version of agenda-setting theory.
} 
(Republican ideology) and a permissive policy strategy (Democratic ideology) in shaping the narcotics policy process, provide us with a useful explanation of the phenomenon. The partisan dynamics also help to highlight the struggle between the two poles of the narcotics policy domain, namely prohibition and criminalization versus treatment and harm reduction. This was particularly evident within the policy dimension of campaign rhetoric and policy proposals. Although partisanship ideology does not appear to play a dominant role in explaining the nature of narcotics policy change, the theory is still relevant to our general understanding of the US narcotics policymaking process.

Hall's (1993) theory of paradigm change (orders of change) was also examined within the context of US narcotics policy change. The discussion focuses on the typology of first order, second order, and third order change in policies. While evidence of a first and a second order change in narcotics policy has occurred, there was no evidence to show the occurrence of a third order or paradigm change in policy. In terms of Hall's (1993) theory, key evidence suggests that a first order change in narcotics policy had occurred during this phase (Clinton and Bush eras). Although a first order change offers some explanation in understanding the incremental change that occurred, this study concludes, based on the supporting evidence, that Hall's (1993) concept of second order change in policy provides a persuasive explanation for the type and nature of US narcotics policy change from 1993 to 2009. In contrast, the concept of a third order change (paradigm), which appears to share similar assumptions with the punctuated equilibrium theory, offers little explanation for the US narcotics policy process during the period under review. In other words, there was no change in terms of a third order kind.

Broadly, the trend of US narcotics policy change has predominantly undergone a second order change (policy instruments) since 1993. Having employed the three theories as competing 
explanations to understand the US narcotics policy process since 1993, this study argues that Hall's theory of orders of change provides a compelling explanation for the US narcotics policy process as compared to the other theories. This argument is based on the theoretical assessment of the relative explanatory power (Studlar, 2002) of the three domestic theories in answering the question of how well each theory performed in explaining policy change, particularly the nature and type of change that have occurred.

As previously discussed, while agenda-setting and partisan ideology provide useful theoretical frameworks in explaining the narcotics policy process, this study contends that they are unable to better explain the type and nature of change that has occurred within the US narcotics policy domain. However, Hall's (1993) theory provides a better explanatory power in explaining the type and nature of change (first order and second order) in the narcotics policy process. More importantly, this study also finds that Hall's (1993) theory fit the three components (policy goal, policy instrument, and settings of a policy instrument) of policy compartmentalization (Capano and Howlett, 2009) in explaining the type of change associated with each component parts (see figures 4.4 and 4.5).

In view of the preceding arguments, the important question to ask is this: to what extent does the US narcotics policy change shape the global narcotics regime? In other words, what are the implications of US narcotics policy change on the global narcotics regime as a result of the dominant influence of the US on the global narcotics regime? The next chapter addresses this question. 


\section{Chapter 5}

\section{US Policy Change: Implications for the Global Narcotics Regime}

\section{Introduction}

This chapter examines the basic question of whether a US domestic policy change is likely to have a similar influence (change or resistance to change) on the global narcotics regime as a result of the dominant role of the US on the global narcotics regime. As stated in the previous chapters, the study employs the concept of regime theory (Young, 1983; Keohane and Nye, 1977: Keohane, 1984, 2005) with specific application of the hegemonic stability theory (Ikenberry, 1989; Kindleberger, 1981) to help with our understanding of how the dominant role of the US shapes many global issue areas, including narcotics control. Again, it is useful to reiterate how the concept of hegemonic power is applied in this chapter. Essentially, the broad ideas of the hegemonic stability theory are applied, but my interpretation of a hegemon, as it relates to the US, is not in the original sense of the theory (see chapter two). In essence, the theory (HST) is broadly applied to demonstrate the dominant and influential role of the US (Bewley-Taylor, 1999a) in shaping the global narcotics prohibition regime since 1909.

The chapter starts from three basic standpoints. First, it discusses the US involvement and role in the global narcotics regime. Second, the chapter examines the evolutionary process (four stages) of a global prohibition regime (Andreas and Nadelmann, 2006) and demonstrates how the global narcotics prohibition regime fits the evolutionary process. Finally, the study shows the influential role of the US in shaping the global narcotics regime with supporting cases. 


\section{The Global Narcotics Problem}

The problem of illegal drugs, with current global proceeds ranging from $\$ 100$ million to more than \$1 trillion per year (Wyler, 2009:1), and the efforts to control them is not only a problem for the United States, but for the international community as a whole. Since 1909, the world community, with the US at the forefront, has been engaged in a global fight against the production, trafficking, and use of narcotic drugs (Nadelmann, 1990; Bewley-Taylor, 1999a; Gerber and Jensen, 2001). As stated in chapter one, illegal drugs are broadly categorized as narcotics or psychotropic substances that are produced, traded, and used across many parts of the global environment. As a result of the international conventions prohibiting these drugs, almost every signatory country's domestic law prohibits the production, trafficking, and use of narcotic drugs (Wyler, 2008:1). Some of the commonly used narcotic drugs include cocaine, coca leaf, heroin, cannabis or marijuana, and opium. The psychotropic substances include ecstasy, ${ }^{106}$ LSD, ${ }^{107}$ amphetamine, and methamphetamine, with only few exceptions of these drugs that are currently permitted for medical and scientific purposes (Wyler, 2009:1).

Although the global efforts to control narcotic drugs have been an integral part of the US foreign policy objectives for decades, Wyler $(2008,2009)$ contends that the debate on narcotic drugs as a potential threat to US national security first emerged on the foreign policy agenda in the late 1960s. Since then, the issue has largely been defined through security and law enforcement approaches by many successive Administrations and Congresses. While the rhetoric on the so-called war on drugs tends to characterize the eras of many presidents, the US Congress has been equally involved in many international efforts at narcotics control. The role of Congress has been through the enactment of various legislations that expanded the powers of many drug

\footnotetext{
${ }^{106}$ Ecstasy is the street name for MDMA (3, 4-Methylenedioxy-N-Methylamphetamine (Wyler, 2009:1).

${ }^{107}$ LSD is the street name for lysergic acid diethylamide (Wyler, 2009:1).
} 
interdiction authorities and criminal penalties for drug production and trafficking from major producing and trafficking countries ${ }^{108}$ into the US (Wyler, 2009:2). Senator John Kerry is on record to have, for example, pushed for a greater involvement of the US in global crime control, especially narcotics during the mid-1980s through to the 1990s.

In the words of Senator Kerry:

We are compelled by the globalization of crime to globalize law and law enforcement... and transnational crime is the new communism, the new monolithic threat... and the United States must lead an international crusade to defeat it. ${ }^{109}$

Apparently, Senator Kerry's line of thinking has been generally shared by other political elites and ordinary Americans (Andreas and Nadelmann, 2006) for some time now. For sure, one might argue that the view expressed by Senator Kerry may not have been exclusive to the 1980s and 1990s alone, but also applicable to recent times (Andreas and Nadelmann, 2006, Wyler, 2009:2). While different views exist on the strategies of narcotics control ${ }^{110}$ (Gerber and Jensen, 2001: 7), it is widely believed that one of the reasons for the relentless effort by the US in the global narcotics control is the fact that the major supply of narcotic drugs into the US comes from outside the US (Bewley-Taylor, 2006,1999a). In effect, the US has for many decades led the international counternarcotics control (supply-reduction) programs on drug growers, processing centers, and transit points in many of the source countries (see appendix 4) while the domestic control programs focus on the disruption of the distribution networks and users as shown in figure 5.1 .

\footnotetext{
${ }^{108}$ See appendix 4, Map of the World Drug Majors in Fiscal Year (FY) 2009.

${ }^{109}$ This quotation was cited in Andreas and Nadelmann (2006: v) Also see Kerry (1997).

${ }^{110}$ Gerber and Jensen (2001:7) argue that the US deliberately exports narcotics prohibition strategy to other nations because of the following reasons (states need enemies, because of the disappearance of the red scare, and the US has become the police force of the world).
} 
Figure 5.1

Global and Domestic Dimensions of US Narcotics Control

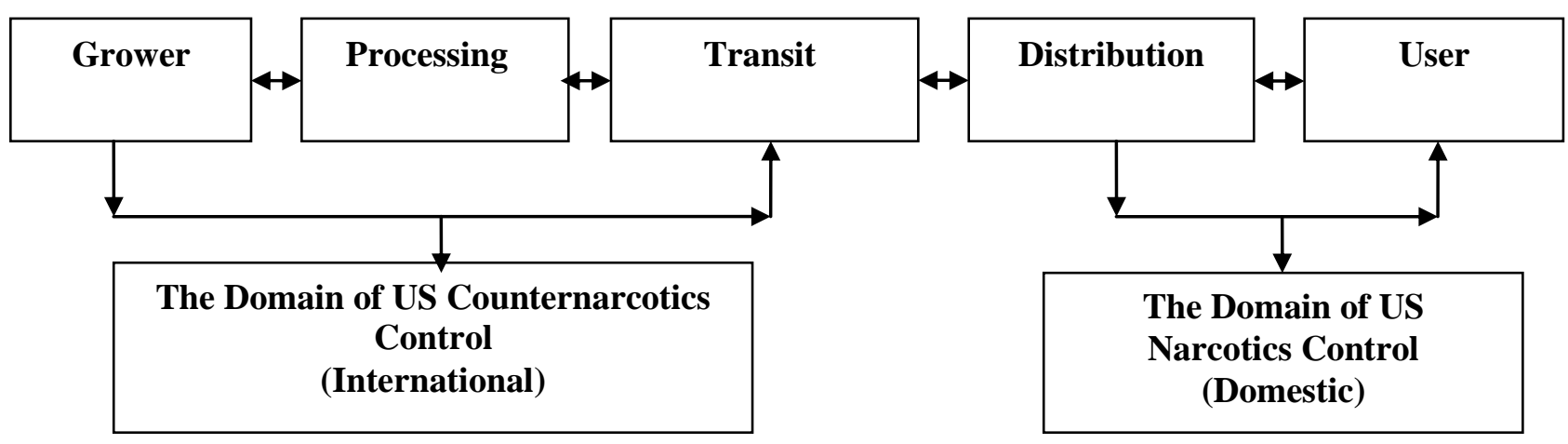

Source: Adapted from Jones (2002:119) with some modifications.

Given the active involvement of the US within the global system because of its dominant influence, it becomes imperative to ask whether a policy change in the US narcotics policy domain is likely to impact the global narcotics regime. In other words, will a change in the narcotics policy domain in the US, or a resistance to change, reflect a similar policy change on the global narcotics regime? As noted, this chapter draws on regime theory (hegemonic stability) from the international relations literature to discuss the implications of a narcotics policy change in the US on the global narcotics regime.

For Andreas and Nadelmann (2006), the internationalization of crime is not new to the contemporary international system. For them, the outcomes of the internationalization of crime are from many years of efforts by many Western powers to export their domestic perception of criminal activities on the rest of the world. The purpose is basically to serve their political and economic interests. Andreas and Nadelmann (2006: vii) conclude that the "global prohibitions and international crime control priorities and practices would not be what they are today if different states with different values had dominated the international society during the past two 
centuries." In the case of narcotics policy, it is common to find that almost all countries adhere to the international treaties prohibiting drugs that are labeled as narcotics, except for scientific and some limited medical purposes (Bewley-Taylor, 2006:29, Nadelmann, 1990).

Among the Western powers that shape and influence many global issue areas, the US stood out as the most influential country in shaping the internationalization of crime, particularly on narcotics prohibition (Andreas and Nadelmann, 2006). The involvement of the US in the global control of narcotics has been shaped by internal and external dynamics for many decades. For example, many religiously affiliated groups and individuals within the US have since the beginning of the twentieth century framed the source of the narcotics problem beyond the boundaries of the US (Bewley-Taylor, 2006, 1999a). According to Bewley-Taylor (2006:29), the attempt by these moral advocates (Protestant culturalism), was to shift the blame to outside sources in order to fight against the use of illegal drug that many deemed morally unacceptable to the American society. While the influence of the moral advocates of the Protestant culture is important in shaping the global involvement of the US in narcotics control, this study argues that the dominant influence (political and diplomatic) of the US offers a better explanation for the US leadership and role in shaping the evolution and maintenance of the global prohibition regime.

\section{United States and the Global Narcotics Regime}

As noted in chapter two, the hegemonic stability theory constitutes an important part of regime theory in the international relations literature. Broadly, international regimes have the principal responsibility of governing the relationship among states in an issue area through agreed principles and norms. These norms can either be implicit or explicit, with members' expectation converging in common areas of global concern (Jervis, 1983; Krasner, 1983). As 
many international relations experts (Waltz, 1979; Axelrod, 1984; Mearsheimer, 2001) agree, the anarchical nature (see chapter two) of the international system creates the incentive for one powerful (hegemon) state to facilitate cooperation of others into a global institutionalized system or regime in support of their interests (Gilpin, 1981; Keohane, 1984; Axelrod, 1984; Byers, 2003). For Martins and Thompson (2007), a state achieves a hegemonic or dominant status if it is able to demonstrate its global leadership, reach, and capability, and also strong enough to impose its interests and values on other states. In fact, Wade (2002) provides a simplified version of the hegemonic concept as a dominant country's ability to make others want the same thing as it wants for itself.

It is undeniable that the international system is complex in structure and function. The complexity of the system is characterized by multifaceted interactions among sovereign states with different interests, values, and agendas, which makes cooperation even in areas of mutual interests sometimes very difficult (Keohane, 1984). Perhaps this explains why it is important to have a hegemonic or a dominant power that can exert its influence and coordinate or coerce others in the evolution and maintenance of regimes within the global system. As previously discussed, Keohane $(1984 ; 2005)$ reminds scholars that international regimes can emerge and be sustained with or without a hegemon. For Keohane (1984; 2005), a hegemonic power may not necessarily be a sufficient condition for the evolution of cooperative relationships or regimes because state actions promote cooperation for the purpose of mutual benefits. Keohane's (1984; 2005) argument is useful in advancing the broader debate on the hegemonic stability theory, but this study believes that Keohane's argument does not diminish the dominant impact of great powers such as the US in shaping issue areas in the international system in line with their norms, values, and interests. 
Within the original sense of the concept, a hegemonic stability theory assumes a situation where a state in the international system becomes so powerful (military, political, economic and technological) to the extent of exerting its influence and control on other states due to the unequal power relations within the system. In most cases, the hegemonic power takes an active responsibility in the maintenance of order within the system (Keohane, 1984; Ikenberry, 1989). For Cronin (2001), the US has been quite influential on the world stage since the beginning of the twentieth century. However, the US assumed the status of a hegemonic power only after the end of World War II and in the post-Cold War era. In an article titled Power and Liberal Order: America's Post War World, Ikenberry (2005:133) describes the current global position of the US as follows:

The American power (military, economic, technological, cultural, and political) is one of the great realities of our age. Never before has one country been so powerful or unrivaled. The United States emerged from the Cold War as the world's only superpower and grew faster than Europe and Japan in the decade that followed. American bases and naval forces encircle the globe.....and for the first time in the modern age, the world's most powerful state can operate on the global stage without the fear of counterbalancing competitors... the world has entered the age of American unipolar.

Many others do share Ikenberry's (2005) perspective that the US is indeed the single most important dominant power within the current post-Cold War global system. Applying a similar idea of a hegemonic concept to the global narcotics issue, it is obvious that the US has successfully utilized its dominant influence to shape the evolution and maintenance of the global narcotics prohibition regime (Room and Paglia, 1999; Kuzmarov, 2008; Bewley-Taylor, 1999a). Before I examine the dominant influence of the US on the global narcotics regime, I will first explore the conceptual pattern of regime formation. Like other regimes in the international system, Andreas and Nadelmann (2006) argue that most global prohibition regimes, such as 
those targeted at the suppression of slavery, piracy, and illegal drug trafficking, appear to follow a theoretical pattern of four stages in their evolutionary process. The next section examines the formation of the global narcotics prohibition regime within the context of the four conceptual steps.

\section{Stages in the Evolution of a Global Prohibition Regime}

\section{First Stage}

According to Andreas and Nadelmann (2006:20-21), most societies prior to the first stage often consider the activity or behavior to be prohibited as entirely legitimate and normal. The case of narcotic drugs in the US and other places in the world are particularly relevant here. In fact, the legitimacy argument of some narcotic drugs in the first stage is supported by a 2009 article in the New York Times titled, Let Me Chew My Coca Leaves by the President of Bolivia, Evo Morales Ayma. ${ }^{111}$ The article, which was based on the President's address to the United Nations Commission on Narcotic Drugs (UNCND) in Vienna, argues that the inclusion of coca leaf in the same category as cocaine in the 1961 UN Single Convention on Narcotic Drugs was a misguided policy that was adopted by the global community. For him, the custom of chewing coca leaves has been in existence in many countries of the Andean region of South America for centuries. Coca leaves not only help to alleviate hunger, but also provide energy to help counter altitude sickness for Bolivians and other mestizo people during their long days of labor intensive works. The President concludes that coca leaves were not only consumed during the past generations, but are equally consumed and very much useful in present times. In his words:

\footnotetext{
111 Ayma, Marales Evo. 2009 “Let Me Chew My Coca Leaves.” New York Times, March 13th, 2009 (Op-ED Columnist), http://www.nytimes.com/2009/03/14/opinion/14morales.html, Retrieved 07/20/2011. Evo Morales Ayma is the current President of Bolivia. Retrieved on 7/20/11.
} 
Millions of people chew coca in Bolivia, Colombia, Peru, northern Argentina and Chile. The coca leaf continues to have ritual, religious and cultural significance that transcends indigenous cultures and encompasses the mestizo population. ${ }^{12}$

In the case of the United States, we have seen in chapter three how drugs such as opium, heroin, cocaine, and marijuana were all legal substances and accessible to anyone who wanted them in the late 1890s to the early 1900s (Bertram, et al., 1996; Musto, 1999). These drugs were not only found in several unregulated medicines for the treatment of regular ailments such as stomach aches and headaches, but others such as cocaine were actually used as an ingredient for the production of wines and other food additives (Meier, 1994:22; Bertram, et al., 1996:61).

\section{Second Stage}

Theoretically, Andreas and Nadelmann (2006) argue that the second stage basically involves a redefinition of the issue not only as a social problem, but also as an evil in itself that demands both national and global attention in policy responses (legislation and treaties) towards its control. In other words, this is the stage where the otherwise normal practice, become denormalized and may also be categorized as a deviant activity. Applying this concept to the US narcotics policy, it is clear that the frequent use of these narcotic drugs, particularly among the immigrant and poor communities, led to a widespread addiction and abuse and the subsequent demand for the control of these drugs.

Pressure was therefore put on the federal government from all angles, particularly from prominent moral and religious advocacy groups such as the Puritan American heritage, to control and prohibit the use of these drugs (Bewley-Taylor, 1999a, 2006). Andreas and Nadelmann (2006:20-21) describe this phenomenon as one of the key characteristics of the second stage in ${ }^{112}$ Ibid, p 1 . 
the evolutionary process of any global prohibition regime. The response from the US federal government to the widespread use of narcotic drugs in early 1900s led to the passage of the 1906 Pure Food and Drug Act (see chapter 3). This was the first major involvement of the US in legislation to control narcotics use (Meier, 1994). As previously discussed, the 1906 Act was significant because it marked a major change from the past years where there was no law regulating narcotics use (Meier, 1994).

\section{Third Stage}

The third stage constitutes one of the most important parts in the evolutionary process for two main reasons. First, this is the stage where the scope of the issue expands onto the global system for possible global debate on the issue. Andreas and Nadelmann (2006:21) describe this third stage as crucial because it is the stage where many regime proponents strongly agitate for global policy proposals or treaties for the suppression or criminalization of the presumed deviant activity. This may or not lead to an international agreement, but often times provide the basis for global collaborative efforts that could eventually lead to the emergence of an international treaty against the activity. The global narcotics prohibition regime is a good case in point.

The second major reason why the third stage is so important is the fact that this where the display of a dominant power or hegemonic influence occurs. During this stage, the state that emerges as the dominant player in the international system tends to exert its influence and power on other states toward the formation of a global regime in the issue area. In most cases, the outcome of the treaty may reflect the interests and values of the dominant power. The hegemonic state can also employ powerful policy tools such as diplomatic pressure, economic incentives,

military threats, and or propaganda campaign strategies to influence other states towards a 
cooperative treaty or an agreement to control the issue (Andreas and Nadelmann, 2006:21). Aside from states, transnational moral entrepreneurs also do influence the process of regime formation at this stage (Andreas and Nadelmann, 2006).

The conceptual assumption described above was clearly evident in the role that the US government and US-affiliated moral entrepreneurs played in the evolution of the global narcotics regime in the early 1920s. For these scholars (Nadelmann, 1990; Bullington, 2004; BewleyTaylor, 1999, 2006), the interest of the US in global narcotics control intensified after the Spanish-American War ended and the US acquired the Philippines. In fact, this was the era when opium use and trafficking was widespread in the region of Asia, especially China. Buxton (2006:31), for example, observes that because the US federal government took direct control of the Philippines, the country did not only inherit the opium retail system, but the US federal government was also forced to take a strong position on the sale and consumption of opium. Backed by influential moral entrepreneurs, ${ }^{113}$ the US pushed for a stronger policy action in prohibiting opium use and other narcotic drugs at the domestic and the international levels (Mandel, 2006).

Clearly, the American influence on the global narcotics control, particularly on the China opium problem, was displayed when the first international conference on opium (Shanghai Conference) was convened by the US in 1909 to specifically address the Chinese opium problem. Buxton (2006:26) argues that the Shanghai Conference had far reaching significance in promoting America's preferred policy approach on the global narcotics control regime. In fact, the influence of the US on the Shanghai Conference was evident in many ways. For example, the

\footnotetext{
${ }^{113}$ Examples of some of these moral entrepreneurs include Charles H. Brent, the Episcopal Bishop in the Philippines, Reverend Wilbur Crafts, the president of the International Reform Bureau (IRB), the American Missionary Organization, and Hamilton Wright, a politically connected Physician (Nadelmann, 1990, Musto 1999, Buxton, 2006).
} 
conference was not only chaired by Bishop Brent, the longtime campaigner for a stiffer narcotics control policy, but the US delegation was also led by Dr. Hamilton Wright, another proponent of a global narcotics prohibition regime (Bullington, 2004; Buxton, 2006).

As earlier noted, the US was not a global hegemon in the true sense of the word by the early 1900s, but it played an influential role in not only convening the Shanghai Conference to discuss the opium problem, but was also active in shaping the global narcotics control treaties towards a supply-side prohibition approach (Buxton, 2006). For Bewley-Taylor (1999:11), the Shanghai Conference had two important implications for the US in terms of its impact on the global narcotics regime. First, it signaled the arrival of the US onto the global stage, and second, the US began to externalize its concept of domestic narcotics prohibition (multilateral relations at the UN) on the global narcotics regime and on other countries through bilateral relations.

\section{Fourth Stage}

According to Andreas and Nadelmann (2006), the fourth stage emerges after efforts by advocates of an international regime in an issue area become successful. Once the idea of regime creation is supported by other states following a redefinition of the issue, an international treaty with institutional structures to support the implementation of the treaty will be established. In some cases, regime proponents may face huge challenges from dissidents and other deviant states who might not want to comply with the treaties. Diplomatic and other forms of pressures are often applied to compel deviant states to enforce the norms of the regime. In the words of Andreas and Nadelmann (2006:21), "it is only at this point that one can speak of a global prohibition regime having fully come into existence." 
In terms of the global narcotics prohibition regime, Andreas and Nadelmann (2006) observe that the United States was primarily responsible for persuading other countries to agree to the establishment of the regime. Given the initial success with the Shanghai Conference, the US convened further international meetings with the goal of cementing its preferred supply-side prohibition approach through binding international treaty agreements (Bullington, 2004:690). The Hague Conventions of 1912 and $1914^{114}$ were the outcome of international meetings toward the global narcotics regime. In fact, before the UN finally approved the 1961 Single Convention Agreement, nine international narcotic treaties were proposed and approved since the 1912 Hague Convention. As expected, the United States was not only involved in the negotiations, but also employed its dominant position to influence the institutional structures and frameworks in the establishment of the global narcotics regime (Nadelmann, 1990; Bewley-Taylor, 1999a; Bullington, 2004).

\section{US Policy Tools and Global Narcotics Control}

As revealed in the discussion, the US has been very influential in the evolution and the maintenance of the global narcotics prohibition regime. In Bullington's (2004:690) words:

The United States had been the prime mover of this early anti-drug legislation, relying on diplomatic pressure and arm twisting to forge a shaky consensus among nations that were generally much less convinced of the need for international controls. This American triumph signaled the beginning of nearly a century during which America literally dominated the direction of drug control and drug policy in the international arena.

\footnotetext{
${ }^{114}$ See table 1.1 in chapter 1 for the chronology of Multilateral Conventions on the Global Narcotics Control (19091988).
} 
Levine (2003:148) shares a similar view on the dominant role of the US on the UN narcotics regime. According to Levine (2003), the global narcotics prohibition has enjoyed a considerable support and legitimacy for many decades because the "US has used the UN as the international agency to create, spread, and supervise world-wide prohibition."

In its effort to externalize the prohibition approach of narcotics control through the global narcotics regime (Bewley-Taylor, 1999a), the US employs some vital policy tools (see table 5.1) in achieving its global narcotics control objectives. Like other powerful countries, the US employs diplomatic influence and pressure as one of its policy tools to shape the global narcotics prohibition regime. As Bewley-Taylor (1999b) observes, the US does not only exploit its dominant influence, but also uses its diplomatic strength within the UN, particularly in the period after the Second World War, to pressure other countries to support its prohibition style approach to global narcotics control.

Table 5.1

\section{US Policy Tools of Influence (Global Narcotics Control)}

\begin{tabular}{|l|l|}
\multicolumn{2}{|c}{ Policy Tools } \\
\begin{tabular}{|l|l|}
\hline Diplomatic & $\begin{array}{l}\text { The US employs diplomatic pressure on other countries both at the } \\
\text { multi-lateral and bilateral levels toward the goal of global narcotics } \\
\text { prohibition. }\end{array}$ \\
\hline Derivative Control & $\begin{array}{l}\text { This policy tool connects non-narcotic issues to narcotic ones in } \\
\text { agreement of other nations so they can get the US economic aid and } \\
\text { political support in other areas. }\end{array}$ \\
\hline This policy tool mandates every US president to present an annual \\
assessment report to Congress on the compliance status (US laws \\
and UN narcotic Conventions) of major drug producing and \\
trafficking countries. US foreign assistance can be withheld from \\
non-compliant countries under the policy provision.
\end{tabular} \\
\hline Financial Leverage & $\begin{array}{l}\text { The US employs its financial leverage as the largest contributor to } \\
\text { the UN to shape policies, including narcotics. }\end{array}$ \\
\hline
\end{tabular}

Source: Table designed by the author based on the information and ideas from these works.

(Bewley-Taylor, 1999a; Hinojosa, 2007; Chepesiuk, 1999:34). 
Derivative control is another important policy tool at the disposal of the US. According to Bewley-Taylor (1999b:151), the US successfully employed and continues to use this policy tool to connect non-narcotic issues to narcotic matters within the United Nations. Bewley-Taylor (1999b:151) describes the policy instrument as this:

By tying the acquiescence of other nations in the Commission on Narcotic Drugs to American economic aid and political support in other areas, the US was able to dominate the decision-making process and play a central role in the instigation and design of anti-narcotics legislation.

Another key policy instrument of influence that the US uses is the certification concept. Generally, the concept is seen as one of the most vital policy tools available to the US narcoforeign policy, especially in terms of its relationship with the Andean countries. It is a policy instrument of diplomatic arm twisting by the US for the purpose of accessing greater influence and control over the global narcotics regime (Chepesiuk, 1999; Bouley, 2001). The certification process, which became effective in 1986, was part of an amendment to the Foreign Assistance Act of 1961 (Chepesiuk, 1999; Bouley, 2001). Under the new certification law, every US president is expected to make an annual assessment of major drug producing countries in a report to Congress. The purpose is to make sure these countries not only comply with the US on all narcotics production and trafficking issues, but also with the goals and objectives of all the UN conventions on narcotic drugs and other psychotropic substances (Bewley-Taylor, 1999a; Hinojosa, 2007).

The law also mandates a president to withhold US foreign assistance from any noncompliant country (Chepesiuk, 1999:34). In a study examining the certification concept for many Latin American countries, Bouley (2001) shares Falco's (1996) views that the certification 
process was designed to boost US efforts in compelling countries in the region to cooperate on limiting the trafficking of narcotic drugs into the United States. It also ensures that US presidents are accountable to the American people through Congress in enforcing a more vigorous approach to global narcotics control.

The financial leverage of the US on the UN constitutes another important policy tool that the US uses to influence the global narcotics regime (see table 5.1). Apparently, the US has been the largest financial contributor to the operations of many agencies of the UN, including the narcotics agencies, although it owed about $\$ 1.4$ billion ${ }^{115}$ in its financial obligations to the UN in the 1990s (Bewley-Taylor, 1999a). On the importance of the US financial leverage on the UN, Bruun et al. (1975) and Bewley-Taylor (1999a) provide a good idea on the importance of this policy tool in shaping the global narcotics regime. For them, the influence of the US within the UN drug control program illustrates its dominant position in many other agencies of the UN because of the US role as the largest financial contributor to the organization. Clearly, the financial leverage of the US on the UN has not diminished in recent years. For example, the Better World Campaign (BWC) reports that the US funding for the UN for the Fiscal Year 2011, include an amount of $\$ 1.887$ billion for peacekeeping operations, $\$ 516$ million for the regular budgets, and $\$ 354$ million for agencies that the US regularly contributes (narcotics agencies included) toward its operations. The BWC also notes that the US currently pays close to a quarter of the UN regular and peacekeeping budget allocations. ${ }^{116}$

\footnotetext{
${ }^{115}$ According to the Better World Campaign (BWC), the organization devoted to promoting a strong US-UN relationship, the arrears owed by the US to the UN was paid off in September 2002. Retrieved from http://www.betterworldcampaign.org/about/ (11/06/11).

${ }^{116}$ The data and information on the financial contributions of the US to many UN agencies are provided on the website of Better World Campaign (BWC). Retrieved from

http://www.betterworldcampaign.org/issues/funding/how-the-us-funds-the-un.html (11/06/11).
} 
Bewley-Taylor (2005:429) elaborates on the financial leverage argument by indicating that "any discussion of the UN drug control system is incomplete without the mention of major donors." For Bewley-Taylor (2005), the UN drug system has generally been considered as the servant of many major top donors such as the US, Sweden, and Japan. Clearly, the US has been the strongest advocate for global prohibition of narcotics control among the top donors (BewleyTaylor, 2005). It is important to reiterate a recent example of US financial dominance and influence over the UNODC. As Bewley-Taylor (2005:429) recounts, the former Executive Director of the UNODC, Mr. Antonio Costa, met in November 2004 with Mr. Robert Charles, head of the US Bureau of International Narcotics and Law Enforcement Affairs (INL) to discuss some possible alternative approaches such as the harm reduction intervention programs to global narcotics control. Realizing the potential threat to the existing prohibition approach from an alternative option, the head of the US Narcotics Bureau was said to have threatened to reduce the US financial support to the UNODC, unless Mr. Costa reassure the US that the UNODC will not offer its support for any global harm reduction intervention program. In order to avoid any cut in funding from the US, the head of the UNODC succumbed to the US demands (Bewley-Taylor, 2005:429).

In fact, a number of respondents for this study share the same view on US dominance within the UN drug system. In one of the responses to an interview question on the dominant role of the US in the global narcotics prohibition regime, one respondent said that:

The US plays very dominant role and has provided an enormous amount of funding to UN antidrug efforts. At one point when the World Health Organization (WHO) was planning to issue a report on the lack of dangerousness of cannabis, the US pressured the WHO to kill the report...At another point when the Liberal government of Canada under Prime Minister Chretien proposed to decriminalize marijuana, the Bush Administration's drug czar, John Walters, threatened trade 
retaliation against Canada regarding timber, fish, and other issues. ${ }^{117}$

In a similar answer to another interview question on whether the US is influential on the global narcotics regime because of its hegemonic status, here is what another respondent said:

Latin American lawmakers, for instance, have moved intellectually and also policy wise toward decriminalization in recent years, but have feared going far because of their northern neighbor. In recent years, the U.S. has also pressured Canada and the U.K from moving ahead with policy changes that would shift away from criminalization. The U.S. fears that drug policy change would compromise the UN conventions. ${ }^{118}$

The preceding analysis has indeed shown that the US is unquestionably powerful and continues to influence and shape the global narcotics regime as well as its bilateral narcotics relations with other states since the 1909 Opium Conference in China. While this study argues that regime theory (hegemonic stability) offers a good explanation for the dominant role of the US in the evolution and the maintenance of the global narcotics regime, it is equally important to consider a possible alternative explanation for the dominance of the US on the global narcotics regime.

Sharing the view of Bruun et al. (1975), Bewley-Taylor (1999b:151), for example, argues that when a superpower exhibits this kind of involvement and control over global issue areas such as the global narcotics policy domain, there is often the possibility of less resistance or unresponsiveness on the issue from other countries. For Bewley-Taylor (1999a:211), the success of the US in "globalizing its drug prohibition policy is attributable to a lack of widespread and forcible opposition." This is particularly crucial in cases where the issue does not appear to contradict the interest of other countries. In other words, the argument assumes that the US is

\footnotetext{
${ }^{117}$ An official interviewed at the Criminal Justice Policy Foundation (CJPF).

${ }^{118}$ An official interviewed at the Drug Policy Alliance (DPA).
} 
likely to receive support and cooperation from other countries on the global efforts to control narcotics as long as such cooperation does not conflict with other countries' interests (Bruun et al., 1975; Bewley-Taylor, 1999b:151). In essence, one might infer from this argument that the preferred narcotics option (prohibition) of the US is largely in place because of similar interests shared by other countries to keep the prohibition regime in existence.

While this alternative explanation for the continuous existence of the regime seems quite convincing in principle, the argument appears not very compelling. This is because it is unlikely that almost every country in the world will continue to adhere to the same narcotics policy option (prohibition) for decades without embracing alternative policy options even in the face of policy failures. In fact, some scholars (Nadelmann, 1990; Lee, 1993; Akiba, 1997; Baggins, 1998; Thoumi, 2009) describe the global narcotics prohibition policy as ineffective in controlling the production, trafficking, and use of narcotic drugs. Although the alternative explanation might be useful to some extent, my argument is that countries could opt and push for an alternative policy regime, if not for the hegemonic influence of the US on these countries through the UN narcotics control system to keep the existing prohibition policy in place.

In other words, the concept of national interest is paramount to a country's interaction with the rest of the world, but it is unlikely that almost all countries that pursue the prohibition policy option would share the same interest (prohibition approach to narcotics control) with the US, if not for the dominance of the US through its global policy tools of control (see table 5.1). This argument is not to however suggest that the US and other countries' interests might not converge with UN policies. It certainly can converge. However, my central argument, which I have attempted to support with earlier discussed cases, is that the existing UN narcotics prohibition regime is largely shaped by the dominant influence of the US on the UN. This 
finding appears to be consistent with earlier scholarly works (Nadelmann, 1990; Bewley-Taylor, 1999a; Andreas and Nadelmann, 2006), which have also underscored the dominant role of the US in externalizing its preferred prohibition approach on the rest of the world.

Again, this study contends that the influential role of the US with its preferred prohibition policy shapes the global narcotics regime. One could conclude that the hegemonic stability theory offers a good theoretical explanation for the existing prohibition option of global narcotics control. In other words, this study argues that the current global narcotics regime is somehow driven by the hegemonic influence of the US. It is therefore imperative, in view of this claim, to revisit the guiding research question of this study, which seeks to find out the implications of US narcotics policy change on the global narcotics prohibition regime.

\section{Two-Level Games: US Policy Change / Global Narcotics Regime}

The foremost objective of this chapter is to demonstrate with evidence through the hegemonic stability theory that US narcotics policy change is likely to provoke a similar change or resistance to change in the global narcotics regime because of the dominant influence of the US on the regime. As previously discussed, the US interacts with other countries in the world on narcotics control from two important levels. The first interaction occurs at the multilateral level under the auspices of the United Nations. The second interaction takes place on bilateral level. These kinds of interactions between the US as a dominant player in the global system and the rest of the world fall within the emerging field of domestic and international politics. According to these scholars (Milner, 1997; Hermann and Hermann, 1989; Hagan, 2001; Mesquita, 2002; Hinojosa, 2007; Hirschi and Widmer, 2010), the interaction between domestic politics and international relations occupies an important field of study in political science in recent times. 
More than four decades ago, Rosenau (1969) wrote on the concept of Linkage Politics to highlight the importance of domestic linkage with international politics. A few decades later, Putnam (1998) developed and extended the ideas of Rosenau (1969) with his concept of twolevel games to enhance the understanding of the link between domestic and international politics. Applying this concept to the US situation, it is noticeable that the display of US hegemonic influence on the global narcotics regime stemmed from the US influence on the regime through its interaction (multilateral and bilateral) with the rest of the world (Bewley-Taylor, 1999b; Nadelmann, 1990; Bullington, 2004; Andreas and Nadelmann, 2006).

As shown in the preceding discussion, based on the evidence from the documentary analysis and the interviews, it is apparent that the US has successfully employed its dominant influence through various policy instruments and diplomatic actions (see table 5.1) to shape the global narcotics regime in line with its domestic interests of narcotics control (Bewley-Taylor, 1999a; Bullington, 2004; Andreas and Nadelmann, 2006). Having established the basis of this argument, the obvious question that emerges is whether the global narcotics regime reflects similar policy changes that have occurred within the US narcotics policy domain. In other words, is the global narcotics policy change being driven by policy changes occurring with the US narcotics policy? Before I examine the dynamics of this question in the next few pages, a brief outlook at the current policy direction of the US will suffice for now.

In his introductory remarks in the 2010 National Drug Control Strategy to Congress, President Barack Obama made the following remarks:

While I remain steadfast in my commitment to continue our strong enforcement efforts, especially along the southwest border, I directed the Office of National Drug Control Policy to reengage in efforts to prevent drug use and addiction and to make treatment available for those who seek recovery. This new, balanced approach will expand efforts for the three critical ways that we can 
address the drug problem: prevention, treatment, and law enforcement. ${ }^{119}$

While the President's strategy emphasizes a balanced approach, the budget commitment of the Administration reveals that law enforcement approach (domestic and international) overrides other treatment and prevention programs (see appendix $3 d$ ). The increasing budgetary allocation and policy attention to law enforcement demonstrates the dominance of the prohibition policy regime even in the Obama administration. Clearly, the over reliance on narcotics prohibition continues to attract criticisms in the US and on the global stage. For many, the existing narcotics prohibition policy approach in the US and the global system has not been able to address the drug problem as expected (Nadelmann, 1990; Fish, 2006; Husak, 2006).

As previously argued, the influential role of the US on the global prohibition regime is evident in the three main international treaties -the 1961 Single Convention on Narcotic Drugs, the 1971 Convention on Psychotropic Substances, and the 1988 UN Convention against Illicit Traffic in Narcotic Drugs and Psychotropic Substances (Albrecht, 2001). These treaties do not only provide the institutional framework for the existing regime, but also reflect much of the US domestic ideas on prohibition (Bewley-Taylor, 1999a:166; Andreas and Nadelmann, 2006). In fact, Comparing the hegemonic role played by Great Britain and other European nations in the late nineteenth century into the twentieth century where global prohibition against piracy and the slave trade reflected their norms, Andreas and Nadelmann (2006:45) observe that the existing global narcotics regime also reflects the prohibition policy interest of the United States.

\footnotetext{
119 The 2010 National Drug Control Strategy report, p iii.
} 
Generally, some reservations still persist among scholars (Nadelmann, 1990; Fish, 2006; Husak, 2006) on the existing prohibition policy option. However, the US and UN authorities have not given any serious attention to the possibility of adopting an alternative policy option (demand-reduction approach) to global narcotics control (Bewley-Taylor, 1999a). In spite of the broad based resistance to policy changes, there are few emerging alternative voices and growing debates regarding the need for some more attention toward a public health approach to global narcotics control.

For example, the Executive Director of the United Nations Office on Drugs and Crime (UNODC) in the 2010 World Drug Report made the following remarks:

Drug addiction is a treatable health condition....and slowly, people are starting to realize that drug addicts should be sent to treatment, not to jail... and treatment is becoming part of mainstream healthcare. ${ }^{120}$

Such a statement coming from a high-profile official within the UN system not only underscores the importance of the emerging discourse on reforms, but also reveals the growing frustrations with the dominance of the existing prohibition regime. A similar sentiment was recently expressed in a report by the Congressional Research Service (CRS) to the US Congress on the policy directions of global narcotics control. The report highlights some of the growing concern over the effectiveness of the prohibition strategy in global narcotics control (Perl, 2003).

In spite of the growing dissatisfaction regarding the existing policy approach, policy officials in both the US and the UN continue to defend the prohibition policy option, to the extent of undermining academic and independently conducted research studies that recommend revisions to the global prohibition policy (Bewley-Taylor,1999a:169). The research in question

${ }^{120}$ The 2010 World Drug Report p. 4. 
was undertaken by WHO/PSA (Program on Substance Abuse), in conjunction with the UN Interregional Crime and Justice Research Institute (UNICRI) between 1992 and 1994. The findings of study indicate that health problems are greater with the use of legal drugs than with occasional use of narcotic drugs such as cocaine and cannabis (Bewley-Taylor, 1999a:169). Fearing that the outcome of the study might pose a threat to their interest (prohibition approach), the UN organization, under pressure from the United States, quickly issued a disclaimer to the report and indicated that the report does not represent the official position of the organization (Bewley-Taylor, 1999a:169). As a matter of fact, this statement is consistent with a similar one made during my interview with an official from the Criminal Justice Policy Foundation. In an answer to one of the interview questions on whether the US plays a dominant role on the global narcotics regime, the respondent, citing some examples among others, stated that:

The US is very dominant within the global narcotics regime and has provided an enormous amount of funding to the UN anti-drug agencies and directly to various nations through wide variety of mechanisms. The US also works closely and influences other UN drug agencies. At one point, the World Health Organization (WHO) was planning to issue a report on lack of dangerousness of Cannabis, but the US pressured WHO to kill the report.

Although the degree of dominance by the US on the global narcotics regime might be subject to diverse interpretations, most of the elites interviewed for this study generally share the view that the US has greater influence on the global narcotics regime than other countries.

It is again evident, based on the above discussion, that the US has tactically employed its influential status not only to help create and maintain a global narcotics prohibition regime, but has also made a tremendous impact in shaping the global regime with prohibition option of narcotics control. On the basis of this argument that the US is influential in shaping the global narcotics regime, the theoretical question that this study seeks to further explore is whether a 
change in narcotics policy within the US policy domain is likely to have a similar change on the global narcotics regime. In other words, the study is interested in the implications of US policy change on the global narcotics regime. As previously noted, the hegemonic stability theory is the underlying theory on which the argument is based. My assumption is that a change or resistance to change in narcotics policy in the US is more likely to have a similar change or resistance to change on the global narcotics regime. For a better understanding of the implications of US policy change on the global narcotics regime, this study integrates the hegemonic stability theory with Hall's (1993) theory of paradigm change (orders of change) to demonstrate the nature and type of change occurring within the global narcotics regime.

It is noticeable, based on Hall's (1993) theory, that a third order (radical) kind of change has not occurred in the global narcotics regime. In essence, the prohibition approach to global narcotics control, which has been in existence for more than a century, is still in place. In other words, the global prohibition regime has not undergone a transformative change in policy from the existing approach (prohibition) to an alternative one (decriminalization). Instead, one might argue that the global regime is undergoing incremental changes (first and second order changes).

As we have noticed in chapter four, a change in routine budgetary allocation provides a good indicator in measuring incremental changes in policy (Rose, 1984). This is also true for the UN and its major agencies, including the narcotics agency (UNODC). Applying this concept (Rose, 1984) to the routine budgetary allocation of the UN narcotics agency, this study argues that the narcotics policy implementation of the agency has undergone incremental changes in policy. For example, the UNODC indicates that the financial contributions toward its budget for global drug and crime control increased by 13 percent from US\$ 215.3 million in 2009 to US\$ 
242.9 million in $2010 .^{121}$ From Hall's (1993) perspective, this kind of incremental change is a basic characteristic of a first order change (settings of a policy instrument) in policy.

Beside the first order kind of changes in policy, it also appears that a second order change in policy is occurring within the UN drug control system. This is evident by the increasing attention to public health approach to narcotics control by the UNODC. For instance, the 2009 annual report of the UNODC indicates the importance of putting health right at the center of global narcotics control. According to the report, ${ }^{122}$ the prevention and treatment of those dependent on illicit drugs should be considered as a crucial demand reduction strategy for global narcotics control. The report adds that "law enforcement efforts to stop or reduce the production and trafficking of illicit drugs (supply-reduction) tend to be ineffective if not combined with prevention of drug use and treatment of drug dependence (demand-reduction). ${ }^{, 123}$ To promote this policy objective, the UNODC has recently launched a new treatment strategy known as Treatnet Phase II. The purpose of this new strategy is to provide effective and quality drug treatment and rehabilitating services for those addicted to drugs in many countries. ${ }^{124}$

Clearly, this appearance of a gradual shift in tone and policy direction of the UNODC indicates an incremental change in the existing policy instrument of prohibition towards a liberal policy option to global narcotics control. In essence, the exclusive prohibition strategy to global narcotics control seems to be giving way to a comprehensive (demand-side and supply-side) approach to global narcotics control. In Hall's (1993) terms, a change to a policy instrument

\footnotetext{
${ }^{121} \mathrm{http} / / / \mathrm{www}$. unodc.org/unodc/en/donors/index.html?ref=menutop, Retrieved on 2/06/12.

${ }^{122}$ UNODC Report (2009: 19). http://www.unodc.org/documents/about-unodc/AR09_LORES.pdf, Retrieved on $11 / 07 / 11$.

${ }^{123}$ Ibid, p. 19 .

${ }^{124}$ The new treatment program of UNODC has started in Africa, Central Asia, Middles East and South America. http://www.unodc.org/treatment/en/index.html Retrieved on 11/07/11.
} 
with the introduction of a new instrument or an adjustment to an old instrument (Studlar, 2009) demonstrates the appearance of a second order change in policy. Indeed, the changing trend from an exclusive prohibition approach towards a comprehensive strategy in global narcotics control is significant to the underlying assumption of this chapter. This is because the new approach (comprehensive) appears to reflect a similar trend of US narcotics policy approach since the 1990s, particularly during the administrations of Clinton and Bush (see chapter four). As this study assumes, it is plausible that the gradual change towards a more comprehensive approach to global narcotics control is a reflection of a similar change (comprehensive approach) occurring within the US narcotics policy domain. Again, my argument is that the global narcotics regime is undergoing a similar nature of change (comprehensive approach) because of the influence of the US on the regime.

Aside from the shift towards a balanced approach to global narcotics control, there are also some emerging international venues for narcotics policy change toward a liberal approach. A good case in point is the Dutch liberal drug policy experiment. The Dutch experiment began in the 1970s with the aim of making soft narcotic drugs such as cannabis available to users as a pragmatic method of responding to the reality of the drug problem (Bullington, 2004; BewleyTaylor, 2006). Interestingly, the liberal experimental approach by the Netherlands not only challenged the basic assumptions of the UN/US backed-prohibition strategy, but the Dutch policy initiative became a reference point for lesson drawing purposes for other countries (Switzerland, Australia, Canada, and other European countries) in recent years. As BewleyTaylor (2006) observes, many European countries since 2000 have adopted a more permissive policies, particularly on cannabis or marijuana. 
In 2001, for example, more than 95 percent of cannabis possession cases were not prosecuted in France. The law on marijuana was also relaxed in other European countries, such as Denmark, Italy, and Germany. Portugal, Spain, and the United Kingdom are the other countries making some changes to their marijuana laws (Bewley-Taylor, 2006:40). Also, the liberal drug policies in some of these countries are connected to the gradual positive response to the harm reduction concept as a result of the increasing spread of the HIV/AIDS disease among many injection drug users. The harm reduction concept became attractive when the needle exchange ${ }^{125}$ program was introduced in many countries for injection drug addicts (Bullington, 2004; Nathanson, 2007). Applying the theoretical concept of orders of change to the cases examined, one might describe these changes as incremental in nature or changes within the domain of first and second order changes in policy on the global regime.

The evidence examined so far shows the existence of some changes in policy within the global narcotics regime. As revealed, first and second order changes appear to be the common types of change that have occurred and currently occurring within the global narcotics regime. However, there is no evidence to suggest the occurrence of a third order type of change (radical) within the regime. Haven established the evidence of these changes, the key question is: to what extent are these changes driven by the influence of the US?

Certainly, this study argues, based on the cases examined that the incremental types (first and second order) of narcotics policy changes that have occurred within the US policy domain reflect similar policy changes on the global narcotics regime. Taking the first and second order types of change, for example, it is apparent that these incremental changes on the global regime

\footnotetext{
${ }^{125}$ For the injection drug users who could not stop injecting drugs, many policy options were introduced in many countries, including sterile needles and needle exchange programs to prevent the spread of HIV/AIDS infection (Nathanson, 2007:78).
} 
reflect similar changes that have occurred within the US policy arena. Also, the ongoing emphasis on a more comprehensive approach to narcotics control in the US appears to reflect a similar trend on the global regime. In terms of the occurrence of a third order (radical) type of change, it is also evident, as earlier noted, that such a change has not occurred (1993-2009) and neither is it occurring within the US or on the global regime. By implication, this study argues that the US through its hegemonic influence has resisted the occurrence of a third order change from taking place both within the US and on the global scene because of its vested interest in preserving the status quo policy of prohibition.

While the evidence analyzed in this study supports the centrality of the hegemonic stability theory in explaining the influence (change or resistance to change) of the US on the global regime, it might also be useful to consider a possible alternative explanation for the changes occurring within the global narcotics regime. In fact, critics of my proposition could argue that the dynamics of regular internal bureaucratic reforms to existing policies, which tend to be normal with any organization, might offer some explanation for the changes occurring within the global prohibition regime. Although there a possibility with this argument or line of thinking, the argument is problematic because a decision to change a globally sensitive policy issue, such as narcotics control could hardly be driven by bureaucratic experts alone with no regard to the dominant player (United States) with vested interest (prohibition approach) within the regime.

Overall, my argument is that the hegemonic stability theory offers a useful conceptual framework in explaining the implications of change (first and second order) and resistance to change (third order) in the US narcotics policy on the global narcotics regime. In other words, the changes (first and second order) in the global narcotics regime have largely been shaped by 
similar changes that are occurring within the US narcotics policy domain. The same assumption holds for the resistance to a third order change by the US on the global narcotics regime because of the non-existence of a similar third order change within the US itself.

In effect, this study proposes that a radical narcotics policy change from the existing prohibition approach to a complete legalization of narcotic drugs in the US, is more likely to result in a similar policy change within the global narcotics prohibition regime. In fact, many respondents (elite interview) for this study expressed similar views. In an answer to one of the questions on the implications of a US domestic policy change on the global narcotics regime, one interviewee said that:

Many countries fear that a US backlash for drug policy changes would compromise the UN conventions. However, a major shift in the US drug policy (for example, California ending marijuana prohibition) would likely have implications for policy change within the Western Hemisphere and /or a global scale. ${ }^{126}$

In the words of another respondent:

Most US allies would rather refrain from challenging the US drug policies. Once the US decriminalizes, nearly every other country will follow suit. ${ }^{127}$

Based on the evidence examined in terms of the dominant influence of the US on the global narcotics regime, this study maintains that the explanation for the non-occurrence of a paradigm change (third order) within the global narcotics regime is somehow driven by the nonexistence of a similar change within the US domestic policy domain. In essence, this observation supports my argument that the US has not only been very instrumental in the evolution of the

\footnotetext{
${ }^{126}$ An official interviewed at the Drug Policy Alliance (DPA).

${ }^{127}$ An official interviewed at the Interfaith Drug Policy (IDP).
} 
global narcotics regime, but has employed its hegemonic influence to shape the global narcotics policy towards its preferred option of prohibition. This conclusion is consistent with my set hypothesis (see chapter two) that the US has successfully resisted pressure for a paradigm (third order) policy change within the global narcotics regime as a result of its dominant influence on the regime. From a broad theoretical assessment, the hegemonic stability theory and Hall's (1993) orders of change provide one of the best frameworks in terms of their applicability to the

global narcotics policy arena. However, the two domestic policy theories (agenda-setting and partisan ideology) could not be usefully employed (applicability) in studying the global narcotics policy change.

\section{Summary}

This chapter has examined the implications of the US narcotics policy change on the global narcotics regime. Grounded in the broad concept of the hegemonic stability theory and orders of policy change, the chapter has demonstrated, using both documentary evidence and data gathered from my elite interviews to show that the US has shaped the evolution and maintenance of the global narcotics prohibition regime. Without doubt, the US continues to influence the regime. Based on the evidence of the influential and dominant role by the United States on the global narcotics regime, the chapter concludes the discussion by stating that a change or resistance to change in the US narcotics policy domain is more likely to reflect a similar change (s) on the global narcotics prohibition regime. 


\section{Chapter 6}

\section{Conclusion}

\section{Introduction}

This work started with two main research questions. First, the study seeks to explore whether policy change has occurred within the US narcotics policy domain, especially from 1993 to 2009 (scope of study). Second, the study investigates whether a change (radical or marginal) or resistance to change to the US narcotics policy is likely to have a similar impact on the global narcotics prohibition regime because of the dominant influence of the US on the regime.

My goal in this concluding chapter is to provide a general assessment of the theories employed to explain the US narcotics policy change over time, and the likely implications of the US narcotics policy change on the global narcotics regime. Also, the chapter summarizes the main theoretical arguments advanced in the study, and the underlying hypotheses as well as the major findings of the study. The study concludes by examining whether any prospect exists for a paradigm or a third order change in both the US and the global narcotics policy. Finally, the limitations of the study are discussed and areas for future research agenda are proposed.

\section{Summary of Theories and Findings}

As we have seen throughout this study, the problem of narcotic drugs has been on the global agenda for more than a century. For many scholars (Bewley-Taylor, 1999a; Bayer and Ghodse, 2000; Buxton, 2008; UNODC, 2010), the first concerted action to address the Chinese opium epidemic in 1909 invariably marked the starting point of the international community's effort in global narcotics control. Following the 1909 Shanghai meeting, a series of other 
international negotiations were held, which eventually led to the passage and adoption of various treaties on global narcotics control. ${ }^{128}$ The three main treaties that currently shape and guide the global narcotics regime include the 1961 Single Convention on Narcotic Drugs, the 1971 Convention on Psychotropic Substances, and the 1988 Convention against Illicit Traffic in Narcotic Drugs and Psychotropic Substances. Generally, the United Nations Office on Drugs and Crime (UNODC) serves as the main guardian of the treaties regarding narcotics control (Albrecht, 2001; UNODC, 2010).

Although many other countries were involved in the passage of these conventions, the US has been the leading country in the establishment of the global narcotics regime. As previously noted, it was the US that convened the first international meeting to address the Chinese opium problem in 1909. The United States also played a key role in instituting the structures for the global narcotics regime (Bewley-Taylor, 1999b; Bayer and Ghodse, 2000). As a matter of fact, the active involvement of the US in the evolution of the global narcotics regime was not by accident. Like other countries, the use of narcotic drugs such as marijuana, cocaine, and opium, among others, was generally not regulated in the late nineteenth century to the early years of the twentieth century (Meier, 1994). Apparently, the widespread use of these drugs led to many forms of abuse and addiction. For Meier (1994), the passage of the 1906 Act (Pure Food), the 1909 Act (Opium Act), and the Harrison Act of $1914{ }^{129}$ were the first major policy responses from the US federal government on narcotics control. With a strong support from moral entrepreneurs for the enactment of punitive narcotics control measures (Nadelmann, 1990;

\footnotetext{
${ }^{128}$ See table 1.1. The chronology of multilateral conventions on global narcotics control (1909-1988).

${ }^{129}$ See table 3.1. The chronology of milestone and phases in the US narcotics control policy.
} 
Andreas and Nadelmann, 2006), the US passed many punitive anti-drug policies from the 1930s through to the 1980s.

Consequently, the US narcotics policy preference for prohibition paradigm with strong institutional interest in law enforcement became the dominant policy approach (Fischer, 1999). The prohibition strategy was later extended to other countries by virtue of US influence on the rest of the world through the global narcotics regime (Bewley-Taylor, 1999a; Andreas and Nadelmann, 2006).

As discussed in the previous chapters, two main perspectives (prohibition and treatment) dominate the debate over narcotics control. Many advocates of the prohibition option (Marshall, 2000; McCaffrey, 2000; McCollum, 2000; Bennett, 2005; Wilson, 2005; Walters, 2005) argue that illegal drug use should generally remain prohibited because public morality will continue to win so long as narcotic drugs are prohibited. Also, the prohibition advocates believe that illicit drugs are not only becoming more readily available and cheaper, but the drug trade has reached an alarming proportion as one of the biggest and most lucrative enterprises, often accompanied by other drug-related criminal activities. For example, the rising crime rate such as murder, rape, and other drug-related forms of violence across the US-Mexico border support my case in point.

Critics of the existing prohibition policy strategy (Fazey, 2003; Fish, 2006; Husak, 2002; Levine, 2003) consider the current narcotics policy regime (domestic and international) as counterproductive, ineffective, and fragmented. It is not surprising therefore that many policy advocacy groups and ordinary citizens are pushing for a shift from the existing prohibition policy towards a public health approach (treatment and prevention) to narcotics control (Levine, 2003; Bewley-Taylor, 2003; Nadelmann, 2000). As noted, the struggle over the US narcotics policy control falls within the context of two competing poles: prohibition (law enforcement approach) 
versus treatment/harm reduction (public health approach). As similar to the tobacco control debate in terms of its economic usefulness or public health concerns (Cairney 2007), it is likely that the tug of war between those who advocate for prohibition or public health approaches to narcotics control will continue to dominate the narcotics policy discourse.

As widely shared, the century-year old prohibition strategy of narcotics control appears to be unchanging from a broader perspective. However, Capano and Howlett (2009:3) remind scholars that policies are generally dynamic and change over time. In essence, policy change is inherent and inexorable with any given policy process. Indeed, the narcotics policy domain within the US and the global arena are certainly not excluded from change. Capano and Howlett (2009) further argue that because of the fluidity of policies, it becomes important to understand the process of stability and change in a policy process. In other words, change is necessary to study in order to understand what, how, and when policies undergo radical or incremental changes (see chapter two).

In view of this theoretical perspective of policy dynamics and change, this study set out to investigate and explore the empirical question of whether policy change has occurred with the US narcotics policy over time, particularly since 1993. To undertake this investigation, the study employed three domestic policy theories (agenda-setting, partisan ideology, and paradigm changelorders of policy change) as competing explanations to examine the US narcotics policy process over time. The overall purpose is to compare and contrast these theories in order to determine the strength or the explanatory power of each theory in explaining the US narcotics policy change. In essence, the comparative assessment of these theories is vital to determine the theory that offers the best explanation for the US narcotics policy change. Also, the hegemonic stability theory was employed to explain the influence of the US as a dominant power on the 
global narcotics regime. The next section will review each theory in terms of its explanatory power and usefulness in explaining the US narcotics policy process and change.

\section{Agenda-Setting}

As many policy scholars (Sinclair, 1986; Baumgartner and Jones, 1993; Studlar, 2002; McLendon, 2003) agree, agenda-setting theory involves a process by which an issue moves from relative obscurity to become a priority issue as a result of some serious attention given to it by policy and political actors. Central to agenda-setting theory are key concepts of issue definition, redefinition, framing, venue shifting, and policy entrepreneurship. The question of how issues change and how the public often responds to an issue are also critical to agenda-setting theory (Baumgartner and Jones, 1993). As previously noted, Studlar (2002:170) offers an insightful perspective on agenda-setting. According to him, regardless of the conceptual varieties of agenda-setting theory, the theory is essentially dependent on few basic elements such as how issues are defined and redefined, and who in most cases constitute the key actors in setting an agenda.

For the purpose of this study, I employed Baumgartner and Jones' (1993) version of agenda-setting theory-punctuated equilibrium-with specific focus on key concepts such as issue definition/redefinition, venue shifting, and policy entrepreneurship in explaining US narcotics policy change over time. In chapter three, for example, I examined the trends of US narcotics policy change within the context of three main historical phases. The findings from the three phases examined show the utility of agenda-setting in explaining the US narcotics policymaking process and change since 1906. For example, the drug issue was not only framed and defined in different ways, but key actors such as Congress, the media, the public, bureaucratic agencies, 
policy entrepreneurs, and other interest groups played a critical role in shaping the policy process.

Although the drug issue received a considerable attention in all the three phases from the key players mentioned above, an important finding of this study reveals that the narcotics policy issue in the second phase (Nixon era) and the third phase (Reagan and Bush eras) received a very high level of presidential attention to the issue (see chapter three) as compared to other phases. Consistent with the work on agenda-setting and US drug policy by Baumgartner and Jones (1993:152-164), this study also finds that the narcotics issue has waxed and waned on both the systemic and institutional agendas, especially during the scope (1993-2009) of the research. Similar to chapter three, I applied Baumgartner and Jones' (1993) version of agenda-setting theory to explain the dynamics of the US narcotics policy change in chapter four. Again, a similar display of agenda-setting theory was clearly evident in explaining the US narcotics policy change since 1993. Using data gathered from the elite interviews I conducted and from the analysis of the documentary data, this study ${ }^{130}$ finds that the concepts of issue definition, venue shifting, and policy entrepreneurship provide us with a better understanding of the US narcotics process.

For example, the study reveals that the 1990s, in particular, witnessed an increasing struggle over a redefining of the drug issue towards a more public health or demand-reduction (treatment and prevention) approach to narcotics control. The medical marijuana movement is particularly important here. The data (interview and secondary documentary analysis) reveal that key anti-prohibition advocacy groups were very instrumental in shaping the redefinition of the marijuana issue, especially at the state government level (see chapter four). The successful

\footnotetext{
${ }^{130}$ As previously mentioned, I categorized the scope (1993-2009) of my study as phase four of the US narcotics policy process. The Clinton and Bush eras are the two political administrations examined in this phase.
} 
redefining of the marijuana issue towards a more public health approach galvanized many advocacy groups and other policy entrepreneurs in shifting the venue of the marijuana issue to the state level for policy change. Indeed, the successes of the ballot and legislative initiatives in changing the marijuana laws at the state level (Ferraiolo, 2007) could largely be explained from the two key concepts -issue definition and venue shifting-of agenda-setting theory.

Clearly, the broad framework of agenda-setting with the concepts of issue definition, venue shifting, and policy entrepreneurship and the role of reform-minded advocacy groups offer very useful theoretical tools in explaining the pattern of the US policy change, particularly on the use of marijuana for medical purposes (see table 4.1). Generally, these conceptual versions of agenda-setting contribute to our understanding of the US narcotics policy change since the 1990s. In addition, these findings appear to be consistent with the two hypotheses set under agenda-setting theory. First, that the scope of the US narcotics policy has widened and is undergoing incremental policy change, and second, that the rise of drug liberalization advocacy groups has led to changes in the US drug policy, particularly at the state level since the 1990s (see chapter two).

\section{Partisan Ideology}

We have seen in the previous chapters that some scholarly works (Entman, 1983; Schmidt, 1996; Imbeau et al., 2001; Studlar, 2002) have found a theoretical utility of partisan ideology in explaining public policy outcomes. Similar to other theories employed, this study investigated whether partisan ideology played any dominant role in the US narcotics policy process. The discussion in the previous chapters reveals that the history of the US narcotics policy has generally been shaped by partisan ideological orientations between Democrats and 
Republicans, which has helped sustained the drug issue on the agenda of major presidential elections since the late 1970s (Bertram et al., 1996).

Clearly, partisan ideology has been evidently shown in the study. Not only has partisanship shaped the US narcotics policy process to some extent, but the concept has also enriched our understanding of the changing patterns of US narcotics policy process through the partisan ideology of the Democratic and the Republican parties. For example, a key finding of this study, which is consistent with the existing literature, reveals that Republican Presidents, to a large extent, generally favor a more restrictive narcotics policy with a strong punitive and law enforcement approach than do Democratic Presidents. For example, after President Nixon declared the so-called war on drugs, the war subsequently escalated (punitive laws on narcotics) under Republican Presidents of Nixon, Reagan, and George H.W. Bush, than under Democratic Presidents. In a similar discussion, Marcy (2010) contends that not only was the domestic law enforcement on narcotics control drastically increased during the administrations of Reagan and George H.W Bush, but the role of the US military in counternarcotics activities in the Andean countries, for example, also saw a dramatic increase during the two administrations (see chapter three). ${ }^{131}$

On the contrary, the ideological approach to narcotics policy by Democrats has generally been towards a more permissive policy approach with emphasis on the public health approach (treatment and educational programs) to narcotics control. The evidence of this approach was clearly shown by the narcotic policies of the Carter and the Clinton administrations (see chapters three and four). In view of the analysis on partisanship and policy outcomes, it is apparent that

\footnotetext{
${ }^{131}$ See phases of US narcotics policy development.
} 
partisan ideology shapes the US narcotics policy process. It must, however, be noted that the concept does not appear to play a dominant role in shaping the US narcotics policy process, let alone provide a persuasive explanation for the policy change process, unlike the other two domestic policy theories (agenda-setting and orders of policy change). Nonetheless, the theory is still useful in our understanding of the US narcotics policy process.

\section{Policy Paradigm Theory (Orders of Change)}

Hall's (1993) theory of policy paradigm approach or orders of change (first order, second order, and third order), particularly the first and second order change (s) in policy not only constitute the main theory of this study, but also the theory that offers a superior explanation, in my estimation, for the changing nature of the US narcotics policy, especially in the 1990s. As previously discussed, Hall (1993) defines policy change as involving alterations or adjustments to a given policy from one level to another. The basic assumption of the theory rests on the logic that all policies are composed of three main parts (policy goals, policy instruments, and settings of a policy instrument) and what actually changes in a given policy is not necessarily the whole policy, but each specific component of the policy. In essence, Hall (1993) argues that one can better understand change (incremental or radical) in a given policy domain when the three key components are examined separately within their respective context. Hall (1993) describes each specific component within the typology of orders of change (see figure 4.2).

In chapter three, for example, the evolutionary process of the US narcotics policy was examined through three different phases. Applying Hall's (1993) concept to each phase clearly reveals that the theory provides a persuasive explanation for the nature of policy changes (first and second order) that have occurred throughout the evolutionary process of the US narcotics 
policy. In fact, a similar pattern of first and second order change in policy was evident in chapter four as well. Another important observation of this study, which also appears to be consistent with the existing narcotics literature is that the prohibition-based narcotics policy in the US and the rest of the world seems unchanging by a third order after more than a century of its adoption. It is based on this appearance of the unchanging nature of US narcotics policy that this study investigated whether policy change (s) has occurred within the US narcotics policy domain.

As previously noted, I employed three domestic policy theories (agenda-setting, partisan ideology, and orders of change) as competing explanations to examine the US narcotics policy process, and therefore change over time. Although these theories offer some useful explanations for US narcotics policy change, this study contends that the agenda-setting theory and partisan ideology were unable to better explain the type and nature of these changes.

For example, Baumgartner and Jones' (1993) work on drug abuse was examined from a broader perspective. Their study explored the changing trend of congressional (formal) and media (systemic) attention to narcotics policy since the early 1900s. While this study believes that the approach by Baumgartner and Jones (1993) is useful in providing a broad perspective of the changing nature and the allocation of attention to US narcotics policy, it appears that their approach (punctuated equilibrium) could not fully explain the nature and types of policy changes that have occurred or occurring.

This is where Hall's (1993) theory (orders of change), especially first order and second order changes in policy become compelling in explaining the US narcotics policy. Although Hall's (1993) concept of a third order change (radical) in policy, which resembles Baumgartner and Jones' (1993) model of punctuated equilibrium, offers no useful explanation for the changes because of the non-existence of a sudden and radical change in the existing narcotics policy, it is 
evidently clear that Hall's conceptualization (first and second order change in policy) offers the superior and persuasive explanation for US narcotics policy change since 1993.

Essentially, the assessment of the three domestic policy theories has clearly shown the differences in the explanatory power of each theory. In other words, while the concept of orders of change has performed very well in explaining the narcotics policy process and change (type and nature), others (agenda-setting and partisanship) have partially explained the narcotics phenomenon. Nonetheless, each theory performed well in explaining their various dimensions of policy. For example, agenda-setting explained the dynamics of policy agendas, while partisan theory explained campaign rhetoric and policy proposals very well. Also, orders of change performed well in explaining policy adoption and implementation. Without doubt, all the three domestic theories examined in this study have broadly enriched and contributed to the overall understanding of the US narcotics policy process over time, particularly from 1993 to 2009 (scope of study).

\section{Hegemonic Stability Theory/Global Narcotics Regime}

As noted in the introductory chapter, two important research questions guided the exploration of this study. First, the study examined whether policy change has occurred with the US narcotics policy or not. Second, the study explored the likely implications of US policy change (radical or marginal) or resistance to change on the global narcotics prohibition regime.

As previously argued, the concept of regime theory (Young, 1983; Keohane and Nye, 1977: Keohane, 1984, 2005) with focus on the hegemonic stability theory (Ikenberry, 1989; Kindleberger, 1981) was employed to understand the dynamics of US policy change on the global narcotics regime. For the purpose of this study, the concept of a hegemonic power was 
applied in a very broad sense of the term and not from the original sense (see chapter two). In essence, I defined the hegemonic influence of the US in this case as a dominant player on the global narcotics regime since the early 1900s (Bewley-Taylor, 1999a).

By integrating Hall's (1993) orders of change with the hegemonic stability theory, it is clear from the analysis that first order changes in policy have occurred within the global narcotics regime. For instance, there has been a shift in budget allocations, tone, and policy instruments of the UNODC. Hall (1993) describes these regular incremental budget changes as first order changes in policy. It is also apparent that there has been a gradual shift in tone and policy toward a public health approach (emphasis on treatment) to global narcotics control by the UNODC (see chapter five). Hall (1993) conceptualizes changes in the policy instruments as second order changes in policy. These findings suggest that the global narcotics regime, like the US policy arena, has undergone both first and second order changes in policy. However, the study does not find any evidence of a third order change (radical or paradigm) within the global narcotics regime.

Based on the evidence discussed, this study argues that the US has successfully employed its influential (hegemonic) status to shape the global narcotics regime towards its preferred prohibition approach. Indeed, the hegemonic stability theory offers a useful framework in explaining the implications of policy changes (first and second order) and resistance to change (third order) in US narcotics policy on the global narcotics regime. In other words, the changes (first and second order) in the global narcotics regime have largely been shaped by similar changes that have occurred and occurring within the US narcotics policy domain. 


\section{The Global Narcotics Policy Regime: Any Prospect for Paradigm Change?}

Given the fact that the US narcotics policy is intertwined with the global narcotics regime, and the dominant influence of the US in the evolution and maintenance of the regime, this study investigated the implications of US policy change on the global narcotics regime as previously noted. Employing the hegemonic stability theory in analyzing the data ${ }^{132}$ in chapter five, this study noticed that (key finding) the dominant influence of the US has largely driven the directions of the global narcotics regime for decades. Consistent with other works (Nadelmann, 1990; Bewley-Taylor, 1999a; Andreas and Nadelmann, 2006), this study also demonstrates the utility of the hegemonic stability theory in explaining the influence of the US on the global narcotics regime. It is also evident that the US has successfully resisted a third order or paradigm change from occurring within the global narcotics prohibition regime (see chapter five). The important question is: are there any prospects for a third order change to the existing global narcotics regime?

Grounded in the earlier argument on regime theory (hegemonic stability), this study looks at the possibility of a third order or paradigm change occurring from two perspectives. First, that a third order change ${ }^{133}$ is more likely to occur once a similar change (third order) occurs in the US. This assumption, as previously discussed in chapter five, is based on the dominant influence of the US on the global narcotics regime. As Bewley-Taylor (1999a) shares with Bruun et al. (1975), the strength of the United States within the overall UN system in terms of its major influence (financial and diplomatic) is strong enough to initiate such a change. Indeed, the famous quote by Abba Eban, the former Israeli Foreign Minister and veteran UN diplomat that,

\footnotetext{
${ }^{132}$ The data in this context include primary data gathered from the elite interview responses and the existing secondary data (scholarly works in the field).

${ }^{133}$ An example will be a change from the existing prohibition policy approach to a liberal policy approach.
} 
"nothing can happen without the Americans.... and .... Everything can happen with them,"134 might be relevant to the global narcotics regime as well. Perhaps, the question of how the US itself can experience a third order change in the first place is an essential aspect of the broader debate that needs to be equally examined.

Although the debate on the US narcotics policy reform is not new, the drug discourse has intensified in recent years with some policy actions toward change happening at the state level. The medical marijuana ballot initiative, as discussed in chapter four, is a case in point. Regardless of the fact that marijuana use is still prohibited under the federal law, the number of states that are enacting laws for the medical use of marijuana (Ferraiolo, 2007) is growing in number. It is likely that windows of opportunity (Kingdon, 1984) might be opened for policy learning and emulation by other states. As more and more states adopt the policy reforms on marijuana, there is the possibility that policy change will occur at the federal level as well. In addition, the relentless pressure from many anti-prohibition advocacy groups (see chapter 3 and 4), and the recent legislative initiative by some members of Congress ${ }^{135}$ for US drug policy reforms is another likely source of future policy change to the US narcotics policy.

Similarly, the increasing external pressures on the US and the UN from global advocacy groups for narcotics policy reform is another possibility that might trigger some degree of narcotics policy change in the near future. In a recent report issued by the Global Commission on Drug Policy (GCDP), for example, nineteen Commissioners ${ }^{136}$ of the GCDP, mostly made up of former presidents, prime ministers, and eminent public figures such as Kofi Annan, the former

\footnotetext{
${ }^{134}$ Cited in Bewley-Taylor, 1999a:213.

${ }^{135}$ Congressman Barney Frank and Congressman Ron Paul recently introduced a marijuana bill in the US Congress. According to them, the goal of the bill, HR 2306, is not to legalize marijuana but to remove it from the list of federally controlled substances so that states can devise their own means to regulate the drug. Source: Los Angeles Times, June 23, 2011. http://latimesblogs.latimes.com/washington/2011/06/marijuana-bill-officially-introduced-tocongress-by-ron-paul-barney-frank.html. Retrieved on 07/20/11.

${ }^{136}$ See appendix six for the names and positions (nineteen Commissioners of the GCDP).
} 
UN Secretary General, noted that the so-called global war on drugs with emphasis on prohibition has failed, with vestiges of devastating consequences for individuals and societies across the world. The Commissioners made a strong recommendation for the adoption of an alternative policy strategy with emphasis on public health approach to global narcotics control.

Apart from the emerging pressure from many international advocacy groups for narcotics policy reforms, there is also a growing criticism from certain countries about the US-backed prohibition approach. The Dutch liberal drug policy experiment, which began in the 1970s with the aim of making soft narcotic drugs (cannabis) available to users, is a good case in point (Bullington, 2004; Bewley-Taylor, 2006). Besides the Dutch experiment, other countries such as Switzerland, Australia, Canada, and other European countries are loosening their marijuana laws (see chapter five). It is possible that the anti-prohibition actions from these countries will fragment the global narcotics regime and create the venue for future policy changes.

Having examined some of the likely cases that might trigger a major change (third order) in US narcotics policy and on the global scale in the near future is not to suggest that a third order change in policy is imminent. Such a radical policy change could not be imminent in the next few years. There are still huge obstacles in the form of strong core policy ideas and institutional constraints, based on the enshrined prohibition approach that must first be eroded. In fact, this study shares the views of Bullington (2004) and Bewley-Taylor (2006) that most regions of the world, especially in Africa, have so far not shown any serious indication to shift their existing prohibition policies toward the direction of some liberal approach to narcotics control.

Perhaps, as Bullington (2004:715) rightly noted, the international narcotics regime with the prohibition and criminalization policy strategy might simply collapse at some point in time. 
For Bullington (2004), just as the former Soviet Union collapsed due to its inherent and incompatible policy contradictions and policy failures, it is likely that the current global narcotics regime might also collapse at some point. A likely scenario for change could also occur from two main sources (endogenous and exogenous). Based on the assumption of this study, I will consider the endogenous source as coming from the US. In a situation where the American public continues to favor a more public health approach to narcotics control, a possibility could arise for a third order change in policy at the federal level. The recent Gallup polls where for the first time more than 50 percent of the American public favors the legalization of marijuana use (see figure 4.2) is a strong indication of the emerging trend of the new public understanding of an old issue. It is likely that this emerging support could be extended to other hard drugs such as cocaine and heroin. Once a policy change occurs in the US, as this study assumes, a similar change might also occur within the global system due to the US influence. Regarding the exogenous sources of change, one could argue that once more and more countries adopt a more liberal narcotics control, it is equally probable that the global regime might fragment to the point where a new international narcotics convention will emerge towards a more liberal approach (public health) to global narcotics control.

\section{Concluding Discussion}

The study started with the goal of investigating whether policy change has occurred with the US narcotics policy process or not. As part of the larger goal, the study also explored the implications of US narcotics policy change on the global narcotics regime. The idea to examine the dynamics of policy change is based on the widely held assumption that the existing prohibition-based strategy of narcotics control appears not only as unchanging from a broader 
perspective, but that the policy has been viewed as generally ineffective, especially on the war on drugs (Sharp, 1994; Levine, 2003; Bewley-Taylor, 2003; Nadelmann, 2005: Fish, 2006).

To investigate these research questions (see chapter two), the study draws on three key theories of the policy process: agenda-setting theory, partisan ideology, and orders of policy change to examine the US narcotics policy change. To equally explain the likely implications of US policy change on the global narcotics regime, the study employed the concept of regime theory with specific reference to the hegemonic stability theory as the theoretical framework for the analysis.

Overall, the theoretical perspectives employed in the study have generally been useful in providing very good explanations for the changing trends in the US narcotics policy process since 1993. As earlier mentioned, key policy theories such as agenda-setting, with conceptual versions of issue definition, venue shifting, and policy entrepreneurship performed better than partisan ideology in explaining the US narcotics policy change (see chapters three and four). While agenda-setting and partisan ideology provide very useful explanations as discussed, this study argues that Hall's (1993) theoretical concept (orders of change), particularly first and second, provides a superior explanation in terms of the nature, scope, and tempo of the US narcotics policy change. Another important finding of the study shows that the US narcotics policy change has been partly driven by the active involvement of many advocacy groups and policy entrepreneurs in the policy change process. The medical marijuana ballot initiative is a very good example (see chapter 4).

Also, the findings of the occurrence of first and second order changes in policy, with the dominance of a second order change in the US narcotics policy domain, is not only unique, but offer a modest contribution to the policy literature. This is because of the fact that this study is 
the first to employ Hall's (1993) conceptual framework to study the dynamics of the US narcotics policy process. From the perspective of US narcotics policy process and change, this study finally concludes (based on the evidence examined in the previous chapters) that the US narcotics policy has largely undergone Hall's conceptual second order change (type) in policy with the tempo (nature) of the change generally slow. This finding tends to be consistent with the set hypothesis (see chapter two) that the US narcotics policy has experienced a second order change in policy since 1993 and the tempo of the policy change has been slow. In effect, Hall's theoretical concept of orders of policy change provides a persuasive explanation for the changing type and nature of the US narcotics policy from 1993 to 2009.

Also, the main research questions of the study have been addressed. For example, the question of whether the US narcotics policy has undergone policy changes has been addressed. Importantly, the US narcotics policy is not only undergoing change, but the types of these changes have generally been incremental in nature. Another important finding of the study reveals that the key policy actors involved in shaping the US narcotics policymaking process are anti-prohibition advocacy groups, interest groups, executive (president), congress, media, and policy entrepreneurs. With respect to the global impact of the US policy change, the application of the hegemonic stability theory provides a useful tool in explaining the influence of the US in the evolution and maintenance of the global narcotics regime. In essence, a global perspective has been gained on the likely impact of a major change (third order) in the US on the global narcotics regime. In fact, this finding is consistent with similar scholarly works (Nadelmann, 1990; Bewley-Taylor, 1999; Andreas and Nadelmann, 2006; Marcy, 2010) in the field, which show a strong US influence and dominance on the international stage, particularly on the global narcotics prohibition regime. 
Another important contribution of this study is by successfully blending the two major fields of public policy and international relations. These fields are some of the growing areas of research in the political science literature in recent years. Recent works such as Mamudu (2005), Appah (2007), and Hinojosa (2007) have used this method of approach in their research.

Finally, the question of whether the US and the global narcotics regime under the UN should continue to formulate and implement narcotic policies based on prohibition approach or to decriminalize and legalize drug use is certainly beyond the scope and judgment of this study. As noted, the purpose of this study is to examine the existing illegal drug problem from empirical and theoretical perspectives in terms of whether the existing policy has undergone policy change (s) and the implications for the global narcotics regime. Based on the available evidence through the data that was generated from the elite interviews and the analysis of the documentary literature, it is apparent that the main purpose of this study has been accomplished.

\section{Limitations of Study}

Similar to other studies of this nature, this study also faced some problems with sampling of the interviewees. My objective was to interview many elites from various US government institutions and UN agencies involved in the formulation and the implementation of the existing narcotics policy, with similar number of elites from advocacy groups opposed to the existing prohibition strategy. While a considerable number of elites from the advocacy groups responded to the questionnaires in a timely manner, it was extremely difficult to get the needed responses from officials (narcotics policy makers) of the US government and the UN agency involved in global narcotics control. 
Nonetheless, I found very relevant and useful information on their narcotics policy preferences (policy goals and instruments) from their policy documents and official websites, which has balanced the argument advanced in the study. Also, the reliance on one case for this study might present some difficulty in making an empirical generalization across other policy areas. However, this methodology (single case analysis) provides scholars, including the author of this study, with an in-depth understanding of a particular policy domain such as the US narcotics policy field.

\section{Future Research Agenda}

Although the theories that this study employed to examine the US narcotics policy process provide very useful theoretical tools in our understanding of the broad process of narcotics policy change, this study argues that Hall's (1993) paradigm theory (orders of change) provides the most persuasive explanation for the US narcotics policy change. The theory's explanatory power offers a better understanding of the trends, nature, type, mode, and tempo of the US narcotics policy change over time. The reviewed policy literature, however, indicates a limited use of the theory (order of change) by policy scholars in studying the process of change in other policy areas. Apart from a few scholars such as Breton et al. (2008), Capano and

Howlett (2009), Studlar (2009), and Skogstad (2009) who have employed the theory (order of change) to study other policy sectors, the theory could be described as generally under-utilized in the field of policy science.

Future research agenda could explore the use of it in investigating policy change in other policy areas. Also, a careful observation regarding the application of Hall's (1993) theory reveals that it can be useful to study policy change at the global level in policy areas such as 
environment and energy. It is also possible to apply Hall's (1993) theoretical concept to the study of foreign policy change. In addition, Hall's (1993) theory can also be employed to study policy change in developing countries like Ghana. Another important area to mention is the subsystems theory and narcotics policy change. Although this study draws on the conceptual idea of subsystems theory in explaining some selected cases regarding the US narcotics policy process (see chapter two and three), the concept was not part of my main theories used for this study. However, this study believes that the subsystems theory can be applied to study the US narcotics policy process in a future research. Finally, a future research project can integrate other theories of the policy process with Hall's (1993) orders of policy change to test the validity and the superiority of the theory in connection with the findings of this study. 


\section{Appendix 1}

Estimated Arrests for Drug Abuse Violations by Age Group, 1970-2007

\begin{tabular}{|l|l|l|}
\hline Year & Adult & Juvenile \\
\hline $\mathbf{1 9 7 0}$ & 322,300 & 93,300 \\
\hline $\mathbf{1 9 7 1}$ & 383,900 & 108,100 \\
\hline $\mathbf{1 9 7 2}$ & 407,300 & 120,100 \\
\hline $\mathbf{1 9 7 3}$ & 463,600 & 165,300 \\
\hline $\mathbf{1 9 7 4}$ & 474,900 & 167,200 \\
\hline $\mathbf{1 9 7 5}$ & 456,000 & 145,400 \\
\hline $\mathbf{1 9 7 6}$ & 464,100 & 145,400 \\
\hline $\mathbf{1 9 7 7}$ & 493,300 & 149,400 \\
\hline $\mathbf{1 9 7 8}$ & 480,000 & 148,700 \\
\hline $\mathbf{1 9 7 9}$ & 435,600 & 123,000 \\
\hline $\mathbf{1 9 8 0}$ & 471,200 & 109,700 \\
\hline $\mathbf{1 9 8 1}$ & 468,100 & 91,800 \\
\hline $\mathbf{1 9 8 2}$ & 584,900 & 91,200 \\
\hline $\mathbf{1 9 8 3}$ & 583,500 & 77,900 \\
\hline $\mathbf{1 9 8 4}$ & 623,700 & 84,700 \\
\hline $\mathbf{1 9 8 5}$ & 718,600 & 92,800 \\
\hline $\mathbf{1 9 8 6}$ & 742,700 & 81,400 \\
\hline $\mathbf{1 9 8 7}$ & 849,500 & 87,900 \\
\hline $\mathbf{1 9 8 8}$ & $1,050,600$ & 104,600 \\
\hline $\mathbf{1 9 8 9}$ & $1,247,800$ & 113,900 \\
\hline $\mathbf{1 9 9 0}$ & $1,008,300$ & 81,200 \\
\hline $\mathbf{1 9 9 1}$ & 931,900 & 78,100 \\
\hline $\mathbf{1 9 9 2}$ & 980,700 & 85,700 \\
\hline $\mathbf{1 9 9 3}$ & $1,017,800$ & 108,500 \\
\hline $\mathbf{1 9 9 4}$ & $1,192,800$ & 158,600 \\
\hline $\mathbf{1 9 9 5}$ & $1,285,700$ & 190,400 \\
\hline $\mathbf{1 9 9 6}$ & $1,295,100$ & 211,100 \\
\hline $\mathbf{1 9 9 7}$ & $1,370,400$ & 213,200 \\
\hline $\mathbf{1 9 9 8}$ & $1,360,600$ & 198,500 \\
\hline $\mathbf{1 9 9 9}$ & $1,365,100$ & 192,000 \\
\hline $\mathbf{2 0 0 0}$ & $1,375,600$ & 203,900 \\
\hline $\mathbf{2 0 0 1}$ & $1,384,400$ & 202,500 \\
\hline $\mathbf{2 0 0 2}$ & $1,352,600$ & 186,200 \\
\hline $\mathbf{2 0 0 3}$ & $1,476,800$ & 201,400 \\
\hline $\mathbf{2 0 0 4}$ & $1,551,500$ & 194,200 \\
\hline $\mathbf{2 0 0 5}$ & $1,654,600$ & 191,800 \\
\hline $\mathbf{2 0 0 6}$ & $1,693,100$ & 196,700 \\
\hline $\mathbf{2 0 0 7}$ & $1,645,500$ & 195,700 \\
\hline & & \\
\hline
\end{tabular}

Source: Crime in the United States, annual, Uniform Crime Reports. Also reported in the Bureau of Justice Statistics. http://bjs.ojp.usdoj.gov/content/glance/tables/drugtab.cfm. Retrieved on 06/15/11. 


\section{Appendix 2}

\section{National Drug Control Budget by Function, FY 1992-2002 (Budget Authority in Millions)}

\begin{tabular}{|c|c|c|c|c|c|c|c|c|c|c|c|}
\hline $\begin{array}{l}\text { FUNCTIONAL } \\
\text { AREAS: }\end{array}$ & $\begin{array}{l}\text { FY } 1992 \\
\text { Actual }\end{array}$ & $\begin{array}{l}\text { FY } 1993 \\
\text { Actual }\end{array}$ & $\begin{array}{l}\text { FY } 1994 \\
\text { Actual }\end{array}$ & \begin{tabular}{|l|} 
FY 1995 \\
Actual
\end{tabular} & $\begin{array}{l}\text { FY } 1996 \\
\text { Actual }\end{array}$ & $\begin{array}{l}\text { FY } 1997 \\
\text { Actual }\end{array}$ & $\begin{array}{l}\text { FY } 1998 \\
\text { Actual }\end{array}$ & $\begin{array}{l}\text { FY } 1999 \\
\text { Actual }\end{array}$ & \begin{tabular}{|l|} 
FY 2000 \\
Final BA
\end{tabular} & \begin{tabular}{|l} 
FY 2001 \\
Enacted
\end{tabular} & $\begin{array}{l}\text { FY 2002 } \\
\text { Request }\end{array}$ \\
\hline \multicolumn{12}{|c|}{ Demand Reduction } \\
\hline \begin{tabular}{|l} 
Drug Abuse \\
Treatment
\end{tabular} & $1,859.7$ & $2,016.7$ & $2,176.7$ & $2,425.5$ & $2,096.2$ & $2,321.3$ & $2,166.5$ & $2,363.9$ & $2,497.9$ & $2,685.7$ & $2,850.1$ \\
\hline $\begin{array}{l}\text { Drug Abuse } \\
\text { Prevention }\end{array}$ & $1,538.7$ & $1,556.4$ & $1,597.4$ & $1,555.5$ & $1,394.2$ & $1,642.1$ & $1,810.7$ & $1,952.2$ & $2,018.4$ & $2,159.8$ & $2,037.5$ \\
\hline $\begin{array}{l}\text { Prevention } \\
\text { Research }\end{array}$ & 157.5 & 164.3 & 174.8 & 179.6 & 212.2 & 230.7 & 249.5 & 285.6 & 320.3 & 355.9 & 403.9 \\
\hline $\begin{array}{l}\text { Treatment } \\
\text { Research }\end{array}$ & 194.4 & 242.0 & 253.6 & 261.2 & 280.8 & 311.7 & 327.9 & 381.9 & 417.3 & 482.5 & 563.0 \\
\hline $\begin{array}{l}\text { Total Demand } \\
\text { Reduction }\end{array}$ & $3,750.3$ & $3,979.4$ & $4,202.5$ & 4,421.9 & $3,983.4$ & $4,505.8$ & $4,554.6$ & $4,983.5$ & $5,253.8$ & $5,683.9$ & $5,854.5$ \\
\hline Percentage & $32 \%$ & $33 \%$ & $35 \%$ & $34 \%$ & $31 \%$ & $31 \%$ & $30 \%$ & $29 \%$ & $29 \%$ & $31 \%$ & $31 \%$ \\
\hline \multicolumn{12}{|c|}{ Domestic Law Enforcement } \\
\hline \begin{tabular}{|l|} 
Criminal \\
Justice System
\end{tabular} & $4,943.0$ & $5,692.4$ & $5,903.2$ & $6,756.9$ & $7,164.9$ & $7,446.4$ & $8,193.1$ & $8,557.6$ & $8,429.0$ & $9,357.7$ & $9,475.6$ \\
\hline $\begin{array}{l}\text { Other } \\
\text { Research }\end{array}$ & 152.6 & 91.9 & 91.9 & 101.4 & 114.3 & 111.8 & 106.4 & 113.2 & 89.6 & 106.1 & 112.0 \\
\hline Intelligence & 98.6 & 138.1 & 123.9 & 125.0 & 114.5 & 142.3 & 190.6 & 277.3 & 309.1 & 345.2 & 358.1 \\
\hline $\begin{array}{l}\text { Total Domestic } \\
\text { Law Enf. }\end{array}$ & $5,194.2$ & $5,922.3$ & $6,119.0$ & $6,983.3$ & 7,393.7 & $7,700.6$ & $8,490.1$ & $8,948.1$ & $8,827.8$ & $9,809.0$ & 9,945.7 \\
\hline Percentage & $45 \%$ & $50 \%$ & $51 \%$ & $54 \%$ & $57 \%$ & $54 \%$ & $56 \%$ & $52 \%$ & $49 \%$ & $54 \%$ & $52 \%$ \\
\hline International & 660.4 & 523.4 & 329.4 & 295.8 & 289.8 & 424.1 & 496.9 & 774.7 & $1,892.9$ & 609.7 & $1,237.0$ \\
\hline Percentage & $6 \%$ & $4 \%$ & $3 \%$ & $2 \%$ & $2 \%$ & $3 \%$ & $3 \%$ & $5 \%$ & $11 \%$ & $3 \%$ & $6 \%$ \\
\hline Interdiction & $1,960.2$ & $1,511.1$ & $1,311.6$ & $1,280.1$ & $1,321.0$ & $1,723.3$ & $1,636.9$ & $2,417.9$ & $1,965.9$ & $1,950.4$ & $2,141.5$ \\
\hline Percentage & $17 \%$ & $13 \%$ & $11 \%$ & $10 \%$ & $10 \%$ & $12 \%$ & $11 \%$ & $14 \%$ & $11 \%$ & $11 \%$ & $11 \%$ \\
\hline TOTALS & $11,565.2$ & $11,936.2$ & $11,962.4$ & $\mid 12,981.1$ & $12,988.0$ & $14,353.7$ & $15,178.6$ & $17,124.2$ & $17,940.3$ & $18,053.1$ & $19,178.8$ \\
\hline
\end{tabular}

Source: ONDCP, 2001. (Budget Summary for FY 2002, with Historical Funding by Function from FY 1992- FY 2002). FY= Financial Year. 


\section{Appendix 3a}

Federal Drug Control Spending by Function, FY 2001- FY 2003 (Budget Authority in Millions)

\begin{tabular}{|c|c|c|c|c|}
\hline & $\begin{array}{l}\text { FY } 2001 \\
\text { Final BA }(\$)\end{array}$ & $\begin{array}{l}\text { FY } 2002 \\
\text { Enacted }(\$)\end{array}$ & $\begin{array}{l}\text { FY } 2003 \\
\text { Requested (\$) }\end{array}$ & $\begin{array}{l}\text { FY 02-FY 03 Change } \\
\text { Dollars } \quad \text { Percent }\end{array}$ \\
\hline \multicolumn{5}{|l|}{ Function } \\
\hline $\begin{array}{l}\text { Treatment (w/Research) } \\
\text { Percent }\end{array}$ & $\begin{array}{l}3,335.0 \\
18.4 \%\end{array}$ & $\begin{array}{l}3,587.5 \\
19.1 \%\end{array}$ & $\begin{array}{l}3,811.7 \\
19.9 \%\end{array}$ & 224.2 \\
\hline $\begin{array}{l}\text { Prevention (w/Research) } \\
\text { Percent }\end{array}$ & $\begin{array}{l}2,578.7 \\
14.3 \%\end{array}$ & $\begin{array}{l}2,548.6 \\
13.5 \%\end{array}$ & $\begin{array}{l}2,473.4 \\
12.9 \%\end{array}$ & $(75.2)$ \\
\hline $\begin{array}{l}\text { Dom. Law Enforcement } \\
\text { Percent }\end{array}$ & $\begin{array}{l}9,463.8 \\
52.3 \%\end{array}$ & $\begin{array}{l}9,513.1 \\
50.5 \%\end{array}$ & $\begin{array}{l}9,451.1 \\
49.3 \%\end{array}$ & $(61.2)$ \\
\hline $\begin{array}{l}\text { Interdiction } \\
\text { Percent }\end{array}$ & $\begin{array}{l}2,054.9 \\
11.4 \%\end{array}$ & $\begin{array}{l}2,074.8 \\
11.0 \%\end{array}$ & $\begin{array}{l}2,289.7 \\
11.9 \%\end{array}$ & $10.4 \%$ \\
\hline $\begin{array}{l}\text { International } \\
\text { Percent }\end{array}$ & $\begin{array}{l}663.2 \\
3.7 \%\end{array}$ & $\begin{array}{l}1,098.8 \\
5.8 \%\end{array}$ & $\begin{array}{l}1,153.0 \\
6.0 \%\end{array}$ & $4.9 \%$ \\
\hline Total & $18,095.7$ & $18,822.8$ & $19,179.7$ & 356.9 \\
\hline \multicolumn{5}{|l|}{ Supply/Demand Split } \\
\hline $\begin{array}{l}\text { Supply } \\
\text { Percent }\end{array}$ & $\begin{array}{l}12,182.0 \\
67.3 \%\end{array}$ & $\begin{array}{l}12,686.7 \\
67.4 \%\end{array}$ & $\begin{array}{l}12,894.6 \\
67.2 \%\end{array}$ & 207.9 \\
\hline $\begin{array}{l}\text { Demand } \\
\text { Percent }\end{array}$ & $\begin{array}{l}5,913.7 \\
32.7 \% \\
\end{array}$ & $\begin{array}{l}6,136.1 \\
32.6 \% \\
\end{array}$ & $\begin{array}{l}6,285.1 \\
32.8 \% \\
\end{array}$ & 149.0 \\
\hline Total & $18,095.7$ & $18,822.8$ & $19,179.7$ & 356.9 \\
\hline
\end{tabular}

Source: ONDCP, 2002 (For FY 2003 Budget Summary p. 6). Detail may not add to totals due to rounding. $\mathrm{FY}=$ Financial Year. 


\section{Appendix 3b}

\section{Federal Drug Control Spending by Function, FY 2004- FY 2006 (Budget Authority in Millions)}

\begin{tabular}{|l|l|l|l|lc|}
\hline & FY 2004 & FY 2005 & FY 2006 & \multicolumn{2}{|l|}{ FY 05-FY 06 Change } \\
& Final BA (\$) & Enacted (\$) & Requested (\$) & Dollars & Percent \\
\hline Function & & & & & \\
\hline $\begin{array}{l}\text { Treatment (w/Research) } \\
\text { Percent }\end{array}$ & $3,028.3$ & $3,109.7$ & $3,251.1$ & 141.4 & $4.5 \%$ \\
\hline $\begin{array}{l}\text { Prevention (w/Research) } \\
\text { Percent }\end{array}$ & $1,962.8$ & $1,969.5$ & $1,565.2$ & $(404.4)$ & $(20.5 \%)$ \\
\hline $\begin{array}{l}\text { Dom. Law Enforcement } \\
\text { Percentage }\end{array}$ & $16.5 \%$ & $16.2 \%$ & $12.6 \%$ & & $2.1 \%$ \\
\hline Interdiction & $3,182.9$ & $3,289.2$ & $3,359.0$ & 69.8 & $8.2 \%$ \\
Percent & $26.8 \%$ & $27.0 \%$ & $27.0 \%$ & & $21.4 \%$ \\
\hline $\begin{array}{l}\text { International } \\
\text { Percent }\end{array}$ & $21.4 \%$ & $2,662.9$ & $2,882.2$ & 219.3 & \\
\hline Total & $1,159.3$ & $1,131.3$ & $1,373.6$ & 242.2 & \\
\hline Supply/Demand Split & $9.8 \%$ & $9.3 \%$ & $11.0 \%$ & & $\mathbf{2 . 2 \%}$ \\
\hline Supply & $\mathbf{1 1 , 8 6 7 . 4}$ & $\mathbf{1 2 , 1 6 2 . 7}$ & $\mathbf{1 2 , 4 3 1 . 1}$ & $\mathbf{2 6 8 . 4}$ & \\
Percent & $\mathbf{6 , 8 7 6 . 2}$ & $\mathbf{7 , 0 8 3 . 5}$ & $\mathbf{7 , 6 1 4 . 8}$ & $\mathbf{5 3 1 . 3}$ & \\
\hline $\begin{array}{l}\text { Demand } \\
\text { Percent }\end{array}$ & $\mathbf{5 7 . 9 \%}$ & $\mathbf{5 8 . 2 \%}$ & $\mathbf{6 1 . 3 \%}$ & & $\mathbf{7 . 5 \%}$ \\
\hline Total & $\mathbf{4 , 9 9 1 . 1}$ & $\mathbf{5 , 0 7 9 . 2}$ & $\mathbf{4 , 8 1 6 . 2}$ & $\mathbf{2 6 2 . 9 )}$ & $\mathbf{( 5 . 2 \% )}$ \\
\hline
\end{tabular}

Source: ONDCP, 2005. (For FY 2006 Budget Summary p. 7). Detail may not add to totals due to rounding. In addition to the resources displayed in the table above, the Administration requested another \$387.6 million in FY 2007 for Emergency Supplemental funding and \$ 266.1 million in FY 2008 for Emergency Designations. These resources were used in the counter drugs operations in Afghanistan. FY= Financial Year. 


\section{Appendix 3c}

Federal Drug Control Spending by Function, FY 2006- FY 2008 (Budget Authority in Millions)

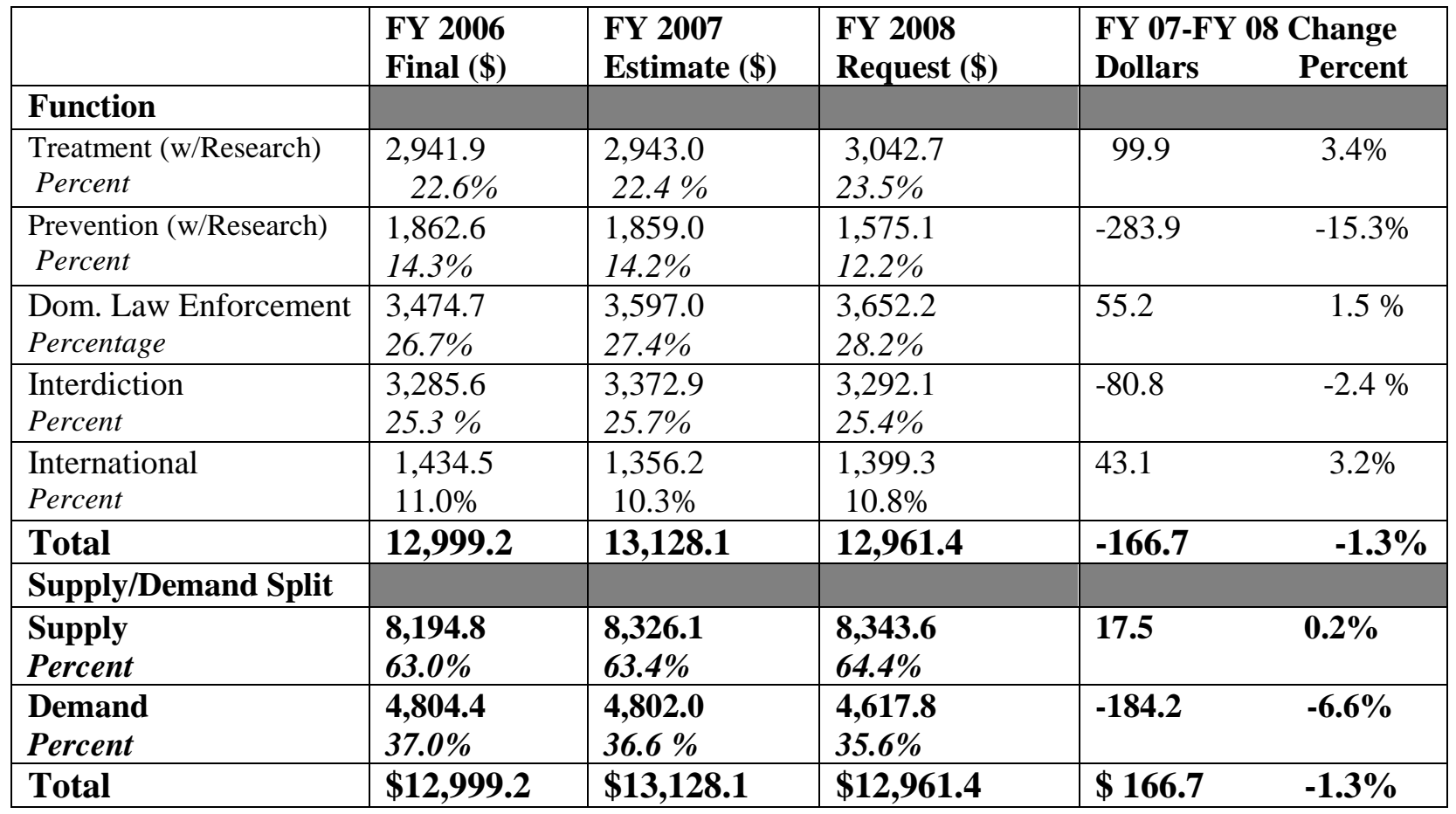

Source: ONDCP, 2007 (For FY 2008 Budget Summary p. 9) Detail may not add to total due to rounding). FY = Financial Year. 


\section{Appendix 3d}

Federal Drug Control Spending by Function, FY 2008- FY 2010 (Budget Authority in Millions)

\begin{tabular}{|c|c|c|c|c|}
\hline & $\begin{array}{l}\text { FY } 2008 \\
\text { Final (\$) }\end{array}$ & $\begin{array}{c}\text { FY } 2009 \\
\text { Enacted (\$) }\end{array}$ & $\begin{array}{l}\text { FY } 2010 \\
\text { Request (\$) }\end{array}$ & $\begin{array}{lr}\text { FY 09-FY } 10 \text { Change } \\
\text { Dollars } & \text { Percent }\end{array}$ \\
\hline \multicolumn{5}{|l|}{ Function } \\
\hline $\begin{array}{l}\text { Treatment } \\
\text { Percent }\end{array}$ & $\begin{array}{r}3,255.2 \\
24.5 \% \\
\end{array}$ & $\begin{array}{r}3,415.9 \\
23.0 \% \\
\end{array}$ & $\begin{array}{r}3,566.0 \\
23.7 \% \\
\end{array}$ & 150.2 \\
\hline $\begin{array}{l}\text { Prevention } \\
\text { Percent }\end{array}$ & $\begin{array}{r}1,750.4 \\
13.2 \% \\
\end{array}$ & $\begin{array}{r}1,791.4 \\
12.1 \% \\
\end{array}$ & $\begin{array}{r}1,601.6 \\
10.6 \% \\
\end{array}$ & $-10.6 \%$ \\
\hline $\begin{array}{l}\text { Dom. Law Enforcement } \\
\text { Percentage }\end{array}$ & $\begin{array}{r}3,544.1 \\
26.7 \% \\
\end{array}$ & $\begin{array}{r}3,653.9 \\
24.6 \% \\
\end{array}$ & $\begin{array}{r}3,737.2 \\
24.8 \% \\
\end{array}$ & $2.3 \%$ \\
\hline $\begin{array}{l}\text { Interdiction } \\
\text { Percent }\end{array}$ & $\begin{array}{r}2,901.4 \\
21.9 \% \\
\end{array}$ & $\begin{array}{r}3,836.2 \\
25.8 \% \\
\end{array}$ & $\begin{array}{r}4,004.1 \\
26.6 \% \\
\end{array}$ & 167.9 \\
\hline $\begin{array}{l}\text { International } \\
\text { Percent }\end{array}$ & $\begin{array}{r}1,824.6 \\
13.7 \% \\
\end{array}$ & $\begin{array}{r}2,147.5 \\
14.5 \% \\
\end{array}$ & $\begin{array}{r}2,160.2 \\
14.3 \% \\
\end{array}$ & $0.6 \%$ \\
\hline Total & $\$ 13,275.8$ & $\$ 14,844.7$ & $\$ 15,069.1$ & $\$ 224.3$ \\
\hline \multicolumn{5}{|l|}{ Supply/Demand Split } \\
\hline $\begin{array}{l}\text { Demand Reduction } \\
\text { Percent }\end{array}$ & $\begin{array}{r}\mathbf{5 , 0 0 5 . 6} \\
\mathbf{3 7 . 7 \%} \\
\end{array}$ & $\begin{array}{r}\mathbf{5 , 2 0 7 . 3} \\
\mathbf{3 5 . 1 \%} \\
\end{array}$ & $\begin{array}{r}5,167.7 \\
34.4 \% \\
\end{array}$ & $-0.8 \%$ \\
\hline $\begin{array}{l}\text { Supply Reduction } \\
\text { Percent }\end{array}$ & $\begin{array}{r}8,270.1 \\
62.3 \% \\
\end{array}$ & $\begin{array}{r}9,637.5 \\
64.9 \% \\
\end{array}$ & $\begin{array}{r}9,901.4 \\
65.6 \% \\
\end{array}$ & 263.9 \\
\hline Total & $\$ 13,275.8$ & $\$ 14,844.7$ & $\$ 15,069.1$ & $\$ 224.3$ \\
\hline
\end{tabular}

Source: ONDCP, 2009 (For FY 2010 Budget Summary p. 9) Detail may not add to total due to rounding). FY = Financial Year. 


\section{Appendix 4}

\section{Map of World Drug Majors in Fiscal Year (FY) 2009}

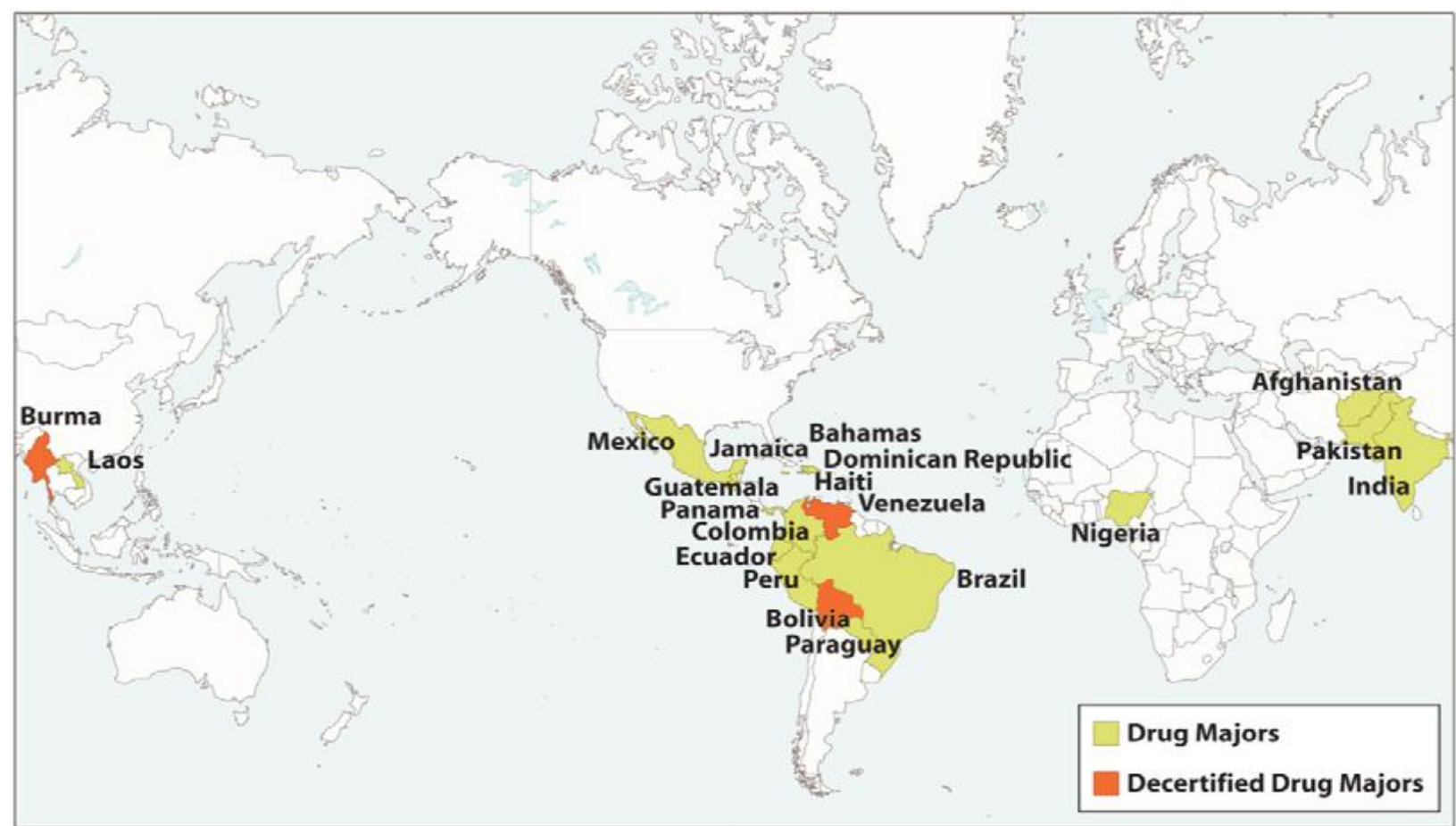

Source: George W. Bush, Presidential Determination No. 2008-28, "Memorandum to the Secretary of State: Major Drug Transit or Major Illicit Drug Producing Countries for Fiscal Year 2009," September 16, 2008, at http://www.state.gov/p/inl/rls/prsrl/ps/109777.htm 


\section{Appendix 5a}

\section{Interview Questions}

\section{Interview Protocol on Policy Advocacy Groups/Other Actors}

\section{Personal Introduction}

Hello,

My name is Felix Kumah-Abiwu. I'm a doctoral student in the department of Political Science at West Virginia University. I'm conducting this elite interview to gather data for my dissertation. The interview is voluntary and any information given during the process will be used only for the purpose of my dissertation and academic advancement of knowledge. Thanks for your participation.

\section{Research Background}

Narcotics control policy of prohibition/criminalization has been the dominant narcotics policy approach in the US for decades. This prohibition strategy has been extended to other countries through the global narcotics regime under the control of the United Nations. However, questions have been raised on the existing policy, which many believe, seems unchanging both in the United States and across the world. The empirical question is whether policy change is occurring with the US narcotics policy or not. In effect, the research seeks to investigate the broad patterns of how policy change (radical or marginal) has occurred or occurring within the US narcotics policy since 1993 (the scope of study is 1993-2009). The study seeks to also explore the implications of policy change in the US on the global narcotics regime as a result of the US influence on the regime. Policy change in this sense is whether there has been a shift with more emphasis on criminalization or with decriminalization of illegal drugs. Your assistance in answering these questions would be appreciated.

\section{(The first, two questions are general demographic questions)}

1a. Are you involved with any policy advocacy group/ activities aimed at shaping US narcotics policy change? (1)___ Yes

(2) _ No

1b. If yes, with which organization are you associated? Or activities are you engaged in?

2. How many years have you been involved with your organization? Or the US narcotics issues?

(Questions 3 to 10 are designed to determine whether change is occurring or not, and if occurring, what is the nature of this change and the role of policy advocacy groups and other actors in shaping US narcotics policy change).

3. The US narcotics policy which is based on prohibition/criminalization seems unchanging after many years of implementation. To some, change is occurring with emphasis on criminalization, while others believe that change is occurring towards decriminalization. Do you see change occurring in any form with the US narcotics policy since 1993 ? 
4. If change is occurring with more emphasis on criminalization, how would describe the nature (e.g change in policy goals, content, instruments) of this change?

5. If change is occurring with more emphasis on decriminalization, how would describe the nature (e.g change in policy goals, content, instruments) of this change?

6. Policy change is sometimes driven by internal or external forces or both. Please identify some of the major forces (internal or external) you consider as the main driving force for the US narcotics policy change? Which of these forces would you consider as the main driving force in US policy change? (1) Internal (2) External (3) Both forces

7. Partisan ideological policy differences between the two leading political parties (Democrats \& Republicans) do shape policy change. From your perspective, how would you describe US narcotics policy change based on the partisan differences?

8. How would you explain the role/strategies of your advocacy organization and other agencies including government agencies in shaping the US narcotics policy change?

9. In your opinion, would you say these policy changes are gradual or rapid?

10. How likely is it that there will be a drastic change of US narcotics policy towards a more liberal (decriminalization of illegal drugs) approach within next few years?

\section{(Questions 11 to 17 are designed to determine the role of the US in the global narcotics prohibition regime and the likely implications of US policy change on the global regime)}

11a. Prohibition and criminalization of narcotics drugs have been the underlying principle of major UN conventions on illicit drugs. The US is the leading country that has consistently pushed for the global adoption of the prohibition regime. How accurate is this statement?

11b. If not so accurate, how would you describe the US role?

12. How would you rate the US dominance of the global narcotics regime before and after the end of the Cold War?

13. How would you generally describe the role of the US in the global prohibition regime?

14a. The US narcotics policy is based on the assumption that the supply of illicit drugs into the US is generally outside the boundaries of the US, hence the country's active role in the global narcotics campaign. Is this assumption correct? Yes (2) No

14b. If no, how would you describe it?

15a. Would you describe the global narcotics prohibition regime as an extension of the US narcotics policy both at the multinational and bilateral levels? (1) Yes (2) No

$15 \mathrm{~b}$. If no, how would you describe the role of the US? 
16a. The US is influential on the global narcotics prohibition regime under the UN as a result of its hegemony status (dominant role) on the international stage. Do you share the view that US domestic narcotics policy change (incremental or radical) is likely to have some implications toward a similar policy change on the global narcotics regime? (a) Yes (b) No (c) Not Sure

$16 \mathrm{~b}$. If yes, in what way(s)?

17. Overall, how would you assess the changing nature of the existing global narcotics prohibition regime? (1) Incremental/gradual (2) Radical/drastic (3) No change.

Thank you! 


\section{Appendix 5b}

\section{Interview Protocol on the Global Narcotics Regime}

\section{Interview Questions}

(The $1^{\text {st }} 2$ questions are general demographic questions)

1a. Are you familiar with the UN (global) narcotics policy issues? Yes No

1b. With which organizations/units are you associated?

2. How many years have you been involved in working for your organization?

\section{(Questions 3 to 8 are designed to determine the role of the US in the global narcotics prohibition regime and the likely implications of US drug policy change on the global narcotics regime)}

3. Prohibition and criminalization of narcotic drugs have been the underlying principle of major UN conventions on illicit drugs. The US is the leading country that has been advocating for the global adoption of the prohibition regime. How accurate is this statement? And if not, how would you describe US role?

4. If this statement is accurate, would you describe the role of the US as a dominant player in the global narcotics regime?

5a. Would you also describe the global narcotics prohibition regime as an extension of the US narcotics policy both at the multinational and bilateral levels? (1)__ Yes (2) __ No

5b. If you do not consider the US as a dominant player on the regime, how would you describe the role of the US in global narcotics control?

6. How likely will there be tensions in terms of change or resistance to change within the existing global narcotics prohibition regime in the next few years? (1) Very Likely (2) Somewhat likely (3) Neutral (4) Unlikely (5) Very unlikely.

7. If it is accurate that the US is influential on the global narcotics prohibition regime under the UN as a result of its hegemonic influence, would you share the view that a policy change (incremental or radical) within the US is likely to have some implications on the global narcotics prohibition regime? (a) Yes (b) No (c) Not Sure

7a. If yes, in what way(s)?

8. Overall, how would you assess the changing nature of the existing global narcotics prohibition regime? (a) Incremental/gradual (b) Radical/drastic (c) No change

Thank you! 


\section{Appendix 5c}

\section{List of Persons Interviewed}

David C. Lewis, MD, Professor Emeritus of Community Health and Medicine, Donald G. Millar Distinguished Professor Emeritus of Alcohol and Addiction Studies, Brown University Center of Alcohol and Addiction Studies.

Eric E. Sterling, J. D., President, The Criminal Justice Policy Foundation.

Grant Smith, Federal Policy Coordinator, Drug Policy Alliance.

Allen St. Pierre, Executive Director and a Member of Board of Directors, Norml Foundation.

Bill Fried, Director of Programs \& Financial Administration, Law Enforcement Against

Prohibition.

Susan Everingham, Drug Policy Research Center, Rand Corporation.

Jeffrey Kahn, Rabbi, Executive Director of Interfaith Drug Policy Initiative.

Nora Callahan, Co-Founder and Director of the November Coalition Foundation.

Marie Nougier, Research and Communication Officer, International Drug Policy Consortium.

Don Wirtshafter, Chairman of the Board, Drug Sense. 


\section{Appendix Six}

\section{Report of the Global Commission on Drug Policy (GCDP)}

Available: at www.globalcommissionondrugs.org Retrieved in June, 2011.

\section{The 19 Commissioners}

Asma Jahangir, human rights activist, former UN Special Rapporteur on Arbitrary, Extrajudicial and Summary Executions, Pakistan.

Carlos Fuentes, writer and public intellectual, Mexico.

César Gaviria, former President of Colombia.

Ernesto Zedillo, former President of Mexico.

Fernando Henrique Cardoso, former President of Brazil (chair).

George Papandreou, Prime Minister of Greece.

George P. Shultz, former Secretary of State, United States (honorary chair).

Javier Solana, former European Union High Representative for the Common Foreign and Security Policy, Spain.

John Whitehead, banker and civil servant, chair of the World Trade Center Memorial Foundation, United States.

Kofi Annan, former Secretary General of the United Nations, Ghana.

Louise Arbour, former UN High Commissioner for Human Rights, President of the International Crisis Group, Canada.

Maria Cattaui, Petroplus Holdings Board member, former Secretary-General of the International Chamber of Commerce, Switzerland.

Mario Vargas Llosa, writer and public intellectual, Peru.

Marion Caspers-Merk, former State Secretary at the German Federal Ministry of Health

Michel Kazatchkine, executive director of the Global Fund to Fight AIDS, Tuberculosis and Malaria, France.

Paul Volcker, former Chairman of the United States Federal Reserve and of the Economic Recovery Board.

Richard Branson, entrepreneur, advocate for social causes, founder of the Virgin Group, cofounder of The Elders, United Kingdom. 
Ruth Dreifuss, former President of Switzerland and Minister of Home Affairs.

Thorvald Stoltenberg, former Minister of Foreign Affairs and UN High Commissioner for Refugees, Norway. 


\section{References}

Abadinsky, Howard. 2005. "Drug Laws and Law Enforcement." In Huggins, Laura (ed.), Drug War Deadlock: The Policy Battle Continues. Stanford: Hoover Institution Press.

Akiba, Okon. 1997. "International Trade in Narcotics Drugs: Implications for Global Security." Futures 29(7):605-616.

Albrecht, Hans-Jorg. 2001. "The International System of Drug Control: Developments and Trends.” In Jurg Gerber and Eric L. Jensen (ed.), Drug War, American Style: The Internationalization of Failed Policy and its Alternatives. New York: Garland Publishing.

Andreas, Peter, and Nadelmann, Ethan. 2006. Policing the Globe: Criminalization and Crime Control in International Relations. New York: Oxford University Press.

Annas, George J. "Reefer Madness-The Federal Response to California's Medical-Marijuana Law." 1997. New England Journal of Medicine: Legal Issues Medicine 337 (6):435-439.

Appah, Frederick. 2007. The Politics of Health Promotion: Analyzing Healthy Public Policy's Impact on Tobacco Control in United States and South Africa.

(A doctoral dissertation submitted to West Virginia University).

Asare, Bossman. 2007. Tobacco Control: Comparative Public Policy in the United States and South Africa. Saarbrucken: VDM Verlag DR. Muller Press.

Asare, B.,Cairney, P., Studlar, D. 2009. "Federalism and Multilevel Governance in Tobacco Policy: The European Union, the United Kingdon, and Devolved UK Institutions." Journal of Public Policy 29 (1):79-102.

Axelrod, Robert. 1984. The Evolution of Cooperation. New York: Basic Books.

Baggins, David, S. 1998. Drug Hate and the Corruption of American Justice. Connecticut: Praeger.

Bakir, Caner. 2009. "Policy Entrepreneurship and Institutional Change: Multilevel Governance of Central Banking Reform.” Governance: An International Journal of Policy, Administration, and Institutions 22 (4):571-598.

Baumgartner, Frank R., and Bryan D. Jones. 1993. Agendas and Instability in American Politics. Chicago: University of Chicago Press.

Baumgartner, Frank R., and Bryan D. Jones. 2009. Agendas and Instability in American Politics. $2^{\text {nd }}$ ed. Chicago: University of Chicago Press. 
Bayer, I and Ghodse, H. 2000. "The Evolution of International Drug Control, 1945-1995.” United Nations International Drug Control Program. Bulletin on Narcotics. Occasional Papers. Volume LI, no. 1 and 2. UN New York.

Beckett, Katherine, Nyrop Kris, Pfingst Lori. 2006. "Race, Drugs, and Policing: Understanding Disparities in Drug Delivery Arrests.” Criminology 44(1):105-137.

Belenko, Steven R. 2000. (ed.). A Documentary History: Drugs and drug Policy in America.

Benavie, Arthur. 2009. Drugs America's Holy War: New York. Routledge Taylor and Francis Group.

Bennett, William. 2005. "Don't Surrender: The Drug War Worked Once. It Can Work Again." In Huggins, Laura (ed.), Drug War Deadlock: The Policy Battle Continues. Stanford: Hoover Institution Press.

Bennett, William. 2005. “Should Drugs be Legalized.” In Huggins, Laura (ed.), Drug War Deadlock: The Policy Battle Continues. Stanford: Hoover Institution Press.

Bennett, Colin, J. and Howlett, Michael. 1992. "The lessons of Learning: Reconciling Theories of Policy Learning and Policy Change.” Policy Sciences 25: 275-294. Kluwer Academic Publishers.

Berg, Bruce. 2004. Qualitative Research Methods for Social Sciences. $5^{\text {th }}$ ed. Boston: Allyn and Bacon.

Bertram, et al. 1996. Drugs War Politics: The Price of Denial. Berkeley: University of California Press.

Berry, Jeffrey.M. 2002. "Validity and Reliability Issues In Elite Interviewing." Political Science and Politics 35: 679-682.

Bewley-Taylor, David.1999a. The United States and International Drug Control, 1909-1997. London: Biddles Ltd.

Bewley-Taylor, David. 1999b. "The Cost of Containment: The Cold War and US International Drug Control at the UN, 1950-58.” Diplomacy \& Statecraft 10 (1): 147-171.

Bewley-Taylor, David. 2003. "Challenging the UN Drug Control Conventions: Problems and Possibilities." International Journal of Drug Policy 14 (2): 171-179. 
Bewley-Taylor, David. 2005. "Emerging Policy Contradiction between the United Nations Drug Control System and the Core Values of the United Nations." International Journal of Drug Policy 16: 423-431.

Bewley-Taylor, David. 2006. "Getting High on the Policy Agenda: Europe, the U.S and the Future of the Global Drug Prohibition Regime." Journal of Transatlantic Studies 4(1): 27-53.

Bewley-Taylor, D., and Woodiwiss, M. 2005. The Global Fix: The Construction of a Global Enforcement Regime. Amsterdam: Transnational Briefing Series.

Birkland, Thomas. 1997. After Disaster: Agenda Setting, Public Policy, and Focusing Events. Georgetown University Press.

Blow, M. Charles. 2011. “Drug Bust.” New York Times, June 10. http://www.nytimes.com/2011/06/11/opinion/11blow.html?emc=eta1. Retrieved on 06/15/2011.

Bouley, Eugene, E. 2001. “The Drug War in Latin America: Ten Years in a Quagmire.” In Jurg Gerber and Eric L. Jensen (ed.), Drug War, American Style: The Internationalization of Failed Policy and its Alternatives. New York: Garland Publishing.

Boyum, David, and Reuter, Peter. 2005. An Analytic Assessment of U.S Drug Policy. American Enterprise Institute Report Washington D.C. The AEI Press.

Breton, E, Richard L, Gagnon F. 2008. "The Role of Health Education in the Policy Change Process: Lesson from Tobacco Control.” Critical Public Health 17:351-64.

Bressers, Hans, and Lulofs, Kris. 2009. "Environmental Negotiated Agreements in the Netherlands". Environmental Politics 8(1):58-77.

Breunig, Christian. Koski, Chris. 2006. "Punctuated Equilibria and Budgets in the American States.” Policy Studies Journal 34(3):363-379.

Brisbin, Richard, and Hunter, Susan. 2007. "Panic Policymaking: Canine Breed Bans in Canada and the United." A paper presented at Western Political Science Association, Las Vergas NV March 8-10. Retrieved on 06/20/2011. http://www.allacademic.com/meta/p_mla_apa_research_citation/1/7/6/5/6/p176563 _index.html 
Brooks, Stephen G. and Wohlforth, William C. 2002. "American Primacy in Perspective.” Foreign Affairs. Council on Foreign Relations. Retrieved on 06/15/2011. http://www.foreignaffairs.com/articles/58034/stephen-g-brooks-and-william-cwohlforth/american-primacy-in-perspective

Bruun, Kettil, Pan Lynn, and Rexed Ingemar.1975. The Gentlemen's Club: International Control of Drugs and Alcohol. Chicago: University of Chicago Press.

Bullington, Bruce. 2004. "Drug Policy Reform and Its Detractors: The United States as the Elephant in the Closet." Journal of Drug Issues 34(3): 687-721.

Burke, Celeste Anna. 1992. "Between Entitlement and Control: Dimensions of U.S Drug Policy.” Social Service Review 66(4): 571-581.

Buxton, Julia. 2008. "The Historical Foundations of the Narcotics Drug Control Regime" Policy Research Working Paper 4553. The World Bank Development Research Group, Macroeconomics and Growth Team. WPS4553.

Buxton, Julia. 2006. The Political Economy of Narcotics: Production, Consumption and Global Markets. Nova Scotia: Fernwood Publishing.

Byers, Michael. 2003. "The Complexities of Foundational Change." In Michael, Byers and Georg, Nolte (ed.), United States Hegemony and the Foundations of International Law. New York: Cambridge University Press.

Capano, G, and Howlett, M., (ed.). 2009. European and North American Policy Change: Drivers and Dynamics. NY: Routledge.

Capano, Giliberto. 2009. "Understanding Policy Change as an Epistemological and Theoretical Problem." Journal of Comparative Policy Analysis 11(1): 7-31.

Capano, Giliberto. 2003. "Administrative Traditions and Policy Change: When Policy Paradigms Matter: The Case of Italian Administrative Reform during the 1990s." Public Administration 81(4): 781-801.

Cairney, P, 2007. "Multiple Lenses Approach to Policy Change: The Case of Tobacco Control Policy in the UK." British Politics 2: 45-68.

Carroll, Rebecca, 2004. 'Under the influence' Harry Anslinger's Role in Shaping America's Drug Policy.” In Erlen, Jonathan, and Spillane, Joseph (ed.), Federal Drug Control: The Evolution of Policy and Practice. New York: Pharmaceutical Products Press. 
Carstairs, Catherine. 2005. "The Stages of the International Drug Control System." Drug and Alcohol Review 24: 57-65.

Cashore, Benjamin, and Howlett, Michael. 2007. "Punctuating Which Equilibrium? Understanding Thermostatic Policy Dynamics in Pacific Northwest Forestry." American Journal of Political Science 51(3):532-551.

Chepesiuk, Ronald. 1999. The War on Drugs: An International Encyclopedia. Santa Barbara: ABC- CLIO, Inc.

Clark, Ian. 2009. "Bringing Back In: The United States and International Order." International Affairs 85(1): 23-36.

Cobb, Roger, W, Keith-Ross Jeannie, and Marc Howard Ross. 1976. “Agenda Building as a Comparative Political Process.” American Political Science Review 70:126-138.

Coleman, John J. 1999. "Unified Government, Divided Government, and Party Responsiveness." The American Political Science Review (93) 4: 821-835.

Congressional Research Service Report (CRS) on international drug control policy (2008). Retrieved from http://www.fas.org/sgp/crs/row/RL34543.pdf on 03/09/2010.

Coulkins, Jonathan, Reuter Peter, Iguchi Martin, Chiesa James. 2005. "How Goes the War on Drugs: An Assessment of U.S Drug Problems and Policy." Rand Drug Policy Research Center. Occasional paper prepared for the Ford Foundation.

Courtwright, David T. 2002. "The Roads to H: The Emergence of the American Heroin Complex, 1898-1956." In Musto et al. (ed.), One Hundred Years of Heroin. London: Auburn House.

Crandall, Russell. 2008. Driven By Drugs: US Policy Toward Colombia. Colorado: Lynne Rienner Publishers.

Crichlow, Scott. 2002. "Legislators' Personality Traits and Congressional Support for Free Trade." Journal of Conflict Resolution 46: 693-711.

Crichlow, Scott. 2005. "Psychological Influences on the Policy Choices of Secretaries of State and Foreign Ministers." Cooperation and Conflict: Journal of the Nordic International Studies Association. 40(2): 179-205.

Crime in the United States. Annual Uniform Report. Reported in the Bureau of Justice Statistics. http://bjs.ojp.usdoj.gov/content/glance/tables/drugtab.cfm Retrieved on 06/15/11. 
Cronin, Bruce. 2001. "The Paradox of Hegemony: America's Ambiguous Relationship with the United Nations.” European Journal of International Relations 7(1):103-130.

Crow, Deserai Anderson. 2010. "Policy Entrepreneurs, Issue Experts, and water Rights Policy Change in Colorado." Review of Policy Research 27(3):299-315.

Denis, Philip and Whitford, Andrew B. 2010. "Presidential Rhetoric and Policy Outcomes: The Presidential and the American Struggle with Heroin Abuse." World Medical \& Health Policy 2(3): Article 8.

Dennis, Michael and White, William 1999. "The Marijuana Legalization Debate: Is there a Middle Ground.” In Inciardi, James (ed), The Drug Legalization Debate. California: Sage Publications, Inc.

Dexter, Lewis, Anthony. 1970. Elite and Specialized Interviewing. Northwestern University Press.

Dieter, Heribert. 2009. "The Decline of Global Economic Governance and the Role of the Transatlantic Powers." Business and Politics 11(3) Article 6.

Donnelly, Jack. 1986. "International Human Rights: A Regime Analysis." International Organization 40 (3): 599-642.

Dresser, Rebecca. 2009. “Irrational Basis: The Legal Status on Medical Marijuana.” Hastings Center Report 39(6): 7-8.

Drexler, Robert W. 1997. Colombia and the United States: Narcotics Traffic and Failed Foreign Policy. Jefferson: McFarland \& Company, Inc.

Drucker, Ernest. 2003. "Deconstructing International Drug Prohibition." International Journal of Drug Policy 14:201-202.

Drug Enforcement Administration (DEA). 2008. A Tradition of Excellence 1973-2008. A DEA Publication.

DuPont, Robert, L. 2002. "Heroin Addiction in the Nation's Capital, 1966-1973." In Musto (ed.), with assistance from Pamela Korsmeyer, and Thomas W. Maulucci. One Hundred Years of Heroin. London: Auburn House.

DuPont, Robert L. 1996. "Harm Reduction and Decriminalization in the United States: A Personal Perspective.” Substance Use \& Misuse 31(14):1929-1945.

Durant, Robert, F and Diehl, Paul F. 1989. "Agendas, Alternatives, and Public Policy: Lessons from the U.S. Foreign Policy Arena.” Journal of Public Policy 9(2):179-205. 
Edwards, George and Dan, Wood. 1999. "Who Influences Whom? The President, Congress, and the Media." American Political Science Review 93(2):327-344.

Eddy, Mark. 2010. "Medical Marijuana: Review and Analysis of Federal and State Policies." Congressional Research Service. CRS Report Prepared for Congress, 7-5700, RL33211. 1- 47. http://www.fas.org/sgp/crs/misc/RL33211.pdf Retrieved on 07/13/2011.

Eisenhardt, Kathleen M. 1989. "Building Theories from Case Study Research." The Academy of Management Review 14 (4): 532-550.

Elliot, Richard, Csete, Joanne. 2005. "Harm Reduction, HIV/AIDS and the Human Rights Challenge to Global Drug Policy." Health and Human Rights 8(2):104-138.

Entman, Robert M. 1983. "The Impact of Ideology on Legislative Behavior and Public Policy in the States." Journal of Politics 45(1):163-182.

Erlen, Jonathan, and Spillane, Joseph. 2004. Federal Drug Control: The Evolution of Policy and Practice. New York: Pharmaceutical Products Press.

Falcon, Mathea. 1989. Winning the Drug War: A National Strategy. New York: Priority Press.

Falcon, Mathea. 1996. “US Drug Policy: Addicted to Failure.” Foreign Policy 102: 120-133.

Farquharson, Karen. 2003. "Influencing Policy Transnationally: Pro- and Anti-Tobacco Global Advocacy Networks.” Australian Journal of Public Administration 62(4): 80-92.

Farnsworth, David. 1983. US-Panama Relations, 1903-1978. A Study of Linkage Politics. Colorado: West View Press.

Faupel, Charles, E. 1991. Shooting Dope: Career Patterns Of Hard-Core Heroin Users. Gainville: University of Florida Press.

Fazey, Cindy. 2003. "The Commission on Narcotic Drugs and the United Nations International Drug Control Program: Politics, Policies and Prospect for Change." International Journal of Drug Policy 14 (2):155-169.

Fellner, Jamie. 2009. "Race, Drugs, and Law Enforcement in the United States." Stanford Law and Policy Review 20(2):257-291. 
Ferraiolo, Kathleen. 2007. "From Killer Weed to Popular Medicine: The Evolution of American Drug Control Policy, 1937-2000.” Journal of Policy History (19):147-179.

Finnemore, Martha. 1996. National Interests in International Society, Ithaca: Cornell University Press.

Fischer, Benedikt. 1999. "Prohibition, Public Health and a Window of Opportunity: An Analysis of Canadian Drug Policy, 1985-1997.” Policy Studies 20(3):197-210.

Fish, Jefferson M. 2006. "Rethinking U.S. Drug Policy.” In Jefferson M. Fish (ed.), Drugs and Society: US Public Policy. New York: Rowman \& Littlefield Publishers, Inc.

Fisher, Gary. 2006. Rethinking Our War on Drugs: Candid Talk about Controversial Issues. Connecticut: Praeger.

Florini, Ann. 1996. “The Evolution of International Norms.” International Studies Quarterly 40 (3): 363-389.

Friesendorf, Cornelius. 2007. US Foreign Policy and the War on Drugs: Displacing the Cocaine and Heroin Industry. New York: Routledge.

Friman, Richard H. 1996. NarcoDiplomacy: Exporting the U.S. War on Drugs. Ithaca: Cornell University Press.

Gerber, Jurg and Jensen, Eric, L. 2001 "The Internationalization of U.S. Policy on Illicit Drug Control.” In Jurg Gerber and Eric L. Jensen (ed.), Drug War, American Style: The Internationalization of Failed Policy and its Alternatives. New York: Garland Publishing.

Gilpin, Robert. 1981. War \& Change in World Politics. New York: Cambridge University Press.

Gilpin, Robert. 1987. The Political Economy of International Relations. Princeton: Princeton University Press.

Givel, Michael. 2010. "The Evolution of the Theoretical Foundations of Punctuated Equilibrium Theory in Public Policy." Review of Policy Research 27(2): 187-198.

Givel, Michael. 2006. "Punctuated equilibrium in limbo: The tobacco lobby and U.S. State Policymaking from 1990 to 2003." Policy Studies Journal, 34(3):405-418.

Goldberg, Ted. 2004. “The Evolution of Swedish Drug Policy.” Journal of Drug Issues 34(3): 1-19.

Goldstein, Avram, and Kalant, Harold. 1993. "Drug Policy: Striking the Right Balance." In Ronald Bayer and Gerald Oppenhelmer (ed.), Confronting Drug Policy: Illicit Drugs in a Free Society. Cambridge: Cambridge University Press. 
Goode, Erich. 2005. Drugs in American Society. $6^{\text {th }}$ edition. New York: McGrawHill.

Golub, Andrew, Johnson Bruce, Dunlap Eloise. 2006. "The Growth in Marijuana Use Among American Youths During the 1990s and the Extent of Blunt Smoking." Journal of Ethnicity in Substance Abuse 4(3\&4): 1-21.

Gordon, Diana. 1994. The Return of the Dangerous Classes: Drug Prohibition and Policy Politics. New York: W.W Norton \& Company.

Gray, Mike. 2000. Drug Crazy: How We Got Into This Mess and How We Can Get Out. New York: Routledge.

Haggard, Stephan, and Beth A. Simmons. 1987. "Theories of International Regimes." International Organization 41: 491-517.

Hagan Joe, 1994. "Domestic Political Systems and War Proneness." Mershon International Studies Review 38 183-207.

Hagan Joe, 2001. "Does Decision Making Matter? Systemic Assumptions vs. Historical Reality in International Relations Theory. Leaders, Groups and Coalitions: Understanding the People and Processes in Foreign Policymaking. International Studies Review 3 (2) $5-46$.

Haas, Peter. 1989. "Do Regimes Matters? Epistemic Communities and Mediterranean Pollution Control." International Organization 43(3): 377-403.

Haas, Peter. 1992. "Introduction: Epistemic Communities and International Policy Coordination," International Organization, 46:1-35.

Hall, Peter. 1993. "Policy Paradigms, Social Learning, and the State: The Case of Economic Policymaking in Britain." Comparative Politics 25(3): 275-296.

Hasenclever, Andreas, Mayer Peter, Rittberger Volker. 1997. Theories of International Regimes. New York: Cambridge University Press.

Hausermann, Silja. 2009. "Policy Flexibility vs. Policy Inertia: Coalitional Dynamics in German Pension Reform." In G. Capano and M. Howlett (ed.), European and North American Policy Change: Drivers and Dynamics. NY: Routledge.

Hermann, Margaret G., and Hermann, Charles F. 1989 "Who Makes Foreign Policy Decisions and How: An Empirical Inquiry." International Studies Quarterly 33(4): $361-87$. 
Hinojosa, Victor. 2007. Domestic Politics and International Narcotics Control: US Relations with Mexico and Colombia 1989-2000. New York: Routledge.

Hirschi, Christian, and Widmer, Thomas. 2010. "Policy Change and Policy Stasis: Comparing Swiss Foreign Policy towards South Africa (1968-94) and Iraq (1990-91).” Policy Studies Journal 38 (3): 537-563.

Howlett, Michael. 1997. "Issue-Attention and Punctuated Equilibria Models Reconsidered: An Empirical Examination of the Dynamics of Agenda-Setting in Canada." Canadian Journal of Political Science 30(1):3-29.

Howlett, Michael., and Ramesh, M. 2002. "The Policy Effects of Internationalization: A Subsystem Adjustment Analysis of Policy Change”. Journal of Comparative Policy Analysis: Research and Practice 4 31-50. Kluwer Academic Publishers.

Howlett, Michael. 1999. "Rejoinder to Stuart Soroko, Policy Agenda-Setting Theory Revisited: A Critique of Howlett on Downs, Baumgartner and Jones, and Kingdon." Canadian Journal of Political Science 31: 495-524.

Huggins, Laura (ed.). 2005. Drug War Deadlock: The Policy Battle Continues. Stanford: Hoover Institution Press.

Husak, Douglas. 2002. Legalize This! The Case for Decriminalizing Drugs. New York: Verso Press.

Husak, Douglas. 2006. "Competing Rationales for Drug Policy Reform.” In Jefferson M. Fish (ed.), Drugs and Society: US Public Policy. New York: Rowman \& Littlefield Publishers, Inc.

Inciardi, James, and Harrison, Lana (ed.), 2000. Harm Reduction: National and International Perspectives. London: Sage Publications, Inc.

Inciardi, James, McBride Duane, Rivers James. 1996. Drug Control and the Courts: London: Sage Publications: Drugs, Health, and Social Policy Series, Volume 3.

Ikenberry, John G. 1989. "Rethinking the Origins of American Hegemony." Political Science Quarterly 104 (3) 375-400.

Ikenberry, John G. 2005. "Power and Liberal Order: America's Postwar World Order in Transition.” International Relations of the Asia Pacific 5(2) 133-152.

Jervis, Robert. 1983. “Security Regimes.” In Stephen Krasner (ed.), International Regimes. Ithaca: Cornell University Press. 
Jervis, Robert. 1983. “Security Regimes.” In Stephen Krasner (ed.), International Regimes. Ithaca: Cornell University Press.

John, Peter, 2003. "Is There Life After Policy Streams, Advocacy Coalitions, and Punctuations: Using Evolutionary Theory to Explain Policy Change?" Policy Studies Journal 31(4) 481- 498.

Johnston, David, and Weiner Tim. 1996. "Seizing the Crime Issue, Clinton Blurs Party Lines." New York Times. August 1. Retrieved on 07/2/11 http://www.nytimes.com/1996/08/01/us/seizing-the-crime-issue-clinton-blurs-partylines.html

Jonnes, Jill. 1996. Hep-Cats, Narcs, and Pipe Dreams: A History of America's Romance with Illegal Drugs. New York: Scribner Press.

Jones, Marlyn, J. 2002. "Policy Paradox: Implications of the U.S Drug Control Policy for Jamaica." Annals of the American Academy of Political and Social Science 582:117-133.

Keck, Margaret E. and Kathryn Sikkink. 1998. Activists Beyond Borders: Advocacy Networks in International Politics. Ithaca: Cornell University Press.

Keohane, Robert O., Joseph Nye, 1977, Power and Interdependence: World Politics in Transition, Boston: Little Brown.

Keohane, Robert. 1983. “The Demand for International Regimes.” In Stephen Krasner (ed.), International Regimes. Ithaca: Cornell University Press.

Keohane, Robert O., 1984. After Hegemony: Cooperation and Discord in the World Political Economy, Princeton: Princeton University Press.

Keohane, Robert O., 2005. After Hegemony: Cooperation and Discord in the World Political Economy, Princeton: Princeton University Press.

Kerry, John. 1997. The New War: The Web of Crime That Threatens America's Security. New York: Simon and Schuster Inc.

Khatapoush, Shereen, Hallfors, Denise. 2004. "Sending the Wrong Message: Did Medical Marijuana Legalization in California Change Attitude about and Use of Marijuana"? Journal of Drug Issues 34(4): 751-770.

Kinder, Douglas, Clark. 1992 "Shutting Out Evil: Nativism and Narcotics Control in the United States.” In Walker III, William, O. (ed.), Drug Control Policy: Essays in Historical and Comparative Perspective. University Park: The Pennsylvania State University Press. 
Kindleberger, Charles P. 1973. The World in Depression, 1929-1939, Berkeley: University of California Press.

Kindleberger, Charles P. 1981. "Dominance and Leadership in the International Economy: Exploitation, Public Goods, and Free Rides." International Studies Quarterly 25 (2): 242254.

King, Gary, Robert O. Keohane, and Sidney Verba.1994. Designing Social Inquiry: Scientific Inference in Qualitative Research. Princeton, New Jersey: Princeton University Press.

Kingdon, John W. 1984. Agendas, Alternatives, and Public Policies. Boston: Little Brown and Company.

Kleber, Herbert, D. 2002. "Methadone: The Drug, the Treatment, the Controversy". In Musto et al. (ed.), One Hundred Years of Heroin. London: Auburn House.

Kornblum, William. 1993. "Drug Legalization and the Minority" In Bayer, Ronald and Oppenheimer, Gerald M (ed.),Confronting Drug Policy Illicit Drugs In Free Society. New York: Cambridge University Press. Milbank Memorial Fund.

Kraska, Peter B. 2003. "The Military as Drug Police: Exercising the Ideology of War.” In Gaines, Larry K, and Kraska, Peter, B. Drugs, Crime \& Justice: Contemporary Perspectives. Long Grove: Illinois.

Krasner, Stephen (ed.). 1983. International Regimes. Ithaca: Cornell University Press.

Krasner, Stephen. 1982. "Structural Causes and Regime Consequences: Regimes as Intervening Variables." International Organization 36 (2) 185-205.

Krogh, Egil., Jr. 2002.” Heroin Politics and Policy Under President Nixon.” In Musto et al. (ed.), One Hundred Years of Heroin. London: Auburn House.

Kuzmarov, Jeremy. 2008. "From Counter-Insurgency to Narco-Insurgency: Vietnam and the International War on Drugs." Journal of Policy History 20 (3): 344-378.

Levitsky, Melvyn. 1991. "U.S Efforts in the International Drug War." In Krauss, Melvyn, B, and Lazear, Edward, P. (ed.), Searching For Alternatives: Drug Control Policy in the United States. Hoover Institution Press Stanford University.

Levine, Harry. 2003. "Global Drug Prohibition: Its Uses and Crisis." International Journal of Drug Policy 14 145-153.

Lee, Li. 1993. “Would Harassing Drug Users Work?” Journal of Political Economy 101(5): 939-959. 
Lindblom, Charles. 1959. “The Science of Muddling Through.” Public Administration Review 19:79-88.

Lipson, Charles. 1982. "The Transformation of Trade: The Sources and Effects of Regime Change." International Organization 36 (2) 417-455.

Lohmann, Susanne and O'Halloran, Sharyn.1994. "Divided Government and U.S Trade Policy: Theory and Evidence." International Organization (48) 4:595-632.

Lowry, William. 2006. "Potential Focusing Projects and Policy Change." Policy Studies Journal 34(3): 313-335.

Lynch, Timothy. 2000. “Tabula Rasa for Drug Policy.” In Lynch, Timothy (ed.), After Prohibition: An Adult Approach to Drug Policies in the $21^{\text {st }}$ Century. Cato Institute. Washington D.C.

MacCoun, Robert, and Reuter, Peter. 2001. Drug War Heresies. Learning from Other Vices, Times and Places. Cambridge: Cambridge University Press.

Macdonald, Scott, and Zagaris, Bruce.1992. International Book on Drug Control. Greenwood Press.

Mamudu, Hadii. 2005. The Politics of the Evolution of Global Tobacco Control: The Formation and Functioning of the Framework Convention on Tobacco Control (FCTC)

(A doctoral dissertation submitted to West Virginia University).

Manderson, Desmond. 1993. From Mr. Sin to Mr. Big: A History of Australian Drug Laws. NY: Oxford University Press

Mandel, Jerry. 2006. "Protestant Missionaries: Creators of the International War on Drugs." In Jefferson M. Fish (ed.), Drugs and Society: U.S. Public Policy. New York: Rowman \& Littlefield Publishers, Inc.

Martins, Eduardo, and Thompson, Timothy. 2007. "The Impasses of U.S Hegemony: Perspectives for the Twenty-first Century." Latin American Perspectives 152(34) No.1:16-28.

Mares, David. 2006. Drug Wars and Coffeehouses: The Political Economy of the International Drug Trade. Washington D C: CQ Press.

Marcy, William. L. 2010. The Politics of Cocaine: How U.S Foreign Policy Has Created a Thriving Drug Industry in Central and South America. Chicago: Lawrence Hill Books. 
Marshall, Donnie, 2000. “Drug Prohibition Is Effective.” In Scott Barbour (ed.), Drug Legalization: Current Controversies. San Diego: Greenhaven Press, Inc.

Marion, Nancy, and Farmer, Rick. 2004. "A Preliminary Examination of Presidential Anticrime Promises.” Criminal Justice Review 29(1): 173-195.

Massing, Michael. 2000. The Fix. Berkeley: University of California Press.

Matsusaka, John G. 2005. "The Eclipse of Legislatures: Direct Democracy in the $21{ }^{\text {st }}$ Century." Public Choice 124:157-177.

McAllister, William, B. 2000. Drug Diplomacy in the Twentieth Century: An International History.New York: Routledge.

McAllister, William, B. 2004. "Habitual Problems: The United States and International Drug Control in Spillane Federal drug Control.” In Erlen, Jonathan, and Spillane, Joseph (ed.), Federal Drug Control: The Evolution of Policy and Practice. New York: Pharmaceutical Products Press.

McBride, Duane, and McCoy, Clyde, B. 2003. "The Drug-Crime Relationship: An Analytical Framework.” In Gaines, Larry K, and Kraska, Peter, B. (ed.), Drugs, Crime \& Justice: Contemporary Perspectives. Long Grove: Illinois.

McCarty, Noland, Poole, Keith T and Rosenthal, Howard. 2006. Polarized America: The Dance of Ideology and Unequal Riches. Cambridge, Massachusetts. The MIT Press.

McCaffrey, Barry, R. 2000. "An International Drug Prohibition Effort Is Needed" In Scott Barbour (ed.), Drug Legalization: Current Controversies. San Diego: Greenhaven Press, Inc.

McCollum, Bill. 2000. "The War on Drugs Should Focus on Reducing the Drug Supply." In Scott Barbour (ed.), Drug Legalization: Current Controversies. San Diego: Greenhaven Press, Inc.

McCool, Daniel, 1998. "The Subsystem Family of Concepts: A Critique and a Proposal." Political Research Quarterly 51:551-570.

McLendon, Michael K. 2003. "Setting the Government Agenda for State Decentralization of Higher Education." The Journal of Higher Education 74(5):479-515.

McMurray, Coleen. 2003. "Medicinal Marijuana: Is It What the Doctor Ordered"? A Gallup Poll Report. Retrieved on 07/13/2011. http://www.gallup.com/poll/10126/MedicinalMarijuana-What-Doctor-Ordered.aspx 
McWilliams, John, C. 1992. "Through the Past Darkly: The Politics and Policies of America's Drug War." In Walker III, William, O. (ed.), Drug Control Policy: Essays in Historical and Comparative Perspective. The Pennsylvania State University Press.

McWilliams, John, C.1990. The Protectors: Harry J. Anslinger and the Federal Bureau of Narcotics, 1930-1962. Newark: University of Delaware Press.

McVay, Douglas. 2006. “The United States and the Netherlands.” In Jefferson M. Fish (ed.), Drugs and Society: US Public Policy. New York: Rowman \& Littlefield Publishers, Inc.

Mearsheimer, John, J. 2001. The Tragedy of Great Power Politics. New York: W.W. Norton \& Company, Inc.

Meier, Kenneth, J. 1994. The Politics of Sin: Drugs, Alcohol, and Public Policy. New York. M.E Sharpe, Inc.

Merriam, Sharan B. 1998. Qualitative Research and Case Study Applications in Education. San Francisco, CA: Jossey-Bass Publishers.

Mesquite de Bruce, Bueno. 2002. "Domestic Politics and International Relations." International Studies Quarterly 46 (1) 1-9.

Millhorn, Misty, Monaghan Megan, Montero Darrel, Reyes Maria, Roman Tony, Tollasken Roy, Walls Becca. 2009. "North Americans' Attitudes Toward Illegal Drugs.” Journal of Human Behavior in the Social Environment 19(2): 125-141.

Milner, Helen.1997. Interests, Institutions, and Information: Domestic Politics and International Relations. Princeton: Princeton University Press.

Mintrom, Michael, and Norman, Phillipa. 2009. "Policy Entrepreneurship and Policy Change." Policy Studies Journal 37(4): 649-667.

Mintrom, Michael; Vergari, Sandra. 1996. “Advocacy Coalitions, Policy Entrepreneurs, and Policy Change.” Policy Studies Journal 24 (3): 420-434.

Morales, Evo Ayma. 2009. "Let Me Chew My Coca Leaves.” New York Times. March 13. http://www.nytimes.com/2009/03/14/opinion/14morales.html

Moravcsik, Andrew. 1997. "Taking Preferences Seriously: A Liberal Theory of International Politics.” International Organization 51:513-553. 
Mortensen, P. 2007. "Stability and Change in Public Policy: A Longitudinal Study of Comparative Subsystem Dynamics." Policy Studies Journal 35(3), 373-395.

Musto, David. 1999. The American Disease: Origins of Narcotics Controls. New York. Oxford University Press.

Musto, David, F., and Korsmeyer, Pamela. 2002. The Quest for Drug Control: Politics and Federal Policy in a Period of Increasing Substance Abuse, 1963-1981. New Haven: Yale University Press.

Nadelmann, Ethan. 1989. "Drug Prohibition in the United States: Costs, Consequences, and Alternatives.” Science New Series 245 (4921): 939-94.

Nadelmann, Ethan. 1990. "Global Prohibition Regimes: The Evolution of Norms in International Society." International Organization 44: 479-526.

Nadelmann, Ethan. 2000. "Drug Policies Should Focus on Harm Reduction" In Scott Barbour (ed.), Drug Legalization: Current Controversies. San Diego: Greenhaven Press, Inc.

Naim, Moises. 2003. “The Five Wars of Globalization.” Foreign Policy 134: 28-37.

Nathanson, Constance, A. 2007. "The Contingent Power of Experts: Public Health Policy in the United States, Britain, and France.” Journal of Policy History 19 (1): 71-94.

Newman, Brian, and Lammert, Kevin. 2011. "Polls and Elections: Divided Government and Foreign Relations Approval.” Presidential Studies Quarterly (41) 2:375-392.

Nye, Joseph. 2010. "The Future of American Power: Dominance and Decline in Perspective." Foreign Affairs 89 (6):2-12.

O'Connell, Thomas J., and Bou-Matar, Che B. 2007. "Long Term Marijuana Users Seeking Medical Cannabis in California (2001-2007: Demographics, Social Characteristics, and Patterns of Cannabis and Other Drug Use of 4117 Applicants." Harm Reduction Journal 4(16): 1-7.

Office of National Drug Control Policy (ONDCP). 1992. National Drug Control Strategy. Washington, DC: Government Printing Office. 1993. National Drug Control Strategy. Washington, DC: Government Printing Office. 1994. National Drug Control Strategy. Washington, DC: Government Printing Office. 
1996. National Drug Control Strategy.

Washington, DC: Government Printing Office.

1998. National Drug Control Strategy.

Washington, DC: Government Printing Office.

2001. National Drug Control Strategy.

Washington, DC: Government Printing Office.

2002. National Drug Control Strategy. Budget

Summary for 2003 Washington, DC: Government Printing Office.

2003. National Drug Control Strategy.

Washington, DC: Government Printing Office.

2004. National Drug Control Strategy.

Washington, DC: Government Printing Office.

2005. National Drug Control Strategy.

Washington, DC: Government Printing Office.

2006. National Drug Control Strategy.

Washington, DC: Government Printing Office.

2008. National Drug Control Strategy.

Washington, DC: Government Printing Office.

2009. National Drug Control Strategy. Budget Summary for

2010 Washington, DC: Government Printing Office.

2010. National Drug Control Strategy.

Washington, DC: Government Printing Office.

Oppenheimer, Gerald M.1993. "To Build the Bridge: The Use of Foreign Models by Domestic Critics of U.S Drug Policy." In Bayer, Ronald and Oppenheimer, Gerald M (ed.), Confronting Drug Policy Illicit Drugs In Free Society. New York: Cambridge University Press. Milbank Memorial Fund.

Padgett, John F. 1980 "Bounded Rationality in Budgetary Research.” American Political Science Review 74: 354-372.

Patton, Michael Quinn. 2002. Qualitative Research and Evaluation Methods. 3rd Edition. Thousand Oaks, CA: SAGE publications. 
Perl, Raphael, 2003. "Drug Control: International Policy and Approaches." Congressional Research Service (Foreign Affairs, Defense, and Trade Division). CRS Issue Brief for Congress.

Perl, Raphael F. 1993. “Clinton's Foreign Drug Policy.” Journal of Inter-American Studies and World Affairs 35(4): 143-152.

Peters, Guy B. 1998. Comparative Politics: Theory and Methods. New York: New York University Press.

Poole, Keith T., and Rosenthal, Howard. 1984. "The Polarization of American Politics." Journal of Politics, 46:1061-1079.

Pralle, Sarah B. 2006a. "The 'Mouse That Roared': Agenda Setting in Canadian Pesticides Politics” The Policy Studies Journal 34(2): 171-194.

Pralle, Sarah B. 2006b. "Timing and Sequence in Agenda-Setting and Policy Change: A Comparative Study of Lawn Care Pesticide Politics in Canada and the US." Journal of European Public Policy 13 (7): 987-1005.

Pralle, Sarah B. 2003. "Venue Shopping, Political Strategy, and Policy Change: The Internationalization of Canadian Forest Advocacy.” Journal of Public Policy 23(3): 233260.

Princen, Sebastiaan. 2007. "Agenda-setting in the European Union: A Theoretical Exploration and Agenda for Research.” Journal of European Public Policy 14(1):21-38.

Putnam, Robert D. 1988. "Diplomacy and Domestic Politics: The Logic of Two-Level Games." International Organization 42(3): 427-460. Also in P. Evans, H.K. Jacobson, and R.D. Putnam (ed.), Double-Edged Diplomacy: International Bargain and Domestic Politics. Berkeley: University of California Press.

Rachal, Patricia. 1982. Federal Narcotics Enforcement: Reorganization and Reform. Boston: Auburn House Publishing Company.

Radin, Berly, and Boase Price Joan. 2000. "Federalism, Political Structure, and Public Policy in the United States and Canada." Journal of Comparative Policy Analysis (2) 1: 65-89.

Reinarman, Craig. 2000. “The Dutch Example Shows that Liberal Drug Laws Can be Beneficial.” In Scott Barbour (ed.), Drug Legalization: Current Controversies. San Diego: Greenhaven Press. 
Reuter, Peter, and MacCoun, Robert. 2002. "Heroin Maintenance: Is the U.S. Experiment Needed"? In Musto et al. (ed.), One Hundred Years of Heroin. London: Auburn House.

Richards, David. 1996. “Elite Interviewing: Approaches and Pitfalls.” Politics 16(3): 199204.

Robinson, et al. 2007. "Explaining Policy Punctuations: Bureaucratization and Budget Change." American Journal of Political Science 51 (1): 140-150.

Rochefort, David A. and Cobb, Roger W. 2004. "Problem Definition: An Emerging Perspective." In David, A. Rochefort and Roger, W.Cobb (ed.), The Politics of Problem Definition: Shaping the Policy Agenda. Kansas: University Press of Kansas.

Room, Robin, and Paglia, Angela. 1999. "The International Drug Control System in the PostCold War era. Managing Markets or Fighting a War?" Drug and Alcohol Review 18(3): 305-315.

Rose, Richard. 1984. Understanding Big Government: The Program Approach. London: Sage Publication.

Rose, Richard. 1990. "Inheritance before Choice in Public Policy." Journal of Theoretical Politics 2(3):263-291.

Rosenau, James N. 1969. Linkage Politics: Essays on the Convergence of National and International Systems. New York: The Free Press.

Ruggie, John Gerard. 1975. "International Responses to Technology: Concepts and Trends." International Organization 34: 557-583.

Russett, Bruce. 1985. “The Mysterious Case of Vanishing Hegemony: or Is Mark Twain Really Dead?" International Organization 39: 207-231.

Ryan, Kevin F. 2001. "Towards an Explanation of the Persistence of Failed Policy: Binding Drug Policy to Foreign Policy, 1930-1962." In Gerber, Jurg, and Jensen, Eric L. (ed.), Drug War, American Style: The Internationalization of Failed Policy and Its Alternatives New York: Garland Publishing.

Sabatier, Paul, and Hank C. Jenkins-Smith. 1999. "The Advocacy Coalition Framework." in Theories of the Policy Process. In Paul A. Sabatier (ed.), Boulder: Westview Press.

Sabatier, Paul A, and Hank C. Jenkins-Smith. 1993. Policy Change and Learning: An Advocacy Coalition Approach. Boulder, San Francisco, and Oxford: Westview Press. 
Serrano, Richard, A. 2011. "Prison Terms for Crack Cocaine Offenses Reduced: The U.S. Sentencing Commission Brings Such with the Shorter Terms Given to Power Cocaine Offenders.” Los Angeles Times. July 1, 2011.

Schmidt, Vivien A., and Radaelli, Claudio M. 2004 "Policy Change and Discourse in Europe: Conceptual and Methodological Issues". West European Politics 27 (2) 183-210.

Schmidt, Manfred G. 1996. "When Parties Matter: A review of the Possibilities and Limits of Partisan Influence on Public Policy." European Journal of Political Research." 30(2):155-183.

Schafer, Mark, and Crichlow, Scott. 2002. "The Process-Outcome Connection in Foreign Policy Decision Making: A Quantitative Study Building on Groupthink.” International Studies Quarterly 46, 45-68.

Schrad, Mark, L. 2010. The Political Power of Bad Ideas: Networks, Institutions, And Global Prohibition Wave. New York: Oxford University Press, USA.

Sharp, Elaine B. 1992. “Agenda-Setting and Policy Results: Lessons from Three Drug Policy Episodes.” Policy Studies Journal 20 (4):538-551.

Sharp, Elaine, B.1994. The Dilemma of Drug Policy in the United States. Harper Collins College Publishers.

Schattschneider, E. E. 1960. The Semi-Sovereign People. New York: Holt, Rinehart and Winston.

Sinha, Jay. 2001. "The History and development of the Leading International Drug Control Conventions." A Report Prepared for the Senate Special Committee on Illegal Drugs. Law and Government Division. Library of Canadian Parliament. Parliamentary Research Branch

Sinclair, Barbara. 1986. "The Role of Committees in Agenda Setting in the U.S Congress." Legislative Studies Quarterly 11(1): 35-45.

Skogstad, Grace, 2009. "Internationalization and Policy Paradigm Change." In G. Capano and M. Howlett (eds.), European and North American Policy Change: Drivers and Dynamics. NY: Routledge.

Soroko, Stuart. 1999. "Policy Agenda-Setting Theory Revisited: Theory Revisited: A Critique of Howlett on Downs, Baumgartner and Jones, and Kingdon." Canadian Journal of Political Science 32: 763-772. 
Soroka, Stuart N. 2002. "Issue Attributes and Agenda-Setting by Media, the Public, and Policymakers in Canada." International Journal of Public Opinion Research 14(3): 264285.

Spillane, Joseph, and McAllister, William B. 2003. "Keeping the Lid On: A Century of Drug Regulation and Control.” Drug and Alcohol Dependence 70: S5-S12.

Spillane, Joseph. 2004. "Debating the Controlled Substances Act.” Drug and Alcohol Dependence 76: 17-29.

Spillane, Joseph F. 2004 "The Road to the Harrison Act: Drugs and Their Control, 1875-1918." In Erlen, Jonathan, and Spillane, Joseph (ed.), Federal Drug Control: The Evolution of Policy and Practice. New York: Pharmaceutical Products Press.

Stares, Paul B.1996. Global Habit: The Drug Problem in a Borderless World. Brookings Institute. Washington D.C.

Stratmann, Thomas. 2000. "Congressional Voting over Legislative Careers: Shifting Positions and Changing Constraints." American Political Science Review 94 (3): 665-676.

Studlar, Donley T. 2009. "Tobacco Control in Western Europe.” In G. Capano and M. Howlett (ed.), European and North American Policy Change: Drivers and Dynamics. New York: Routledge.

Studlar, Donley T. 2002. Tobacco Control: A Comparative Politics in the United States and Canada. New York: Broadview Press.

Studlar, Donley T. 2005. "The Political Dynamics of Tobacco Control in Australia and New Zealand: Explaining Policy Problems, Instruments, and Patterns of Adoption." Australian Journal of Political Science, 40:255-274.

Studlar, Donley T. 2004. "Tobacco Control Policy Instruments in a Shrinking World: How Much Policy Learning?” In D. Levi-Faur and E. Vigoda-Gadot (ed.), International Public Policy and Management Policy Learning Beyond Regional, Cultural, and Political Boundaries, (Marcel and Dekker, 2004).

Substance Abuse and Mental Health Services Administration. 2010. Results from the 2009 National Survey on Drug Use and Health: Volume I. Summary of National Findings (Office of Applied Studies, NSDUH Series H-38A, HHS Publication No. SMA 104586 Findings). Rockville, MD.

Thoumi, Francisco. 2009. “The International Drug Control Regime's Straight Jacket: Are there any policy Option?" Trends Organized Crime 13(1):75-86. 
Thoumi, Francisco. 2003. Illegal Drugs, Economy, and Society in the Andes. Baltimore: The Johns Hopkins University Press.

The 2009 National Survey on Drug Use and Health: Summary of National Findings Volume I. 2010. Substance Abuse and Mental Health Services Administration. Office of Applied Studies, NSDUH Series H-38A, HHS Publication No. SMA 10-4856 Findings). Rockville, MD.

The Global Commission on Drug Policy (GCDP). The 2011 Report on the War on Drugs. Retrieved on 07/10/2011. http://www.globalcommissionondrugs.org/Report

The Pew Research for the People and the Press. 2010. "Broad Public Support for Legalizing Medical Marijuana: Modest Rise in Percentage Favoring General Legalization. Pew Research Center Publications. http://pewresearch.org/pubs/1548/broadpublic-support-for-legalizing-medical-marijuana. Retrieved on 07/ 7/2011

Treaster, Joseph. 1994. "New Focus on Drugs: President's Strategy Reflects Concern About Crime and Changing Priorities." New York Times. February 12. Retrieved on 07/05/11. http://www.nytimes.com/1994/02/12/us/new-focus-drugs-president-s-strategy-reflectsconcern-about-crime-changing.html

UNODC, World Drug Report 2010 (United Nations Publication, Sales No. E.10.XI.13). p.7 UNODC (United Nations Office on Drugs and Crime).

UNODC, World Drug Report 2010 (United Nations Publication. Sales No. E 10. XI.13) UNODC (United Nations Office on Drugs and Crime).

Waddell, Ian G. 1970. "International Narcotics Control." The American Journal of International Law 64 (2):310-323.

Wade, Robert, Hunter. 2002. "US Hegemony and the World Bank: The Fight over People and Ideas." Review of International Political Economy 9(2):201-229.

Walker III, William, O. 1989. Drug Control in the Americas. Albuquerque: University of New Mexico Press.

Walters, John. 2005. "No Surrender: The Drug War Saves Lives.” In Huggins, Laura (ed.), 2005. Drug War Deadlock: The Policy Battle Continues. Stanford: Hoover Institution Press.

Walters, John, P., and O'Gara, James F.X. 2000. "Prohibition Is Essential to the War on Drugs." In Scott Barbour (ed.), Drug Legalization: Current Controversies. San Diego: Greenhaven Press, Inc. 
Waltz, Kenneth N. 1979. Theory of International Politics. Reading, Massachusetts: Addison-Wesley.

Wendt, Alexander. 1992. "Anarchy is What States Make of it: the Social Construction of Power Politics." International Organization 46:391-425.

Weaver, David H. 2007. “Thoughts and Agenda Setting, Framing, and Priming.” Journal of Communication 57: 142-147.

Whiteside, Henry O. 1997. Menace in the West Colorado and the American Experience with Drugs, 1873-1963. Colorado Historical Society, Office of Research and Publication.

White, William L. 2002. "Trick or Treat? A Century of American Responses to Heroin Addiction." In Musto et al. (ed.), One Hundred Years of Heroin. London: Auburn House.

Wilson, James. 2005. “Against the Legalization of Drugs.” In Huggins, Laura (ed.), Drug War Deadlock: The Policy Battle Continues. Stanford: Hoover Institution Press.

Wilson, Carter, 2000. "Policy Regimes and Policy Change.” Journal of Public Policy 20(3): 247274.

Wisotsky, Steven. 1986. Breaking the Impasse in the War on Drugs. NY: Greenwood Press.

Wisotsky, Steven. 1990. Beyond the War on Drugs: Overcoming Failed Policy. New York: Prometheus Books.

Worsham, Jeffrey. 1998. "Wavering equilibriums: Subsystem Dynamics and Agenda Control." American Politics Quarterly 26(4):485-512.

Worsham, Jeffrey. 2006. "Up in Smoke: Mapping Subsystem Dynamics in Tobacco Policy." Policy Studies Journal 34(3):347-452.

Worsham, Jeffrey. 1997. Other People's Money: Policy Change, Congress, and Bank Regulation. Westview Press.

Wright, Gerald C and Schaffner, Brian F. 2002. "The Influence of Party: Evidence from the State Legislatures.” American Political Science Review 96(2): 367-379.

Wyler, Liana, Sun. 2008. "International Drug Control Policy.” Congressional Research Service (International Crime, Foreign Affairs, Defense, and Trade Division). CRS Issue Brief for Congress.

Wyler, Liana, Sun. 2009. "International Drug Control Policy.” Congressional Research Service (International Crime, Foreign Affairs, Defense, and Trade Division). CRS Issue Brief for Congress. 
Young, Oran. 1983. "Regime Dynamics: The Rise and fall of International Regimes." In Stephen Krasner (ed.), International Regimes. Ithaca: Cornell University Press.

Young, Oran. 1989. “The Politics of International Regime Formation: Managing Natural Resources and the Environment.” International Organization 43(3): 349-375.

Young, Oran (ed.). 1999. The Effectiveness of International Environmental Regimes. Causal Connections and Behavioral Mechanisms. Cambridge: MIT Press.

Zerai, Assata, and Banks, Rae. 2002. Dehumanizing Discourse, Anti-Drug Law, and Policy in America: A “Crack Mother's Nightmare. Burlington: Ashgate Publishing Company.

Zimring, Franklin E, and Hawkins, Gordon. 1992. The Search for Rational Drug Control. New York: Cambridge University Press. 